\title{
CORROSIÓN DE ACEROS INOXIDABLES MARTENSÍTICOS 13CrNiMo DE BAJO CONTENIDO DE CARBONO DE USO EN LAS INDUSTRIAS DE GAS Y PETRÓLEO
}

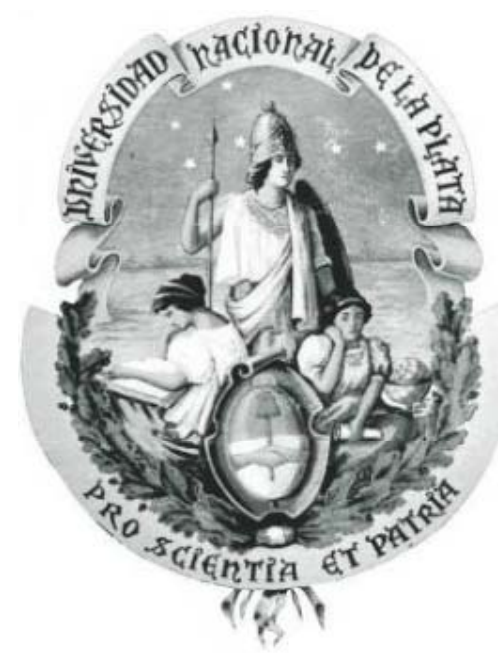

Tesis doctoral presentada por CLAUDIA MARCELA MENDEZ

ante la

Facultad de Ingeniería de la Universidad Nacional de La Plata para acceder al grado académico de DOCTOR EN INGENIERIA

Departamento de Mecánica

Dirección de tesis:

Co Dirección:

Jurado de tesis:
Dr. Claudio A. Gervasi Ing. Carlos Llorente Dra. Silvia M. Ceré Dr. Carlos A. Giudice 


\section{Resumen}

Los aceros inoxidables $13 \mathrm{CrNiMo}$ con bajo contenido de carbono, surgen como alternativa para el reemplazo de materiales más caros en el uso como sistemas de transporte de fluidos de las industrias de gas y petróleo, con concentraciones importantes de cloruros, $\mathrm{pCO}_{2}, \mathrm{pH}_{2} \mathrm{~S}$ y temperatura elevadas. El bajo contenido en carbono permite salvar algunos problemas vinculados a la operación de soldadura. Con el fin de obtener una alta tenacidad, se realizan tratamientos térmicos de precalentamiento y de post soldadura, los mismos se aplican sobre la zona de soldadura, e involucran además al metal base, produciendo en este tipo de materiales en particular, un cambio en el tenor de austenita retenida en toda la matriz a temperatura ambiente, en una clara modificación de la microestructura del metal.

En esta tesis se estudia el impacto que las variaciones en la microestructura tienen sobre la película pasiva formada sobre la aleación de acero inoxidable $13 \mathrm{CrNiMo}$ y la influencia de esta última sobre la corrosión localizada. Además se determinan las propiedades estructurales y electrónicas de la película pasiva formada, vinculándolas a la susceptibilidad a la corrosión localizada.

Para el estudio se tomaron muestras de la aleación sometidas a diferentes tratamientos térmicos post soldadura y se caracterizaron microestructuralmente determinando el contenido de austenita retenida en cada caso. Las muestras fueron sometidas a medidas potenciodinámicas cíclicas para hallar su susceptibilidad a la corrosión localizada. Tanto el potencial de picado como el potencial de repasivación se desplazaron en el sentido anódico a medida que el porcentaje de austenita retenida aumentaba en la muestra. Las muestras sometidas a tratamientos que involucran dobles revenidos promovieron mayor porcentaje de austenita retenida.

Dada la correlación hallada entre los potenciales de picado y el tenor de austenita retenida, se dispone de una indicación de que la formación de las películas pasivas formadas sobre la superficie, muestren la misma tendencia. Medidas cronopotenciométricas revelan que el espesor de las películas aumenta en función del mayor contenido de austenita retenida.

Los estudios de Mott Schottky, muestran que la película pasiva se comporta como un semiconductor tipo $\mathrm{n}$ con una densidad de donores que es esencialmente independiente del potencial en el estado pasivo. La impedancia de la interfase ha sido modelada 
convenientemente considerando una versión corregida del modelo de defectos puntuales, lo que permite obtener el coeficiente de difusión de esos defectos y una estimación del espesor de la película. La velocidad de auto-reparación de la película pasiva tiende a ser más rápida en el material cuyo contenido de austenita retenida es mayor.

La conformación estructural de película es de doble capa, así como la estructura de las películas anódicas para otros aceros inoxidables. 


\section{Publicaciones}

Los resultados obtenidos en la presente tesis fueron presentados en diferentes ámbitos académicos como ser reuniones científicas, congresos internacionales y revistas. La siguiente es una lista de todas las publicaciones producidas:

Revistas:

- "Analysis of the impact of alloy microstructural properties on passive films formed on low-C 13CrNiMo martensitic stainless steels", C.A. Gervasi, C.M. Méndez, P.D. Bilmes, C.L. Llorente, Materials Chemistry and Physics 126 (2011) 178-182, ISSN 0254-0584. Marzo 2011.

- "Microstructure, heat treatment and pitting corrosion of $13 \mathrm{CrNiMo}$ plate and weld metals", P.D. Bilmes, C.L. Llorente, C.M. Méndez, C.A. Gervasi, Corrosion Science, ISSN: 0010-938X, №51, 876-881. Abril 2009.

\section{Congresos:}

- XX Congreso de la Sociedad Iberoamericana de Electroquímica, SIBAE 2012, Fortaleza, Brasil, 25-30 de marzo de 2012. "Estructura y propiedades electrónicas de la película pasiva de aceros inoxidables softmartensíticos en solución buffer de fosfato", Méndez, Claudia Marcela; Gervasi, Claudio Alfredo; Bilmes, Pablo David; Llorente, Carlos Luis.

- VIII Jornadas Científico Tecnológicas de la Facultad de Ciencias Exactas, Químicas y Naturales, IT.05, 2 al 4 de noviembre de 2011. "Propiedades semiconductoras de las películas pasivas formadas sobre aceros inoxidables softmartensícitos", Mendez, Claudia M., Gervasi, Claudio A., Bilmes, Pablo D., Llorente, Carlos L.

- XI Congreso Binacional de Metalurgia y Materiales, Conamet/SAM 2011, Rosario, Argentina, del 18 al 21 de octubre del 2011. "Propiedades semiconductoras de las películas pasivas formadas sobre aceros inoxidables softmartensíticos" Claudia M. Mendez, Claudio A. Gervasi, Pablo D. Bilmes, Carlos L. Llorente.

- XVII Congreso Argentino de Fisicoquímica, 3 al 6 de mayo de 2011, Córdoba, Argentina. "Propiedades de las películas pasivas formadas sobre aceros inoxidables soft martensíticos", Méndez, Claudia Marcela; Gervasi, Claudio Alfredo; Bilmes, Pablo David; Llorente, Carlos Luis.

- VII Latincorr de la NACE, Quito, Ecuador, 31 de agosto al 3 de setiembre del 2010. "Pasividad de acero inoxidables soft martensíticos en solución buffer de fosfato ácido disódico", C. M. Méndez, C.A. Gervasi, P. Palacios, P.D. Bilmes, C.L. Llorente.

- VII Jornadas Científico Tecnológicas, de la Facultad de Ciencias Exactas, Químicas y Naturales, 28 al 30 de octubre del 2009. ISBN no: 978-950-579-144-6. CD-ROM. "Formación y reducción de películas pasivas en aceros soft martensíticos en 
solución buffer de fosfato ácido disódico" C. M. Mendez, Ruiz, Elsa R., Palacios, Patricia. y Kruyeniski, Julia.

- $9^{\circ}$ Congreso Internacional de Metalurgia y Materiales SAM-CONAMET 2009: Primeras Jornadas Internacionales de Materiales Nuclares, compilado por José Ovejero García, 1 a ed., Buenos Aires, Comisión Nacional de Energía AtómicaCNEA, 2009. CD-ROM. Págs 908-913. ISBN 978-987-1323-13-5. "Comportamiento pasivo y susceptibilidad al picado de aceros inoxidables soft martensíticos" P.D. Bilmes, C.L. Llorente, C. M. Méndez, E.R. Ruiz, C.A. Gervasi. 


\section{Agradecimientos}

Gracias a Dios por Su cuidado y por rodearme de las siguientes personas que fueron y son una bendición para mi vida:

- A mi familia, Andres y Dana, por el aliento constante y por haberme "bancado" mis viajes a La Plata, las horas frente a la computadora, etc. Mejor equipo no puedo tener, los amo.

- A mi Director por la paciencia con que compartió sus conocimientos, y por estar dispuesto a escuchar o leerme en los chats a pesar de sus ocupaciones. Es un privilegio trabajar con vos Claudio.

- A mi Co Director por su disposición.

- A mis compañeros de trabajo, los del Laboratorio de Materiales de la Facultad de Ciencias Exactas, Química y Naturales (Alicia, Nati, Carlos, Mónica, Miriam, Ale, Vero), por el ánimo, por cubrir mis ausencias y por el ambiente de trabajo, sea cual sea la situación, si las cosas se ponían densas o si salían bien siempre nos podíamos reir y cantar.

- A Silvina por albergarme en La Plata, por poder compartir ese tiempo de estar lejos de casa, me sentí mimada.

- A los que tuve oportunidad de conocer en el INIFTA por brindarme su cordialidad.

- A mis compañeros de las cátedras de Fisicoquímica lc y llc, por cubrir mí trabajo cuando tuve que viajar o escribir la tesis. 


\section{Indice}

CAPÍTULO 1 ................................................................................................................................... 1

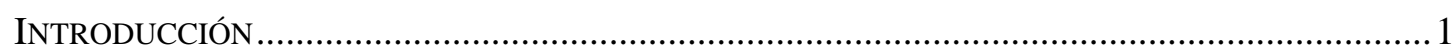

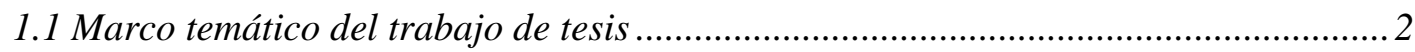

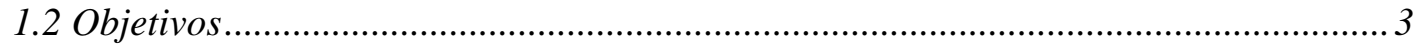

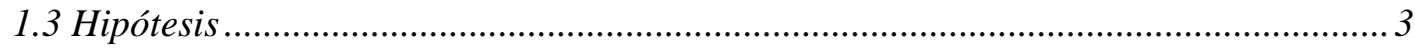

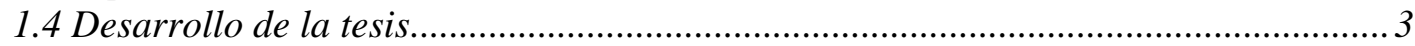

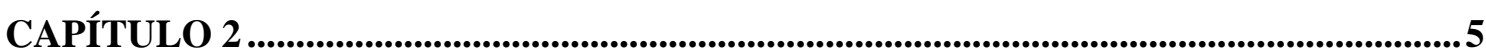

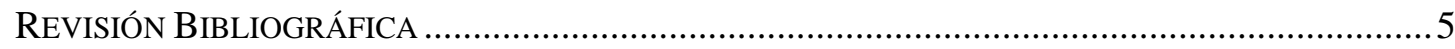

2.1 Metalurgia física de los aceros inoxidables martensíticos ...................................... 5

2.2 Metalurgia física de los aceros inoxidables softmartensíticos.................................... 6

2.2.1 Solidificación y transformaciones de fase en los metales de soldadura de los

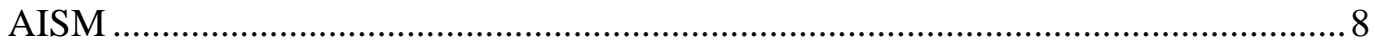

2.3 Efecto microestructural de los elementos de aleación ............................................... 9

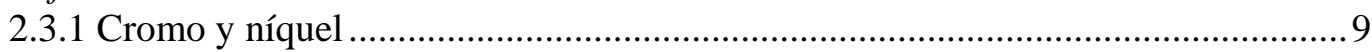

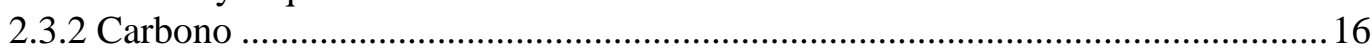

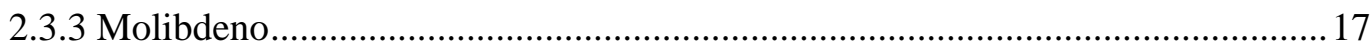

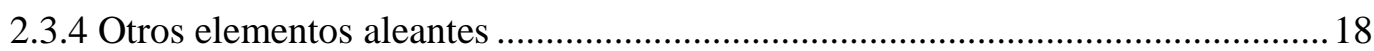

2.4. Evaluación del contenido de ferrita delta residual y de austenita .............................18

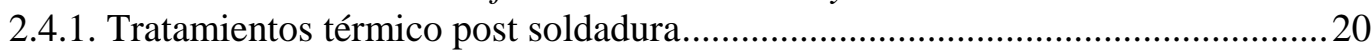

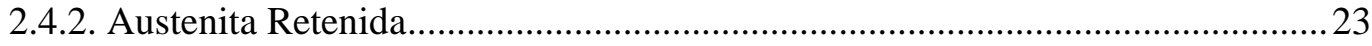

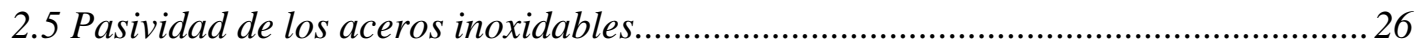

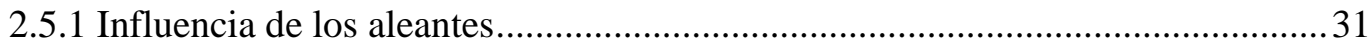

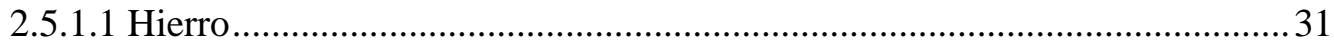

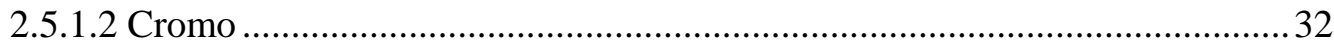

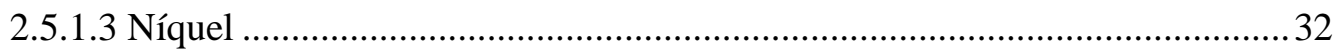

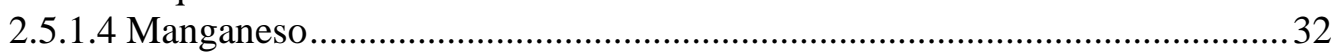

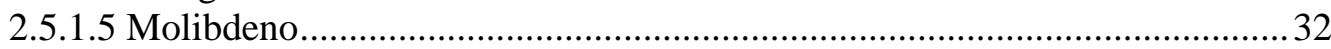

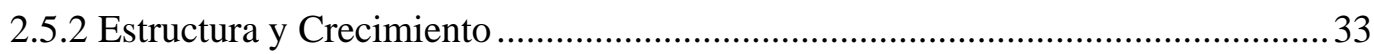

2.6 Tipos de corrosión que sufren los aceros inoxidables ............................................... 34

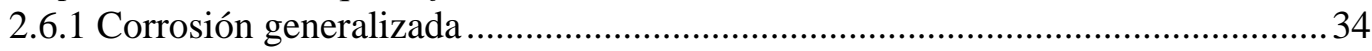

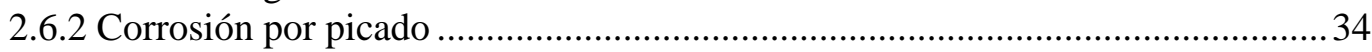

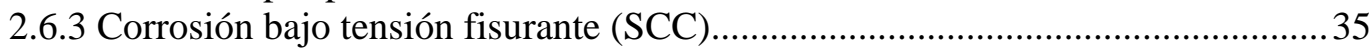

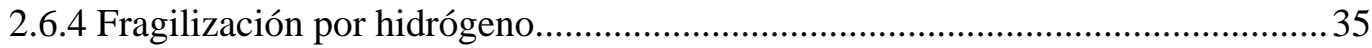

2.6.5 Agrietamiento bajo tensión inducido por la presencia de sulfuros (SSC)............36

2.7 Corrosión del acero inoxidable soft / super martensítico $13 \mathrm{Cr}$..................................36

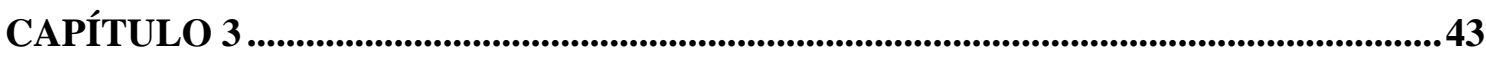

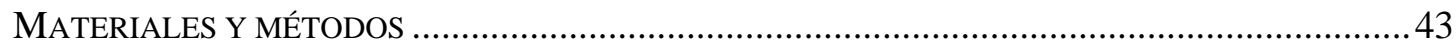

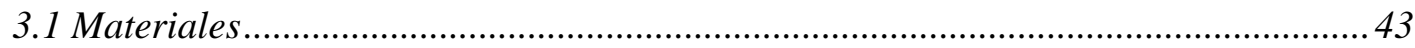

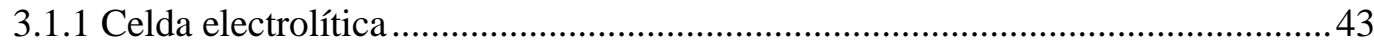

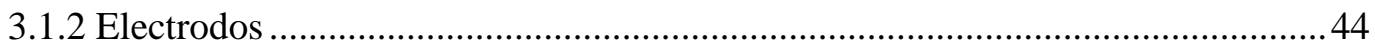

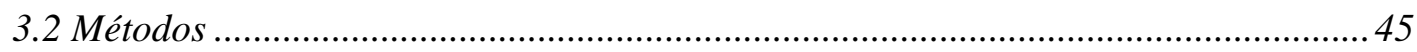

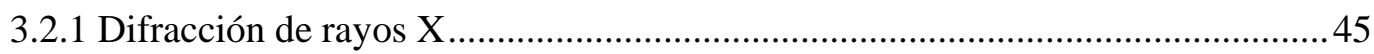

3.2.2 Medidas potenciodinámicas cíclicas de polarización - Corrosión por picado.... 45

3.2.3 Curvas de polarización potenciodinámicas ....................................................47

3.2.4 Curvas de polarización cuasi-estacionarias ........................................................49

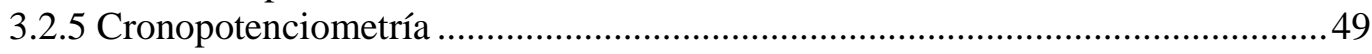

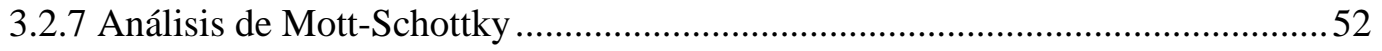




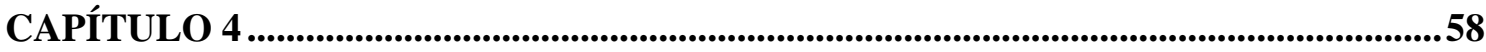

MICROESTRUCTURA, TRATAMIENTO TÉRMICO Y CORROSIÓN POR PICADO …..........................58

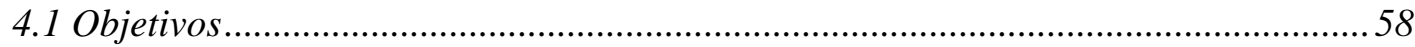

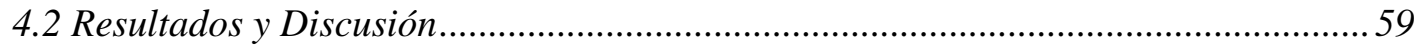

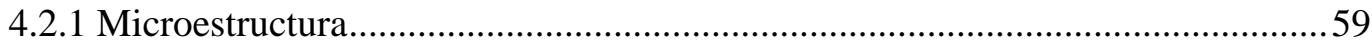

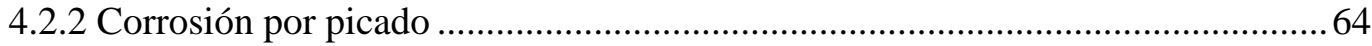

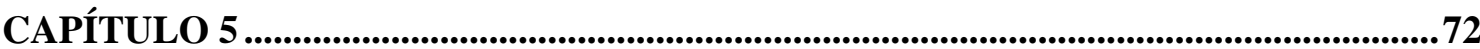

ANÁLISIS DEL IMPACTO DE LAS PROPIEDADES MICROESTRUCTURALES DE LA ALEACIÓN 13CRNIMO SOBRE LA FORMACIÓN DE SUS PELÍCULAS PASIVANTES .......................................... 72

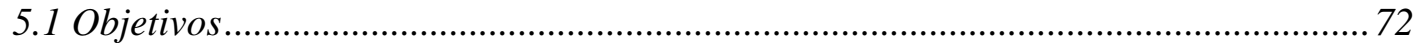

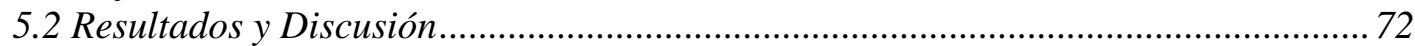

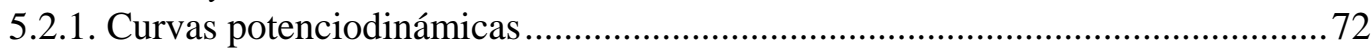

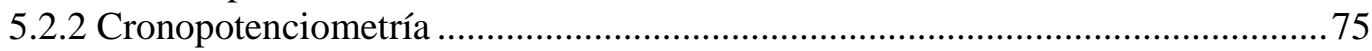

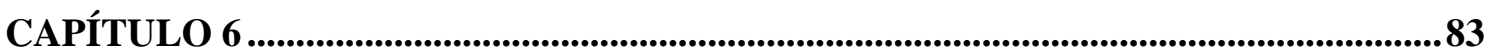

PROPIEDADES SEMICONDUCTORAS, ESTRUCTURA DE LAS PELÍCULAS PASIVAS Y

CARACTERIZACIÓN DE LA FORMACIÓN ANÓDICA DE PELÍCULAS PASIVAS EN SOLUCIÓN BUFFER

DE FOSFATO POR ESPECTROSCOPIA DE IMPEDANCIA ELECTROQUÍMICA (EIS) .........................83

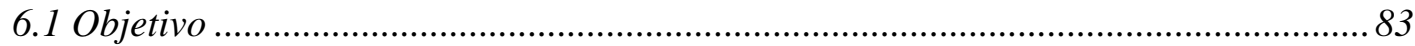

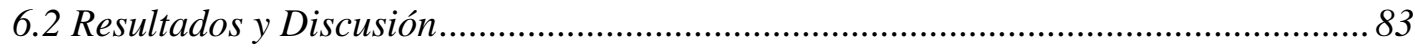

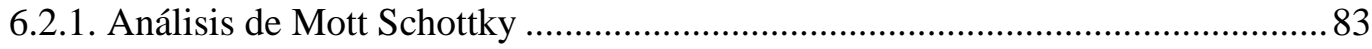

6.2.2. Espectroscopía Fotoelectrónica de Rayos X ....................................................91

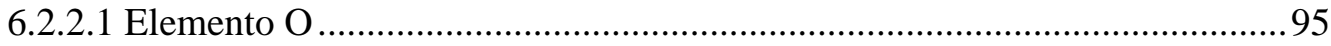

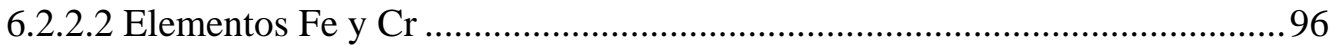

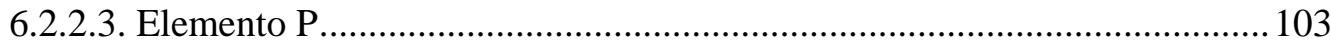

6.2.3 Análisis teórico de la impedancia de películas pasivantes de acero inoxidable

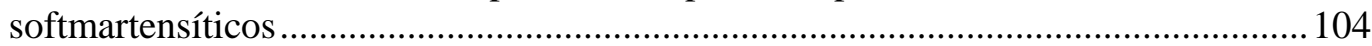

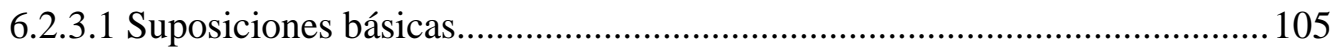

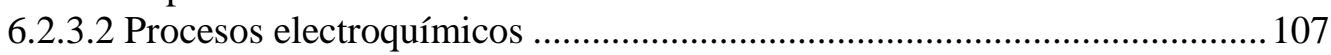

6.3.3.3 Derivación de la función de transferencia del sistema ...............................110

6.2.4. Resultados de la impedancia de películas pasivantes de aceros inoxidables

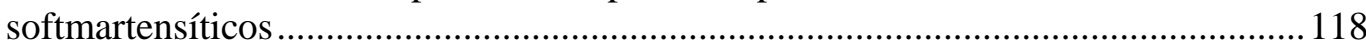

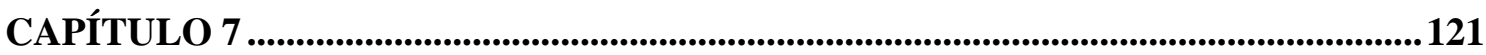

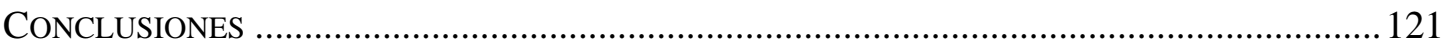

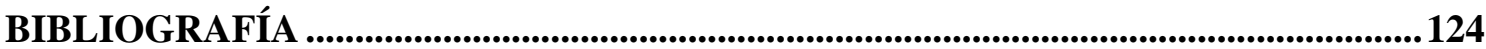




\section{LISTA DE FIGURAS}

Figura 2.1. Esquema de posicionamiento de los aceros inoxidables soft martensíticos dentro

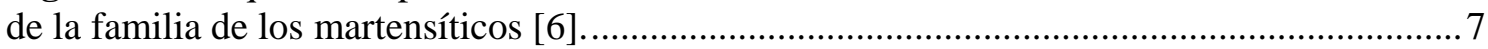

Figura 2.2. Muestra el diagrama de fase del Fe-Cr. ......................................................... 10

Figura 2.3. Muestra el diagrama de fase del Fe-Ni. ..........................................................10

Figura 2.4. Líneas de líquidus y sólidus en los diagramas binarios $\mathrm{Fe}-\mathrm{Cr}$, $\mathrm{Cr}-\mathrm{Ni}$ y Ni-Fe, y su correlación con las áreas de líquidus y sólidus en el diagrama ternario Fe-Cr-Ni. El perfil A define el diagrama cuasibinarios para contenidos de hierro constantes (Fig.2.3) [12] ...........11 Figura 2.5. Diagrama cuasibinario esquemático para el perfil de concentración A de Figura 2.5 .

Figura 2.6. Esquema de las secuencias de solidificación, transformaciones de fase en estado sólido y morfologías de ferrita delta resultantes, en aceros inoxidables austeníticos [13].......13 Figura 2.7. Diagrama cuasibinario representativo de los aceros inoxidables soft martensíticos del tipo 13Cr/4Ni [10].

Figura 2.8. Microestructura de acero 13Cr6NiMo en el estado "como soldado". Se aprecia la presencia de martensita, austenita retenida y ferrita delta residual [12]. 1000X......................15 Figura 2.9 Microestructura de acero 13Cr6NiMo en el estado "como soldado". Se aprecia la presencia de martensita, austenita retenida y ferrita delta residual [12]. 3000X..................... 15

Figura 2.10. La influencia de Ni en la extensión del campo de fase $\gamma$ del sistema Fe-Cr.......16 Figura 2.11. Influencia del $\mathrm{C}$ en la extensión del campo de fase del sistema Fe-Cr..............17 Figura 2.12. Diagrama de fase ternario Fe-Cr-C con 13\% Cr...........................................17 Figura 2.13. Influencia del $\mathrm{C}$ y Mo en la extensión del campo de fase del sistema Fe-Cr. ....18 Figura 2.14. Diagrama de Schaeffler. Localización de aceros inoxidables con contenido de cromo y martensíticos de bajo carbono.

Figura 2.15. Diagrama de Balmforth. Localización de aceros inoxidables martensíticos con contenido de cromo y bajo carbono.

Figura 2.16. Partículas de austenita en una matriz de ferrita. Metal de soldadura 13Cr4NiMo con revenido $600^{\circ} \mathrm{C} / 2 \mathrm{hs}, 3000 \mathrm{X}$ [12].

Figura 2.17. Esquema de la estructura refinada del doble revenido: (a) $950^{\circ} \mathrm{C} / 1 \mathrm{~h} /$ aire, listón Martensita $\left(\mathrm{M}_{1}\right)$, (b) $950^{\circ} \mathrm{C} / 1 \mathrm{~h} /$ aire $+670^{\circ} \mathrm{C} /$ durante el calentamiento. $\mathrm{T}_{\mathrm{m}}$ : martensita templada, $\gamma$ : austenita, (c) $950^{\circ} \mathrm{C} / 1 \mathrm{~h} /$ aire $+670^{\circ} \mathrm{C} / 2 \mathrm{~h} /$ aire (despues del enfriamiento). $\mathrm{T}_{\mathrm{m}}$ : martensita templada, $\mathrm{M}_{1}$ : listón Martensita, $\gamma$ : austenita, (d) $950^{\circ} \mathrm{C} / 1 \mathrm{~h} /$ aire $+670^{\circ} \mathrm{C} / 2 \mathrm{~h} / \mathrm{aire}+$ $600^{\circ} \mathrm{C} / 2 \mathrm{~h} /$ aire. $\mathrm{T}_{\mathrm{m}}$ : martensita templada, $\gamma$ : austenita [21].

Figura 2.18. Influencia del contenido en cromo en la velocidad de corrosión de aleaciones Fe-Cr en contacto con la atmósfera.

Figura 2.19. Gradientes composicionales en produndidad determinados mediante medidas de XPS de una película pasivante formada anódiamente sobre un acero inoxidable en solución de 0,1 $\mathrm{M} \mathrm{HCl}+0,4 \mathrm{M}$ de $\mathrm{NaCl}$ y del sustrato metálico subyacente [37]. ..................................29 Figura 2.20. Estimación de los espesores de óxidos en aleaciones Fe15Cr en 0,5 $\mathrm{M} \mathrm{H}_{2} \mathrm{SO}_{4}$, y para el Fe10Cr y Fe20Cr en 1M NaOH, en función del potencial, utilizando XPS..................30 Figura 2.21. Velocidad de corrosión para el acero 13Cr en función de la concentración de

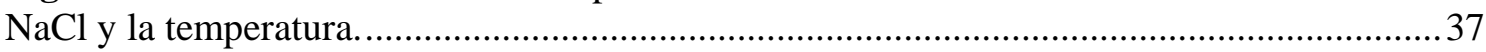

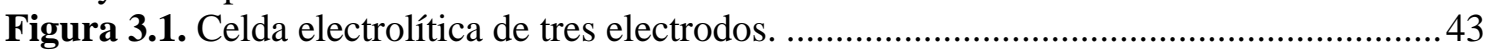

Figura 3.2. Curva de polarización cíclica en la que señalan los potenciales característicos...46

Figura 3.3. Esquema de barrido de polarización anódico ................................................... 48

Figura 3.4. Circuito equivalente simple propuesto por Randles. Diagrama de Nyquist de la respuesta en impedancia teórica de este sistema metal/electrolito...........................................51

Figura 3.5. Gráfico de contornos de precisión del equipamiento usado para las mediciones de impedancia electroquímica.................................................................................................52

Figura 3.6. Superficie irradiada con una fuente de fotones de alta energía que provoca la emisión de electrones. 
Figura 3.7. "Superficie práctica” que se observa mediante el análisis XPS de la superficie de

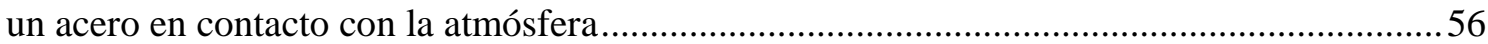

Figura 3.8. Evolución de los espectros XPS de alta resolución Fe2p obtenidos en la superficie de un acero laminado en frío con el tiempo de bombardeo por iones argón............................57

Figura 4.1. Partículas de austenita en una matriz de ferrita en acero inoxidable 13CrNiMo..59 Figure 4.2. Matriz ferrítica para el acero inoxidable 13CrNiMo con tratamiento térmico de acuerdo a la condición E a 1000x (a) y 2000x (b).

Figura 4.3. Partículas de austenita en la matriz de martensita revenida para el acero inoxidable 13CrNiMo con tratamiento térmico de acuerdo a la condición M x1000 (a) y x2000 (b) .

Figura 4.4. Patrones de difracción de rayos $\mathrm{X}$ en una muestra con tratamiento térmico en la condición M.

Figura 4.5. Patrones de difracción de rayos $\mathrm{X}$ en una muestra con tratamiento térmico en la condición E.

Figura 4.6. Curva de polarización potenciodinámica cíclica en medio desaireado conteniendo $0,05 \mathrm{M} \mathrm{K}_{2} \mathrm{SO}_{4}+0,04 \mathrm{M} \mathrm{NaCl}(\mathrm{pH}=4,1)$, velocidad de barrido $0,5 \mathrm{mV} / \mathrm{s}$, para una muestra bajo la condición B. En la Figura se indican los potenciales de picado y de repasivación......66 Figura 4.7. Distribución del potencial de picado dado por la probabilidad acumulada P(E) (ecuación 4.1) como una función del potencial E, para una muestra preparada bajo la condición B. El potencial a P = 0,5 es representativo para el material y su condición de preparación.

Figura 4.8. Austenita retenida (\% peso) vs. potencial de picado $\left(E_{P}\right)$ para diferentes condiciones de preparación como se indica en el texto.

Figura 4.9. Austenita retenida (\% peso) vs. potencial de repasivación ( $\left.E_{P}\right)$ para diferentes condiciones de preparación como se indica en el texto.

Figura 4.10. Austenita retenida (\% peso) vs. potencial de repasivación ( $\left.E_{P}\right)$ para diferentes condiciones de preparación como se indica en el texto, para el metal de soldadura, extraído de la referencia [87].

Figura 4.11. Micrografía SEM donde se observa el crecimiento de una picadura semiesférica en acero inoxidable $13 \mathrm{CrNiMo}$ en $0,05 \mathrm{M} \mathrm{K}_{2} \mathrm{SO}_{4}+0,04 \mathrm{M} \mathrm{NaCl}(\mathrm{pH}=4,1) \ldots \ldots \ldots \ldots \ldots \ldots . . . . .71$

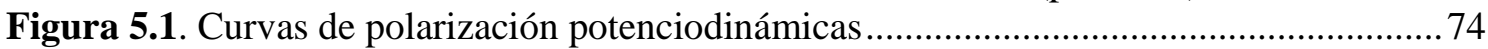

Figura 5.2. Datos de polarización quasi-estacionaria para la oxidación metálica.................... 75

Figura 5.3. Transitorio de potencial típico obtenido por electrorreducción mediante la aplicación de un escalón galvanostático, de un film anódico pasivante previamente crecido y

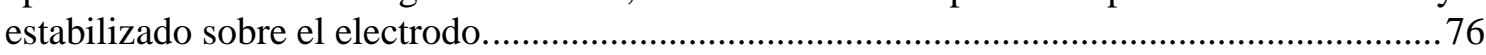

Figura 5.4. Transitorio de potencial típico de la reducción galvanostática del film anódico

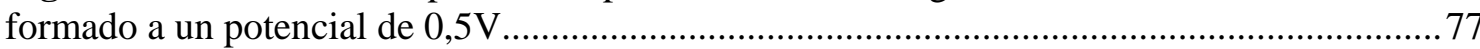

Figura 5.5. Transitorio de potencial típico de la reducción galvanostática del film anódico

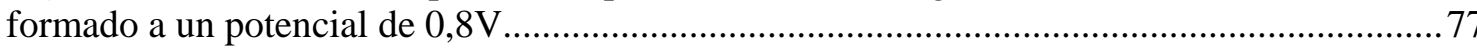

Figura 5.6. Transitorios de potencial típico de la reducción galvanostática del film anódico

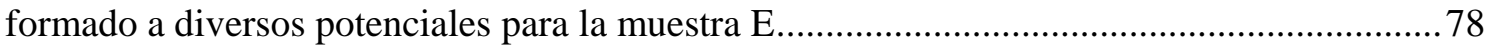
Figura 5.7. Transitorios de potencial típico de la reducción galvanostática del film anódico formado a diversos potenciales para la muestra $\mathrm{M}$.

Figura 5.8. Variaciones de los espesores de las películas reducidas galvanostáticamente durante $\tau_{2}$

Figura 6.1. Gráficas de Mott-Schottky a diferentes potenciales de formación de película para las muestras E (a) y M (b)

Figura 6.2. Gráficas de Mott-Schottky para las muestras $\mathrm{M}$ y E pasivadas durante 1 hora a 0,7 V a partir de valores de C obtenidos mediante la expresión de Brug.

Figura 6.3. Gráficas de Mott-Schottky para las muestras $\mathrm{M}$ y $\mathrm{E}$ pasivadas durante 1 hora a $0,7 \mathrm{~V}$ a partir de $\mathrm{C}$ a $10 \mathrm{kHz}$.

Figura 6.4. Curva de polarización obtenida mediante barrido del potencial a $10 \mathrm{mV} / \mathrm{s}$ en el sentido catódico en medio aireado. 
Figura 6.5. Curvas de polarización a $1 \mathrm{mV} / \mathrm{s}$ en sentido anódico con y sin oxígeno

Figura 6.6. Diagrama de bandas para el semiconductor tipo n derivados de la información de las gráficas de Mott-Schottky.

Figura 6.7. Porcentaje de elementos en la película formada sobre 13CrNiMo en función del tiempo de bombardeo, muestra $\mathrm{E}$ (a) y $\mathrm{M}(\mathrm{b})$.

Figura 6.8. Espectro de $\mathrm{O} 1 \mathrm{~s}$ para la muestra $\mathrm{M}$ a $0 \mathrm{~min}(\mathrm{a})$ y $60 \mathrm{~min}$ (b).............................95

Figura 6.9. Espectro de $\mathrm{O} 1 \mathrm{~s}$ para la muestra $\mathrm{E}$ a $0 \mathrm{~min}(\mathrm{a})$ y $60 \mathrm{~min}$ (b).............................95

Figura 6.10. Espectro de $\mathrm{Fe} 2 \mathrm{p}_{3 / 2}$ para la muestra $\mathrm{M}$.......................................................98

Figura 6.11. Espectro de Fe2p $\mathrm{p}_{3 / 2}$ para la muestra E......................................................... 99

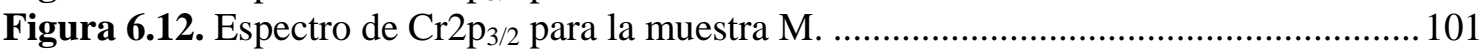

Figura 6.13. Espectro de Cr2p $\mathrm{p}_{3 / 2}$ para la muestra E.......................................................... 102

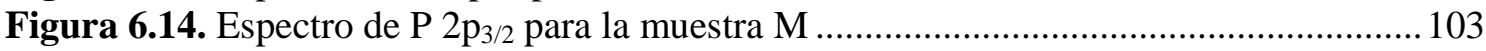

Figura 6.15. Espectro de $\mathrm{P} 2 \mathrm{p}_{3 / 2}$ para la muestra E. ........................................................... 104

Figura 6.16. Esquema de los procesos de transportes de vacancias y de las reacciones interfaciales que ocurren en la película pasivante. ............................................................. 107

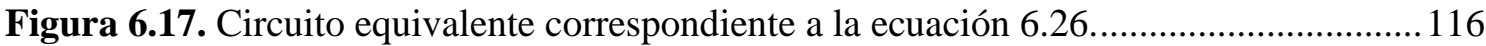

Figura 6.18. Diagramas de Bode para los aceros inoxidables softmartensíticos pasivados a un potencial de $0,2 \mathrm{~V}$ en solución buffer de fostato. 


\section{Nomenclatura}

\begin{tabular}{|c|c|}
\hline Símbolo & Descripción \\
\hline$\varepsilon$ & Constante Dieléctrica de la película pasiva $\left(8,85 \times 10^{-14} \mathrm{~F} \mathrm{~cm}^{-1}\right)$ \\
\hline$\tau$ & Tiempo de Transición (minutos) \\
\hline$\varepsilon_{0}$ & Permitividad del vacío \\
\hline$\phi_{\mathrm{r}}$ & Caída de Potencial electrodo de referencia-solución \\
\hline A & Austenítico \\
\hline AES & Espectroscopía Electrónica Auger \\
\hline $\mathrm{AF}$ & Austenítico-Ferrítico \\
\hline AISM & Acero inoxidable softmartensítico \\
\hline BBC & Body Central Cubic \\
\hline $\mathrm{C}_{\mathrm{SC}}$ & Capacidad de la región del espacio de cargas \\
\hline $\mathrm{C}_{\mathrm{H}}$ & Capacidad de Helmholtz \\
\hline $\mathrm{D}$ & Coeficiente de Difusión \\
\hline DL-EPR & Técnica de Reactivación Electroquímica Potenciodinámica \\
\hline$D_{0}$ & Coeficiente de difusión de vacancias de oxígeno \\
\hline e & Carga del electrón $\left(1,6 \times 10^{-19} \mathrm{C}\right)$ \\
\hline$E_{b p}$ & Potencial de Banda Plana \\
\hline$E_{C}$ & Potencial Asociado del Plateau de Corriente \\
\hline $\mathrm{E}_{\text {corr }}$ & Potencial de corrosión \\
\hline ECS & Electrodo de Calomel Saturado \\
\hline$E_{\text {ext }}$ & Potencial Aplicado \\
\hline$E_{f}$ & Potencial film \\
\hline$E_{\text {form }}$ & Potencial de Formación de la Película Pasiva \\
\hline $\mathrm{E}_{\mathrm{fs}}$ & Potencial film-solución \\
\hline$E_{m f}$ & Potencial metal-film \\
\hline ENH & Electrodo Normal de Hidrógeno \\
\hline$E_{p}$ & Potencial de Picado \\
\hline$E_{R}$ & Potencial de Repasivación \\
\hline $\mathrm{E}_{\mathrm{r}}$ & Potencial Reversible \\
\hline ESCA & Espectroscopía Electrónica para el Análisis Químico \\
\hline ESM & Electrodo de Mercurio-Sulfato Mercurioso Saturado \\
\hline $\mathrm{F}$ & Ferrítico \\
\hline f & Frecuencia $(\mathrm{Hz})$ \\
\hline FA & Ferrítico-Austenítico \\
\hline FCAW & Flux Cored Arc Welding -Soldadura de Arco de Núcleo Fundente \\
\hline GMAW & Gas Metal Arc Welding - Soldadura de Arco Metálico con Gas \\
\hline HFM & Modelo de Alto Campo \\
\hline$I_{d}$ & Corriente Desplazativa \\
\hline IFM & Modelo de Interfase \\
\hline ISS & Ion Scattering Spectroscopy \\
\hline$j$ & Densidad de corriente $\left(\mathrm{A} / \mathrm{cm}^{2}\right)$ \\
\hline $\mathrm{k}$ & Constante de Boltzmann \\
\hline $\mathrm{L}$ & Espesor de película pasiva $(\AA ̊)$ \\
\hline MS & Metal de Soldadura \\
\hline
\end{tabular}




\begin{tabular}{ll}
\hline$N_{D}^{\prime}$ & Densidad de Estados profundos adicionales \\
\hline$N_{d}$ & Densidad de estados donores \\
\hline NERP & Número Equivalente de Resistencia al Picado \\
\hline PCA & Potencial de Circuito Abierto \\
\hline PDM & Modelo de Defectos Puntuales \\
\hline SEM & Microscopía Electrónica de Barrido \\
\hline SIMS & Secondary lon Mass Spectrometry \\
\hline SMAW & Shielded Metal Arc Welding - Soldadura Manual con Electrodo \\
\hline SSC & revestido \\
\hline STM & Stress Sulphide Cracking \\
\hline TTPS & Microscopía de Efecto Túnel \\
\hline$V_{\text {ox }}$ & Tratamientos Térmicos post Soldadura \\
\hline XANES & Volumen molar del óxido (cm ${ }^{3} /$ mol) \\
\hline XPS & X-ray absorption near edge structure \\
\hline ZAC & Espectroscopía Fotoelectrónica de Rayos X \\
\hline & Zona Afectada por el Calor \\
\hline
\end{tabular}




\section{CAPÍTULO 1}

\section{Introducción}

El acero al carbono protegido frente a la corrosión mediante el agregado de inhibidores se ha utilizado tradicionalmente para tuberías, pero el costo de mantenimiento de tal política anticorrosiva es una desventaja. Para lograr un equilibrio entre el capital y los costos de mantenimiento en la distribución de los líquidos que no son muy agresivos, se han desarrollado durante la década del 60 , aceros inoxidables $13 \mathrm{Cr}$ con bajo contenido de carbono (0,02\%), en una amplia gama de contenidos Mo, de esa forma se obtienen diversos grados de resistencia a la corrosión de acuerdo con la concentración de cloruro, $\mathrm{pCO}_{2}, \mathrm{pH}_{2} \mathrm{~S}$ y la temperatura. En principio, el bajo contenido de carbono permite que el tubo se suelde de manera satisfactoria, sin tratamiento térmico post soldadura. La gama de proveedores de materiales se ha incrementado notablemente y los aceros se han adoptado en una serie amplia de aplicaciones, con muchas más oportunidades de ser considerado a futuro [1].

Los aceros inoxidables $13 \mathrm{Cr}$ convencionales, se han utilizado con éxito en líneas de tuberías para pozos de petróleo y producción de gas en ambientes dulces a altas temperaturas por lo general hasta unos $125^{\circ} \mathrm{C}$. Estos aceros poseen una estructura básica martensítica y logran propiedades específicas, tanto mecánicas como con respecto a la corrosión y al desgaste, por medio de variaciones de composición química y tratamientos térmicos. En general, el campo de aplicación de los aceros inoxidables martensíticos se encuentra volcado mayoritariamente a la fabricación y/o reparación por recargues de soldadura, de álabes para turbinas hidráulicas y a vapor, componentes de máquinas, elementos de corte, instrumental quirúrgico y odontológico. Sin embargo, el alto contenido de carbono plantea problemas a la hora de realizar una soldadura, necesitándose tratamientos térmicos post soldadura por varias horas a fin de lograr una dureza aceptable y buena tenacidad en la zona afectada por el calor (ZAC).

Las primeras aplicaciones a gran escala del los aceros martensíticos $13 \% \mathrm{Cr}$ fue en sistemas de tuberías utilizados en el campo de Arun Mobil a partir de 1980 (AISI 410). Con el fin de obtener una alta tenacidad, incluso para las condiciones ambientales bastante benignas de Indonesia, se realizaron tratamientos térmicos de precalentamiento y de post 
soldadura. Las instalaciones siguen funcionando con éxito. Hoy en día tal grado no sería considerado, ya que en la mayoría de las aplicaciones actuales los requisitos de tenacidad nunca podrían ser satisfechos por las aleaciones clásicas de $\mathrm{Cr} 13$ [2] .

El desarrollo de los aceros inoxidables soft martensíticos comenzó en Europa, principalmente como aleaciones de fundición. Durante las décadas del '80-90 se impusieron en el mercado mundial como nuevos materiales de alta performance y relativo bajo costo para numerosas aplicaciones donde competían con aceros inoxidables más costosos [3]. La introducción de los grados soldables realmente comenzó alrededor de 1995, cuando tanto Statoil como NAM comenzaron a pre-calificar los materiales de tubos sin costura para líneas de conducción. Así se obtiene un nuevo grupo de materiales entre los que se destacan los denominados aceros inoxidables soft-martensíticos (AISM) [4]. Sus últimos desarrollos dieron ya lugar a nueva familia de materiales denominados aceros inoxidables supermartensíticos, de menor contenido de carbono $(C<0,02 \%)$.

Los AISM debido al bajo contenido de carbono y la adición de níquel, poseen altos valores de tenacidad al impacto y con durezas entre 250 y $400 \mathrm{HV}$. Después que el enfriamiento de la soldadura es completado, la microestructura consiste de martensita de bajo carbono con pequeñas cantidades de ferrita delta y austenita sobrenfriadas. Con tratamientos térmicos la tenacidad al impacto puede ser incrementada en desmedro de una ligera baja tanto en dureza como en resistencia mecánica.

Se han hecho esfuerzos para limitar la dureza en la zona de la soldadura, sin embargo no existen datos sobre el efecto de la dureza en las propiedades pertinentes al servicio y no se ha demostrado que la dureza sea de modo fehaciente un parámetro de control. En la actualidad, el interés se centra en la corrosión y la corrosión bajo tensión de la zona afectada por el calor, pero también se requiere prestar atención a cuestiones de integridad mecánica y, en particular a los efectos del hidrógeno [5].

\subsection{Marco temático del trabajo de tesis}

Aunque mucho se ha logrado, en un período relativamente corto desde el inicio del desarrollo de estos materiales, todavía quedan cuestiones que requieren mayor esfuerzo de investigación, particularmente en el campo de la corrosión. 
Más aún, la escasa bibliografía publicada respecto del comportamiento de estos materiales en diferentes medios corrosivos, resultó de estímulo adicional para emprender este estudio de los aceros inoxidables $13 \mathrm{Cr}$ con bajo contenido de $\mathrm{C}$.

Adicionalmente, se plantea como objeto de estudio el impacto que las variaciones de microestructura tienen en la película pasivante que sobre esos materiales se desarrolla y en definitiva el impacto de esta última sobre la corrosión localizada.

\subsection{Objetivos}

- Identificar las variables que gobiernan la susceptibilidad a la corrosión localizada de los aceros soft martensíticos que han sido sometidos a diferentes tratamientos térmicos.

- Cuantificar la influencia que sobre estas formas de corrosión tienen las variables mencionadas.

- Determinar rangos aceptables de los diferentes parámetros que gobiernan las formas de corrosión consideradas

- Realizar un estudio mecanístico y fenomenológico de los procesos de corrosión involucrados, para poder desarrollar bases teóricas de predicción en distintas condiciones de servicio.

- Caracterizar las películas pasivantes formadas en diferentes condiciones microestructurales del metal base e interpretar el impacto de las propiedades estructurales y electrónicas del film pasivante en el desarrollo de la corrosión localizada.

\subsection{Hipótesis}

Es posible correlacionar las condiciones metalúrgicas de los aceros softmartensíticos con las propiedades electrónicas de la película pasiva y por ende de su resistencia a la corrosión.

\subsection{Desarrollo de la tesis}

La revisión de la bibliografía relevante en cuanto a la metalurgia de los aceros softmartensíticos, las transformaciones estructurales que sufren debido a los tratamientos térmicos post soldadura y los estudios de la corrosión, se desarrolla en el Capítulo 2. 
En el Capítulo 3 se presentan los materiales y métodos utilizados para el desarrollo de la investigación y análisis de los resultados.

En el Capítulo 4 se discute, en base a los resultados obtenidos, los aspectos de la influencia de los tratamientos térmicos post soldadura en la microrestructura de los aceros, por ende sobre la resistencia a la corrosión por picado.

En el Capítulo 5 se analiza el impacto de las propiedades microestructurales de la aleación $13 \mathrm{CrNiMo}$ sobre la formación de sus películas pasivantes

En el Capítulo 6 propiedades electrónicas

En el Capítulo 7 impedancia

Finalmente en el Capítulo 8 se exponen las conclusiones a las que se arriba con la presente tesis y se dan algunas recomendaciones para futuros trabajos. 


\section{CAPÍTULO 2}

\section{Revisión Bibliográfica}

\subsection{Metalurgia física de los aceros inoxidables martensíticos}

Dentro de los aceros inoxidables, la familia de los martensíticos con $12-13 \%$ de $\mathrm{Cr}$, tiene la propiedad fundamental de ser endurecibles por tratamientos térmicos. Estos aceros poseen una estructura martensítica y logran propiedades especificas, tanto mecánicas como a la corrosión y al desgaste, por medio de variaciones de composición química y tratamientos térmicos. En general, el campo de aplicación de los aceros inoxidables martensíticos se encuentra volcado mayoritariamente a la fabricación y/o reparación por recargues de soldadura, de álabes para turbinas hidroeléctricas y a vapor, componentes de máquinas, elementos de corte, instrumental quirúrgico y odontológico, etc. Estos aceros tienen un compromiso tecnológico, fundamentalmente por su baja tenacidad, en particular a bajas temperaturas, y porque presentan fuertes dificultades en la soldadura dado que tienen relativamente altos contenidos de carbono y composiciones químicas estrechamente balanceadas.

La relativamente pobre soldabilidad de estos aceros, su sensibilidad a la fisuración en frío y las bajas tenacidades obtenidas en las uniones soldadas, condujo durante la década del ‘60 al desarrollo de los aceros inoxidables martensíticos con 13\% de $\mathrm{Cr}$ y bajo carbono [1]. Dentro de este grupo de materiales se destacan los denominados aceros inoxidables soft martensíticos [4]. El desarrollo de los aceros inoxidables soft martensíticos comenzó en Europa, principalmente como aleaciones de fundición. No obstante, en virtud de las actuales y modernas tecnologías de elaboración de los aceros que permiten un preciso control composicional y extremadamente bajos contenidos de carbono, nitrógeno e impurezas, es en la actualidad donde realmente se están fabricando en gran variedad de grados e imponiendo en el mercado mundial como materiales de muy alta perfomance y relativo bajo costo para numerosas aplicaciones [3]. 


\subsection{Metalurgia física de los aceros inoxidables softmartensíticos}

Los Aceros Inoxidables Soft Martensíticos (AISM) están definidos por contenidos de cromo entre 13 y $17 \%$ y un bajo tenor de $C(<0,03)$. Esto mejora notablemente la soldabilidad, la resistencia a la corrosión y la tenacidad al impacto del material. Debido al bajo carbono, cuentan con contenidos variables de níquel (4 a 6\%), el más potente austenitizante después del carbono y el nitrógeno. De esta forma se evita una alta presencia de ferrita delta en la microestructura, que perjudica la tenacidad al impacto y eleva la temperatura de transición dúctil-frágil. También estos grados de aceros inoxidables, para mejorar la resistencia a la corrosión, disminuir los riesgos de fragilización de revenido y resistir el ablandamiento durante el revenido, presentan adiciones de molibdeno entre 0,5 y 2,5\% dependiendo de la aplicación específica. Para algunas aplicaciones, en especial para la industria del gas y petróleo, estos aceros compiten como una alternativa económica frente a los clásicos aceros inoxidables dúplex con $22 \%$ de cromo, ya que su costo es un $50 \%$ menor; como también han sido utilizados para la fabricación de álabes de turbinas hidráulicas, bombas, compresores, maquinaria naval, propulsores de navegación, tuberías de conducción a alta presión y en las industrias química, petroquímica y aeronáutica. Los AISM son una generación previa al desarrollo de los Aceros Inoxidables Super Martensíticos, ver Figura 2.1. 


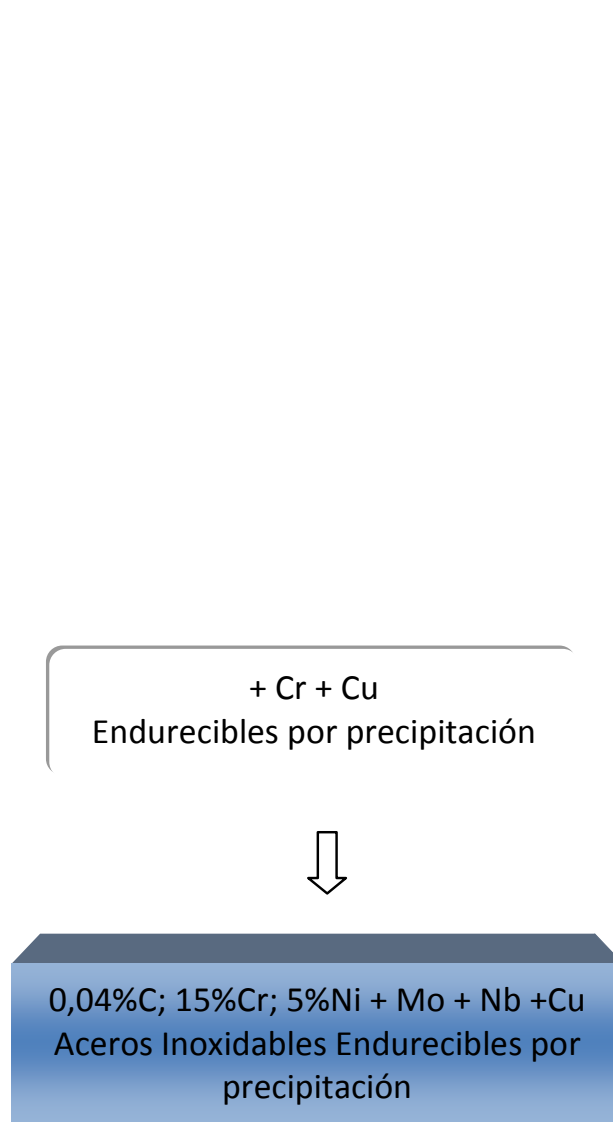

$0,01 \% \mathrm{C} ; 12 \% \mathrm{Cr} ; 2-6,5 \% \mathrm{Ni} ; 0-2,5 \% \mathrm{Mo}$
Acero Inoxidable Super Martensítico

$12 \% \mathrm{Cr}$
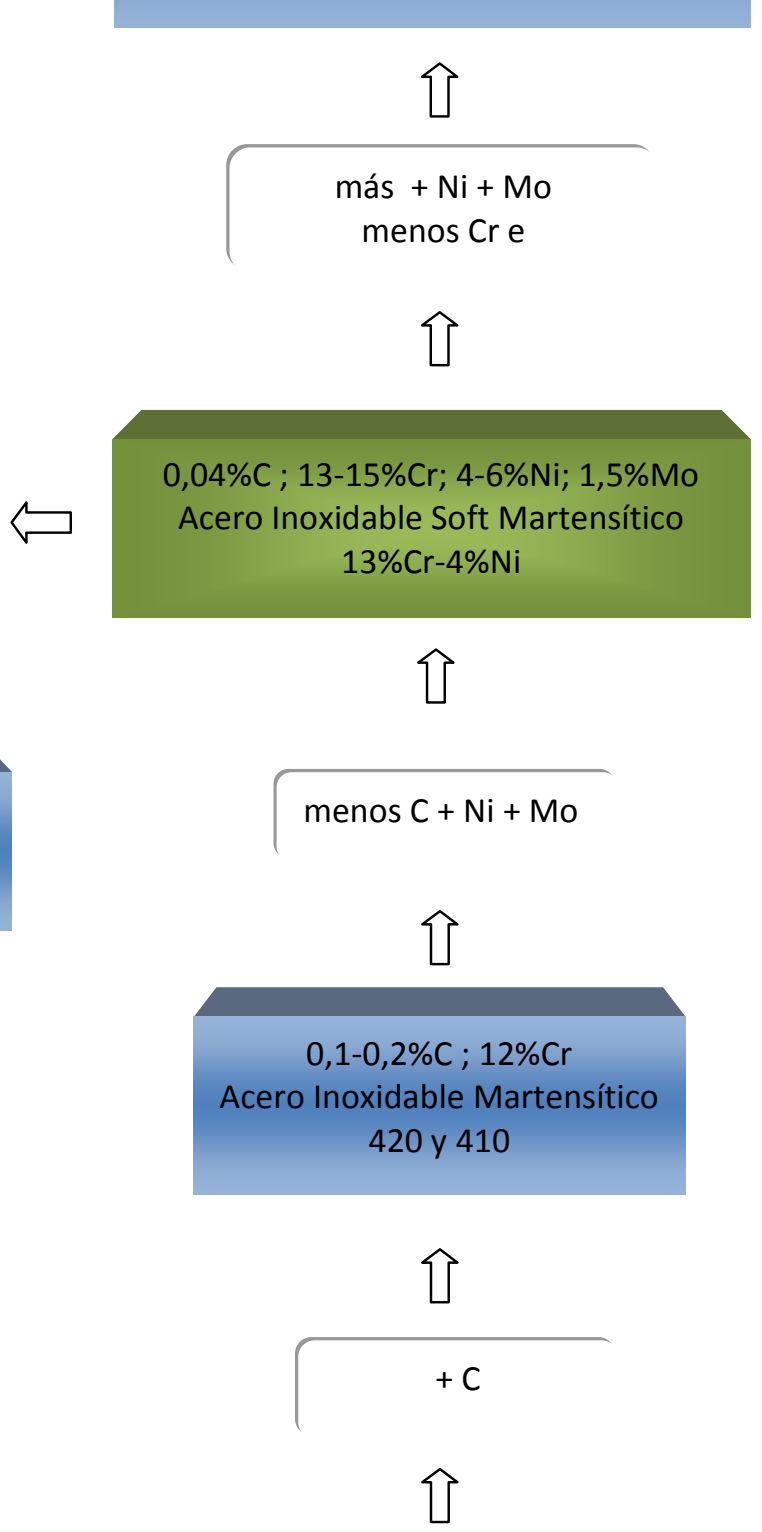

$0,1 \% \mathrm{C} ; 11-12 \% \mathrm{Cr}$

Acero Inoxidable Ferrítico

Figura 2.1. Esquema de posicionamiento de los aceros inoxidables soft martensíticos dentro de la familia de los martensíticos [6].

Los grados más comunes de AISM se muestran en la Tabla 2.1, destacándose las aleaciones $13 \% \mathrm{Cr}-4 \% \mathrm{NiMo}$ y $13 \% \mathrm{Cr}-6 \% \mathrm{NiMo}$. 
Tabla 2.1. Grados de AISM.

\begin{tabular}{|c|c|c|c|c|c|c|}
\hline Grado & \%C & \%Cr & \%Ni & \%Mo & \%Nb & \%Cu \\
\hline $13-1$ & 0,10 & 13 & 1 & - & - & - \\
\hline $13-2$ & 0,05 & 13 & 1,5 & 0,4 & - & - \\
\hline $13-4$ & 0,05 & 13 & 4 & 0,4 & - & - \\
\hline $13-4-1$ & 0,05 & 13 & 4 & 1,5 & - & - \\
\hline $13-6$ & 0,05 & 13 & 6 & 0,4 & - & - \\
\hline $13-6-1$ & 0,05 & 13 & 6 & 1,5 & - & - \\
\hline $14-5 \mathrm{PH}$ & 0,05 & 14 & 5 & 1,5 & 0,2 & 1,5 \\
\hline $16-5-1$ & 0,05 & 16 & 5 & 1,5 & - & - \\
\hline $16-6$ & 0,05 & 16 & 6 & - & - & - \\
\hline $17-4$ & 0,05 & 17 & 4 & - & - & - \\
\hline $17-4-1$ & 0,05 & 17 & 4 & 1,5 & - & - \\
\hline
\end{tabular}

La soldabilidad de estos AISM está caracterizada por: formación de martensita de bajo carbono en el metal de soldadura (MS) y en la zona afectada por el calor (ZAC), lo cual disminuye notablemente la sensibilidad a la fisuración en frío; y bajo contenido de ferrita delta en el metal de soldadura con el consiguiente incremento en la tenacidad al impacto. Normalmente, y en particular cuando se requieren altos valores de tenacidad al impacto en el metal de soldadura, es necesario realizar tratamientos térmicos post soldadura (TTPS) [7][8][9][10]. Estos incluyen revenidos o dobles revenidos, pudiendo también incluirse un solubilizado previo.

Los AISM presentan una importante resistencia a la corrosión y a la erosión por cavitación. Dado que el contenido de carbono es bajo respecto a los clásicos martensíticos AISI 420, la resistencia a la corrosión es superior, particularmente a temperaturas superiores a $\operatorname{los} 150^{\circ} \mathrm{C}[4]$.

En cuanto a las propiedades mecánicas, los AISM alcanzan niveles de tensión de fluencia entre 620-800 MPa, resistencia a la tracción 800-950 MPa, y alargamientos entre 15-25\%. La tenacidad es muy buena hasta temperaturas inferiores a -50 ㅇ․

\subsubsection{Solidificación y transformaciones de fase en los metales de soldadura de los} AISM

En la solidificación de los AISM, las estructuras de colada de los lingotes son modificadas y transformadas por las operaciones de trabajado mecánico en caliente y por los tratamientos térmicos de solubilización, homogeneización y recristalización, de forma de eliminar la segregación, precipitaciones de fases indeseables y modificar las 
microestructuras de acuerdo a los requerimientos necesarios. En cambio en el metal de soldadura, tales posibilidades son bastante limitadas ya que sólo en algunas situaciones los componentes soldados pueden ser deformados en caliente o sometibles a tratamientos térmicos post soldadura.

En todos los casos los metales de soldadura, después del proceso de soldadura por fusión, adquieren una determinada estructura de solidificación. En el caso de soldaduras multipasadas, las pasadas o cordones de soldadura someten a los cordones previamente depositados a ciclos térmicos los cuales no se realizan bajo condiciones controladas y sobre todo afectan el depósito de soldadura, siendo las velocidades de enfriamiento altas y los tiempos de recalentamientos cortos, resultando la estructura final del metal de soldadura no homogénea y muy diferente del metal base

Sin embargo, esto no siempre es negativo, ya que es posible en muchos casos generar finas estructuras de granos en el metal de soldadura, y debido a los rápidos enfriamientos, se impide la precipitación de fases nocivas. Debido a las diferencias estructurales entre metal de soldadura y metal base, la composición química del primero puede modificarse adecuadamente teniendo en cuenta las condiciones específicas del proceso de soldadura, para satisfacer los mismos requerimientos aplicables al metal o acero base [11].

\subsection{Efecto microestructural de los elementos de aleación}

\subsubsection{Cromo y níquel}

Del análisis del diagrama de constitución Fe-Cr se desprende que con el incremento de cromo se restringe el campo de la austenita, hasta hacerlo desaparecer cuando el cromo supera el $12 \%$ (Figura 2.2). Esto significa que el cromo es un elemento fuertemente ferritizante y que por encima del $12 \%$ de cromo ocurre la transformación fase de (austenita, $\gamma$ ) $\rightarrow$ (ferrita, $\delta$ ó $\alpha$ ). Ambas ferritas ( $\delta$ ó $\alpha$ ) representan el mismo tipo de estructura cristalina, cúbica centrada en el cuerpo (BCC - Body Central Cubic). En solidificación y soldadura, la ferrita que es formada primariamente desde el líquido es normalmente llamada ferrita delta $(\delta)$, mientras que aquella que procede por transformación secundaria desde la fase austenítica por transformación $\gamma \rightarrow \alpha$, es llamada ferrita alfa $(\alpha)$. Los dos tipos de ferrita muestran diferentes estructuras de grano, la $\delta$-ferrita es a menudo gruesa en comparación con la $\alpha$-ferrita y su morfología conserva las características de la microestructura de la solidificación. 


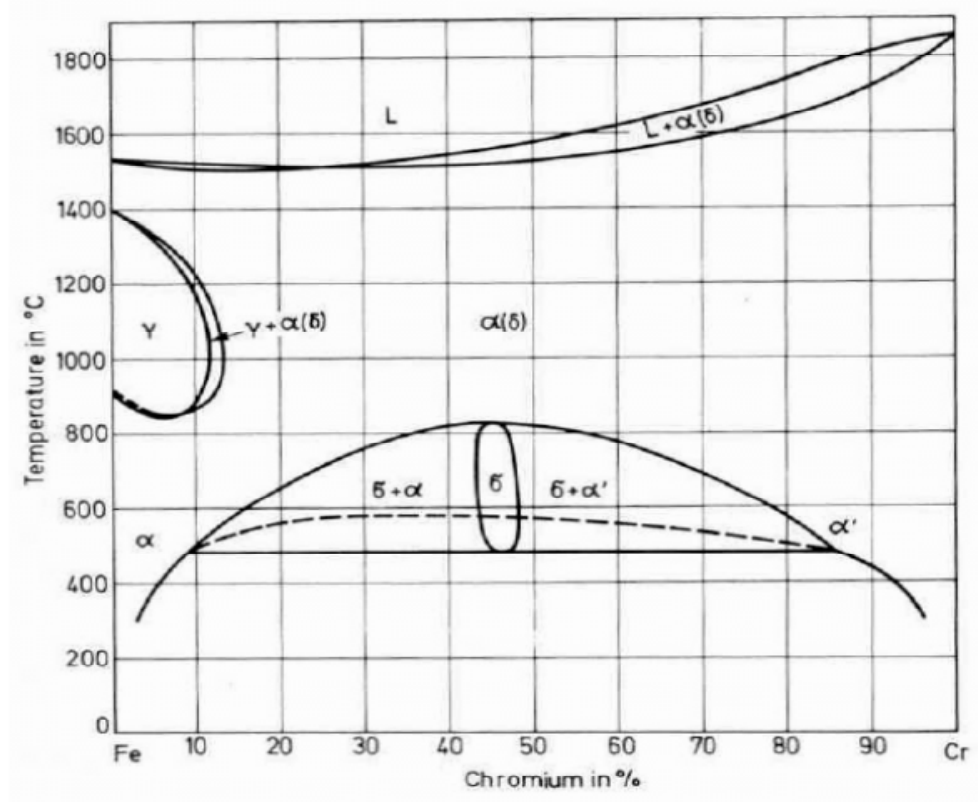

Figura 2.2. Muestra el diagrama de fase del Fe-Cr.

El níquel promueve fuertemente la formación de austenita, la Figura 2.3 muestra el diagrama Fe-Ni. Por encima del $5 \%$ de $\mathrm{Ni}$ aproximadamente, el líquido no solidifica como ferrita $(\delta)$ sino como cristales de austenita $(\gamma)$. La formación de ferrita desde el líquido se limita a una pequeña región, y esta ferrita transforma en austenita durante el enfriamiento en el rango de temperaturas de $1400-1450^{\circ} \mathrm{C}$. El Ni expande el campo de fase austenítico y por lo tanto es un elemento austenitizante.

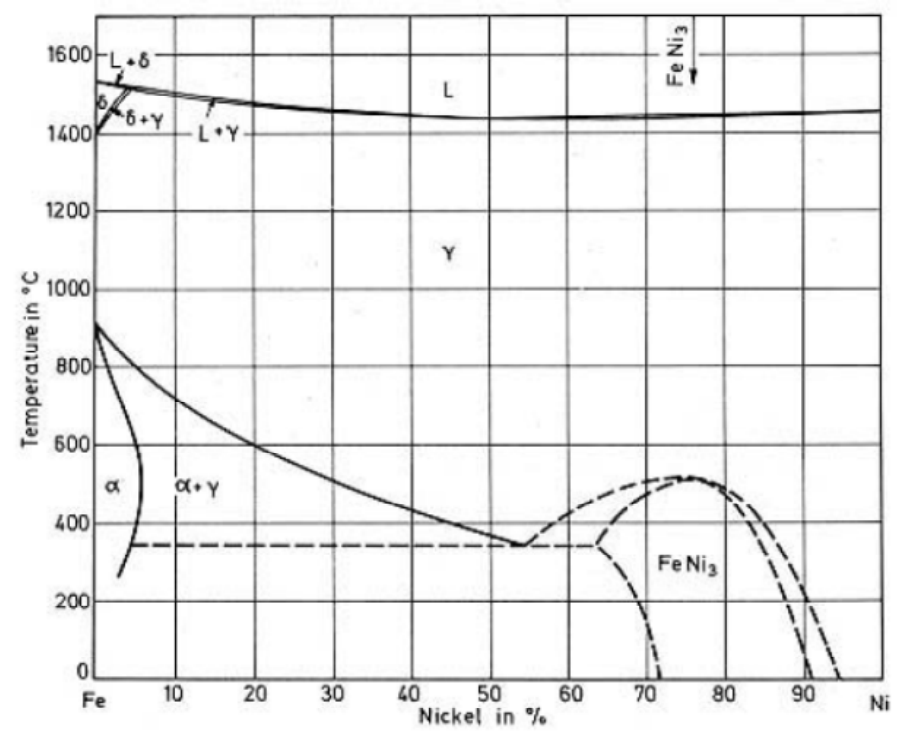

Figura 2.3. Muestra el diagrama de fase del Fe-Ni. 
Para el caso de aleaciones ternarias $\mathrm{Fe}-\mathrm{Cr}-\mathrm{Ni}$, el origen de las microestructuras de soldadura puede entenderse con las superficies de líquidus del diagrama ternario, Figura 2.4, y su correlación con los diagramas binarios correspondientes. El rango de líquidus en la Figura 2.4, es distinguido por la conexión entre el eutéctico del sistema $\mathrm{Cr}-\mathrm{Ni}$ y el peritéctico Fe-Ni. A la izquierda de esta línea la solidificación procede por formación de cristales de ferrita y a la derecha de la línea, por formación de cristales de austenita.

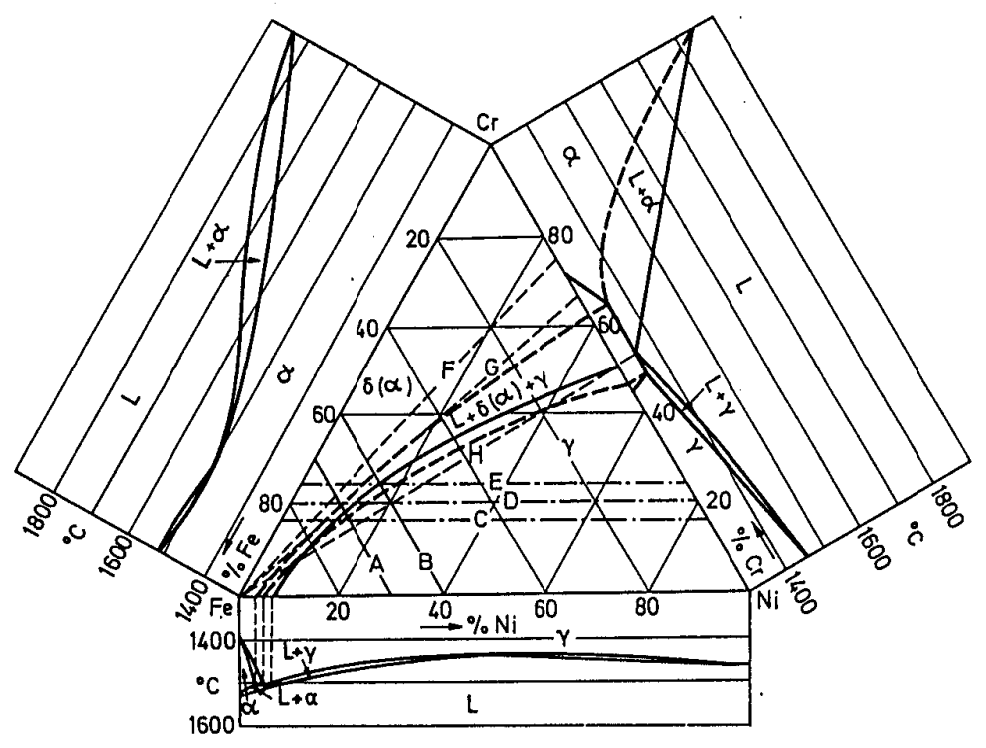

Figura 2.4. Líneas de líquidus y sólidus en los diagramas binarios $\mathrm{Fe}-\mathrm{Cr}, \mathrm{Cr}-\mathrm{Ni}$ y $\mathrm{Ni}-\mathrm{Fe}$, y su correlación con las áreas de líquidus y sólidus en el diagrama ternario $\mathrm{Fe}-\mathrm{Cr}$-Ni. El perfil $\mathrm{A}$ define el diagrama cuasibinarios para contenidos de hierro constantes (Fig.2.3) [12].

El diagrama de la Figura 2.5 es representativo de las secuencias de solidificación que presentan la mayoría de las aleaciones austeníticas en función de la relación de los contenidos de cromo y níquel. De esta manera puede apreciarse que de acuerdo a cual sea la relación cromo/níquel será el modo primario de solidificación: austenítico (A) y austenítico-ferrítico (AF) para relativamente altos contenidos de $\mathrm{Ni}$; y ferrítico-austenítico (FA) y ferrítico (F) para altos contenidos de cromo. Estos modos de solidificación determinarán las subsecuentes transformaciones de fase, la segregación y las morfologías de ferrita delta resultantes, en toda la microestructura de los metales de soldadura de estos materiales. La condición de solidificación primaria en modo ferrítico (e), es la que corresponde para el caso de los aceros inoxidables soft martensíticos y sus metales de soldadura (Figura 2.6). 


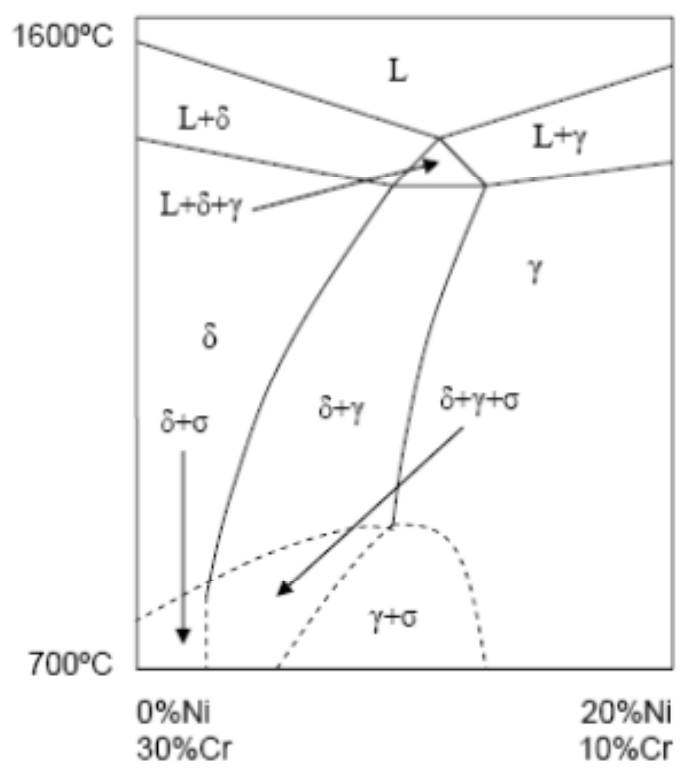

Figura 2.5. Diagrama cuasibinario esquemático para el perfil de concentración A de Figura 2.5 .

En la Figura 2.4 es representado también el perfil de concentración (F) que da lugar al diagrama cuasibinario representativo de los aceros inoxidables soft martensíticos del tipo 13Cr/4Ni (Figura 2.7). 


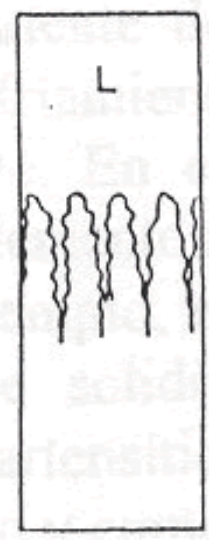

a

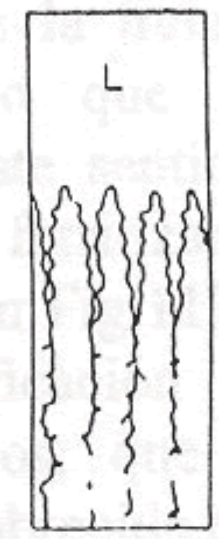

b

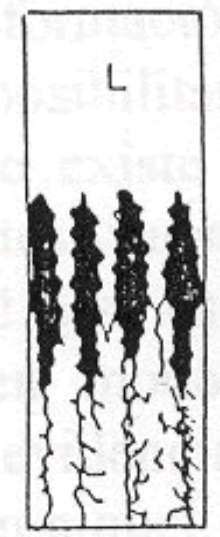

c

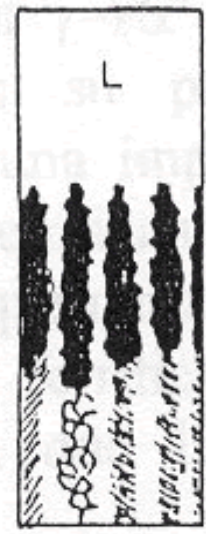

d

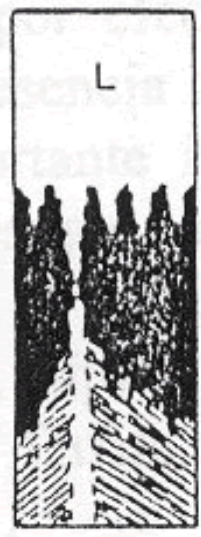

e

L: liquid

Austenite

$\square$ Delta Ferrite

Primary Solidification in austenite

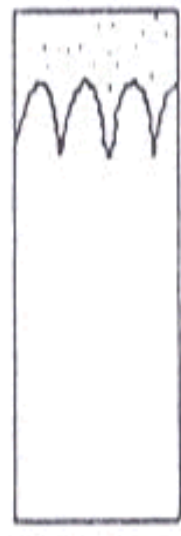

a

Austenite

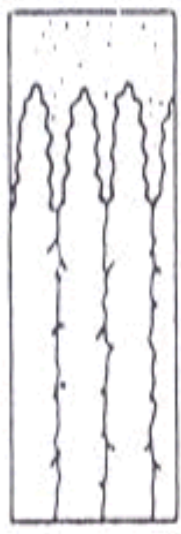

b

Primary Solidification in delta ferrite

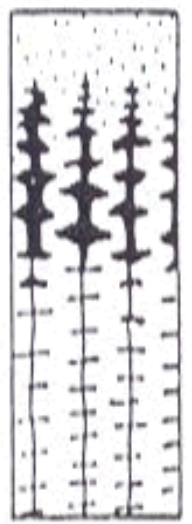

c

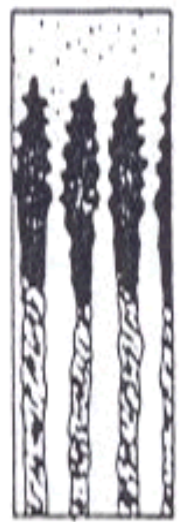

d

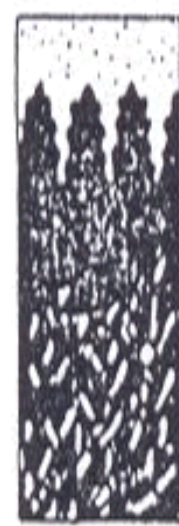

$\mathrm{e}$

Eutectic Interdendritic Lathy Widmanstätten Ferrite Ferrite Ferrite Ferrite

\section{L: liquid $\square$ Delta Ferrite $\square$ Austenite}

Figura 2.6. Esquema de las secuencias de solidificación, transformaciones de fase en estado sólido y morfologías de ferrita delta resultantes, en aceros inoxidables austeníticos [13].

Es posible observar que la solidificación comienza por formación de cristales de ferrita delta mediante un modo de solidificación ferrítico (F) y con posteriores transformaciones en estado sólido $\delta \rightarrow \gamma \rightarrow \alpha$. En las condiciones reales de operaciones de soldadura con enfriamientos superiores a los del equilibrio, las microestructuras resultantes están compuestas de martensita $\alpha^{\prime}$, y alguna presencia de $\delta$ y $\gamma$ (normalmente $<5 \%$ volumen de cada fase, para la mayoría de los procesos clásicos de soldadura). La ferrita delta queda como fase sobrenfriada con una estructura de solidificación, remanente de la incompleta 
transformación $\delta \rightarrow \gamma$ que ocurre mediante un mecanismo de crecimiento Widmanstätten. De aquí que las morfologías de ferrita delta observables a temperatura ambiente tengan una apariencia acicular. La austenita, normalmente denominada austenita retenida, es el remanente de la transformación $\gamma \rightarrow \alpha^{\prime}$ por efecto de las altas velocidades de enfriamiento que posibilitan su presencia metaestable a temperatura ambiente. En este sentido existe una importante influencia de la segregación de los elementos ferritizantes y austenitizantes que estabilizan dichas fases.

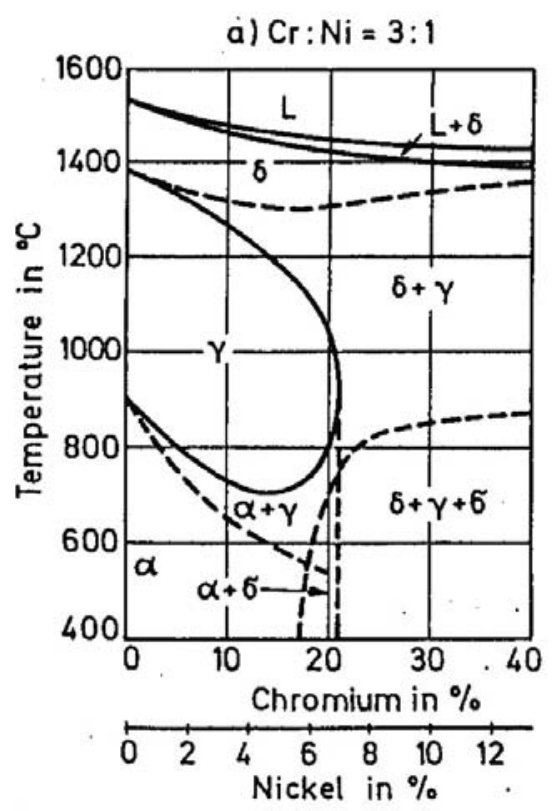

Figura 2.7. Diagrama cuasibinario representativo de los aceros inoxidables soft martensíticos del tipo $13 \mathrm{Cr} / 4 \mathrm{Ni}[10]$.

En virtud de la alta templabilidad de los AISM, la transformación martensítica ocurre mediante enfriamiento al aire. Las Figuras 2.8 y 2.9 son microestructuras de estos aceros en el estado "como soldado" donde se pueden apreciar la presencia de martensita, austenita retenida y ferrita delta residual. La martensita producida en estos metales de soldadura es denominada muchas veces martensita tenaz en virtud de su muy bajo contenido de carbono ( $C<0,03$ ó 0,07 dependiendo del tipo de consumible para un dado proceso de soldadura (SMAW, GMAW, FCAW). La ferrita delta se presenta como un entramado acicular y las submicroscópicas partículas de austenita se ubican entre láminas de martensita. Las fases residuales de ferrita delta y austenita retenida, pueden ser disueltas por solubilizados a altas temperaturas, típicamente mediante tratamientos térmicos post soldadura de solubilizado y temple [8]. Normalmente son empleadas temperaturas entre los 950 y $1050^{\circ} \mathrm{C}$. Mediante 
estos tratamientos es posible obtener estructuras enteramente martensíticas que pueden ser sometidas, si los requerimientos lo exigen, a revenidos posteriores.

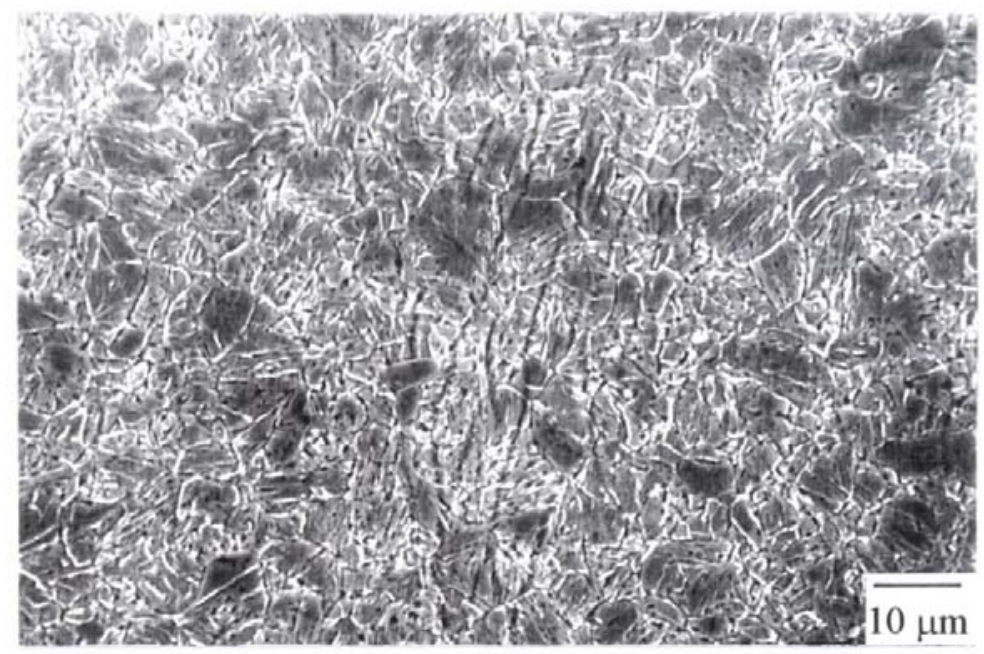

Figura 2.8. Microestructura de acero $13 \mathrm{Cr} 6 \mathrm{NiMo}$ en el estado "como soldado". Se aprecia la presencia de martensita, austenita retenida y ferrita delta residual [12]. 1000X.

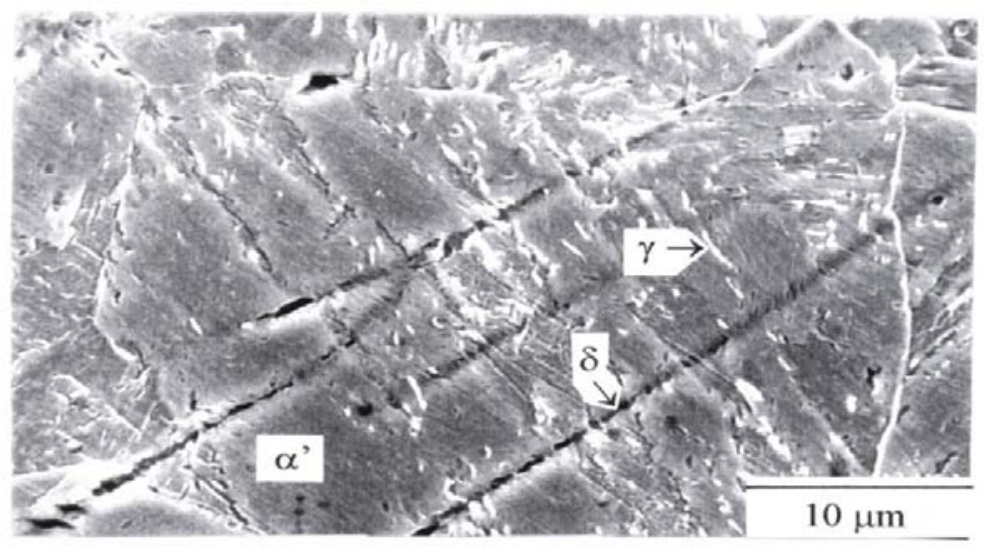

Figura 2.9 Microestructura de acero 13Cr6NiMo en el estado "como soldado". Se aprecia la presencia de martensita, austenita retenida y ferrita delta residual [12]. 3000X.

La Figura 2.10 muestra la influencia del $\mathrm{Ni}$ en el sistema Fe-Cr. El efecto del Ni es importante para los aceros inoxidables martensíticos de bajo carbono y la Figura 2.7 muestra claramente como el campo de la fase $\gamma$ es ampliado por la adición de Ni. La transformación secundaria se reduce de 900 a $700^{\circ} \mathrm{C}$. Debido a la extensión del campo de fase $\gamma$ la formación de la indeseable $\delta$-ferrita se puede evitar. 


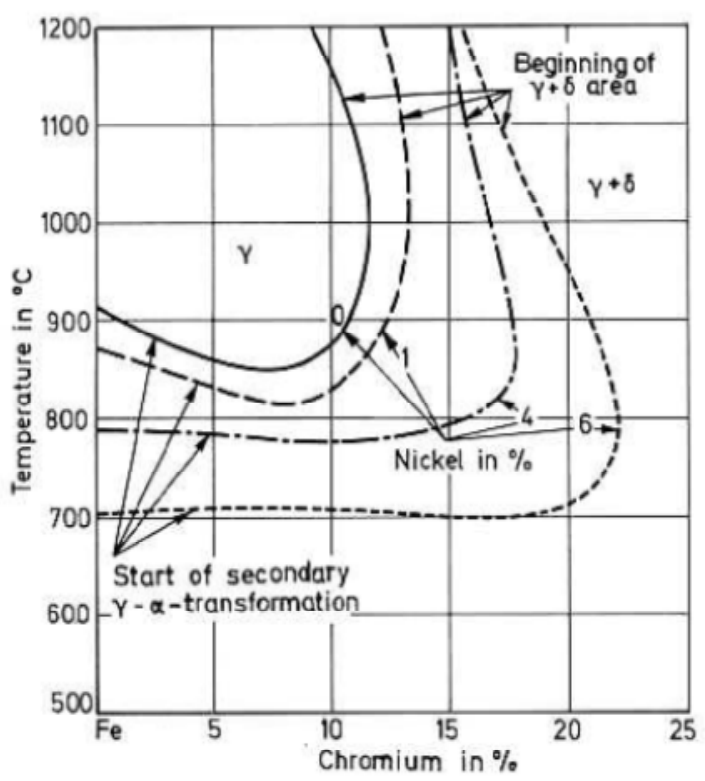

Figura 2.10. La influencia de Ni en la extensión del campo de fase $\gamma$ del sistema Fe-Cr.

\subsubsection{Carbono}

El carbono tiene un efecto fuertemente austenitizante, en particular expandiendo el rango bifásico $\delta$ - $\gamma$ (Figura 2.11), hacia más altos contenidos de cromo con la posibilidad de formación de carburos. En AISM, el contenido de carbono es muy bajo y la pérdida de efecto austenitizante es compensada por el agregado de níquel. De esta forma el acero mejora sus propiedades mecánicas, principalmente ductilidad y tenacidad, por reducción del contenido de ferrita $(\delta)$ y de su tamaño de grano, mediante el procesamiento en el rango austenítico. El cromo es un fuerte formador de carburos del tipo, $\mathrm{Cr}_{23} \mathrm{C}_{6}, \mathrm{Cr}_{7} \mathrm{C}_{3}$ y $\mathrm{Cr}_{3} \mathrm{C}_{2}$. Los dos primeros pueden formarse en aceros inoxidables. En muchos caso, sin embargo, una mezcla de $(\mathrm{Fe}, \mathrm{Cr})_{23} \mathrm{C}_{6}$ también es formado. Esto normalmente se designa como $\mathrm{M}_{23} \mathrm{C}_{6}$. De acuerdo a la Figura 2.12 esto se muestra para $\mathrm{Cr} 13 \%$ y el carburo se precipita por debajo de $700^{\circ} \mathrm{C}$, incluso a muy bajo contenido de carbono (por debajo de $0,01 \%$ ).

El carbono y el nitrógeno en presencia de cromo y molibdeno, puede conducir a la formación de una amplia gama de precipitados del tipo $M_{23} C_{6}$ y $M_{2} X$, reduciendo la concentración de cromo y molibdeno en la matriz, y por lo tanto disminuyendo la resistencia a la corrosión. 

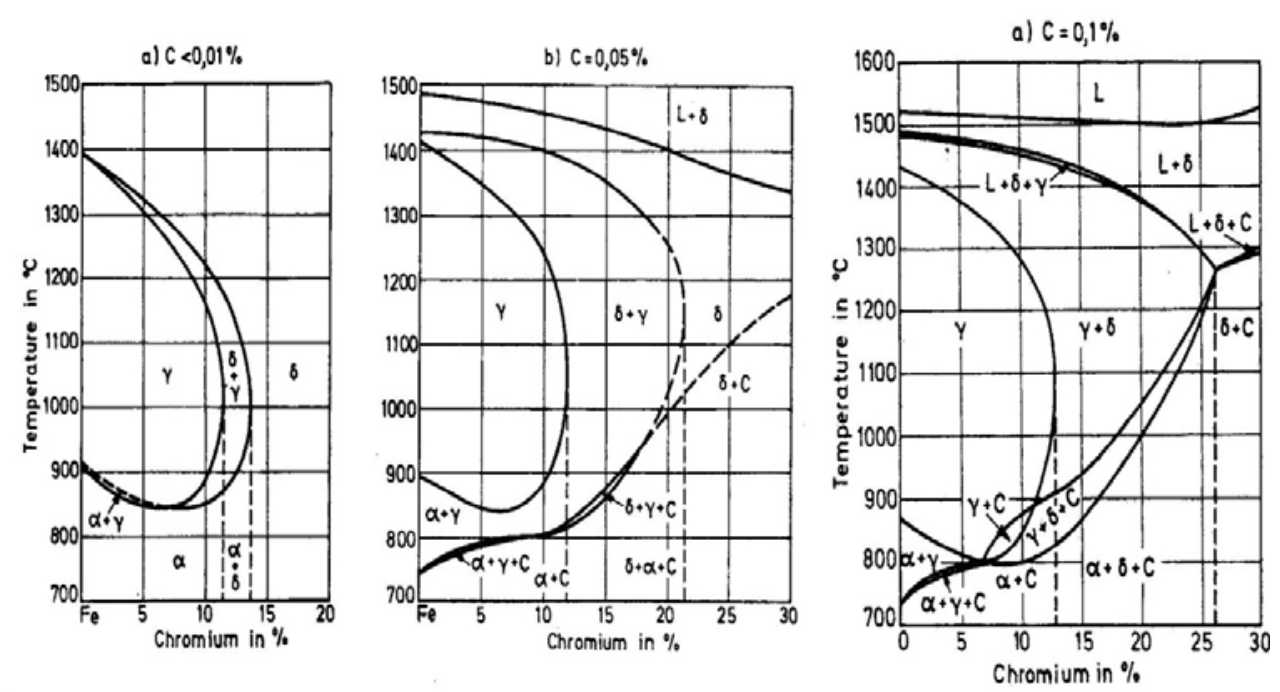

Figura 2.11. Influencia del $\mathrm{C}$ en la extensión del campo de fase del sistema Fe-Cr.

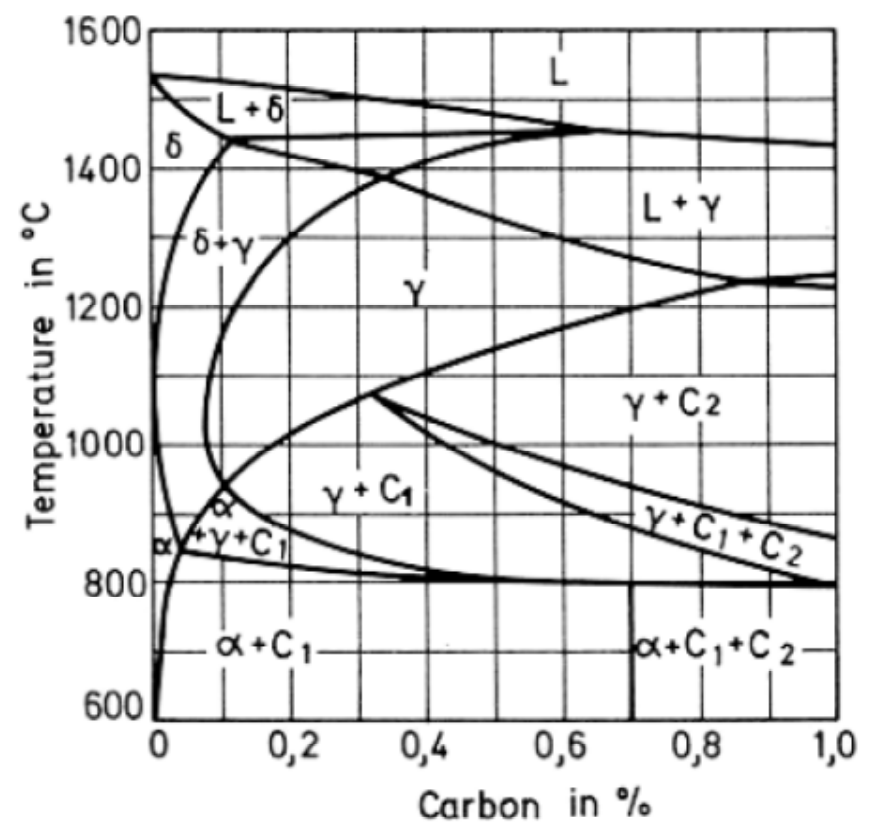

Figura 2.12. Diagrama de fase ternario $\mathrm{Fe}-\mathrm{Cr}-\mathrm{C}$ con $13 \% \mathrm{Cr}$.

\subsubsection{Molibdeno}

El molibdeno es un elemento muy importante en los aceros inoxidables. Tiene el mismo efecto que el $\mathrm{Cr}$ aumentando la resistencia a la corrosión considerablemente. El Mo promueve fuertemente la formación de ferrita. Por ello su contenido debe ser equilibrado por la adición de elementos que estabilizan la austenita, como el carbono, el nitrógeno o el níquel. Dependiendo de la agresividad del medio la cantidad de molibdeno utilizado oscila entre el 0-3\% en peso. El Mo contrae el campo de la fase $\gamma \mathrm{Fe}$, ver Figura 2.13 donde el 
efecto combinado de Mo y $\mathrm{C}$ es resumido. Junto con el Fe, el Mo forma fases intermetálicas. En los aceros inoxidables martensíticos, sin embargo el contenido de Mo se limita a un máximo de $3 \%$ y las fases de estos por lo tanto no tienen interés en esta tesis.

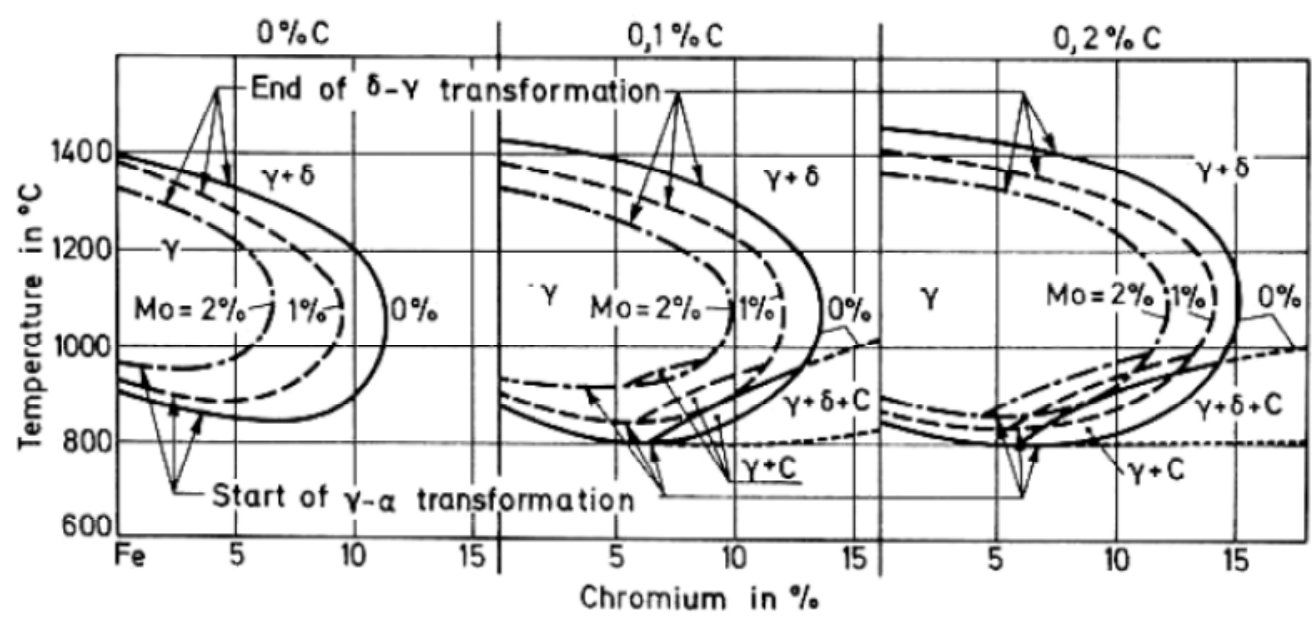

Figura 2.13. Influencia del C y Mo en la extensión del campo de fase del sistema Fe-Cr.

\subsubsection{Otros elementos aleantes}

El manganeso es un formador de austenita y el incremento del mismo hace que la transformación $\gamma \rightarrow \alpha$ sea desplazada a temperaturas más bajas. Como resultado la austenita puede llegar a ser estable a temperatura ambiente. El titanio es un formador de ferrita y posee una alta afinidad con el carbono, así también como con el nitrógeno. Por eso se utiliza el Nb para arrestar el titanio estable y libre. Con respecto a los AISM, el Ti se añade con el fin de restringir el crecimiento del grano en zona de fusión debido a la precipitación de pequeñas partículas de TiN.

El niobio es un formador de ferrita, y posee alta afinidad al C. Este efecto es usado en los metales de soldadura y aceros, para arrestar al $\mathrm{C}$ y formar el carburo de niobio ( $\mathrm{NbC})$, mejorando así la resistencia a la corrosión intergranular.

\subsection{Evaluación del contenido de ferrita delta residual y de austenita}

El Diagrama de Schaeffler (Figura 2.14) ilustra los efectos de los elementos aleantes sobre la microestructura de metales de soldadura de aceros inoxidables, teniendo en cuenta velocidades de enfriamiento usadas generalmente en las operaciones de soldadura. En el sector denominado " $\mathrm{M}$ " (martensita) el contenido de cromo equivalente llega aproximadamente hasta 15\%, mientras que el níquel equivalente está entre 5 y $10 \%$ para 
metales de soldadura de aceros inoxidables con más de $12 \%$ de $\mathrm{Cr}$. Para el caso de aceros $13 \% \mathrm{Cr}$ con $4-6 \%$ de $\mathrm{Ni}$, es posible encontrar además de martensita, cierta presencia de austenita retenida y de ferrita delta.

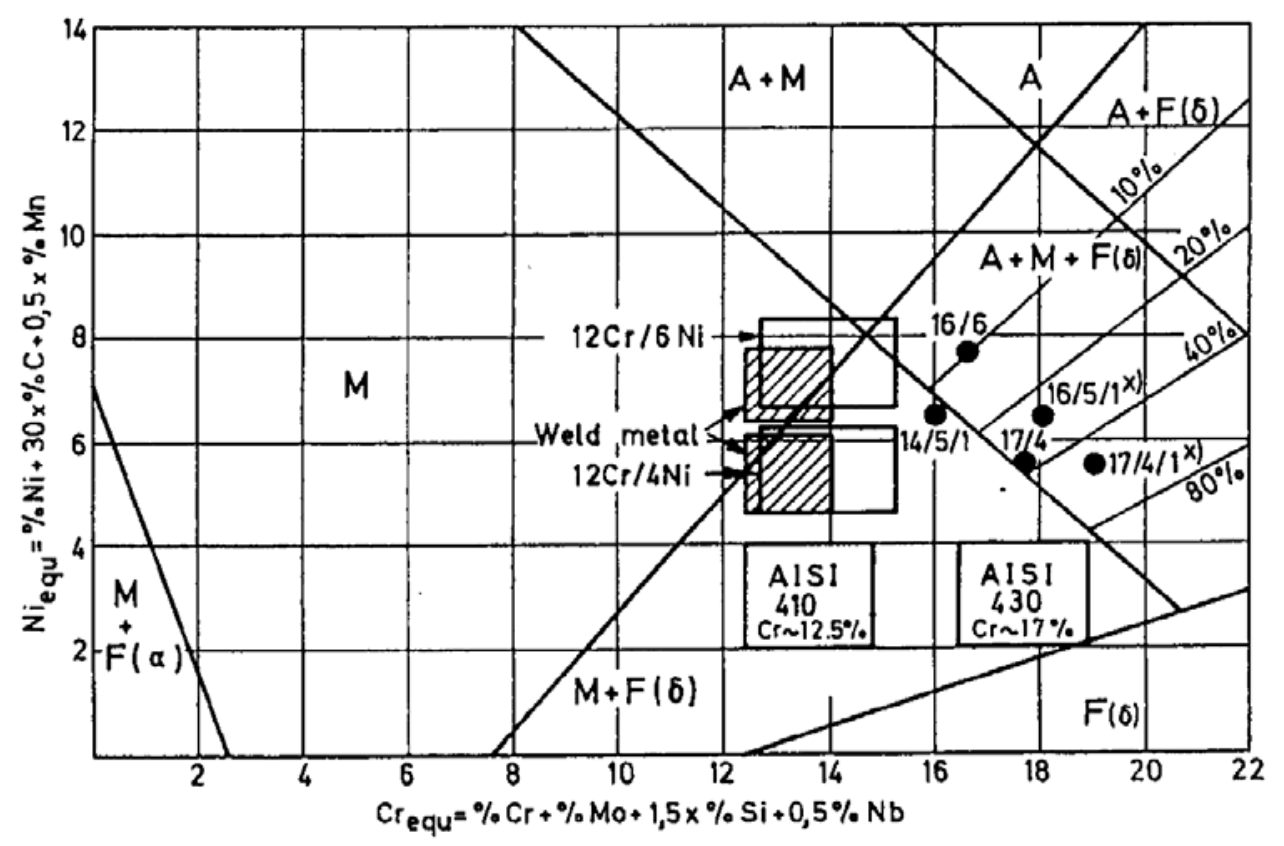

Figura 2.14. Diagrama de Schaeffler. Localización de aceros inoxidables con contenido de cromo y martensíticos de bajo carbono.

La relación cromo/níquel, es lo que determina el modo primario de solidificación, así como también los otros elementos aleantes que están presentes en el metal de soldadura, y la dilución del metal de soldadura con el metal base. En este sentido, el diagrama de Schaeffler, si bien con sus limitaciones, brinda una herramienta práctica muy valorable para correlacionar composición química y estructuras y determinar contenidos de ferrita delta en los metales de soldadura, permitiendo en particular para los grados austeníticos evaluar su resistencia a la fisuración en caliente. Este diagrama, desarrollado para metales de soldadura sin TTPS provee también una gruesa guía para materiales fundidos y forjados. En abscisas y ordenadas se expresan los contenidos de $\mathrm{Cr}$ equivalente y $\mathrm{Ni}$ equivalente, que para el caso de los AISM permite ubicarlos en una ventana de composición tal que sus contenidos de ferrita delta no superan el $10 \%$ en volumen [7].

Otro diagrama utilizado más recientemente, Figura 2.15, es el de Balmforth y Lippold [14], desarrollado para aceros inoxidables ferríticos-martensíticos que cubren un rango de composición que abarca la mayoría de los aceros inoxidables comerciales ferríticos y 
martensíticos. Los aceros softmartensíticos se encuentran en este diagrama con un contenido de ferrita delta menor a $20 \%$.

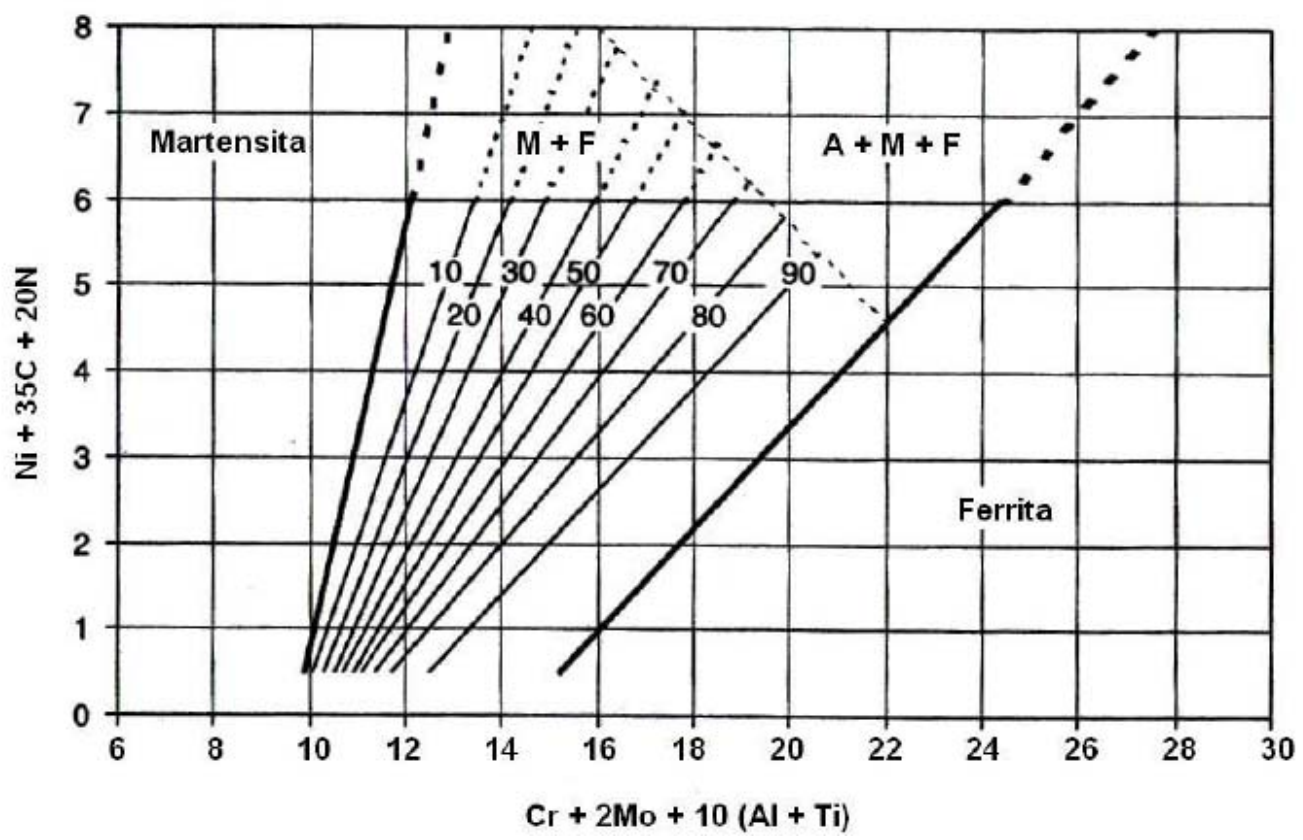

Figura 2.15. Diagrama de Balmforth. Localización de aceros inoxidables martensíticos con contenido de cromo y bajo carbono.

\subsubsection{Tratamientos térmico post soldadura}

Los AISM, particularmente los $13 \mathrm{Cr} / 4 \mathrm{Ni}$ y $13 \mathrm{Cr} / 6 \mathrm{Ni}$ poseen una gran soldabilidad. Cuando se requieren altos valores de tenacidad al impacto, hay que realizar TTPS. Estos tratamientos incluyen revenidos intercríticos alrededor de $A_{c 1}$ (temperatura a la cual comienza la formación de austenita) o doble revenido con y sin tratamiento de solubilizado.

Sus soldaduras requieren que sus metales de aporte tengan una restricción en los rangos composicionales de los aleantes, mayor respecto de la que tienen los productos fundidos o forjados. Esto asegura que la ferrita delta luego esté por debajo de ciertos valores límites. La razón de esos estrechos rangos composicionales obedece a que en soldadura, en la mayoría de los casos el metal depositado no es reaustenizado, templado y revenido como sí lo es el metal base; el metal de soldadura comúnmente es sometido a un revenido post soldadura.

Aquellos AISM con contenidos de Ni por encima de 3,5\%, tienen una particularidad metalúrgica, la formación de una muy fina dispersión austenita retenida estable que no se transforma en martensita con el enfriamiento al aire luego del revenido a temperaturas 
intercríticas entre 580 y $620^{\circ} \mathrm{C}$ [13]. A mayores temperaturas de revenido, la tenacidad al impacto disminuye, toda vez que las partículas de austenita retenida se pueden transformar a martensita durante el enfriamiento posterior al revenido. En estado "as weld", esta estructura es mayoritariamente martensita de bajo carbono, aunque con ferrita delta y austenita residual (ambas en bajos porcentajes, menores al 10\% y 5\% en volumen, respectivamente). Las islas de ferrita representan la herencia de las dendritas primarias de solidificación, y la austenita residual representa la incompleta transformación de austenita a martensita ocurrida en la solidificación de la soldadura. El níquel presenta una fuerte tendencia a la segregación interdendrítica por lo cual estas zonas podrán encontrarse enriquecidas en austenita residual [13].

Después de los TTPS se producen cambios microestructurales, debido a transformaciones y precipitaciones de fases que producen la estructura secundaria caracterizada por los siguientes constituyentes:

- Martensita revenida: constituida por ferrita alfa $(\alpha)$ y finos y bien distribuidos carburos $\left(\mathrm{M}_{23} \mathrm{C}_{6}\right)$. Esta microestructura brinda una muy buena combinación de resistencia mecánica y tenacidad.

- Austenita: constituida tanto por la fina austenita estable producida en la solidificación de la soldadura, como por la producida durante el revenido intercrítico (alrededor de los $600^{\circ} \mathrm{C}$ ). No existen en la literatura diferenciaciones entre ambos tipos de austenita, en particular en metales de soldadura. En productos de fundición, ambas austenitas pueden distinguirse en virtud del mayor tamaño de la austenita estable [7]. Desde el punto de vista de estabilidad frente a la transformación martensítica, responden de igual manera. En este sentido, las mediciones de austenita en estructuras primarias y secundarias por medio de técnicas muy precisas, como espectroscopía Mössbauer, comprueban que ambas austenitas se suman y no son transformables a martensita [1]. La literatura reporta que las razones de la estabilidad de la austenita estarían asociadas a fenómenos de segregación en dicha fase, que hacen descender su temperatura de comienzo de transformación martensítica [1][7][8][10][15].

- Ferrita delta: fácilmente distinguible por apropiados reactivos metalográficos.

En la Tabla 2.2 se muestran valores de propiedades mecánicas para varios metales de soldadura de AISM en distintas condiciones de TTPS. Asimismo, se presentan las 
temperaturas de inicio de transformación martensítica. Después de los TTPS pueden obtenerse muy buenas combinaciones de alta tenacidad.

Tabla 2.2. TTPS aplicados a metales de soldadura de AISM, obtenidos a partir de diferentes procesos de soldadura, y sus propiedades mecánicas [8].

\begin{tabular}{|c|c|c|c|c|c|c|c|c|c|c|c|c|c|c|c|c|}
\hline \multirow{3}{*}{$\begin{array}{l}\text { Grade } \\
\text { Short designation }\end{array}$} & \multirow{3}{*}{$\begin{array}{l}\text { AWS A5.4-81 } \\
\text { resp. 9-81 }\end{array}$} & \multirow{3}{*}{$\begin{array}{l}\text { Welding } \\
\text { process }\end{array}$} & \multirow{3}{*}{$\begin{array}{l}\text { IPT } \\
{ }^{\circ} \mathrm{C}\end{array}$} & \multirow{3}{*}{$\begin{array}{l}\text { Condition } \\
\text { heat treatment } \\
\text { temperature }{ }^{\circ} \mathrm{C} / \text { time }\end{array}$} & \multicolumn{4}{|c|}{ Mechanical properties } & \multirow{2}{*}{\multicolumn{5}{|c|}{ Chemical composition in \% }} & \multicolumn{2}{|c|}{$\begin{array}{c}\text { Structural } \\
\text { proportion in } \%\end{array}$} & \multirow{3}{*}{$\begin{array}{l}\text { Martensite } \\
\text { trans- } \\
\text { formation } \\
\mathrm{M}_{S} \text { point }{ }^{\circ} \mathrm{C}\end{array}$} \\
\hline & & & & & \multirow{2}{*}{$\begin{array}{l}0.2 \mathrm{YS} \\
\mathrm{N} / \mathrm{mm}^{2}\end{array}$} & \multirow{2}{*}{$\begin{array}{l}T S \\
\mathrm{~N} / \mathrm{mm}^{2}\end{array}$} & \multirow{2}{*}{ El. } & \multirow{2}{*}{$\begin{array}{l}I E / J \\
\mathrm{CVN}\end{array}$} & & & & & & \multirow{2}{*}{$\begin{array}{l}\text { Delta } \\
\text { ferrite }\end{array}$} & \multirow{2}{*}{ Austenite } & \\
\hline & & & & & & & & & $\mathrm{C}$ & $\mathrm{Cr}$ & Mo & $\mathrm{Ni}$ & Others & & & \\
\hline $12 \mathrm{Cr} / 1 \mathrm{Ni} \mathrm{L}$ & E $410 \mathrm{Ni}$ & SMAW & 230 & as welded & 755 & 994 & 12.0 & 23 & 0.032 & 12.01 & - & 1.45 & - & $12-18$ & $0-2$ & 290 \\
\hline & & & 230 & annealed $700 / 2 \mathrm{~h}$ & 554 & 678 & 21.8 & 85 & & & & & & & & \\
\hline & & & 150 & annealed $700 / 2 \mathrm{~h}$ & 541 & 673 & 21.0 & 68 & & & & & & & & \\
\hline $13 \mathrm{Cr} / 4 \mathrm{Ni} / \mathrm{MoL}$ & E $410 \mathrm{NiMo}$ & SMAW & 130 & as welded & 891 & 1073 & 13.0 & 36 & 0.031 & 12.28 & 0.50 & 4.58 & - & $1-3$ & $2-6$ & 240 \\
\hline & & & & tempered $600 / 2 \mathrm{~h}$ & 720 & 891 & 19.0 & 73 & & & & & & & & \\
\hline & & & & quenched + tempered & 710 & 864 & 19.5 & 95 & & & & & & & & \\
\hline $13 \mathrm{Cr} / 4 \mathrm{Ni} / \mathrm{MoL}$ & ER $410 \mathrm{NiMo}$ & GMAW & 130 & & 775 & 885 & 18.9 & 88 & 0.022 & 1282 & 0.48 & 3.96 & - & & $2-5$ & \\
\hline $13 \mathrm{Cr} / 4 \mathrm{Ni} / \mathrm{Mo} \mathrm{L}$ & ER $410 \mathrm{NiMo}$ & GTAW & 130 & & 742 & 855 & 21.7 & 132 & 0.018 & 1248 & 051 & 4 & $\pi$ & $1-3$ & $2-5$ & 240 \\
\hline $13 \mathrm{Cr} / 6 \mathrm{Ni} / \mathrm{Mo} \mathrm{L}$ & - & SMAW & 120 & as welded & 834 & 1062 & 12.8 & 31 & 0.018 & & 0.51 & 4.44 & - & $1-3$ & $2-5$ & 240 \\
\hline & & & & $\begin{array}{l}\text { as welded } \\
\text { tempered } 600 / 2 \mathrm{~h}\end{array}$ & 621 & 879 & 18.0 & 58 & 0.028 & 12.36 & 0.58 & 5.76 & - & $0-2$ & $8-10$ & 220 \\
\hline & & & & quenched + tempered & 637 & 825 & 20.8 & 68 & & & & & & & & \\
\hline & & & & $950 / 1 \mathrm{~h} / \mathrm{air}+600 / 2 \mathrm{~h}$ & & & & & & & & & & & & \\
\hline $16 \mathrm{Cr} / 6 \mathrm{Ni} / \mathrm{MoL}$ & - & SMAW & 80 & as welded & 480 & 1115 & 7.4 & 27 & 0.037 & 16.11 & 0.57 & 5.68 & - & $7-10$ & $\sim 12$ & 120 \\
\hline & & & & tempered $540 / 10 \mathrm{~h}$ & 785 & .984 & 16.4 & 42 & & & & & & & & \\
\hline $16 \mathrm{Cr} / 5 \mathrm{Ni} /$ & - & SMAW & 70 & as welded & 432 & 1080 & 8.8 & 33 & 0.044 & 15.97 & 1.36 & 4.93 & - & $9-12$ & $25-33$ & 120 \\
\hline $1 \mathrm{MoL}$ & & & & tempered $540 / 10 \mathrm{~h}$ & 743 & 1045 & 15.7 & 38 & & & & & & $9-12$ & $16-26$ & \\
\hline & & & & tempered $580 / 10 \mathrm{~h}$ & 708 & 1038 & 14.2 & 41 & & & & & & $9-12$ & 14 & \\
\hline $14 \mathrm{Cr} / 6 \mathrm{Ni} /$ & - & SMAW & 70 & as welded & 363 & 1054 & 13.2 & 32 & 0.035 & 13.53 & 1.95 & 6.18 & $\mathrm{Cu}=2.7$ & $1-3$ & $>50$ & 110 \\
\hline $2 \mathrm{MoL}+\mathrm{Cu}+\mathrm{N}$ & & & & $\begin{array}{l}\text { quenched + tempered } \\
1050 / 2 \mathrm{~h} / \text { air }+580 / 4 \mathrm{~h}\end{array}$ & 787 & 1032 & 19.2 & 52 & & & & & $\mathrm{Nb}=0.2$ & $1-3$ & $12-22$ & \\
\hline $16 \mathrm{Cr} / 6 \mathrm{Ni} / \mathrm{MoL}$ & - & SMAW & 70 & as welded & 417 & 957 & 13.6 & 45 & 0.031 & 15.89 & 0.56 & 5.83 & $\mathrm{Cu}=1.6$ & - & - & 100 \\
\hline$+\mathrm{Cu}+\mathrm{Nb}$ & & & & tempered $540 / 3 \mathrm{~h}$ & 633 & 988 & 18.3 & 43 & & & & & $\mathrm{Nb}=0.2$ & & & \\
\hline $17 \mathrm{Cr} / 5 \mathrm{Ni} / \mathrm{MoL}$ & E 630 & SMAW & 70 & as welded & 742 & 943 & 5.3 & 40 & 0.042 & 16.63 & 0.42 & 4.48 & $\mathrm{Cu}=3.4$. & - & - & - \\
\hline$+\mathrm{Cu}+\mathrm{Nb}$ & & & & $\begin{array}{l}\text { quenched + tempered } \\
1050 / \mathrm{h} / \mathrm{air}+480 / 12 \mathrm{~h}\end{array}$ & 1236 & 1382 & 14.2 & 14 & & & & & $\mathrm{Nb}=0.3$ & & & \\
\hline
\end{tabular}

Para alcanzar las propiedades mecánicas óptimas y de resistencia a la corrosión, las soldaduras deben ser sometidas a TTPS que incluyan solubilización y temple. El solubilizado es realizado en el campo austenítico a temperaturas entre $950-1050^{\circ} \mathrm{C}$ para asegurar la disolución de las fases residuales de ferrita delta y austenita residual, con posterior enfriamiento (temple) al aire, resultando una estructura prácticamente $100 \%$ martensítica. Esto repercute en un aumento de la resistencia mecánica del material. Además, la disolución de ferrita delta no sólo mejora la tenacidad al impacto, sino también la resistencia a la corrosión, ya que la ferrita delta puede representar una región de ataque corrosivo localizado.

Los procesos que pueden presentarse son principalmente la precipitación de carburos y/o carbonitruros, y la precipitación de austenita retenida como resultado del templado, debido al bajo contenido carbono precipitará una menor cantidad de carburos. A 
temperaturas altas el carbono está disuelto en toda la matriz. En este estado se mantiene durante la transformación de austenita a martensita. La precipitación de los carburos y/o carbonitruros ocurre en gran parte dentro del grano de martensita y en menor medida en el borde, por ello es menos probable la corrosión en los bordes de grano. Depende del contenido de nitrógeno también podría haber precipitación de carbonitruros. No existe la posibilidad fragilización por fase sigma ya que el contenido de cromo en AISM es pequeño. La fragilización sólo podría darse en algunos grados con $17 \%$ de cromo y luego de grandes tiempos de exposición a temperaturas de $550^{\circ} \mathrm{C}[16]$.

\subsubsection{Austenita Retenida}

En el caso de los AISM el revenido intercrítico (aproximadamente a $600^{\circ} \mathrm{C}$ ) genera una precipitación de una fina dispersión de partículas de austenita. Esta es la llamada austenita retenida. Las temperaturas pueden llegar a ser menores que $600^{\circ} \mathrm{C}$ pero ello está determinado por el nivel de segregación durante la solidificación y las condiciones de enfriamiento.

Las partículas de austenita precipitan tanto en bordes de grano primario como entre las láminas de martensita y bordes de "packets" , ver Figura 2.16.

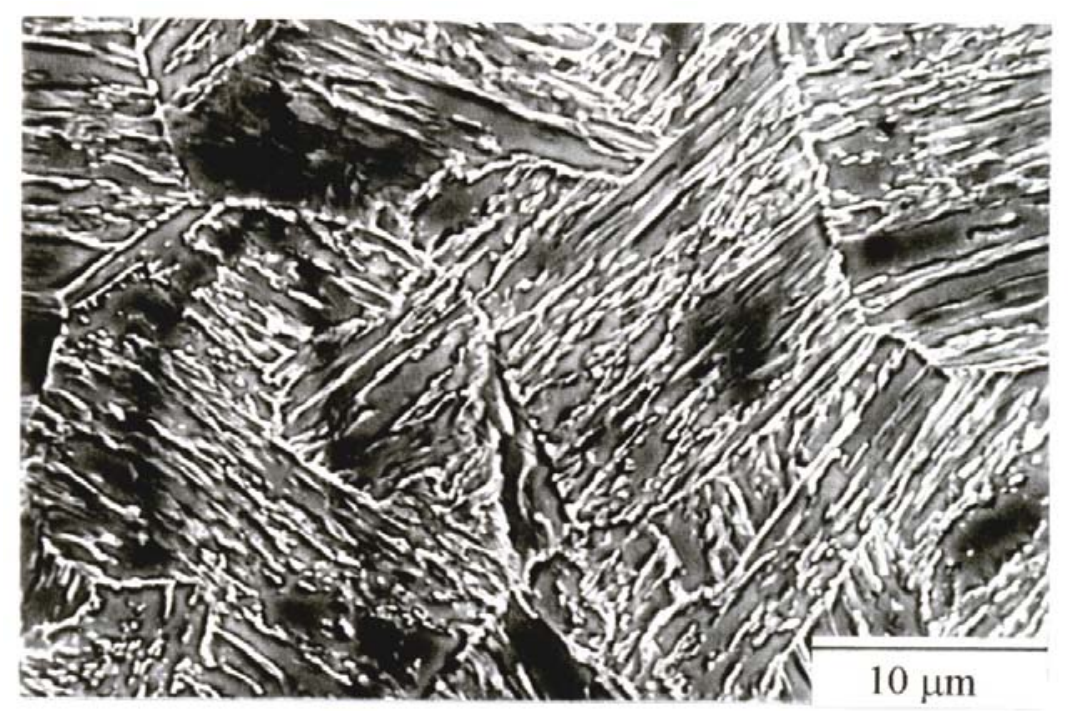

Figura 2.16. Partículas de austenita en una matriz de ferrita. Metal de soldadura $13 \mathrm{Cr} 4 \mathrm{NiMo}$ con revenido $600^{\circ} \mathrm{C} / 2 \mathrm{hs}, 3000 \mathrm{X}[12]$.

El resultado de la austenita retenida después del tratamiento térmico es beneficioso para la ductilidad y la tenacidad. Mientras que la dureza y resistencia mecánica se 
mantienen constantes, la resistencia a la corrosión por picado es muy pobre debido a la aparición de precipitados enriquecidos en Cr en los límites de grano [17].

Así, ha sido sugerido [12] que este tipo de fina dispersión de austenita retenida podría desarrollarse por un mecanismo de corte de la red cristalina.

La formación de austenita desde martensita o martensita revenida puede ser extremadamente rápida en particular para aceros conteniendo níquel.

Para los AISM, la formación de austenita estable comienza alrededor de los $580^{\circ} \mathrm{C}$, alcanzando un contenido máximo en $620^{\circ} \mathrm{C}$ y luego desciende con el aumento de temperatura, dado que va perdiendo estabilidad y puede entonces transformar a martensita "fresh". Esto requiere en la mayoría de los casos tratamientos térmicos de doble revenido.

Existen tres rangos de temperaturas de revenido para aceros del tipo $13 \mathrm{Cr} / 4 \mathrm{NiMo}$ [1][15][18][19,20]:

-Revenidos por debajo de los $600^{\circ} \mathrm{C}$, donde las estructuras no presentan apreciable presencia y efectos de austenita retenida y tampoco de martensita "fresh".

-Revenidos entre 600 y $625^{\circ} \mathrm{C}$ y contenidos de carbono en $0,03 \%$. Se obtiene la precipitación de austenita retenida.

-Revenidos por encima de $625^{\circ} \mathrm{C}$. En estos casos la austenita que se formó es inestable y parte de ella transforma a martensita fresh y parte queda como austenita retenida. 

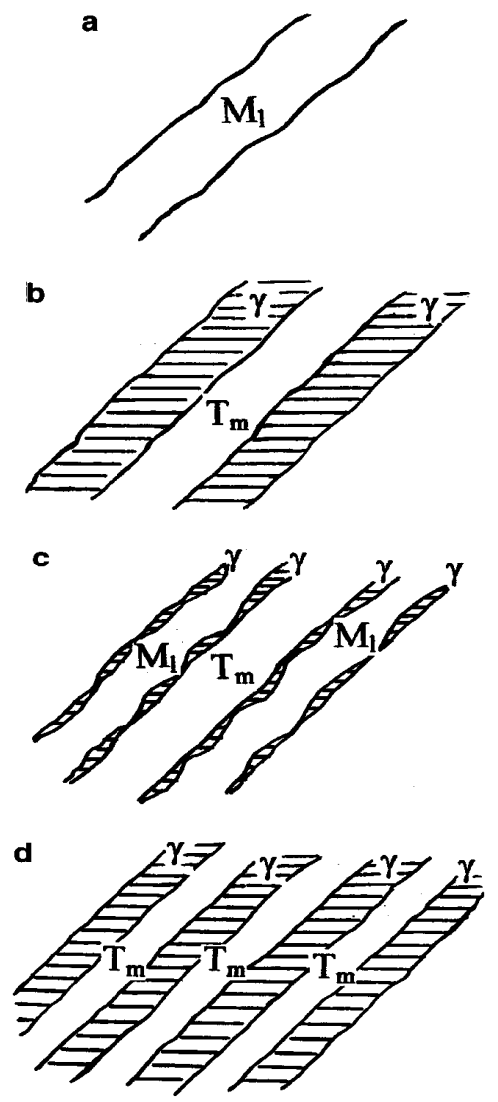

Figura 2.17. Esquema de la estructura refinada del doble revenido: (a) $950^{\circ} \mathrm{C} / 1 \mathrm{~h} /$ aire, listón Martensita $\left(\mathrm{M}_{1}\right)$, (b) $950^{\circ} \mathrm{C} / 1 \mathrm{~h} /$ aire $+670^{\circ} \mathrm{C} /$ durante el calentamiento. $\mathrm{T}_{\mathrm{m}}$ : martensita templada, $\gamma$ : austenita, (c) $950^{\circ} \mathrm{C} / 1 \mathrm{~h} /$ aire $+670^{\circ} \mathrm{C} / 2 \mathrm{~h} /$ aire (despues del enfriamiento). $\mathrm{T}_{\mathrm{m}}$ : martensita templada, $\mathrm{M}_{1}$ : listón Martensita, $\gamma$ : austenita, (d) $950^{\circ} \mathrm{C} / 1 \mathrm{~h} /$ aire $+670^{\circ} \mathrm{C} / 2 \mathrm{~h} /$ aire $+600^{\circ} \mathrm{C} / 2 \mathrm{~h} /$ aire. $\mathrm{T}_{\mathrm{m}}$ : martensita templada, $\gamma$ : austenita [21].

La precipitación de austenita estable puede hacerse más masiva mediante dobles revenidos [22], Figura 2.17; y esto mejora las propiedades mecánicas. Si el primer revenido es realizado a temperaturas donde la austenita precipitada comienza a inestabilizarse (por ej. $625-670^{\circ} \mathrm{C}$ ) durante el enfriamiento del primer revenido transformará parte de ella a martensita fresh. Un revenido secundario realizado ahora a $600^{\circ} \mathrm{C}$ provocará que en virtud de mayores interfases de nucleación para austenita estable (las nuevas interfases austenita estable/martensita fresh) los contenidos de esta fase aumentan sin perder sus características morfológicas submicroscópicas. Lo que se consigue es un "refinamiento" de la estructura con mayor contenido de austenita estable. 


\subsection{Pasividad de los aceros inoxidables}

Una de las características más importantes de los aceros inoxidables, y de ahí el origen de su nombre, es su resistencia a la corrosión. La misma depende de la formación de una película superficial pasivante que le confiere un alto grado de nobleza a la aleación.

La determinación de la curva de polarización anódica de los aceros inoxidables en una dada solución permite poner en evidencia los cambios de la velocidad de disolución del mismo para valores crecientes del potencial. La corriente crece rápidamente desde el potencial de reposo del electrodo activo en la denominada zona de disolución activa hasta alcanzar la región de transición entre los estados activo y pasivo. Esta última está caracterizada bien por un pico de corriente simple con una brusca disminución de la corriente anódica a partir de un potencial crítico (potencial de pasivación), por una corriente límite que se extiende durante unas décimas de volt y es atribuida a la formación de una película difusional o una capa salina no protectora previa a la pasivación, o por múltiples picos de corriente, comúnmente dos o tres, que revelan prepasivación y pasivación conforme a un mecanismo complejo de reacción. A partir de aquí la corriente anódica, de varios órdenes de magnitud menor, permanece por lo general constante en una amplia zona de potencial en la denominada región pasiva (corriente de pasivación). A potenciales más positivos que aquellos de la pasividad, ocurre el fenómeno de transpasividad, caracterizado por una corriente anódica que vuelve a crecer algunos órdenes de magnitud por formación de especies superficiales de valencia superior. Finalmente tiene lugar la descomposición del medio electrolítico que para electrolitos acuosos corresponde al desprendimiento de oxígeno.

Los aceros inoxidables fueron ideados hace 100 años atrás por Monnartz [23]. Hoy en día, su uso se encuentra en crecimiento a una tasa de un $5 \%$ anual en el mundo. Los mismos se encuentran en constante desarrollo. La literatura muestra que la resistencia a la corrosión de los aceros inoxidables puede ser mejorada entre otras formas mediante el agregado de aleantes. Esto es posible porque la composición y otras propiedades de la película pasivante dependen de los elementos aleantes, el medio corrosivo, el tratamiento superficial y la temperatura [24]. Numerosos investigadores han contribuido al presente conocimiento de los procesos que gobiernan el crecimiento y rotura de la película pasiva como una función de la composición del material y del medio ambiente. Es conocido que la película pasiva se adapta a los cambios en el potencial eléctrico o la concentración de iones en los electrolitos. 
Sus propiedades proveen la clave para la resistencia de los aceros inoxidables a los ataques corrosivos.

La película pasivante es una película adherente, invisible, densa y estable, que aísla al material del medio. La misma puede disminuir la corriente de disolución en varios órdenes de magnitud [25].

En todos los casos se observa una característica común: la pasividad aparece por encima de un cierto potencial, llamado potencial de Flade. La pasivación puede producirse aplicando una corriente exterior o usando un oxidante suficientemente energético como para llevar al metal a un potencial por encima del de Flade. Franck [26] y Vetter [27] destacan que el potencial de Flade varía con el pH de las soluciones, según una ecuación del tipo:

$$
E_{\text {Flade }}=E_{0}-0,059 . p H
$$

Su composición ha sido estudiada durante años, Fontana [28], Mahla y Nielsen [29], utilizando técnicas de difracción de electrones, encontraron que la capa pasiva contenía $\mathrm{Cr}_{2} \mathrm{O}_{3}$ y $\mathrm{Cr}(\mathrm{OH})_{3}$. Años más tarde y con el desarrollo de técnicas modernas de análisis de superficies, varios investigadores [30,31] encontraron que, al poner en contacto un acero inoxidable austenítico con soluciones acuosas ácidas, la película pasiva formada, consistía de una capa interna de óxidos de cromo $(+3)$ y hierro $(+3)$, compuesta mayoritariamente por $\mathrm{Cr}_{2} \mathrm{O}_{3}$, y una capa externa de hidróxidos.

Sin duda alguna, el elemento esencial para la formación y estabilización de la capa pasivante es el $\mathrm{Cr}$. Para que se forme esta película protectora, es necesario adiciones superiores al $12 \%$. En la Figura 2.18 se observa que la presencia de $12 \%$ de $\mathrm{Cr}$ en el acero expuesto a la atmósfera reduce de manera significativa la velocidad de corrosión. 


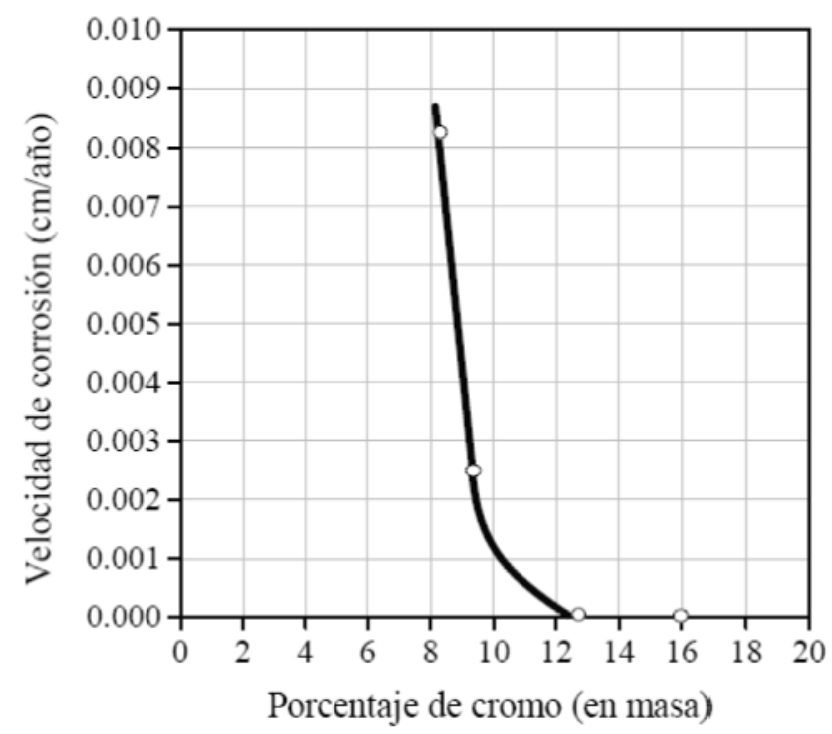

Figura 2.18. Influencia del contenido en cromo en la velocidad de corrosión de aleaciones Fe-Cr en contacto con la atmósfera.

Originalmente la teoría de formación de la película se debe a Michael Faraday, quien en el siglo XIX estudió superficies de hierro. Una revisión temprana de las investigaciones de la película fue escrita por Uhlig [32]. Una introducción general de la teoría de la pasividad fue publicada por Sato [33], mientras las propiedades electrónicas de la película pasiva en diferentes materiales han sido más recientemente consideradas por Schultze y Lohrengel [34].

La espectroscopía electrónica ha sido usada en la primer parte de la década de 1970 para estudiar la composición y el espesor de las películas pasivantes, incluyendo la determinación de los estados de oxidación y la distribución porcentual atómica en profundidad de los diferentes elementos constituyentes de la película. La Espectroscopía Fotoelectrónica de Rayos X (XPS, también conocida como ESCA, Espectroscopía Electrónica para el Análisis Químico) y la Espectroscopía Electrónica Auger (AES) han sido mayormente utilizadas, pero otros métodos secundarios como SIMS (Secondary Ion Mass Spectrometry) e ISS (Ion Scattering Spectroscopy) también proveen información importante.

Basado en los análisis de superficies, se ha sugerido un modelo de tres capas para la película pasiva formada en aceros inoxidables austeníticos en solución ácida: la capa externa de la película consiste en una película de hidróxido por encima y una capa doble de óxido por debajo. La película de oxi-hidróxido se forma anódicamente sobre una región superficial del metal base que está enriquecida en níquel, el origen de tal enriquecimiento es la 
oxidación selectiva de Fe y $\mathrm{Cr}$ durante la polarización anódica. La Figura 2.19 se obtiene a partir de medidas de XPS sobre la película pasivante. La película de óxido resulta enriquecida en cromo y por debajo de la interfase metal/película se observa un fuerte enriquecimiento en níquel. En soluciones alcalinas, la oxidación para formar un catión metálico en la solución acuosa es baja para el Fe y alta para el $\mathrm{Cr}$; esto afecta el nivel de enriquecimiento de cromo en la película. La región externa consiste de una capa enriquecida de hierro, una característica que se ha observado también con XPS [35]. En el centro de la película pasiva, existe un fuerte enriquecimiento de $\mathrm{Cr}$, mientras que en la región más próxima a la interfase metal/película la composición corresponde a la del metal. Esto implica que el enriquecimiento en $\mathrm{Cr}$ es causado por la disolución de Fe. La investigación de capas pasivas en diversos metales con XPS e ISS ha sido reportado por Strehblow [36].

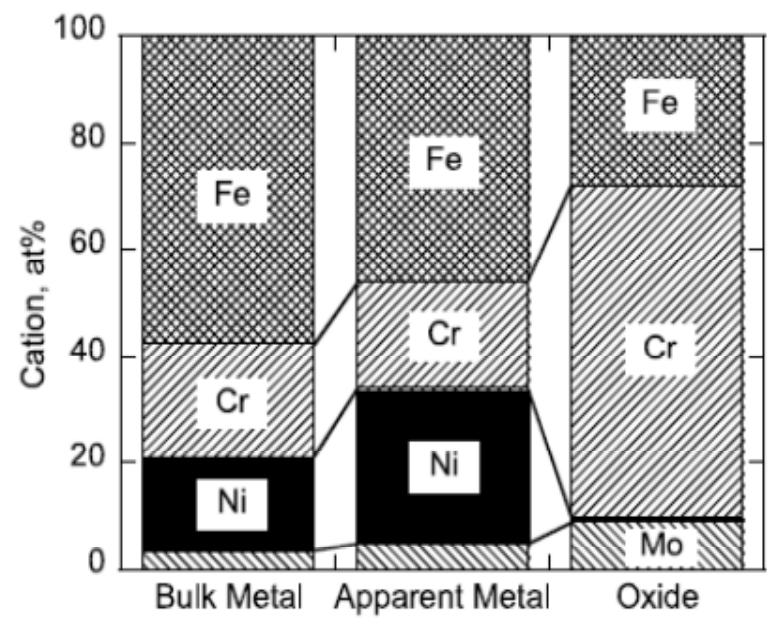

Figura 2.19. Gradientes composicionales en produndidad determinados mediante medidas de XPS de una película pasivante formada anódiamente sobre un acero inoxidable en solución de $0,1 \mathrm{M} \mathrm{HCl}+0,4 \mathrm{M}$ de $\mathrm{NaCl}$ y del sustrato metálico subyacente [37].

En cuanto a la influencia del medio ambiente en la composición de la película, la película pasiva intercambia especies con el electrolito y como consecuencia altera su espesor y composición hasta alcanzar un estado estacionario para el cual estos dejan de cambiar. Entre los factores más destacados que influyen sobre la película podemos citar el potencial, la presencia de haluros en el electrolito, el pH y la temperatura.

El espesor de la película pasivante de los aceros inoxidables crece linealmente con el potencial aplicado. Esto se ilustra en la Figura 2.20 para aleaciones de $\mathrm{Fe} 15 \mathrm{Cr}$ en ácido sulfúrico [38] frente a Fe10Cr y Fe20Cr en solución de hidróxido de sodio [39]. En solución básica las películas son considerablemente más gruesas, ya que la disolución es menor. El 
aumento observado del espesor de película con el potencial en una solución ácida se debe principalmente a la formación de óxido; la formación de hidróxido en la película es independiente del potencial $[37,40]$.

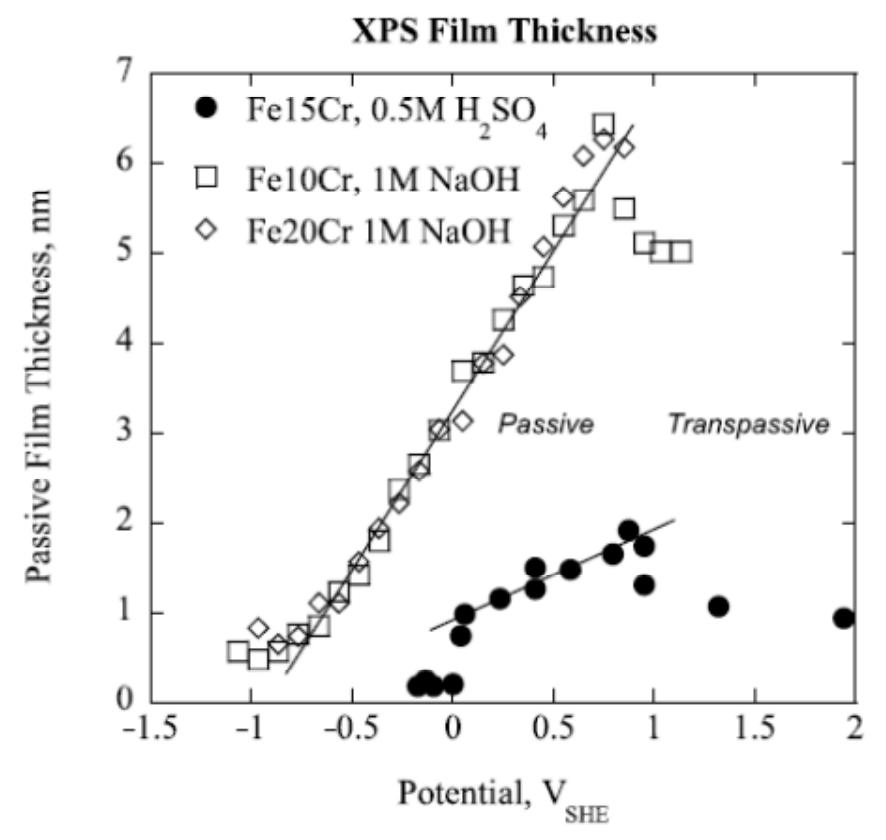

Figura 2.20. Estimación de los espesores de óxidos en aleaciones $\mathrm{Fe} 15 \mathrm{Cr}$ en $0,5 \mathrm{M} \mathrm{H}_{2} \mathrm{SO}_{4}, \mathrm{Y}$ para el Fe10Cr y Fe20Cr en $1 \mathrm{M} \mathrm{NaOH}$, en función del potencial, utilizando XPS.

Maurice et al. han estudiado el desarrollo de la película pasiva con el tiempo [41]. Entre 20 minutos y 20 horas de polarización, se encuentra que existe un pequeño cambio en el espesor de la película. También se observa que la capa de óxido crece a expensas de la capa de hidróxido.

La composición química de la película también varía con el potencial. Para aleaciones Fe-Cr, ocurre un enriquecimiento en $\mathrm{Cr}$ de la película en la región de potenciales bajos de la pasividad, pero en la parte alta disminuye ya que la estabilidad del Fe aumenta. El Cr puede llegar al estado oxidado de valencia +6 , soluble. A altos valores de potencial en la pasividad, el Fe funciona como un estabilizador sobre el $\mathrm{Cr}(+3)$, las aleaciones $\mathrm{Fe}-\mathrm{Cr}$ son estables en un rango más amplio de potenciales que el cromo puro. Números de oxidación mayores son también dominantes hacia el extremo superior de la región pasiva como se confirma por XANES [42].

La presencia de ciertos aniones adsorbidos en la superficie, o que se encuentran incorporados en la película pasiva pueden ser perjudiciales para la estabilidad de la película e iniciar la formación de picaduras. En cuanto al cloruro, existe un gran número de 
publicaciones que se explayan sobre los efectos en el picado. Tres modelos son frecuentemente citados: la adsorción que lleva a la disolución localizada, la penetración de aniones en la película que conduce al debilitamiento de los enlaces de óxido, y el quiebre de la película provocando grietas y dislocaciones [43]. No es posible establecer un mínimo de contenido de cloruros en la película, frecuentemente se cita entre el 1 al 5\%. Debido a que la película es muy delgada y a la posible presencia de defectos estructurales, no es fácil distinguir entre las especies adsorbidas y las incorporadas. Utilizando AES y XPS, se muestra que, en medios conteniendo sulfatos los mismos se encuentran presentes o cercanos a la superficie de la película $[44,45]$. Los cloruros enriquecen la superficie de la película pasiva, y su distribución con respecto a los sulfatos es más homogénea [46], especialmente a temperaturas elevadas [40]. Mischler y colaboradores, han demostrado que el Mo reduce el contenido de cloruros y sulfatos en la superficie de la película [47]. Mitrovic-Scepanovic et al. [48] encontraron que los cloruros tienen una mayor tendencia que los sulfatos a penetrar la película pasivante en las aleaciones Fe-Cr. La penetración de los cloruros en la película intacta pudo ser investigada a partir de la formación de la película en un medio libre de cloruros, y luego exponerla a una solución con cloruros. Cada uno de los experimentos han sido llevadas a cabo por Hubschmid y colaboradores en aleaciones de Fe-25Cr-X [49].

El mayor efecto del incremento de $\mathrm{pH}$ es la menor disolución en la película, como consecuencia a mayor pH las películas son más gruesas y existe una mayor proporción de Fe en las mismas, ya que los óxidos de hierro son más estables en solución básica. El efecto del $\mathrm{pH}$ fue ilustrado por Schmutz y Landolt, que compararon la respuesta de dos aleaciones $\mathrm{FeCr}$ y FeCrMo en soluciones ácidas y básicas [50]. Strehblow et al. [38,39] encontraron espesores gruesos de películas en soluciones básicas. También encontraron un incremento en el óxido de iones Fe (+3).

\subsubsection{Influencia de los aleantes}

\subsubsection{Hierro}

En solución ácida, la polarización anódica de aleaciones $\mathrm{Fe}-\mathrm{Cr}$ en la región pasiva provoca una disolución de Fe, dejando la película pasiva enriquecida en Cr. Este comportamiento es gobernado por la diferencia de difusión de $\mathrm{Fe} \mathrm{y} \mathrm{Cr}$ en la película [35,51]. La capa externa de la película se encuentra enriquecida en Fe. Esto es posible debido a la alta velocidad de difusión del Fe a través de la película. A 0,58V referidos al Electrodo 
Normal de Hidrógeno (ENH), la valencia del Fe pasa de 2 a 3 [38] en una solución de ácido, para una solución básica el potencial correspondiente es de -0,3V (ENH) [52].

\subsubsection{Cromo}

Para una moderada polarización anódica en soluciones ácidas, la película pasiva consiste esencialmente de $\mathrm{Cr}$ en estado de oxidación +3. Cuando el potencial crece por encima del límite de estabilidad del mismo, (alrededor de 0,6-0,8V (ENH)) la película pasiva cambia su composición química y la fracción de $\mathrm{Fe}^{+3}$ crece. Para soluciones ácidas, la fracción de catión $\mathrm{Cr}$ en la película pasiva es normalmente de 50-70\%. En soluciones básicas, la solubilidad del $\mathrm{Cr}$ se incrementa, resultando en una mayor fracción de Fe.

\subsubsection{Níquel}

El níquel es oxidado más lentamente que el $\mathrm{Fe}$ y el $\mathrm{Cr}$. Consecuentemente, el enriquecimiento de $\mathrm{Ni}$ en el estado metálico se da en la interfase óxido/metal. El enriquecimiento podría llegar a dar nitruro de níquel [53]. El aumento del contenido de $\mathrm{Ni}$ puede disminuir la velocidad de disolución de $\mathrm{Fe} \mathrm{y} \mathrm{Cr}$, una observación mediante microscoppía de efecto tunel (STM) indica que la película pasiva formada sobre aceros inoxidable austeníticos muestran un mayor grado de orden que los correspondientes aceros inoxidables ferríticos.

\subsubsection{Manganeso}

Adiciones de $\mathrm{Mn}$ a los aceros inoxidables han incrementado la solubilidad del nitrógeno y del molibdeno, ambos tienen un fuerte beneficio sobre la resistencia al picado $[54,55]$.

\subsubsection{Molibdeno}

El Mo se incorpora en la película pasiva, hallándose como óxidos complejos con diferentes estados de oxidación. El estado de oxidación +6 enriquece la superficie, en cambio el estado de oxidación +4 muestra una distribución más homogénea a través de toda la película[56]. 


\subsubsection{Estructura y Crecimiento}

Además de la composición química de la película pasiva, su estructura es un parámetro vital que influye sobre la resistencia a la corrosión. Las primeras investigaciones relacionadas con la estructura cristalina de una película pasiva en aleaciones $\mathrm{Fe}-\mathrm{Cr}$ fueron hechas por McBee y Kruger en 1972 [57] utilizando un microscopio de transmisión electrónica con detector de difracción de electrones. Ellos indican que las aleaciones con $24 \% \mathrm{de} \mathrm{Cr}$ presentan una estructura amorfa, mientras que entre $0 \%$ y $10 \%$ el $\mathrm{Cr}$ resultaba en una estructura cristalina del tipo espinela.

Para una película que cubre toda la superficie, existen dos tipos de procesos limitantes de la velocidad global de crecimiento: uno el transporte a través de la película asistido por un alto campo eléctrico, el segundo la transferencia de carga en alguna de las dos interfases límites es decir entre película/metal o película/electrolito. Estos modelos se refieren como de alto campo (HFM) o de interfase (IFM), respectivamente. La mayoría de los modelos presentados en la literatura dan ecuaciones de crecimiento que se reducen a cualquiera de los dos anteriores. Si el campo eléctrico aumenta con el incremento del potencial, el crecimiento de la película se encontrará limitada por la conducción en alto campo del ión a través del óxido (HFM). Una formalización sencilla de este concepto fue descripta por Verwey [58]. El HFM es de uso generalizado para la modelización de corrientes pasivas, y puede ser representado por la ecuación:

$$
\frac{\partial d}{\partial t}=r_{g} k_{1}^{h f} e^{B U / d}
$$

donde $\mathrm{d}$ es el espesor de la película, $\mathrm{r}_{\mathrm{g}}$ es la fracción de crecimiento, $\mathrm{k}_{1}{ }^{\mathrm{hf}}$ como una constante del modelo de alto campo que contiene el volumen específico y la valencia, B es una constante propia del óxido en cuestión, y U es el potencial aplicado. Para el HFM, el espesor de la capa pasiva se encuentra en denominador del argumento del término exponencial.

La alternativa de control de velocidad por alto campo es una limitante de la velocidad de reacción en la interfase metal/película o en la interfase película/electrolito. Una reacción limitante de la velocidad en la interfase metal/película es la base para el Modelo de Defectos 
Puntuales (PDM) que se introdujo en los años 80. Los fundamentos del PDM se han desarrollado y discutido ampliamente en una serie de publicaciones de Macdonald [59-65].

\subsection{Tipos de corrosión que sufren los aceros inoxidables}

La corrosión que presentan los aceros inoxidables que se utilizan en el transporte de petróleo y gas puede dividirse en tres formas más usuales: corrosión por $\mathrm{CO}_{2}$ (llamada corrosión dulce), fisuración en medios conteniendo $\mathrm{H}_{2} \mathrm{~S}$ (proceso catódico de agrietamiento bajo tensión inducida por la presencia de sulfuros (SSC o stress sulphide cracking), ) y fisuración en medios ácidos. La concentración tolerable de sulfuro de hidrógeno en medio corrosivo para el manejo seguro de un acero inoxidable supermartensítico es de una presión parcial de 0,01 MPa, a diferencia de $3 \mathrm{MPa}$ para el $\mathrm{CO}_{2}$. Los problemas de corrosión con $\mathrm{CO}_{2}$ se encuentran en pozos de más de 5000 metros profundidad, esto debido al aumento de presión y la temperatura. Las causas y el mecanismo de las formas más comunes de corrosión encontradas en tuberías se presentan a continuación.

\subsubsection{Corrosión generalizada}

Este ataque es uniforme en toda la superficie expuesta, a menudo deja depósitos de corrosión. Generalmente en líneas de conducción de petróleo y gas el $\mathrm{CO}_{2}$ es responsable de dicho ataque. $\mathrm{El} \mathrm{CO}_{2}$ es un ácido débil que al hidratarse es más corrosivo, este fenómeno se encuentra acelerado por la temperatura y la presión parcial del gas. Generalmente aquí la corrosión se mide por pérdida de peso.

\subsubsection{Corrosión por picado}

Es una forma de corrosión muy localizada que se presenta en metales que normalmente se encuentran pasivados. Usualmente ocurre una pérdida porcentual de material relativa al peso de la estructura que es despreciable hasta que ocurre la falla. La picadura puede iniciarse en el interior de un defecto, como una raya sobre el metal o ligeras variaciones en la composición u otras heterogeneidades superficiales [66]. La solución se vuelve más concentrada, ácida y densa en el interior de la picadura a medida que progresa su crecimiento. 
Existe una relación empírica para predecir la resistencia al picado de aceros inoxidables que se denomina número equivalente de resistencia al picado y que se calcula en términos de los contenidos de cromo, molibdeno y nitrógeno, Tabla 2.3 y que se expresa por [67]:

$$
\mathrm{NERP}=\mathrm{Cr}+3,3 . \mathrm{Mo}+16 . \mathrm{N} \% \text { en peso }
$$

Tabla 2.3. Composición de seguridad de acuerdo a la ecuación 2.2

\begin{tabular}{|l|l|}
\hline Elemento & Composición (\% peso) \\
\hline $\mathrm{Cr}$ & $18,6-25,3$ \\
\hline Mo & $2,2-4,4$ \\
\hline $\mathrm{N}$ & $0,048-0,22$ \\
\hline
\end{tabular}

Los aceros supermartensíticos tienen un valor de NERP entre $12-20$.

\subsubsection{Corrosión bajo tensión fisurante (SCC)}

Es la corrosión que se produce por una acción combinada de un esfuerzo de tracción aplicado a un material en un ambiente corrosivo específico. Se presenta como pequeñas grietas que se propagan en dirección perpendicular a la tensión aplicada, resultando en una falla frágil. Las grietas pueden producirse a niveles de esfuerzos relativamente bajos con respecto a la resistencia a la tracción del material. No necesariamente debe existir un esfuerzo externo, ya que la tensión puede ser residual, producto de un cambio brusco de temperatura y una contracción irregular, o la diferencia de coeficientes de expansión entre dos fases de una aleación [66].

\subsubsection{Fragilización por hidrógeno}

Es el agrietamiento resultante de la interacción del material con el hidrógeno culminando en la formación de fisuras con pérdida de la resistencia mecánica de la aleación. Macroscópicamente hablando, la fragilización es similar a la corrosión bajo tensión ya que un metal dúctil presenta una rotura frágil al ser sometido a tensión en una atmósfera conteniendo hidrógeno. Las grietas producidas durante la fragilización por hidrógeno generalmente son transgranulares. El hidrógeno difunde intersticialmente a través de la red cristalina y en concentraciones de unas pocas partes por millón. Una serie de mecanismos se 
han propuesto para explicar la fragilización por hidrógeno: la mayoría de ellos se basan en la interferencia de las dislocaciones con hidrógeno disuelto.

\subsubsection{Agrietamiento bajo tensión inducido por la presencia de sulfuros (SSC)}

Es un caso especial de fragilización por hidrógeno comúnmente se asocia a los aceros de alta resistencia. El agrietamiento surge de las reacciones de corrosión con posterior absorción de hidrógeno en el metal. La presencia de azufre a partir del $\mathrm{H}_{2} \mathrm{~S}$ acelera la fragilización ya que retarda la recombinación del hidrógeno atómico para formar hidrógeno molecular sobre la superficie del metal, con el consecuente aumento de la difusión de la especie atómica hacia el interior del metal. Kondo y colaboradores encontraron que la solución más favorable es reducir el contenido de hidrógeno en el metal [68,69].

Se utilizan criterios de dureza para clasificar el uso recomendado de aceros en medios sulfurados de forma de evitar la corrosión bajo tensión. De acuerdo a la NACE (National Association of Corrosion Engineers) Norma MR0175 [70] el límite máximo de dureza para evitar la corrosión bajo tensión para aceros inoxidables martensíticos en $\mathrm{CO}_{2}$ y $\mathrm{H}_{2} \mathrm{~S}$ es $240 \mathrm{HV}$ (dureza Vickers).

\subsection{Corrosión del acero inoxidable soft / super martensítico $13 \mathrm{Cr}$}

Hashizume y col. [70] expusieron muestras de aceros inoxidables $13 \mathrm{Cr}$ de bajo contenido de carbono y $0 \%$ a $1,9 \%$ de $\mathrm{Mo}$ en medios que contenían $5 \% \mathrm{NaCl}+0,5 \%$ $\mathrm{CH}_{3} \mathrm{COOH}$ con $0,0035 \mathrm{MPa} \mathrm{H}_{2} \mathrm{~S}+0,0965 \mathrm{MPa} \mathrm{CO}$ variando el pH por adición de $\mathrm{NaOH}$, a una temperatura de $24^{\circ} \mathrm{C}$ por 96 horas. La delimitación de las condiciones de disolución activa o de estado pasivo expresada en términos de la composición del material depende de los niveles de $\mathrm{Cr}$, Ni, Mo y C. La despasivación dependiente del pH ocurre a valores entre 3,6 y 3,8. A pesar de que el Mo fue considerado como el principal factor en la reducción del pH de despasivación, lo más notable es que en todo el rango de composición ensayado el Mo sólo bajo 0,2 unidades de $\mathrm{pH}$.

Drugli et al. observaron un comportamiento de corrosión activa para los aceros inoxidables de bajo C $13 \mathrm{CrNiMo}$ (con $2 \%$ de Mo), en material base sometido a un tratamiento de pulido mecánico grueso y en soldaduras sin tratamiento, en solución fuertemente amortiguada (buffer de acetato de sodio $4 \mathrm{~g} / \mathrm{l}$ ) a pH 3,5 (1 g/l NaCl, 0,1 MPa $\mathrm{CO}_{2}, 0,0008 \mathrm{MPa} \mathrm{H}_{2} \mathrm{~S}$ ) a $20^{\circ} \mathrm{C}$. En ausencia del buffer, en la interfase metal-solución el 
aumento del $\mathrm{pH}$ fue suficiente para generar un comportamiento pasivo. Lo mismo sucedió cuando se acopló con acero al carbono, el menor potencial estacionario resultante del acoplamiento respecto del potencial de corrosión fuera de la cupla resultó en un aumento del pH. Sin embargo, cuando el acoplamiento fue llevado a cabo en solución buffer a 3,8, el acero $13 \mathrm{Cr}$ que se encontraba apenas pasivado sin acoplar se activa a potenciales menores de los que surgen cuando está asociado al acero al carbono [71].

Varios estudios [72-74] son resumidos en la Figura 2.21, allí se muestra la dependencia de la velocidad de corrosión con la concentración de cloruros en solución para aceros inoxidables martensíticos $13 \mathrm{Cr}$ convencionales y modificados para contener bajos contenidos de C. Para los aceros modificados en soluciones de concentraciones del $10 \% \mathrm{NaCl}$ o mayores la velocidad de corrosión es relativamente alta a $200^{\circ} \mathrm{C}$ y a $150^{\circ} \mathrm{C}$ presenta un valor de 0,1 mm/año, siendo este valor el usado usualmente como criterio límite para ser aceptado.

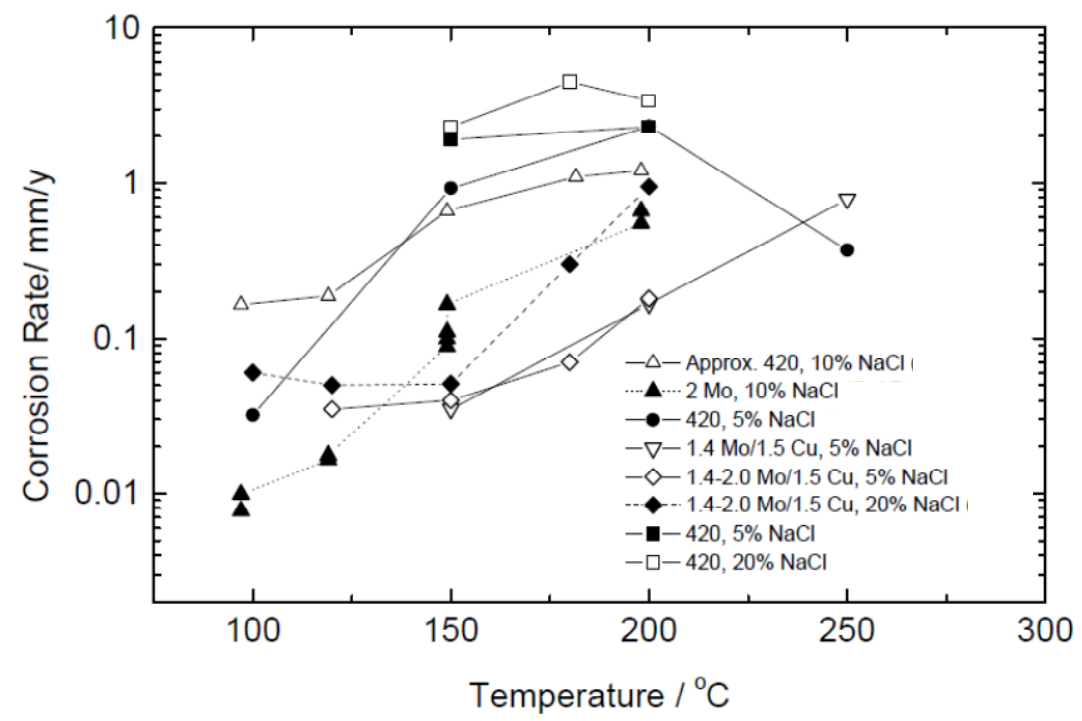

Figura 2.21. Velocidad de corrosión para el acero $13 \mathrm{Cr}$ en función de la concentración de $\mathrm{NaCl}$ y la temperatura.

Sakamoto et al. [72] informan que la velocidad de corrosión resulta relativamente insensible a $\mathrm{H}_{2} \mathrm{~S}$ a $150^{\circ} \mathrm{C}$ hasta $0,1 \mathrm{MPa}$, pero muestra algo de sensibilidad a los $200^{\circ} \mathrm{C}$. También se indica que el ión bicarbonato ejerce solo un efecto pequeño. Ya que el acero permaneció en el estado activo en el rango probado, esto simplemente indica que la reducción catódica de iones hidrógeno es más significativa que la de los iones bicarbonato. 
Kimura et al. [75] estudiaron la influencia de la austenita retenida en la velocidad de corrosión y la susceptibilidad al picado del acero $13 \mathrm{Cr}$ modificado enfriado y luego revenido, con lo cual obtienen diversos contenidos de austenita entre 3 y $40 \%$. Los estudios fueron conducidos a temperatura ambiente en varios medios conteniendo diferentes concentraciones de cloruros, $\mathrm{CO}_{2}(0,1 \mathrm{MPa})$ y $\mathrm{H}_{2} \mathrm{~S}(0,004 \mathrm{MPa})$ y valores de $\mathrm{pH}$ entre 2,8 y 4,5. En este caso los resultados indicaron que la austenita retenida no tiene impacto apreciable en la corrosión, aunque los valores informados se corresponden con el número promedio de sólo tres pruebas. Por otro lado, las cantidades de $\mathrm{Cr}$ y Mo que precipitaron en forma de carburos y nitruros disminuyen a medida que el contenido de austenita retenida aumenta. Esto también llevó el potencial de picado a valores más nobles [76]. En este punto cabe mencionar que los resultados informados para aceros inoxidables martensíticos tratados superficialmente mediante procesamiento láser mostraron, a este respecto, un claro efecto beneficioso [77].

Ueda et al. [78] estudiaron el efecto del Mo en la corrosión por picado en $5 \% \mathrm{NaCl}, 3$ $\mathrm{MPa} \mathrm{CO}_{2}, 0,001 \mathrm{MPa} \mathrm{H}_{2} \mathrm{~S}$ a $150^{\circ} \mathrm{C}$. La velocidad de corrosión y la susceptibilidad al picado son bajas con contenidos del $2 \%$ Mo pero se hacen más significativas para el $1 \%$ de Mo, en las mismas condiciones.

Abayarathna y Kane [79] realizaron ensayos de exposición de cupones a un medio corrosivo durante 60 días. En la práctica la corrosión por picado fue la forma dominante sobre la generalizada, esto a temperaturas bajas, pero a altas temperaturas comienza a hacerse más evidente la presencia de corrosión generalizada. La corrosión por picadura fue menor en un acero supermartensítico $13 \mathrm{Cr}$ que contenía $2,1 \mathrm{Mo}$ y $5,5 \mathrm{Ni}$.

Estos autores $[80,81]$ también se refieren a la caída en las velocidades de crecimiento de la picadura con el tiempo de exposición al medio corrosivo, algo que cabe esperar ya que el crecimiento de una picadura se reduce a medida que aumenta su profundidad debido a la caída ohmica IR y los efectos de transporte de masa más pronunciados. Un factor adicional es que debe haber una corriente catódica (por ejemplo de reducción de protones) fuera de la picadura que es igual a la corriente total anódica (de disolución metálica) en el interior de la picadura. Al comienzo del proceso de picado cuando el área expuesta por la picadura es pequeña y el número de éstas es bajo, la velocidad de crecimiento es alta. Sin embargo, a medida que el área activa para la reacción anódica aumenta en cada picadura su velocidad de crecimiento disminuye 
Huizinga y Liek [82] ensayaron un acero del tipo 420 en dos soluciones, una con alta concentración de cloruros y otra con baja concentración de cloruros pero bajo atmósfera de $\mathrm{CO}_{2}$. Encontraron a partir del análisis de curvas de polarización durante 31 horas de ensayo, una disminución del potencial a circuito abierto en la segunda solución con el aumento del tiempo de inmersión desde $-630 \mathrm{mV}$ SCE en muestras recién inmersas hasta $-730 \mathrm{mV}$ SCE luego de 31 horas. Determinaron además el desarrollo de un potencial de repasivación que se vuelve más positivo que el de circuito abierto a medida que aumenta el tiempo del ensayo lo que indica una pasividad estable a mayores tiempos. Además, el potencial de picado se vuelve mucho más noble que el de circuito abierto lo que muestra un menor riesgo de picado. Para la solución con alta concentración de cloruros el comportamiento es cualitativamente similar pero con existencia de mayor riesgo por desarrollo de corrosión por picado. Esto subraya el hecho que un potencial de circuito abierto bajo no quiere decir necesariamente comportamiento activo del material, sino más bien refleja condiciones de pH más alto que estabilizan el film además de una lenta cinética de la reacción de reducción.

Turnbull y colaboradores [83] también midieron bajos potenciales de corrosión a temperatura ambiente en soluciones $5 \% \mathrm{NaCl}$ para valores de $\mathrm{pH}$ por arriba del correspondiente a una condición de despasivación. En soluciones más ácidas, el potencial puede ser aún tan activo como $-650 \mathrm{mV}$ SCE pero el acero está en estado activo por lo que una polarización en sentido anódico permite detectar el pico de disolución activa. Por cierto, en el estado activo, una disminución de $\mathrm{pH}$ todavía puede conducir a potenciales más nobles.

Datos referidos a la corrosión de aceros inoxidables martensíticos (de los tipos convencional, soldable y aleado $13 \mathrm{Cr}$ ) fueron analizados críticamente [83]. Los aceros $13 \mathrm{Cr}$ con bajo contenido de carbono y con adiciones de Mo y Ni muestran una mejorada resistencia a la corrosión en comparación con los aceros martensíticos convencionales en medios conteniendo $\mathrm{CO}_{2} \circ \mathrm{SH}_{2}$ en bajas concentraciones.

Case y col. [80] dirigieron sus estudios a dilucidar el impacto de la concentración de $\mathrm{H}_{2} \mathrm{~S}$ en la corrosión por picado en aceros $13 \mathrm{Cr}$ modificados, tanto para material base como de soldadura. Los ensayos fueron realizados en solución $7 \% \mathrm{NaCl}$ conteniendo $0,4 \mathrm{~g} / \mathrm{l}$ de acetato de sodio y con un $\mathrm{pH}$ ajustado a 4,5 con $\mathrm{HCl}$. Concluyeron que la polarización anódica por arriba del potencial redox de la cupla $\mathrm{S} / \mathrm{H}_{2} \mathrm{~S}$ (-277 mV SCE para $1 \% \mathrm{H}_{2} \mathrm{~S}, 0,001$ MPa y $-307 \mathrm{mV}$ para $10 \% \mathrm{H}_{2} \mathrm{~S}, 0,01 \mathrm{MPa}$ ) no tiene valor en estudios de la corrosión por 
picado ya que la oxidación del $\mathrm{H}_{2} \mathrm{~S}$ deviene en el proceso dominante. El material de soldadura exhibió una menor corriente de pasividad que el material base pero una mayor susceptibilidad al picado dada por un menor potencial de repasivación y la aparición de picado cerca de la línea de fusión. Los ensayos realizados en ausencia de ácido sulfhídrico confirman el rol fundamental del mismo en la generación de picaduras para las condiciones de exposición usadas. Sobre el metal base, las condiciones de no aparición de corrosión por picado están asociadas a un límite de concentración del $1 \% \mathrm{H}_{2} \mathrm{~S}$ pero no para el metal de soldadura. Estos autores observaron que debido a factores de limitación en el transporte de materia para el acceso del $\mathrm{H}_{2} \mathrm{~S}$ al interior de la picadura, las velocidades de crecimientos pueden resultar significativamente mayores a temperatura ambiente donde las picaduras tienden a ser más abiertas que a mayor temperatura con películas pasivantes en su exterior más protectoras y acceso a la base de la picadura más dificultoso, en consonancia con la obra de Ueda et al. [84] .

Aquino et al. [85] compararon la susceptibilidad a la corrosión generalizada de las tres zonas de una junta soldada, material base, zona afectada por el calor y metal de soldadura. Se probaron en una solución $3,56 \%$ en masa de $\mathrm{NaCl}$ a una temperatura de $24^{\circ} \mathrm{C}$. El metal de soldadura muestra la mayor resistencia comparativa al picado como resultado de la martensita resultante del enfriamiento posterior al ciclo térmico de la soldadura. Este ciclo térmico produce redisolución de carburos de cromo y/o nitruros en la ZAC, mejorando así los valores del potencial de picado respecto de los obtenidos en el metal base.

Ensayos de corrosión llevados a cabo con metal de soldadura supermartensítico expuesto a un fluido proveniente de un pozo petrolífero conteniendo pequeñas cantidades de $\mathrm{H}_{2} \mathrm{~S}$ revelaron que la corrosión bajo tensión fisurante en presencia de sulfuros ocurre principalmente en conjunción con un ataque precedente de corrosión por picado [86].

La influencia de la microestructua en el picado de un acero inoxidable $\mathrm{Fe}-13 \mathrm{Cr}-<0,03 \mathrm{C}$ 4,7Ni-0,5Mo-0,7Si-0,7Mn fue estudiada cuando el metal es sometido a diversos TTPS. Estos TTPS generan en el material diferentes contenidos de austenita retenida. Mediante curvas de polarización potenciodinámicas cíclicas realizadas en solución $0,05 \mathrm{M} \mathrm{K}_{2} \mathrm{SO}_{4}+0,04 \mathrm{M} \mathrm{NaCl}$ $(\mathrm{pH}=4,1)$ desaireada, a $25 \pm 2^{\circ} \mathrm{C}$, se obtiene una correlación entre la microestructura y el potencial de corrosión, hallándose que los mismos se hacen más nobles al aumentar el porcentaje de austenita retenida [87]. Motivado en las conclusiones del estudio previamente descripto Pereda et al. evaluaron la influencia de los ciclos térmicos de soldadura por arco 
sumergido en un acero inoxidable sofmartensítico $13 \mathrm{Cr}$ en tres zonas: metal de soldadura, metal base y ZAC, en una solución aireada $1 \mathrm{M} \mathrm{NaCl}+1 \mathrm{M} \mathrm{NaSO}_{4}$, a temperatura ambiente. Al concluir el ciclo de soldadura, se observa que no existen diferencias significativas en el contenido de austenita retenida entre el metal base y la ZAC. La susceptibilidad al picado es similar entre las zonas estudiadas. El metal de soldadura sin embargo es el que mayor resistencia ofrece a la corrosión por picado, esto se debe a que contiene un adicional de Mo $2 \%$ en peso [88].

Aplicando la técnica de reactivación electroquímica potenciodinámica, ó DL-EPR, para establecer el grado de sensitización de un material, cuando la sensitización aumenta el potencial de picado se encuentra a valores menos anódicos [89].

Anselmo et al. midieron potenciales de picado en aceros inoxidables super martensíticos (Fe-0,027C-10,53Cr-6,19Ni-2,53Mo-0,41Cu) en agua de mar sintética saturada con $\mathrm{CO}_{2}$, en presencia y ausencia de oxígeno. La concentración de cloruros varió en el alcance $2.10^{4}-8.10^{4} \mathrm{ppm}$, con temperaturas de 5,25 y $60^{\circ} \mathrm{C}$. Como era de esperar el potencial de picado se desplazó en la dirección activa con el aumento de concentración de cloruros y la temperatura [90]. Un incremento en el contenido de cromo en el film pasivo obtenido en soluciones que contienen $\mathrm{CO}_{2}$ provoca un aumento de la disolución de hierro, de acuerdo con estudios previos en aceros convencionales $13 \mathrm{Cr}$ [91].

La capa salina que se forma en el fondo de las picaduras en los aceros inoxidables se cree que controla la cinética del picado vía su disolución [92-94]. La identificación y la caracterización de la cinética de disolución y repasivación de una acero inoxidable super martensítico (Fe-0,02C-12,3Cr-6,5Ni-2,6Mo) fueron llevadas a cabo bajo condiciones de disolución anódica potenciostática [95]. El uso de una picadura artificial de geometría unidimensional en electrodos de alambre colocados en un soporte inerte y expuesto a soluciones de $\mathrm{NaCl}$ permitió concluir que las cinéticas de repasivación y disolución están controladas por el contenido de $\mathrm{Cr}$, Ni y Mo en el metal base.

El calentamiento producido durante las operaciones de soldadura no sólo altera la microestructura, como se mencionó, sino promueve reacciones de oxidación a alta temperatura en la superficie interna de la soldadura. El tipo y espesor de la capa de óxido que se desarrolla en la ZAC depende de la relación temperatura, tiempo y del potencial de oxígeno en el gas protector. Enerhaug et al. [96] Ilevaron a cabo una detallada investigación para explicar porqué la ZAC de una soldadura de un acero super martensítico es más 
susceptible al picado que el metal base adyacente. El examen metalográfico revela el cambio microestructural en las diferentes regiones de la ZAC. La región totalmente austenitizada (cuyo producto de transformación es martensita no-revenida) presenta bajos valores de dureza lo que indica la presencia de considerables cantidades de austenita retenida a temperatura ambiente. Los resultados de este trabajo fueron interpretados en términos de un mecanismo de desprendimiento del óxido superficial rico en hierro que es responsable de la iniciación del picado, mientras que la microestructura subyacente fue considerada como un factor menos relevante en las condiciones experimentales utilizadas. 


\section{CAPÍTULO 3}

\section{Materiales y métodos}

\subsection{Materiales}

\subsubsection{Celda electrolítica}

Los experimentos se realizaron en una celda convencional de vidrio de tres electrodos, a saber, electrodo de trabajo, electrodo de referencia y contraelectrodo (Figura 3.1).

La celda está provista de un sistema para burbujeo de gas inerte en caso de que se necesite eliminar la presencia de oxígeno de la solución. La circulación gaseosa puede mantenerse por encima del nivel del líquido previamente desoxigenado durante la ejecución del experimento, para asegurar una atmósfera controlada sobre la solución pero sin alterar el régimen hidrodinámico.

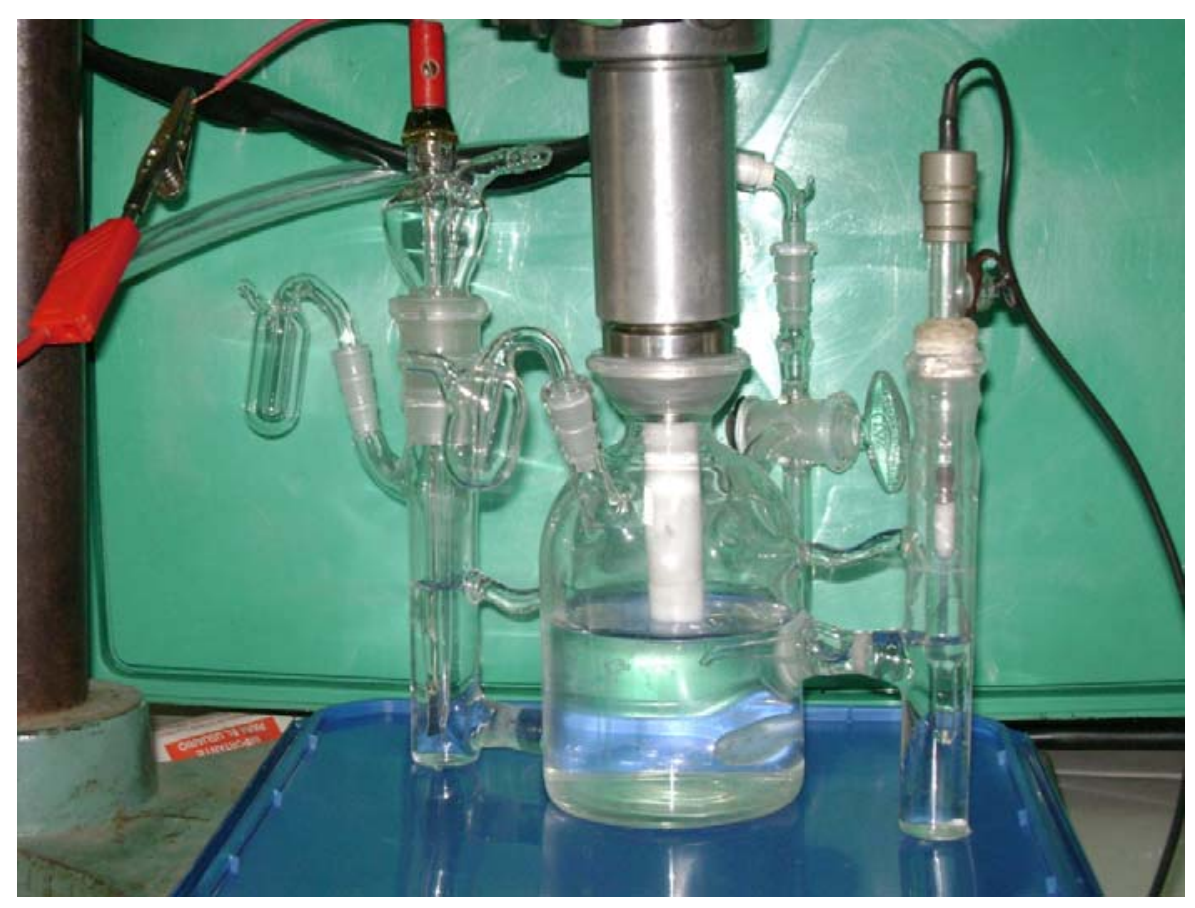

Figura 3.1. Celda electrolítica de tres electrodos. 
Además posee un capilar de Luggin cuya función es minimizar la caída óhmica entre el electrodo de referencia y la superficie del electrodo de trabajo. La distancia máxima de acercamiento del capilar de Luggin está determinada por la no interferencia en la distribución de corriente sobre la superficie del electrodo de trabajo.

\subsubsection{Electrodos}

Los electrodos de trabajo se obtuvieron de una placa de acero inoxidable $13 \mathrm{CrNiMo}$, cuya composición se muestra en la Tabla 3.1, y fueron sometidos a diferentes tratamientos térmicos, como se indica en la Tabla 3.2.

Tabla 3.1. Composición Nominal (\%)

\begin{tabular}{|l|l|l|l|l|l|l|l|l|}
\hline Grado & $\mathbf{C}$ & $\mathbf{M n}$ & $\mathbf{S i}$ & $\mathbf{C r}$ & $\mathbf{N i}$ & $\mathbf{M o}$ & $\mathbf{S}$ & $\mathbf{P}$ \\
\hline $\mathbf{1 3 C r N i M o}$ & 0,03 & 0,6 & 0,3 & 12,74 & 3,71 & 0,53 & 0,01 & 0,008 \\
\hline
\end{tabular}

Tabla 3.2. Descripción de los tratamientos térmicos

\begin{tabular}{|c|c|c|c|}
\hline Condición & $\begin{array}{c}\text { Tratamientos } \\
\text { térmicos }\end{array}$ & $\begin{array}{c}\text { Temperatura } \\
\text { (oC) }\end{array}$ & $\begin{array}{c}\text { Tiempo } \\
\text { (h) }\end{array}$ \\
\hline A & Como soldado & - & - \\
\hline B & Revenido & 600 & 2 \\
\hline E & solubilización + & $950+$ & 1 \\
& revenido & 550 & 2 \\
\hline G & solubilización + & $950+$ & 1 \\
& revenido & 600 & 2 \\
\hline H & Solubilización + & $950+$ & 1 \\
& Doble revenido & $670+$ & 2 \\
& & 600 & 2 \\
\hline M & Solubilización + & $950+$ & 1 \\
& Doble revenido & $670+$ & 2 \\
& & 600 & 8 \\
\hline P & Doble revenido & $670+$ & 2 \\
& & 600 & 2 \\
\hline
\end{tabular}

Como contraelectrodo se utilizó una chapa de platino de gran área, ya que permite mantener bajos los sobrepotenciales de las reacciones de electrodo y por lo tanto la tensión de bornes de la celda con un funcionamiento más eficiente del potenciostato/galvanostato. 
En cuanto al electrodo de referencia se utilizó uno de calomel saturado (ECS), $\mathrm{Hg} / \mathrm{Hg}_{2} \mathrm{Cl}_{2}, \mathrm{KCl}$ (sat), que tiene un potencial reversible de $-0,242 \mathrm{~V}$ referido al electrodo normal de hidrógeno (ENH) ó uno de mercurio-sulfato mercurioso saturado (ESM), $\mathrm{Hg} / \mathrm{Hg}_{2} \mathrm{SO}_{4}$, $\mathrm{K}_{2} \mathrm{SO}_{4}$ (sat) con un potencial reversible de $-0,65 \mathrm{~V}$ vs ENH, el uso de uno u otro dependerá de la solución donde se realizará la medida.

\subsection{Métodos}

\subsubsection{Difracción de rayos $\mathrm{X}$}

La difracción de rayos $X$ es una técnica muy poderosa usada para identificar fases cristalinas presentes en los materiales y para medir propiedades estructurales tales como tensiones, tamaños de grano, estado epitaxial, composición de fase, orientación preferencial y defectos estructurales. También permite determinar el espesor de las capas delgadas y multicapas y los ordenamientos y espaciados atómicos de los materiales amorfos y de las interfases (incluidos los polímeros).

Se trata de una técnica de no contacto y no destructiva, lo cual la hace ideal para el estudio in situ de los materiales. Es una técnica muy sensible en el análisis de elementos con valor alto del número atómico, ya que la intensidad difractada por éstos es mucho mayor que la de los elementos que presentan bajo valor del número atómico.

Para cada condición de tratamiento térmico aplicado sobre las muestras estudiadas, se determinaron las fracciones en volumen de austenita por difracción de rayos $\mathrm{X}$ a través de un análisis de Rietveld [97] utilizando el programa Fullprof [98,99]. Los patrones de difracción de rayos $X$ se obtuvieron a temperatura ambiente con un difractómetro Philips PW 1710, que acopla un monocromador de grafito al haz difractado. Los estudios de difracción se efectuaron utilizando un difractómetro con radiación Cu-K $\alpha$ en el rango $10 \leq 2 \theta$ $\leq 120$ a intervalos de $0,02^{\circ}$ por paso.

\subsubsection{Medidas potenciodinámicas cíclicas de polarización - Corrosión por picado}

Este método caracteriza el inicio de la formación con crecimiento estable de picaduras según el potencial alcanzado durante el barrido potenciodinámico al cual la corriente anódica aumenta rápidamente por sobre los valores de la corriente de pasividad. Cuanto más noble es este potencial, obtenido a una velocidad de barrido fija, la aleación utilizada es menos susceptible a la iniciación de esta forma de corrosión localizada por picado. Los 
resultados de este ensayo no pretenden correlacionarse en una manera cuantitativa con la velocidad de propagación de picaduras que se podría observar en servicio.

Una típica curva de polarización anódica potenciodinámica se muestra en la Figura 3.2. El único atributo de esta polarización es que muestra los procesos de corrosión rápidamente, facilitando así el estudio en el laboratorio. En la curva se observan tres rasgos distintivos: i) el potencial al cual la corriente anódica aumenta considerablemente luego de mantenerse en un nivel pasivo (Potencial de picado crítico ó de quiebre, $E_{\mathrm{p}}$ ); ii) un ciclo de histéresis (diferencia entre el barrido ascendente y descendente) y iii) el potencial al cual se ha cerrado el ciclo de histéresis duran el barrido descendente después de la propagación de la corrosión localizada (potencial de repasivación, $E_{R}$ ). Las picadura estables se forman a potenciales más nobles que $E_{P}$ y crecerán a potenciales más nobles que $E_{R}[100]$.

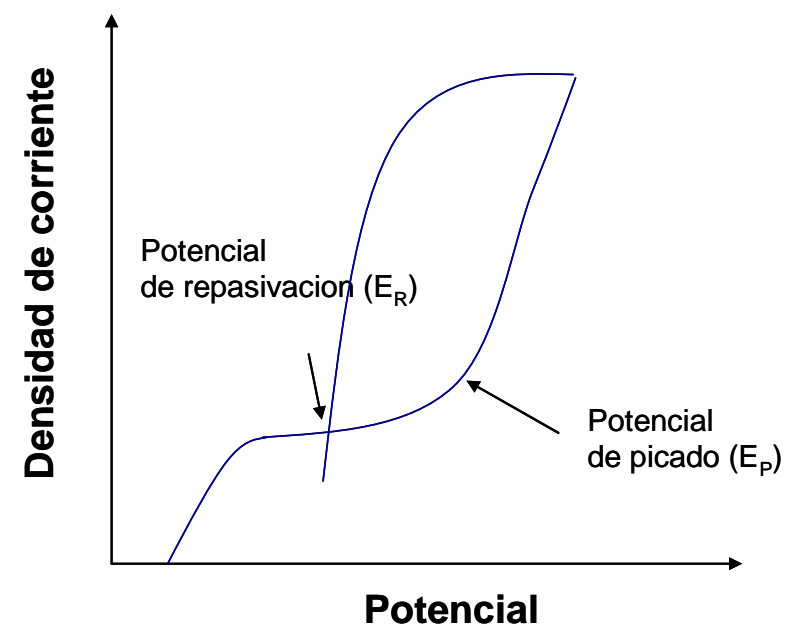

Figura 3.2. Curva de polarización cíclica en la que señalan los potenciales característicos.

Previo a la realización de los experimentos potenciodinámicos las muestras de área expuesta de $1 \mathrm{~cm}^{2}$ se sometieron inicialmente a un pulido mecánico con papel abrasivo y pasta de diamante para luego ser electropulidas en una mezcla de $\mathrm{HClO}_{4}(62 \mathrm{ml})$, metanol $(700 \mathrm{ml})$, butil cellosolve $(100 \mathrm{ml})$ y $\mathrm{H}_{2} \mathrm{O}(137 \mathrm{ml})$. Las medidas se llevaron a cabo a una velocidad de barrido del potencial de $0,5 \mathrm{mV} / \mathrm{s}$.

Los experimentos se llevaron a cabo a temperatura ambiente $\left(25 \pm 2^{\circ} \mathrm{C}\right)$ en solución $0,05 \mathrm{M} \mathrm{K}_{2} \mathrm{SO}_{4}+0,04 \mathrm{M} \mathrm{NaCl}(\mathrm{pH}=4,1)$, preparada con reactivos de grado analítico y agua Milli- $Q^{T M}$ y desoxigenada. 
Esta solución fue originalmente propuesta en la literatura [101] para este tipo de aceros inoxidables. Varias décadas atrás Uhlig et al. reportaron el efecto inhibidor que tiene el anión sulfato en la corrosión por picado en los aceros inoxidables en soluciones con cloruro [102]. La relación de concentraciones entre cloruro/sulfato tiene influencia tanto en la nucleación de picaduras como en el crecimiento de las mismas [103]. La decisión experimental de utilizar una solución de sulfato que contiene cloruros se basa en el hecho de que se asegura un amplio rango de pasividad (llevando los potenciales críticos a potenciales más nobles). Esto, a su vez, permite una repasivación con mayor precision y evaluar los potenciales de picado de las experiencias electroquímicas. Se utilizó un sistema electroquímico IM6d Zahner para la realización de estos experimentos electroquímicos.

\subsubsection{Curvas de polarización potenciodinámicas}

La polarización del electrodo mediante una señal eléctrica de perturbación se utiliza comúnmente como reemplazo de la variación de la capacidad oxidante de un medio electrolítico real y por tanto como una fuente de información respecto a que lo ocurre en un electrodo particular en su dependencia con el potencial, por ejemplo, si se corroe, se pasiva, etc. El potencial del electrodo es desplazado, "polarizado", respecto de su valor de equilibrio o potencial reversible en el medio de prueba al pasar una corriente entre el electrodo de trabajo y el contraelectrodo inerte. Una curva de polarización esquemática se ilustra en la Figura 3.3. Como se observa allí, el barrido comienza en el punto 1 y progresa en sentido de los potenciales positivos hasta finalizar en el punto 2 . Hay varios detalles salientes en esta curva. El potencial de circuito abierto está localizado en el punto A. A este potencial la suma de las corrientes anódicas y catódicas es cero y por lo tanto también es nula la corriente neta medida. Esto es debido al hecho que el potenciostato solo mide la corriente que debe aplicar para alcanzar el deseado nivel de polarización. A medida que el potencial aumenta, entramos en la región $B$, que es denominada la región de disolución activa. En esta región, la oxidación metálica es la reacción dominante. El punto $\mathrm{C}$ se conoce como potencial de pasivación, y a medida que el potencial aumenta por sobre este valor la densidad de corriente disminuye (región D) hasta alcanzar rápidamente un valor de corriente bajo e independiente del potencial que es la corriente del estado pasivo (región pasiva - región E). Una vez que el potencial alcanza un valor suficientemente positivo (punto $F$, potencial de ruptura de la pasividad) la corriente crece rápidamente (región G). Este aumento puede 
deberse a diferentes fenómenos dependiendo de la combinación aleación/medio electrolítico (picado, transpasividad, evolución de oxígeno, etc.). Nuevamente, vale la pena remarcar que este diagrama esquemático ilustra algunas de las posibles regiones presente en una curva de polarización obtenida mediante un barrido anódico.

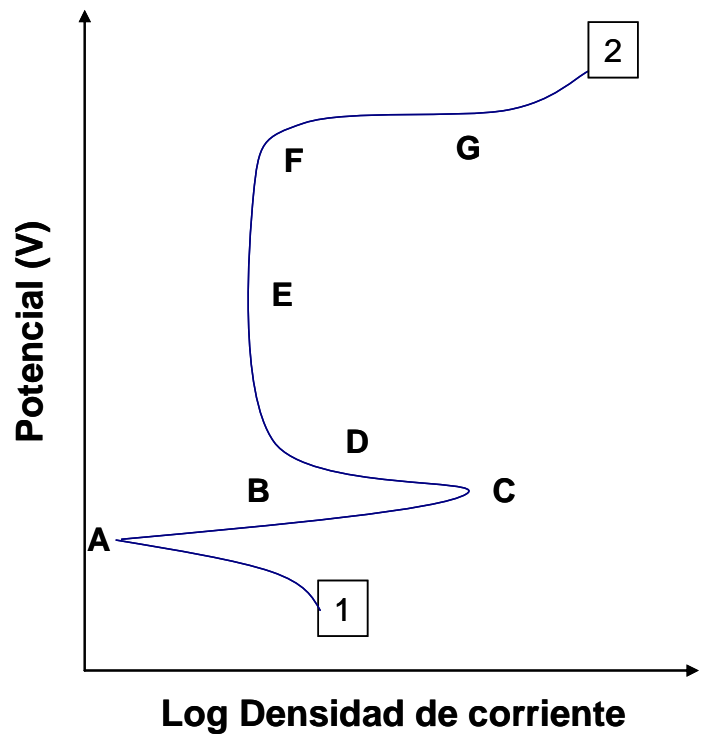

Figura 3.3. Esquema de barrido de polarización anódico

Para este tipo de experimentos se empleó como electrolito una solución de $\mathrm{Na}_{2} \mathrm{HPO}_{4}$ $0,5 \mathrm{M}(\mathrm{pH} 9,2)$, a una temperatura de $25^{\circ} \pm 1^{\circ} \mathrm{C}$. Esta solución se comporta como buffer, manteniéndose constante el $\mathrm{pH}$ durante las experiencias.

Previo al registro de las curvas descriptas, se burbujeó $\mathrm{N}_{2}$ durante 1 hora en el seno de solución electrolítica, y luego sobre solución durante el desarrollo del experimento, de forma de mantener la solución libre de oxígeno disuelto.

El electrodo de trabajo se precatodizó durante un tiempo de 30 segundos antes de cada medida, a un sobrepotencial catódico de $-400 \mathrm{mV}$ respecto del potencial de circuito abierto, a fin de reducir cualquier óxido superficial que se hubiese formado por exposición al aire previo a su incorporación en la celda. Se utilizó como electrodo de referencia uno de calomel saturado (ECS). La velocidad de barrido de fue $1 \mathrm{mV} / \mathrm{s}$.

El equipo utilizado fue un Potenciostato LYP M7 (asistido por un multímetro BRYMEN Mobile-Loger DMM) y una rampa LYP Electronics. 


\subsubsection{Curvas de polarización cuasi-estacionarias}

Las corrientes pasivas se midieron luego de un barrido inicial como se describió para la obtención de la curva de polarización potenciodinámica y hasta alcanzar la región de pasividad. Una vez en esta región y seguido de una estabilización potenciostática por $2 \mathrm{~h}$ a valores de potencial seleccionados se midieron las corrientes y se calcularon las densidades de corriente de pasividad relativas al área geométrica de las muestras j para cada potencial de estabilización. El tiempo de estabilización resultó de registrar el decaimiento de corriente en función del tiempo a potencial fijo en un experimento inicial y seleccionando de ese registro el tiempo más corto para el cual el correspondiente valor de corriente difería en menos de un $1 \%$ del valor estacionario final luego de $20 \mathrm{~h}[104]$.

\subsubsection{Cronopotenciometría}

La cronopotenciometria, según se aplica en este trabajo, nos permite registrar la evolución temporal del potencial del electrodo conteniendo la película pasivante formada sobre la muestra previamente, y como respuesta a la aplicación de una señal de perturbación en la forma de un escalón de corriente de sentido catódico. Esta respuesta está vinculada con los procesos de electrorreducción que se producen en la interfase película y/o electrodo y el medio electrolítico. Para cada especie que se electrorreduce durante la aplicación del escalón de corriente, el potencial permanece casi invariable (plateau de potencial) mientras la concentración de la especie reaccionante va disminuyendo. Cuando la concentración es suficientemente pequeña, se observa un salto de potencial hacia el valor propio de la electrorreducción de otro sistema redox más difícil de reducir, o finalmente de la reacción de descomposición del electrolito acuoso por electrorreducción.

El tiempo transcurrido en la región del plateau de potencial es conocido como tiempo de transición. Este tiempo tiene una relación directa con la masa de la especie reaccionante como lo predicen las leyes de Faraday.

Se llevaron a cabo reducciones galvanostáticas de películas anódicas previamente formadas a potencial fijo durante 2 horas. Los potenciales a los cuales se trabajaron son aquellos que se encuentran en la zona de pasividad y transpasividad del material. Luego se

aplicó una densidad de corriente de $-3 \mu \mathrm{A} / \mathrm{cm}^{2}$, a fin de reducir la película mientras se registraron los transitorios de potencial resultantes. 
Se empleó como electrolito una solución de $\mathrm{Na}_{2} \mathrm{HPO}_{4}$ 0,5 M (pH 9,2), a una temperatura de $25 \circ \pm 1$ 으

El equipo utilizado fue un Potenciostato LYP M7 (asistido por un multímetro BRYMEN Mobile-Loger DMM) y una rampa LYP Electronics.

\subsubsection{Espectroscopía de Impedancia Electroquímica (EIS)}

Esta técnica permite realizar una caracterización dinámica del sistema a través de la respuesta en corriente que éste proporciona cuando se lo perturba con una señal de potencial sinusoidal de pequeña amplitud y frecuencia variable. El uso de una señal de perturbación de baja amplitud ofrece una información más real sobre el comportamiento del sistema, al no ocasionar cambios irreversibles en mismo, y al variar la frecuencia de perturbación en un amplio rango se posibilita la detección, en un solo experimento, de la mayor parte de los procesos de relajación que tienen lugar en la interfase metal/electrolito, aun cuando tengan con constantes de tiempo muy diferentes.

La interpretación de los resultados experimentales mediante ajuste paramétrico a un modelo teórico puede realizarse utilizando como expresión del modelo de la interfase estudiada un análogo eléctrico o circuito equivalente que tiene la misma respuesta que el sistema material estudiado. Sin embargo siempre es necesaria la conversión final de los parámetros macroscópicos del circuito eléctrico en parámetros microscópicos del sistema y sus procesos fisicoquímicos.

La impedancia del sistema, $Z$, en función de la frecuencia angular $\omega=2 \pi f$ (con $f$ frecuencia en $\mathrm{Hz}$ ), cuando se representa en un plano complejo de coordenadas parte real ( $\mathrm{Z}^{\prime}$ $\circ \mathrm{Zr}$ ) y parte imaginaria ( $\left.\mathrm{Z}^{\prime \prime} \circ \mathrm{Zi}\right)$, forma lo que se conoce como diagrama de de Nyquist. La Figura 3.4 muestra una representación de la impedancia del circuito equivalente propuesto por Randles [105], junto con el sistema electroquímico que simula. Los parámetros macroscópicos del modelo (ecuación de la impedancia del circuito equivalente) se pueden determinar por ajuste paramétrico mediante la aplicación de cuadrados mínimos no-lineales y complejos. Así, la resistencia óhmica entre el electrodo de trabajo y el de referencia $\left(R_{\Omega}\right)$ viene dada por el punto de corte de altas frecuencias del diagrama de impedancia con el eje real, y corresponde a la resistencia del electrolito. Por otra parte, la reacción electroquímica sobre el electrodo de trabajo metálico en este caso puede representarse mediante la resistencia de transferencia de carga $\left(R_{t}\right)$ y coincide con el diámetro de la semicircunferencia. 
Aparte de esta semicircunferencia formada a altas y medias frecuencias, la cual se atribuye a un control por activación, el diagrama de impedancia puede presentar a bajas frecuencias diferentes trazados vinculados a la existencia de otros posibles procesos en el sistema (efectos de difusión, adsorción de especies intermedias, falta de homogeneidad superficial y aparición de películas superficiales). Finalmente, sobre el electrodo de trabajo del lado de la solución electrolítica estará siempre presente una acumulación de cargas de valor igual y signo opuesto a la acumulación de cargas inducida en la superficie del metal en lo que se conoce como capacidad de la doble capa eléctrica $\left(C_{d 1}\right)$. La corriente desplazativa o de carga del capacitor de interfase es claramente una corriente transitoria que al potencial de corriente continua o estacionario sobre el cual se debe realizar la medida de impedancia tiene valor nulo.
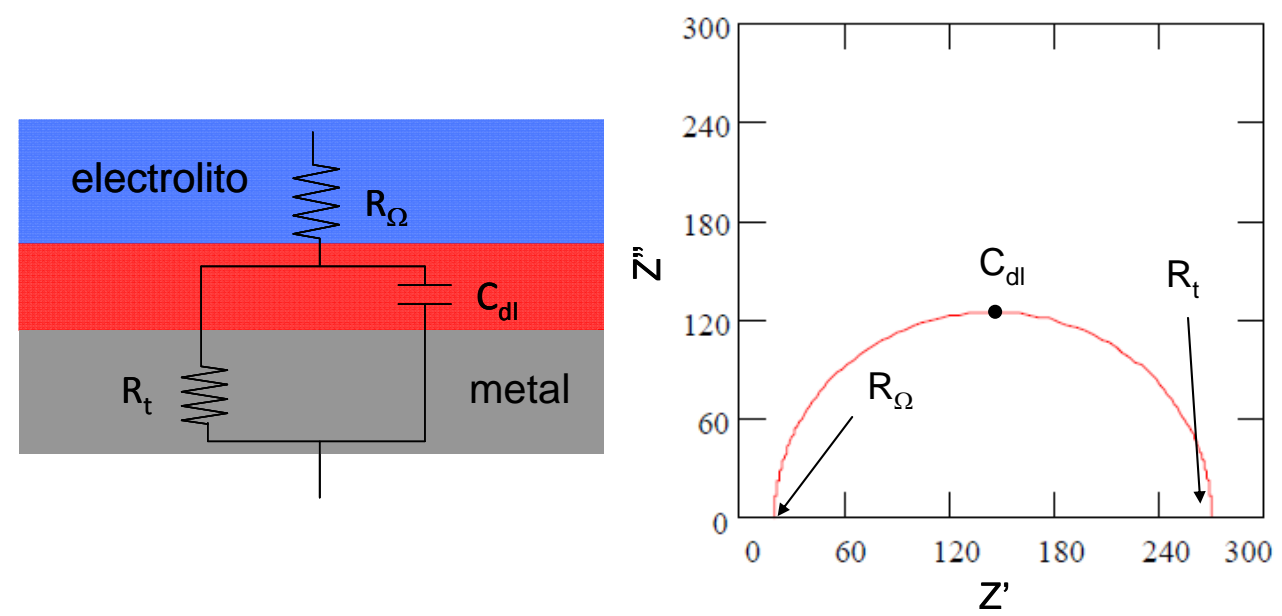

Figura 3.4. Circuito equivalente simple propuesto por Randles. Diagrama de Nyquist de la respuesta en impedancia teórica de este sistema metal/electrolito.

Los límites operativos para las medidas de impedancia se pueden establecer con relación a la Figura 3.5, que muestra un diagrama de contornos de precisión. El diagrama muestra los límites del potenciostato o del generador del Analizador de Respuesta de Frecuencia (FRA) como un diagrama de Bode del módulo de la impedancia. Las líneas del diagrama encierran un área, en términos del módulo de la impedancia y de la frecuencia de medición, dentro de la cual debe caer la impedancia experimental para tener aceptables niveles de precisión. El diagrama corresponde al equipamiento utilizado en este trabajo Zahner IM6 para dos condiciones de precisión y una tercera región correspondiente al uso de un elemento que permite expandir su uso para sistemas con alta impedancia (HiZprobe). 


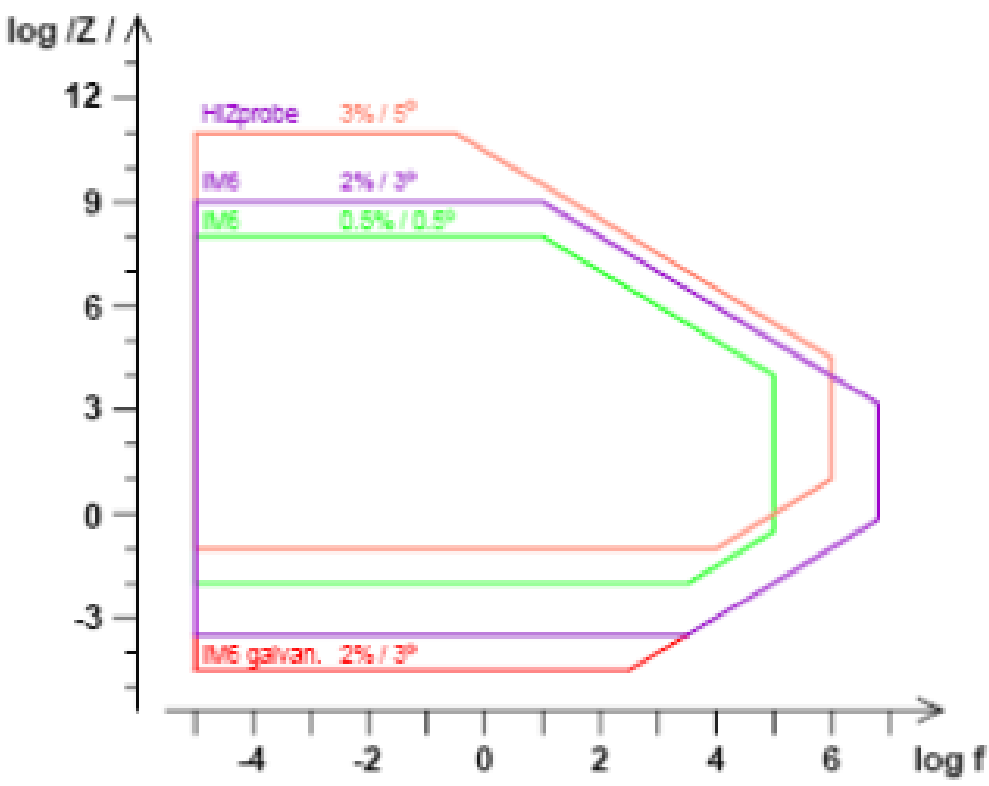

Figura 3.5. Gráfico de contornos de precisión del equipamiento usado para las mediciones de impedancia electroquímica.

Sobre las muestras se formaron películas pasivas en el rango de potenciales del comportamiento pasivo, durante el tiempo de 2 horas, previo a la medida de la impedancia interfacial.

Se empleó como electrolito una solución de $\mathrm{Na}_{2} \mathrm{HPO}_{4}$ 0,5 $\mathrm{M}(\mathrm{pH} 9,2)$, a una temperatura de $25^{\circ} \pm 1^{\circ} \mathrm{C}$

Los espectros de impedancia experimentales fueron medidos aplicando una señal sinusoidal de perturbación de $10 \mathrm{mV}$ de amplitud, en el alcance de frecuencias de $10^{5} \mathrm{~Hz}-$ $10^{-3} \mathrm{~Hz}$.

Se utilizó un sistema electroquímico IM6d Zahner que cuenta con un analizador de respuestas de frecuencia y el resto de los requerimientos para la realización de medidas de impedancia, adquisición de datos y herramientas de análisis.

\subsubsection{Análisis de Mott-Schottky}

Los diagramas de Mott-Schottky permiten obtener información sobre el comportamiento semiconductor de un material de electrodo, en particular el de las películas pasivas formadas anódicamente sobre metales y aleaciones [106]. La relación de MottSchottky surge de resolver la ecuación de Poisson para los espacios de cargas formados en una interfase electrolito/semiconductor, que toma la forma de la ecuación 3.1 


$$
\frac{1}{\mathrm{C}_{\mathrm{sC}}{ }^{2}}=\frac{2}{\varepsilon \varepsilon_{0} \mathrm{eN}_{\mathrm{q}}}\left(\mathrm{E}-\mathrm{E}_{\mathrm{bp}}-\frac{\mathrm{kT}}{\mathrm{e}}\right)
$$

donde $\mathrm{C}_{\mathrm{SC}}$ es la capacidad de la región del espacio de cargas dentro del semiconductor, $\mathrm{N}_{\mathrm{q}}$ es la densidad de estados donores o aceptores (donores para un semiconductor tipo $n$ ), $\varepsilon$ es la constante dieléctrica de la película pasiva (= 12 [107]), $\varepsilon_{0}=8,85 \times 10^{-14} \mathrm{~F} \mathrm{~cm}^{-1}$ la permitividad del vacío, e $=1,6 \times 10^{-19} \mathrm{C}$ es la carga del electrón, $\mathrm{k}$ la constante de Boltzmann, $\mathrm{T}$ la temperatura y $E_{b p}$, el potencial de banda plana. El término $\mathrm{kT} / \mathrm{e}$ es de orden despreciable frente a los valores de potencial en la región de estudio. Se debe destacar aquí además que esta ecuación contiene algunas suposiciones escondidas: 1) todos los niveles donores o aceptores están totalmente ionizados; 2) los niveles de dopantes están uniformemente distribuidos e inmóviles, 3) el nivel de Fermi esta como mínimo a $2 \mathrm{kT}(0.05 \mathrm{eV})$ de la banda más cercana y 4) no ha ocurrido inversión de portadores.

Las películas pasivas formadas sobre metales y aleaciones se caracterizan por ser semiconductores altamente dopados [108].

El diagrama de Mott-Schottky es una representación gráfica de $\mathrm{C}_{\mathrm{sc}}^{-2}$ en función del potencial del electrodo E. A partir de la zona lineal del gráfico, se pueden obtener los parámetros $\mathrm{N}_{\mathrm{q}}$ y $\mathrm{E}_{\mathrm{bp}}$, característicos del semiconductor. Este diagrama se construye a partir de mediciones de la impedancia a altas frecuencias de donde se puede obtener el valor de la capacidad del electrodo.

El análisis de Mott-Schottky se realizó pasivando anódicamente el electrodo al potencial de formación y aplicándole luego escalones sucesivos de potencial catódico de 0,05 V de amplitud. A cada potencial se midió el espectro de impedancia en una zona de altas frecuencias $(100 \mathrm{kHz}-1 \mathrm{kHz})$. El cálculo de la capacidad del óxido se realizó de dos maneras: a) suponiendo la aplicabilidad de un circuito equivalente RC serie para describir la respuesta de la impedancia interfacial en la región de más altas frecuencias de medida y fijando f =10 kHz (ecuación 3.2) donde Z" es la parte imaginaria de la impedancia medida y b) a partir de la expresión de Brug (ecuación 3.3) considerando la validez de un circuito equivalente resultante de $R_{\Omega}$ (resistencia de la solución) en serie con una impedancia compuesta de una combinación en paralelo entre un elemento de fase constante CPE cuya 
impedancia es la de la ecuación 3.4, y $R_{c t}$ que representa la resistencia de polarización del electrodo

$$
\begin{gathered}
C=\frac{1}{\omega Z^{\prime \prime}} \\
C_{\text {eff }}=\left[\frac{Y_{0}}{\left[R_{\Omega}^{-1}+R_{C T}^{-1}\right]^{1-n}}\right]^{\frac{1}{n}} \\
Z_{C P E}=(j \omega)^{-n} / Y_{0}
\end{gathered}
$$

En cualquier caso la capacidad del espacio de cargas del óxido semiconductor se encuentra en conexión serie con la capacidad de la doble capa eléctrica. Sin embargo como ésta última es al menos 10 veces más grande que la primera para soluciones de concentración de la usada aquí y por estar ambas capacidades en conexión serie, es que la capacidad que se mide es muy cercana a la capacidad del óxido solamente, pudiéndose despreciar la capacidad de la doble capa.

\subsubsection{Medidas de Microscopía Electrónica de Barrido (SEM)}

Las superficies de las muestras fueron examinadas con un microscopio FEI Quanta 200 operado a $25 \mathrm{kV}$, previamente se pulieron mecánicamente con pasta de diamante $(1<\mu \mathrm{m})$ y sometieron a un ataque en solución con reactivo de Vilella $(5 \mathrm{ml} \mathrm{de} \mathrm{HCl}, 1 \mathrm{~g}$ de ácido pícrico, $100 \mathrm{ml}$ de etanol) a temperatura ambiente, para revelar aspectos microestructurales, ya que delinea fases secundarias (carburos, ferrita delta).

\subsubsection{Espectroscopía Fotoelectrónica de rayos X (XPS)}

La espectroscopía de fotoelectrones generados por rayos $\mathrm{X}$ consiste en excitar una superficie con fotones de rayos $\mathrm{X}$, con lo cual se arrancan electrones de los átomos de la muestra a estudiar, ver Figura 3.6 . 


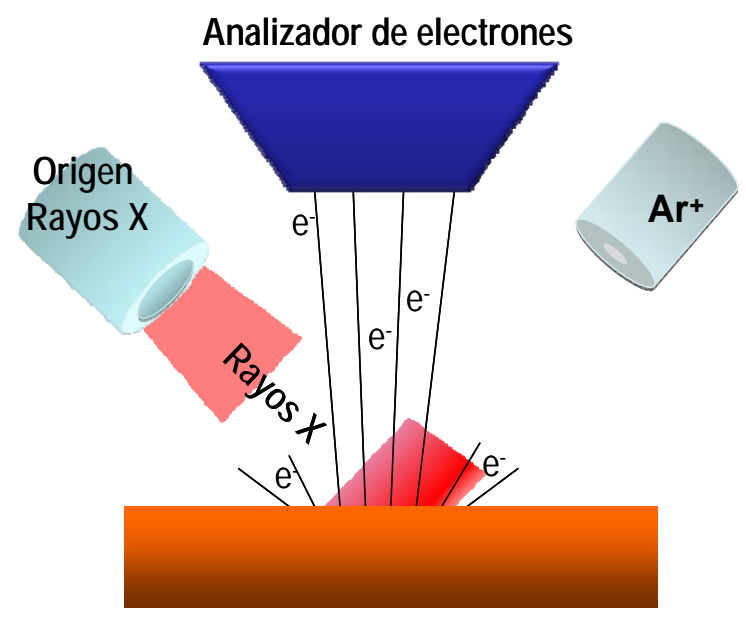

Figura 3.6. Superficie irradiada con una fuente de fotones de alta energía que provoca la emisión de electrones.

La medida de la energía de ligadura de los electrones de los niveles internos de los átomos (localizados en una región superficial de unas pocas capas atómicas) así como las intensidades de los picos de fotoemisión permiten determinar el estado de oxidación y la concentración de los átomos superficiales. Además el uso de la técnica con resolución angular y el análisis en profundidad mediante el decapado progresivo de la muestra por bombardeo con Ar iónico resultan de enorme utilidad en diversas áreas. Una de las aplicaciones fundamentales del XPS es el estudio de las superficies. Este estudio permite detectar los elementos presentes en la superficie, cuantificarlos y en casos particulares, con los estudios adecuados, se puede obtener los estados de oxidación y entornos de coordinación de los elementos presentes en esas superficies, mediante el bombardeo de electrones.

En la figura 3.7 se modeliza la "superficie práctica" que se observa mediante el análisis XPS de la superficie de un acero en contacto con la atmósfera. La formación de óxidos e hidróxidos de hierro en la superficie más externa del material (aproximadamente $6 \mathrm{~nm}$ de espesor) está relacionada con la presencia de grupos $\mathrm{OH}^{-}$y agua por el contacto con la atmósfera de laboratorio. Aunque la mayor parte de las técnicas de análisis de superficies proporcionan información referente a un espesor mayor que una monocapa, la contribución de esta primera capa es siempre superior a la de las siguientes capas más profundas.

La fuente de rayos $\mathrm{X}$ más utilizadas son las que emplean ánodos de $\mathrm{Al}$ o $\mathrm{Mg}$, otros ánodos son de $\mathrm{Si}, \mathrm{Zr}$, $\mathrm{Ag}$, $\mathrm{Ti}$ o $\mathrm{Cr}$. La radiación $\mathrm{X}$ es monocromatizada antes de llegar a la 
muestra mediante el uso de un cristal de cuarzo. Esto permite aprovechar el rango de energía en que la intensidad de la radiación $X$ es máxima (normalmente un ancho de $1-2$ eV), evitar los picos satélites de fluorescencia de rayos $X$, e impedir que electrones de alta energía provoquen golpes de calor a la muestra y la degraden.

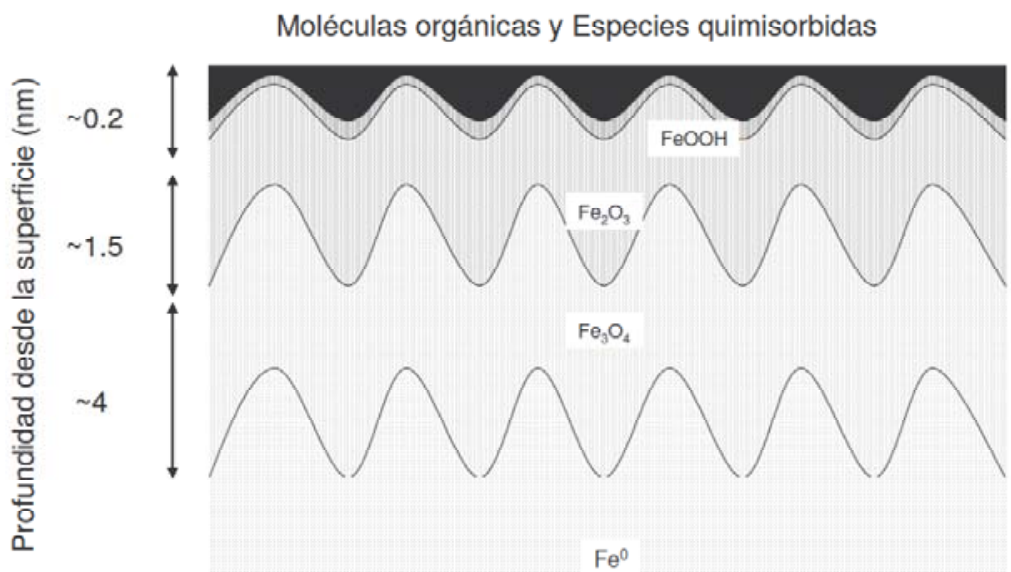

Figura 3.7. "Superficie práctica" que se observa mediante el análisis XPS de la superficie de un acero en contacto con la atmósfera

En un análisis de XPS se ha de realizar un amplio barrido del espectro, cubriendo un rango de unos $1000 \mathrm{eV}$, y posteriormente se ha de mirar con más detalle rangos más pequeños, de unos $20 \mathrm{eV}$. En el eje horizontal se muestran valores de energía de enlace. El eje vertical representa la intensidad o cuentas medidas, Figura 3.8. Además se puede medir a diferentes profundidades variando el tiempo de decapado.

La energía de ligadura de los picos asociados a la emisión de fotoelectrones está muy bien definida permitiendo identificar el estado de oxidación de cationes y aniones. Así, átomos no equivalentes del mismo elemento (diferencia en el estado de oxidación, en las moléculas que lo rodean o en la posición en la red) provocan un cambio apreciable (típicamente entre 1-3 eV). 


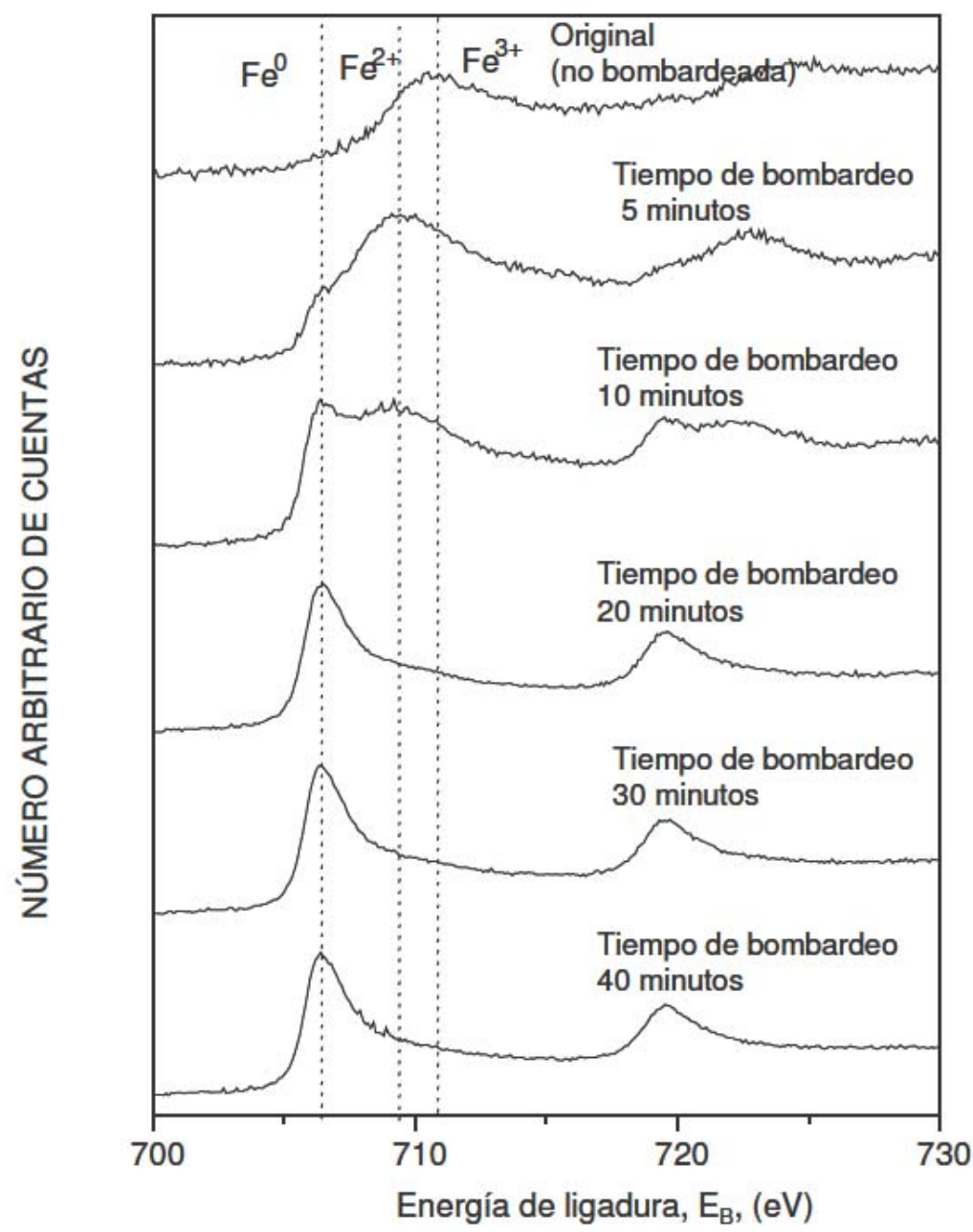

Figura 3.8. Evolución de los espectros XPS de alta resolución Fe2p obtenidos en la superficie de un acero laminado en frío con el tiempo de bombardeo por iones argón.

Las medidas de XPS se realizaron en un equipo ESCA 3 Mark II instrument, con radiación de rayos $\mathrm{X} \mathrm{MgK}_{\alpha}(\mathrm{h} v=1253,6 \mathrm{eV})$ como fuente de excitación. La información se obtuvo de la superficie de los electrodos pasivados anódicamente así como en profundidad mediante aplicación de erosión con argón iónico por diferentes tiempos. Los espectros se tomaron con radiación de $\mathrm{MgK}_{\alpha}$, excepto la región llamada Survey_Al que se tomo con AlK $\alpha$. La cuantificación en átomos por ciento se realizó usando los factores de sensibilidad relativos y suponiendo que los elementos están distribuidos homogéneamente en el volumen detectado (espesor de aprox. $4 \mathrm{~nm}$ ).

Las películas pasivas examinadas fueron formadas durante 2 horas a potenciales fijados dentro de la región pasiva. Luego de su formación fueron lavadas y secadas al aire. 


\section{CAPÍTULO 4}

\section{Microestructura, tratamiento térmico y corrosión por picado}

\subsection{Objetivos}

En el presente capítulo se presenta una caracterización microestructural de las muestras de aceros inoxidables $13 \mathrm{CrNiMo}$ con bajo tenor de C, sometidas a diversos tratamientos térmicos post-soldadura y una evaluación de la susceptibilidad a la corrosión por picado de cada muestra térmicamente tratada. El objetivo primario es establecer la influencia que las modificaciones en la microestructura, propias de los materiales estudiados, tienen en la corrosión por picado.

En este capítulo se siguió la misma metodología que en un trabajo precedente del grupo de trabajo [87]. La mencionada metodología incluyó iguales condiciones de ensayo así como idéntica caracterización de las muestras ensayadas. Solo el material fue cambiado desde un metal de soldadura (estudio previo) a un metal base (estudio presente). Esto resulta necesario, no simplemente porque la metodología hubiese ya resultado exitosa sino principalmente, pues esta parte del trabajo apunta a llevar a cabo un análisis comparativo de los resultados. Todavía más importante es el hecho que esta evaluación comparativa es en alto grado relevante [109][110][111]. Así, la consideración de la metalurgia de la soldadura de los materiales estudiados, requiere tener en cuenta los siguientes aspectos:

(a) una junta soldada debería tener la misma resistencia a la corrosión que el metal base al cual se encuentra unido;

(b) modificaciones en la composición ó cambios en la mecánica o en la metalurgia debido a los procesos de soldadura pueden introducir problemas de corrosión en la microestructura del metal base adyacente a la soldadura;

(c) cuando se exponen a un ambiente corrosivo el metal de soldadura se corroe más, o menos comparandolo con el metal base.

En consecuencia, en este trabajo los tratamientos térmicos simulando los ciclos térmicos en la postsoldadura, han sido llevados a cabo de forma de realizar una 
comparación de la susceptibilidad a la corrosión localizada del metal de soldadura y base de los aceros inoxidables softmartensíticos $13 \mathrm{CrNiMo.}$

\subsection{Resultados y Discusión}

\subsubsection{Microestructura}

Las microestructuras de todas las muestras están compuestas de una malla típica de martensita con partículas precipitadas de austenita retenida en diversos porcentajes, ya sea en los límites de grano o en el interior de los granos de martensita (tanto en las fronteras o en las redes de borde de grano). Se observó que la morfología de la austenita retenida corresponde a los precipitados de partículas-laminillas con un pequeño espesor algo menor a $1 \mu \mathrm{m}$ (Figura 4.1)

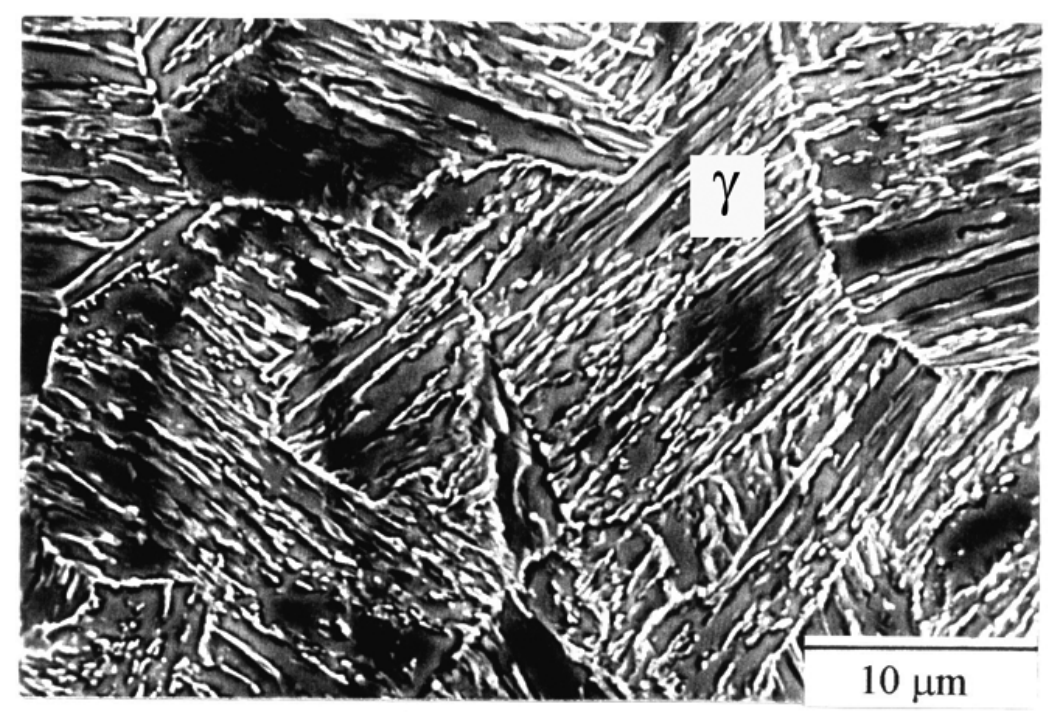

Figura 4.1. Partículas de austenita en una matriz de ferrita en acero inoxidable $13 \mathrm{CrNiMo.}$

La realización del revenido subcrítico por debajo de $600^{\circ} \mathrm{C}$ (condición E) representa una estructura ferrítica que no contiene una cantidad correspondiente de austenita retenida, Figura 4.2. 


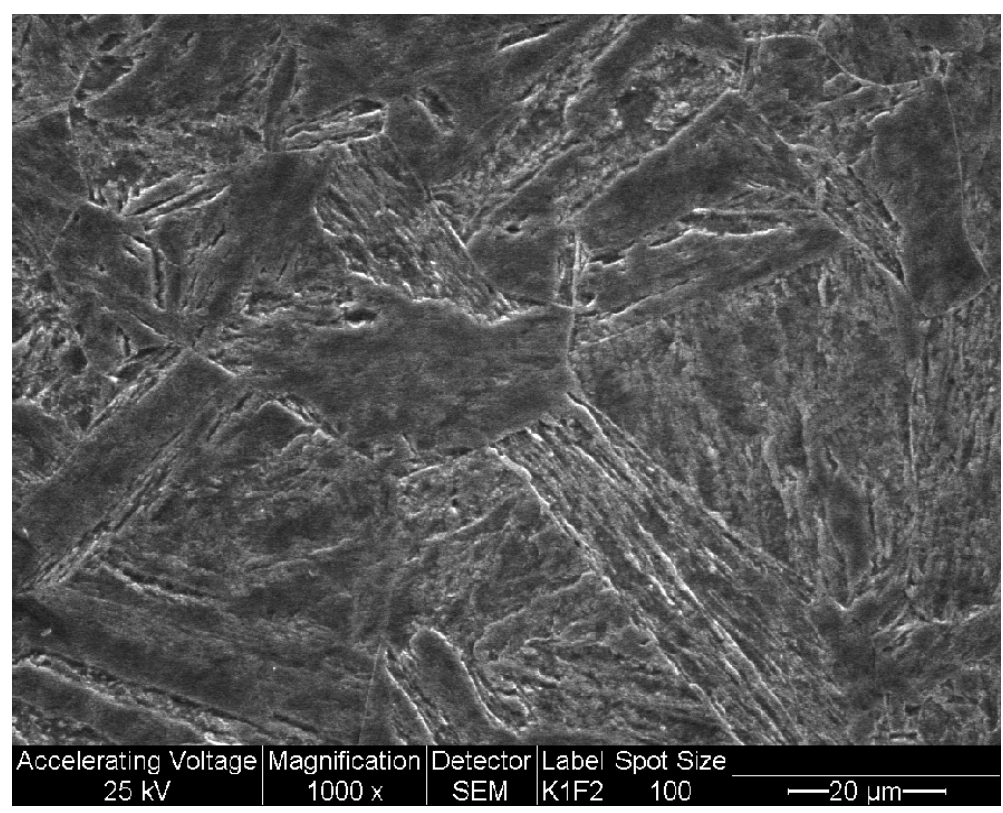

(a)

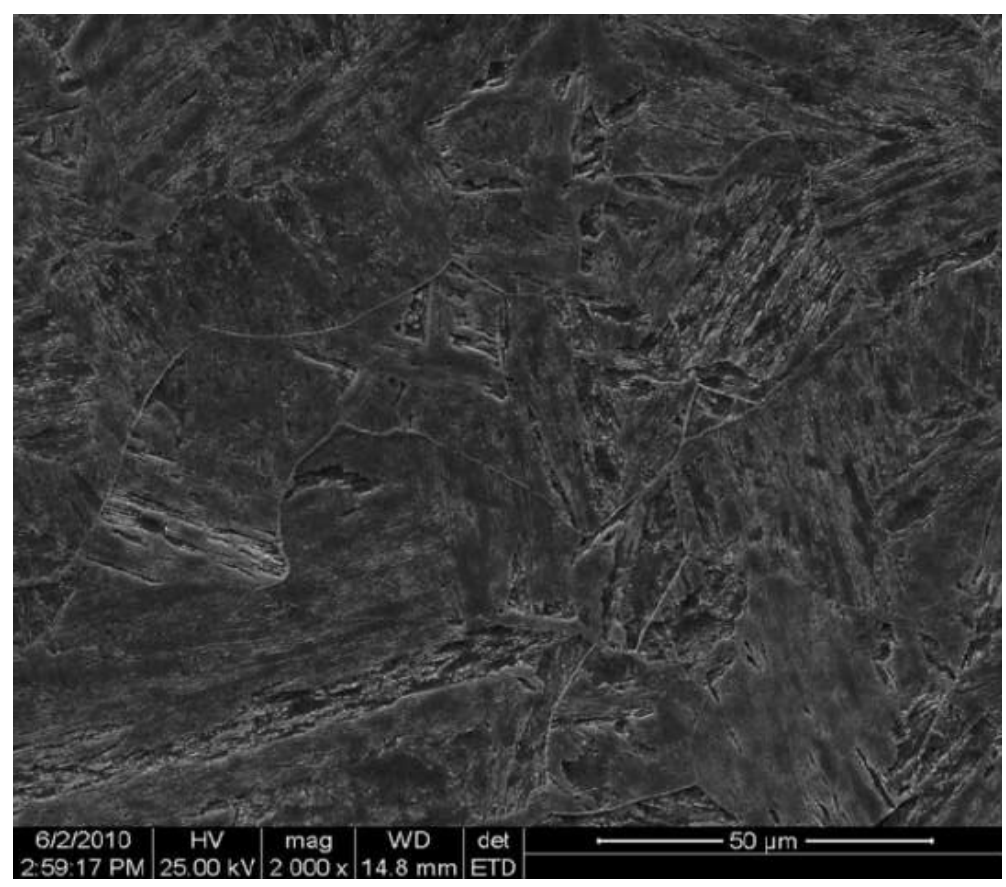

(b)

Figure 4.2. Matriz ferrítica para el acero inoxidable $13 \mathrm{CrNiMo}$ con tratamiento térmico de acuerdo a la condición E a 1000x (a) y 2000x (b).

El temple intercrítico a $600^{\circ} \mathrm{C}$ (condiciones $\mathrm{B}$ y G) produjo la descomposición de la martensita junto con la precipitación de una dispersión muy fina de austenita, ya que se 
sabe que la precipitación de austenita tiene lugar a temperaturas de templado ligeramente superio a $\mathrm{Ac}_{1}$.

La precipitación de austenita retenida puede hacerse más masiva mediante dobles revenidos [22] y esto influencia notoriamente las propiedades mecánicas. Si el primer revenido es realizado a temperaturas donde la austenita precipitada comienza a inestabilizarse (por ej. $625-670^{\circ} \mathrm{C}$ ) durante el enfriamiento del primer revenido transformará parte de ella a martensita fresh. Un revenido secundario realizado ahora a $600^{\circ} \mathrm{C}$ provocará que en virtud de mayores interfases de nucleación para la austenita retenida (las nuevas interfases austenita estable/martensita fresh) los contenidos de esta fase aumenten sin perder sus características morfológicas submicroscópicas. Lo que se consigue es un "refinamiento" de la estructura con mayor contenido de austenita retenida, o sea; mayor cantidad de similares partículas de austenita retenida que están más próximas entre sí. Esto repercute en un importante incremento en tenacidad al impacto respecto de efectuar un sólo revenido, disminuyendo por esto en poca magnitud la tensión de fluencia. En tal sentido, experiencias en metales de soldadura FCAW de AISM del tipo 13Cr/4NiMo $[112,113]$ con contenidos de $C$ de $0,07 \%$ muestran que mediante doble revenido a $670+$ $600^{\circ} \mathrm{C}$, el porcentaje de austenita estable en la microestructura incrementa un $25 \%$ respecto del contenido para la condición de simple revenido a $600^{\circ} \mathrm{C}$. En virtud de lo anterior también aumenta la tenacidad al impacto en un 30\% (73 joule a temperatura ambiente) y la tensión de fluencia sólo desciende un 3,5\% hasta valores de $784 \mathrm{MPa}$. Esto comprueba la efectividad del doble revenido para aumentar tenacidad sin una pérdida importante de resistencia mecánica. En las microestructuras con revenido doble se observa un refinamiento estructural. Este corresponde a un mayor contenido de austenita junto con una distribución más uniforme (condiciones $\mathrm{H}, \mathrm{M}$ y P). La Figura 4.3 muestra el resultado para la condición $\mathrm{M}$. 


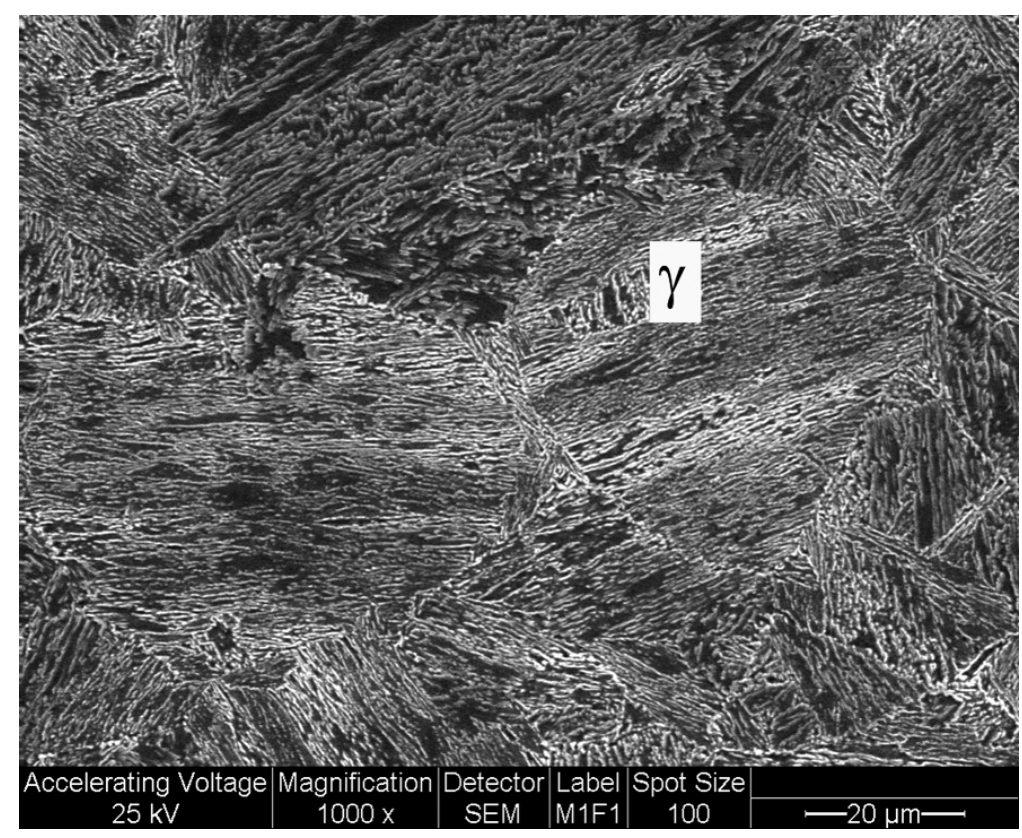

(a)

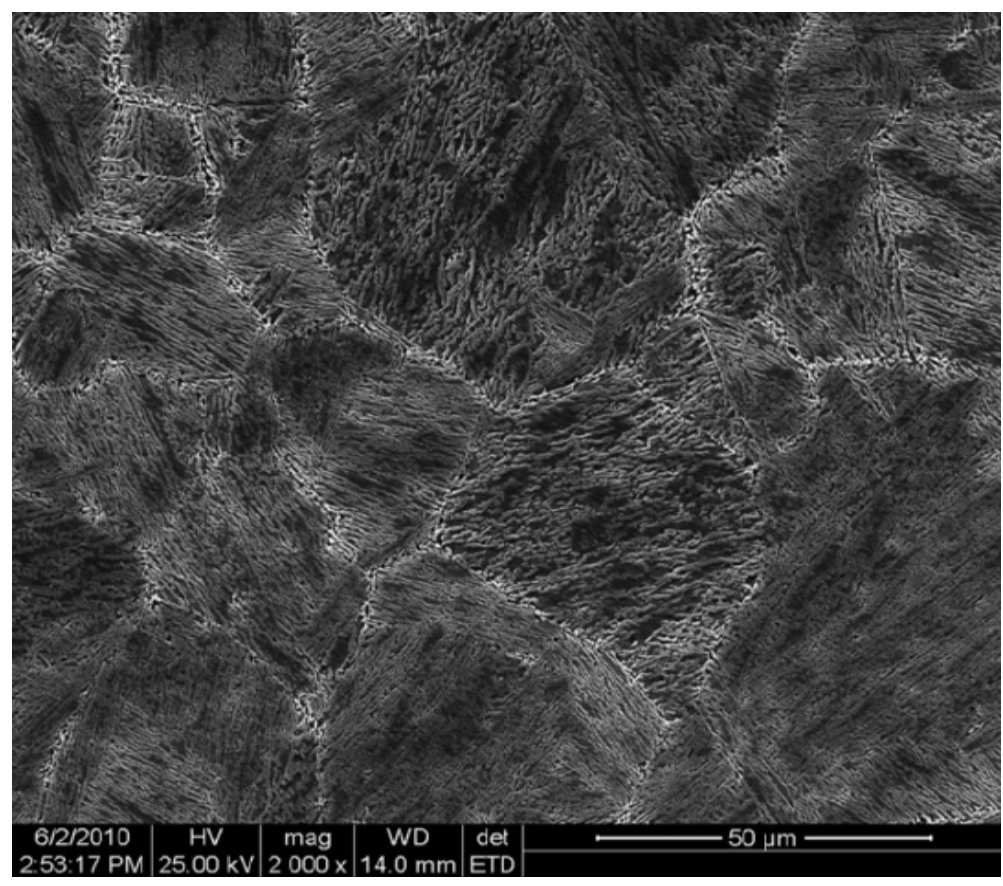

(b)

Figura 4.3. Partículas de austenita en la matriz de martensita revenida para el acero inoxidable $13 \mathrm{CrNiMo}$ con tratamiento térmico de acuerdo a la condición $\mathrm{M} \times 1000$ (a) y x2000 (b) . 
En la tabla 4.1 se muestran los contenidos de austenita retenida resultantes de la aplicación de los diferentes tratamientos térmicos.

Tabla 4.1. Descripción de los tratamientos térmicos y contenidos de austenita retenida obtenidos.

\begin{tabular}{|c|c|c|c|c|}
\hline Condición & $\begin{array}{l}\text { Tratamientos } \\
\text { térmicos }\end{array}$ & $\begin{array}{c}\text { Temperatura } \\
\text { (ㅇ) }\end{array}$ & $\begin{array}{l}\text { Tiempo } \\
\text { (h) }\end{array}$ & $\begin{array}{c}\text { Contenido Austenita } \\
\text { (vol \%) }\end{array}$ \\
\hline A & Como soldado & - & - & 6 \\
\hline B & Revenido & 600 & 2 & 16 \\
\hline$E$ & $\begin{array}{l}\text { solubilización + } \\
\text { revenido }\end{array}$ & $\begin{array}{c}950+ \\
550\end{array}$ & $\begin{array}{l}1 \\
2\end{array}$ & 2 \\
\hline G & $\begin{array}{c}\text { solubilización + } \\
\text { revenido }\end{array}$ & $\begin{array}{c}950+ \\
600\end{array}$ & $\begin{array}{l}1 \\
2\end{array}$ & 8 \\
\hline H & $\begin{array}{l}\text { Solubilización + } \\
\text { Doble revenido }\end{array}$ & $\begin{array}{c}950+ \\
670+ \\
600\end{array}$ & $\begin{array}{l}1 \\
2 \\
2\end{array}$ & 18 \\
\hline$M$ & $\begin{array}{c}\text { Solubilización + } \\
\text { Doble revenido }\end{array}$ & $\begin{array}{c}950+ \\
670+ \\
600\end{array}$ & $\begin{array}{l}1 \\
2 \\
8\end{array}$ & 22 \\
\hline $\mathbf{P}$ & Doble revenido & $\begin{array}{c}670+ \\
600\end{array}$ & $\begin{array}{l}2 \\
2\end{array}$ & 20 \\
\hline
\end{tabular}

Los espectros de difracción de rayos $\mathrm{X}$ para las muestras con tratamiento térmico en las condiciones $\mathrm{M}$ y $\mathrm{E}$ se muestran en las Figuras 4.4 y 4.5 , respectivamente, y pueden ser analizados comparativamente. La Figura 4.4 corresponde a una muestra con austenita retenida como resultado del doble revenido a $670^{\circ} \mathrm{C}+600^{\circ} \mathrm{C}$, mientras que la Figura 4.5 corresponde a una muestra sin austenita retenida como resultado de un revenido único a $550^{\circ} \mathrm{C}$. 


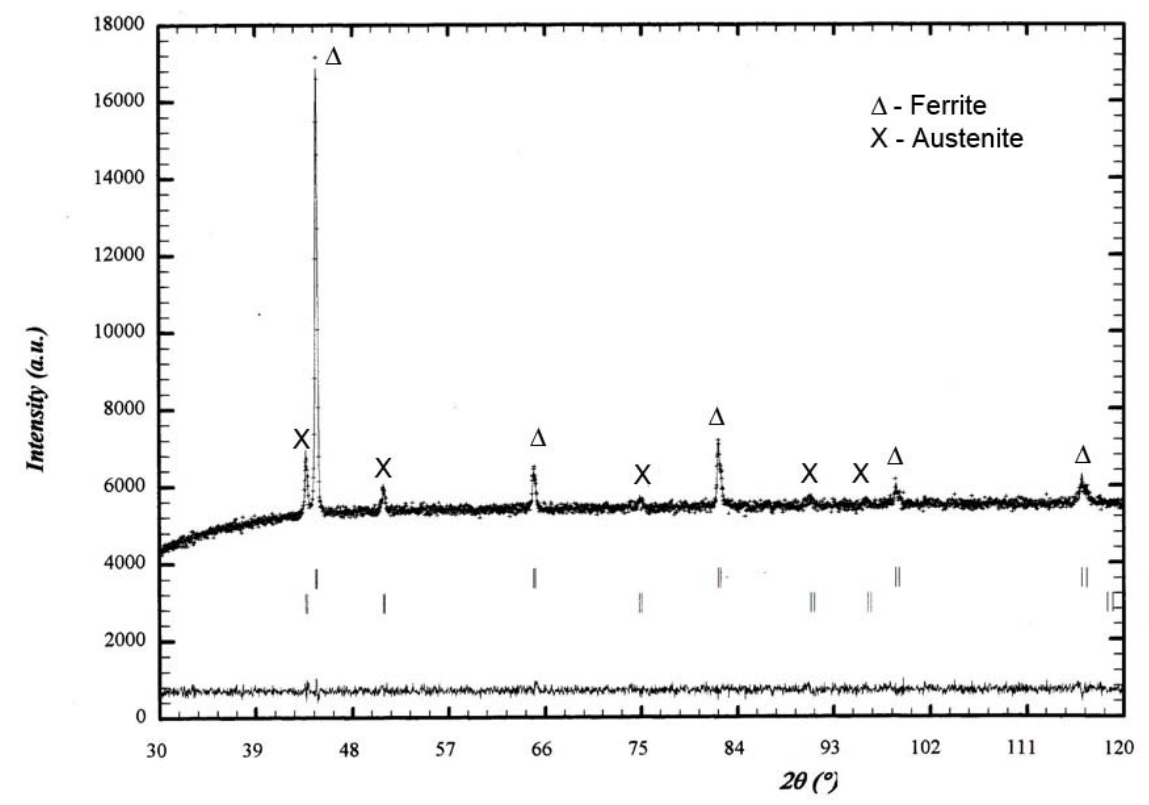

Figura 4.4. Patrones de difracción de rayos $X$ en una muestra con tratamiento térmico en la condición $\mathrm{M}$.

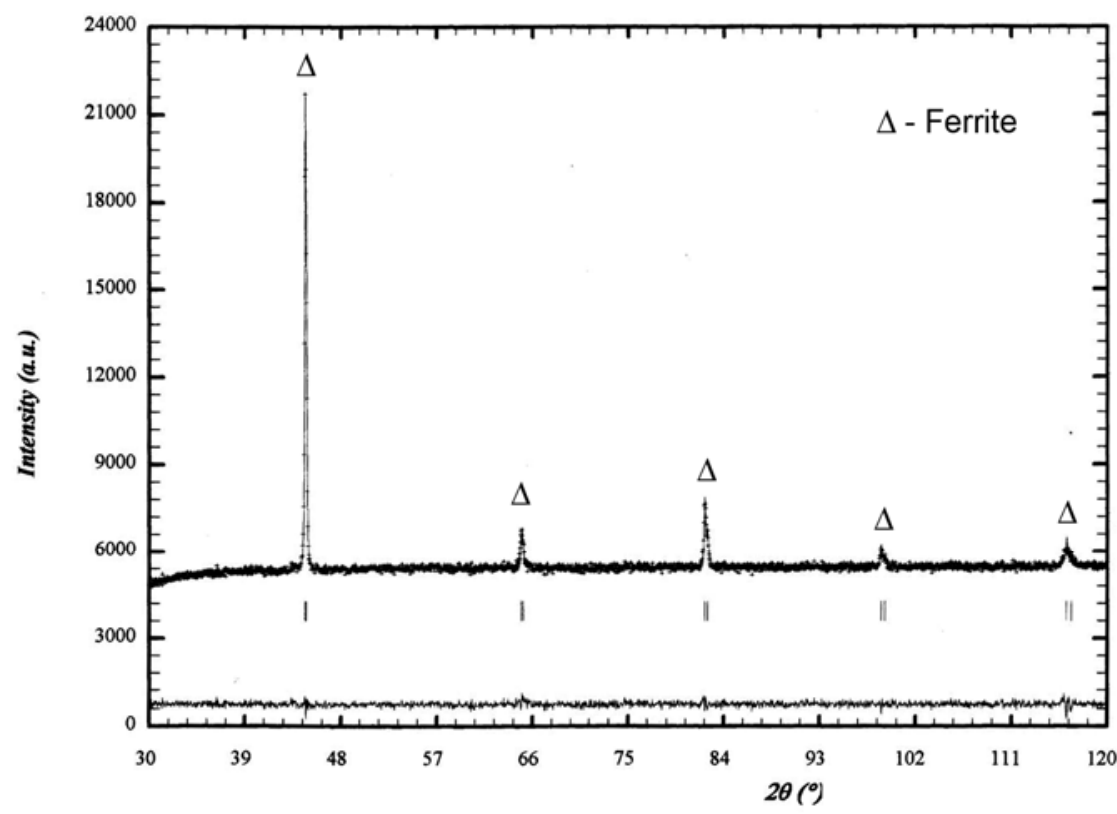

Figura 4.5. Patrones de difracción de rayos $X$ en una muestra con tratamiento térmico en la condición $\mathrm{E}$.

\subsubsection{Corrosión por picado}

Corrosión por picado se encontró en un acero inoxidable formado como un film delgado por deposición por sputtering, es decir, libre de inclusiones no metálicas que representan la heterogeneidad típica que afecta localmente la formación de la película 
pasivante y que puede conducir a la creación de una picadura [114][115]. En consecuencia, se puede afirmar que la ruptura de la pasividad es uno de los orígenes de iniciación de la picadura [116][117][109]. A su vez, la composición de la capa de óxido varía de acuerdo a la microestructura subyacente.

Para los aceros inoxidables, los tratamientos térmicos, el pulido mecánico y el granallado u otras limpiezas abrasivas pueden ser perjudiciales para la resistencia al picado, mientras que las películas formadas después del decapado en $\mathrm{HNO}_{3}+\mathrm{HF}$ o pasivación en $\mathrm{HNO}_{3}$ resultan usualmente beneficiosos [110]. Los tratamientos térmicos en aire generan una capa de óxido de cromo y una región empobrecida de cromo debajo de ella. El óxido es removido mecánicamente y la región agotada en cromo se elimina por decapado químico [110].

Los estudios electroquímicos de corrosión por picado demuestran, como se indicó en la parte introductoria de este trabajo, que existen dos potenciales característicos, el de picado y el de repasivación. Picaduras estables se forman a potenciales más nobles que el potencial de picado, $E_{p}$, aunque picaduras pre-existentes pueden crecer a potenciales más nobles que el potencial de repasivación, $E_{R}$, el cual resulta ser, a su vez, más activo que $E_{p}$ [111].

Una típica curva potenciodinámica de polarización cíclica, con barrido iniciado en sentido anódico, se muestra en la Figura 4.6, para una muestra tratada bajo las condiciones B (ver Tabla 4.1). 


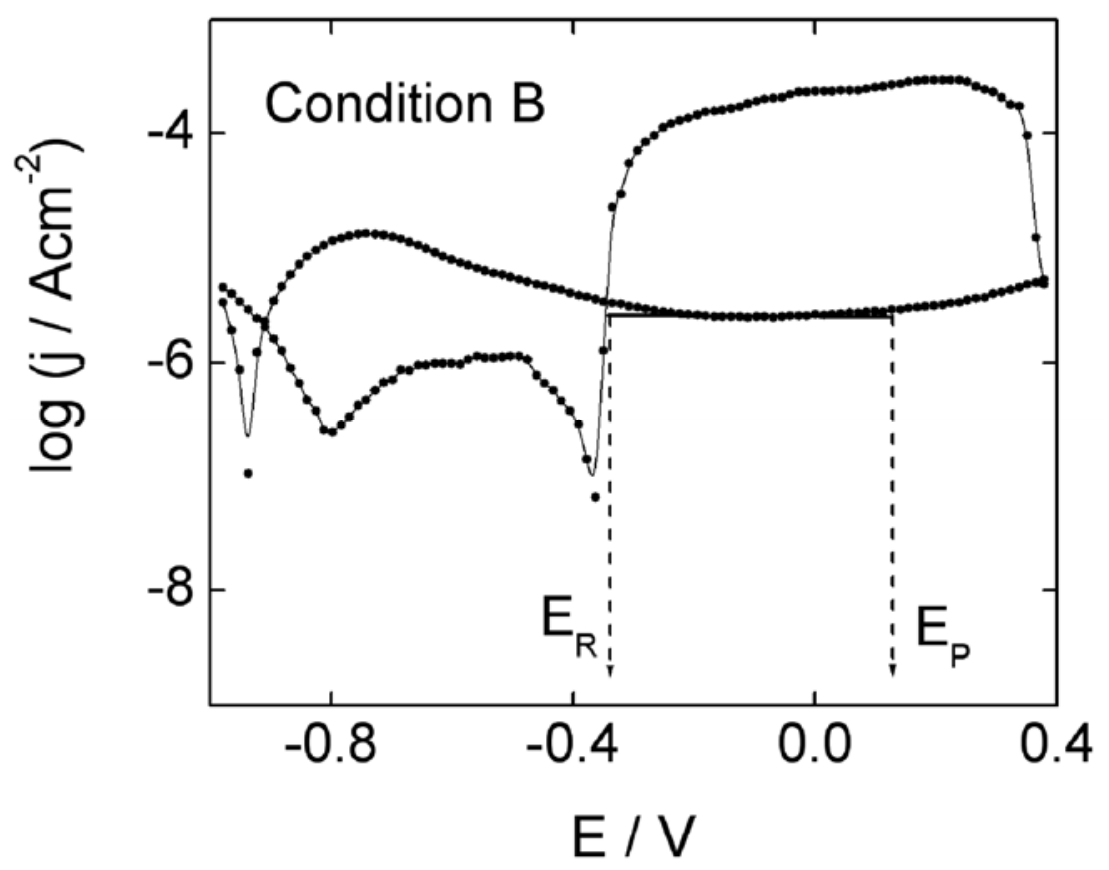

Figura 4.6. Curva de polarización potenciodinámica cíclica en medio desaireado conteniendo $0,05 \mathrm{M} \mathrm{K}_{2} \mathrm{SO}_{4}+0,04 \mathrm{M} \mathrm{NaCl}(\mathrm{pH}=4,1)$, velocidad de barrido $0,5 \mathrm{mV} / \mathrm{s}$, para una muestra bajo la condición B. En la Figura se indican los potenciales de picado y de repasivación.

Dado que los valores de $E_{p}$ exhibieron la dispersión típica para un proceso de picado, por lo menos veinte barridos idénticos se realizaron para cada condición, es decir, para cada tratamiento térmico diferente, como se indicó anteriormente. El amplio conjunto de valores de $E_{p}$ que se obtuvo para cada condición, se analizó de acuerdo con el enfoque estocástico normal teniendo en cuenta una probabilidad acumulada del proceso de picado $P$ (E) [100] [118], dada por la siguiente función de distribución:

$$
P(E)=n /(1+N)
$$

donde $\mathrm{N}$ es el número total de muestra estudiadas, y $\mathrm{n}$ es el número de muestras que presentaron picaduras a un potencial $E$ o inferior. El potencial correspondiente a $P=0,5$ fue considerado como el valor $E_{p}$, representativo de la muestra y en sus condiciones de preparación. La Figura 4.7 muestra la probabilidad derivada del picado como función del potencial para una muestra preparada bajo la condición B. El potencial correspondiente a P $=0,5$ se indica en la Figura. 


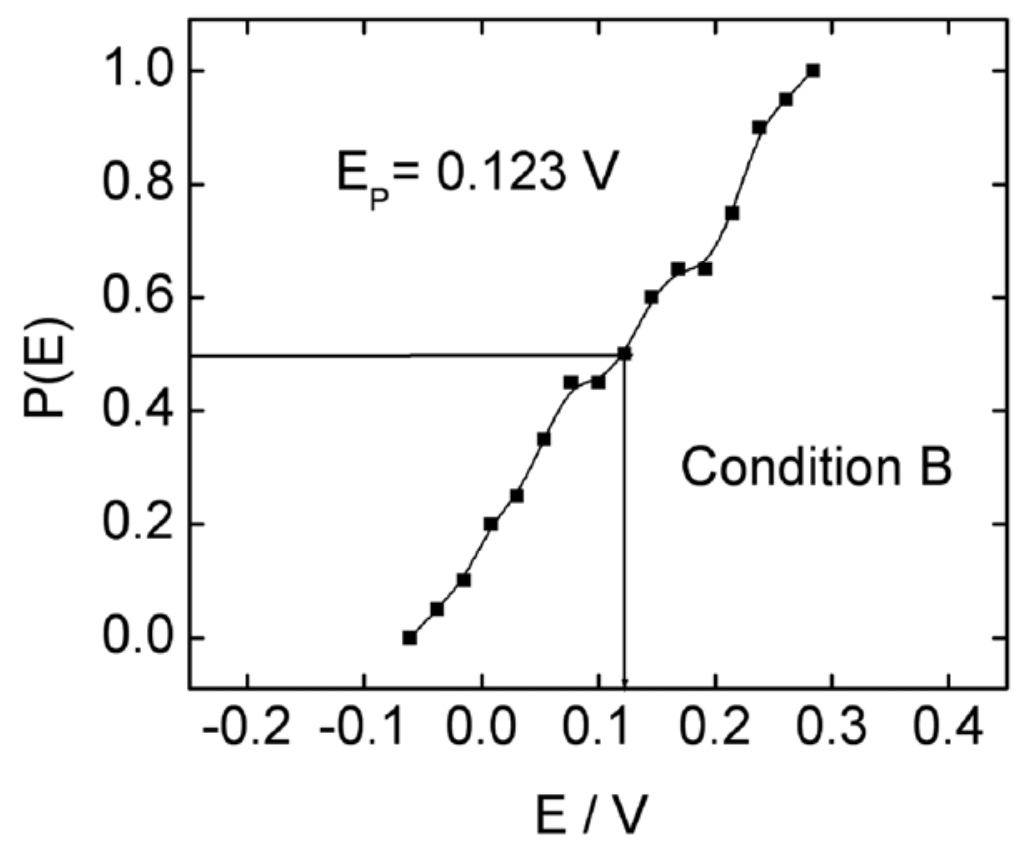

Figura 4.7. Distribución del potencial de picado dado por la probabilidad acumulada $P(E)$ (ecuación 4.1) como una función del potencial E, para una muestra preparada bajo la condición $\mathrm{B}$. El potencial a $\mathrm{P}=0,5$ es representativo para el material y su condición de preparación.

Con respecto a $E_{R}$, estos valores variaron linealmente con el logaritmo de la densidad de carga que ha circulado asociada al ciclo de histéresis durante el barrido de retorno del potencial [119]. El potencial para una cantidad arbitrariamente seleccionada de densidad de carga de propagación de picaduras $\left(q=0,1 \mathrm{C} / \mathrm{cm}^{2}\right.$ ) fue considerado como un valor normalizado $E_{R}$ a ser usado para comparar las diferentes muestras entre sí.

Las Figuras 4.8 y 4.9 muestran los potenciales de picado $E_{p}$ y de repasivación $E_{R}$, respectivamente, graficados en función de la cantidad de austenita retenida que resulta de los diversos tratamientos térmicos aplicados.

La dependencia lineal encontrada tanto para $E_{p}$ como para $E_{R}$, confirmó los resultados previos obtenidos con muestras preparadas a partir de metal de soldadura, ver Figura 4.10. El cambio en la dirección de potenciales nobles se encuentra relacionado al aumento del contenido de austenita retenida, lo que, a su vez, corresponde a una mayor resistencia al picado. 


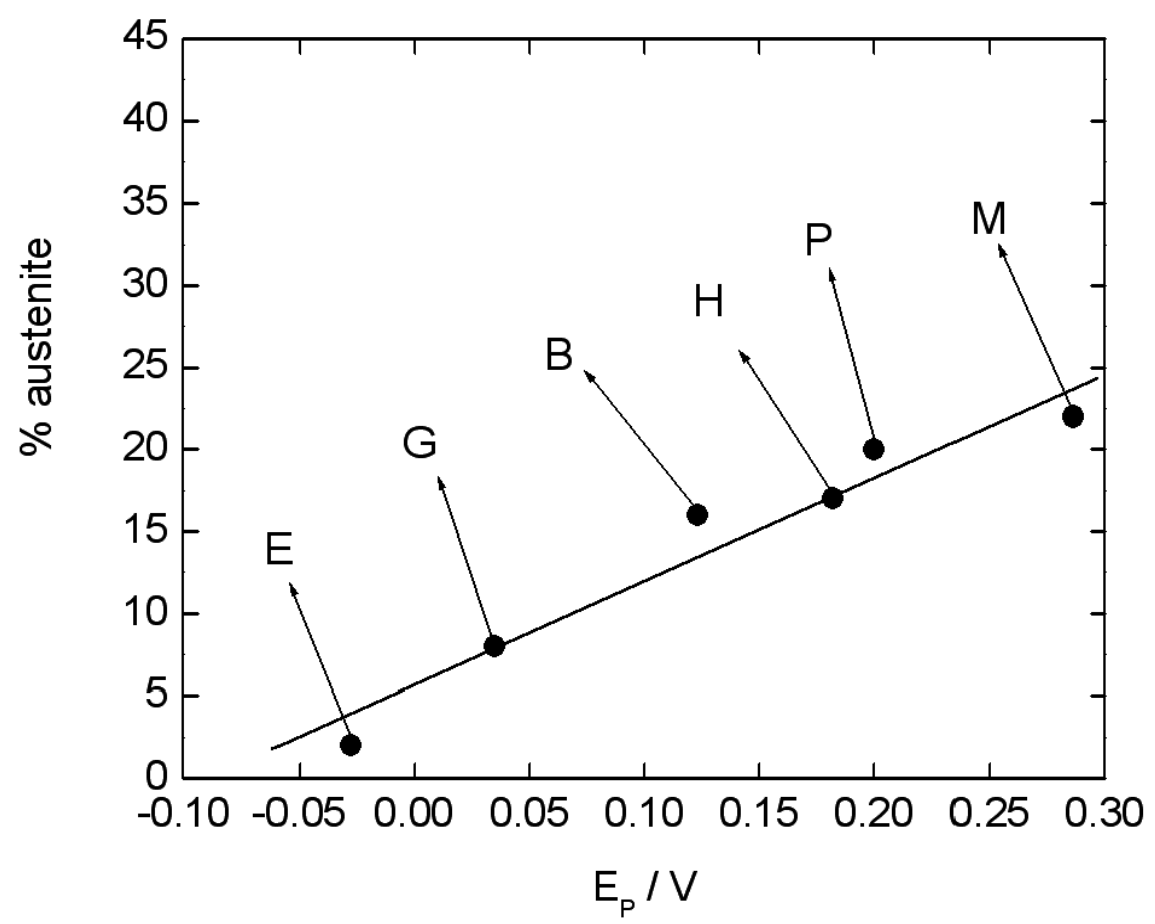

Figura 4.8. Austenita retenida (\% peso) vs. potencial de picado $\left(E_{p}\right)$ para diferentes condiciones de preparación como se indica en el texto.

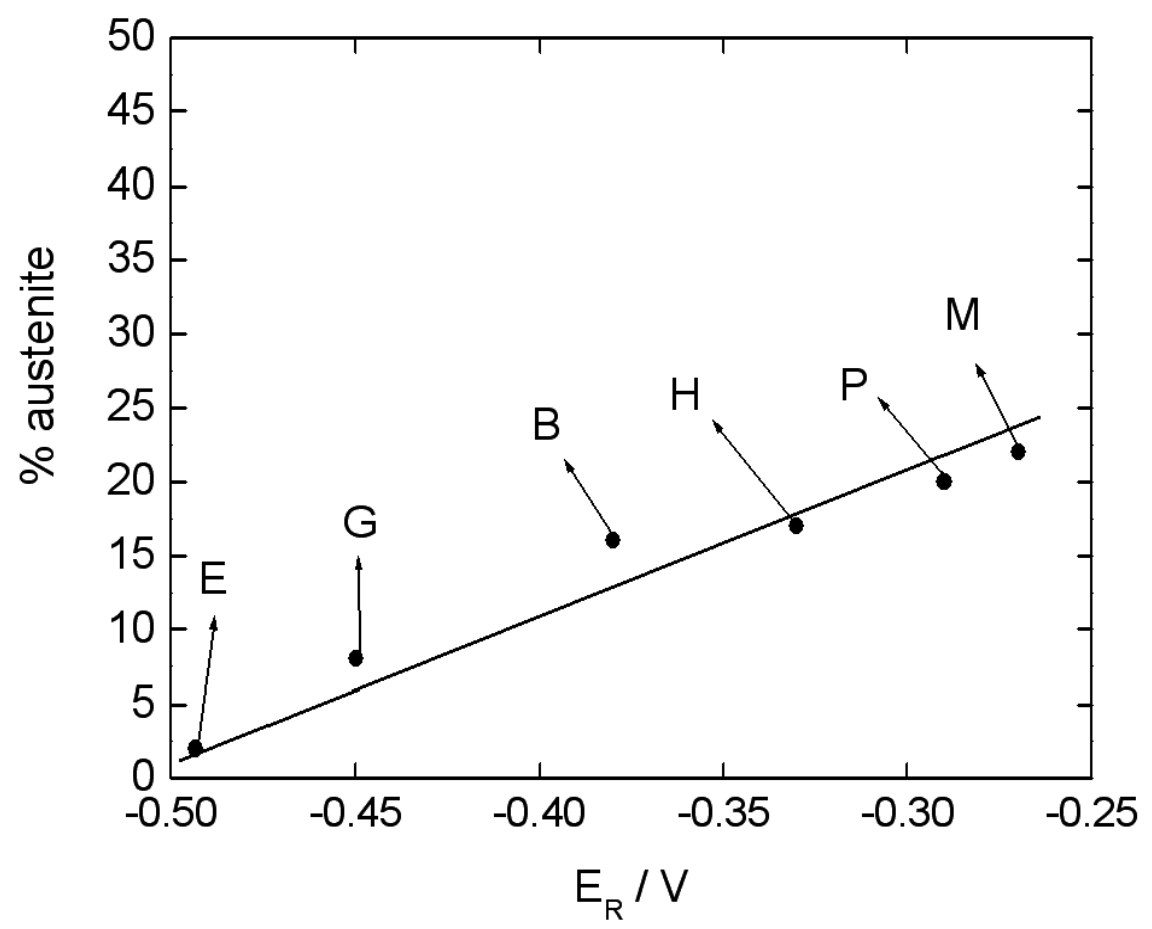

Figura 4.9. Austenita retenida (\% peso) vs. potencial de repasivación ( $E_{p}$ ) para diferentes condiciones de preparación como se indica en el texto. 

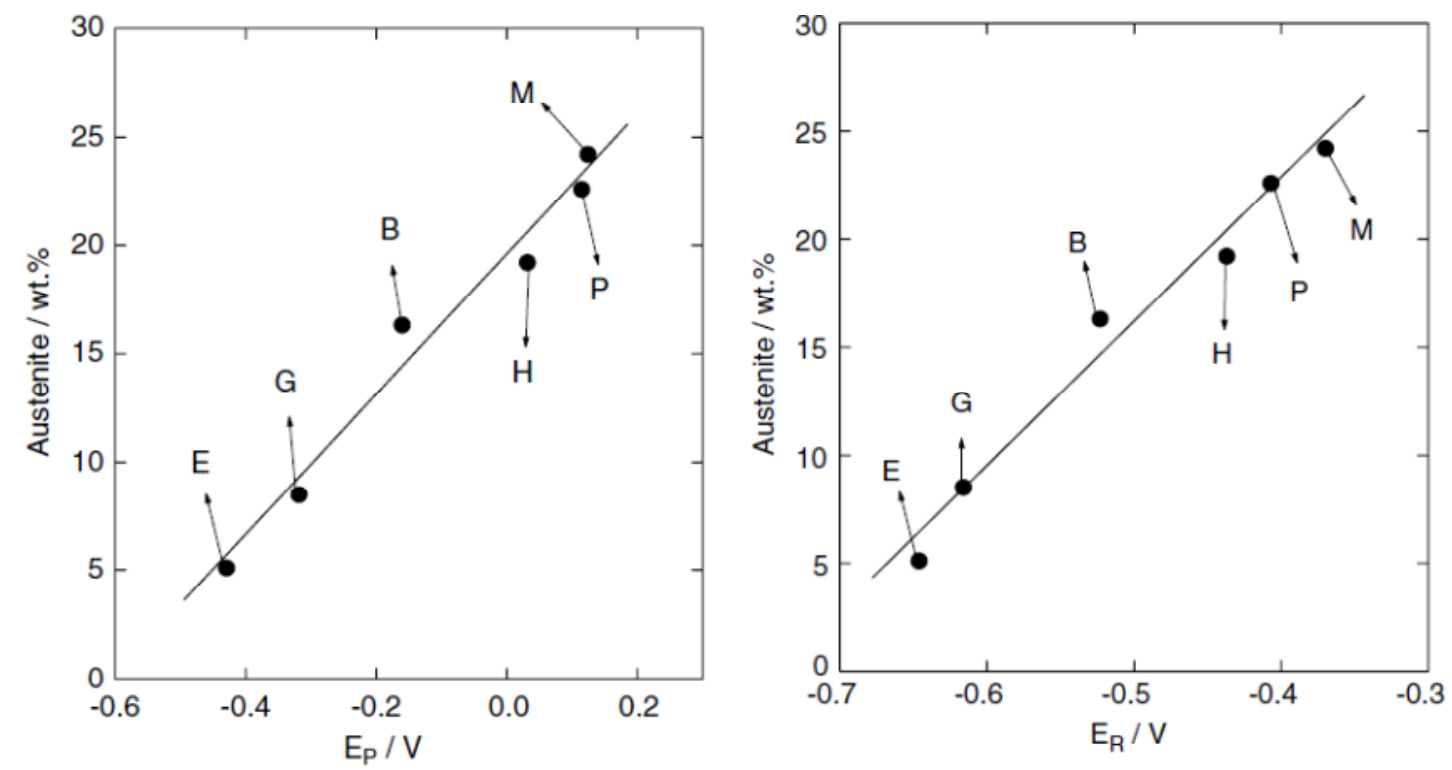

Figura 4.10. Austenita retenida (\% peso) vs. potencial de repasivación ( $E_{\mathrm{p}}$ ) para diferentes condiciones de preparación como se indica en el texto, para el metal de soldadura, extraído de la referencia [87].

La resistencia al picado mejoró al utilizar un doble revenido en las condiciones de tratamiento térmico. Estos resultados indican que, bajo estas condiciones de trabajo, la resistencia al picado fue fuertemente afectada por dos factores microestructurales, la cantidad y tamaño de carburos y el contenido de austenita retenida [87].

Esto puede interpretarse como resultado de un refinamiento estructural que tiene lugar luego del doble revenido, de acuerdo al modelo previamente presentado [120][21]. El simple revenido a $600^{\circ} \mathrm{C}$ produjo una microestructura compuesta de martensita revenida y algo de austenita retenida. El doble revenido, inicialmente a $670^{\circ} \mathrm{C}$ y luego a $600^{\circ} \mathrm{C}$, generó la precipitación de nuevas partículas-placas estables de austenita a través de nuevas interfases formadas (martensita/austenita), mientras que la martensita nueva derivó en martensita revenida. Relevante resulta igualmente el hecho que, largos tiempos de revenido a $600^{\circ} \mathrm{C}$ ( 8 horas para la condición M) promovieron mayores contenidos de austenita retenida con respecto al doble revenido en las condiciones de menor tiempo ( 2 horas para la condición $\mathrm{H}$ y P).

Por lo tanto como resultado de este doble revenido, el número de plaquetas de austenita se incrementó y presentan además una distribución más uniforme. Más aún, ya que la transformación es difusional, la austenita resulta enriquecida en elementos como níquel, carbón y nitrógeno, lo que en definitiva determina disolución o refinamiento de 
partículas de carburos y carbonitruros. Todo este proceso, a su vez, determinó una menor susceptibilidad a la corrosión por picado [[87] y las referencias allí]. Del mismo modo que para el acero inoxidable martensítico UNS S42000 tratado mediante técnica laser para producir fusión superficial, el mejoramiento en la resistencia a la corrosión por picado resultó de la disolución y refinamiento de partículas de carburos y de la presencia de austenita retenida, como se evidencia por los incrementos lineales de los potenciales de picado y repasivación con el contenido de austenita retenida. [87][77].

Una comparación entre los resultados presentados en las Figuras 4.8 y 4.9 y los obtenidos previamente en muestras de metal de soldadura, Figura 4.10 [87], muestran que tanto los valores de $E_{p}$ y $E_{R}$ son siempre más noble para el metal base que para el metal de soldadura, para cada fracción de volumen de austenita retenida. Sin embargo, la diferencia en los valores de $E_{p}\left(\Delta E_{p}\right)$ entre metal base y metal de soldadura, disminuye con el aumento del contenido de austenita retenida, mientras que para contenidos de austenita retenida $\geq$ $20 \%$ en peso los valores de $\Delta \mathrm{E}_{\mathrm{p}}$ resultan despreciables. Estos resultados se corresponden con el punto de vista que la condición beneficiosa del metal de base (con estructura más homogénea, con menor densidad de inclusiones y otros defectos que actúan como sitios de iniciación de picaduras) se vuelve menos determinante del comportamiento que el efecto beneficioso de un alto contenido de austenita retenida (asociado con refinamiento estructural y un aumento en contenido de $\mathrm{Cr}$ disuelto [121]). La diferencia en valores $E_{R}$ $\left(\Delta E_{R}\right)$ decrece con el incremento del contenido de austenita retenida en una forma menos marcada. Por lo tanto, la influencia relativa del contenido de austenita (medida como la proporción entre las pendientes $\delta E / \delta[\% a u s t])$ es 2,13 para $E_{p}$ mientras que para $E_{R}$ es sólo 1,25. Esto refleja el hecho que el efecto beneficioso de la austenita retenida en la cinética de la repasivación que desencadena un freno al crecimiento de picaduras en desarrollo estable (relacionada con $E_{R}$ ) no es tan fuerte como su efecto en la presencia de sitios de iniciación de picaduras (relacionada con $\mathrm{E}_{\mathrm{p}}$ ).

El tamaño y forma de la picadura dependerá de las condiciones experimentales seleccionadas. En los ensayos electroquímicos se generan picaduras de forma regular con morfología hemisférica (Figura 4.11). En consecuencia, estas picaduras crecieron sin seguir la orientación cristalográfica del metal y cruzan la interfaz entre cristalitas. Se ha indicado que éste es el resultado de la presencia del anión sulfato en el electrolito [116]. 


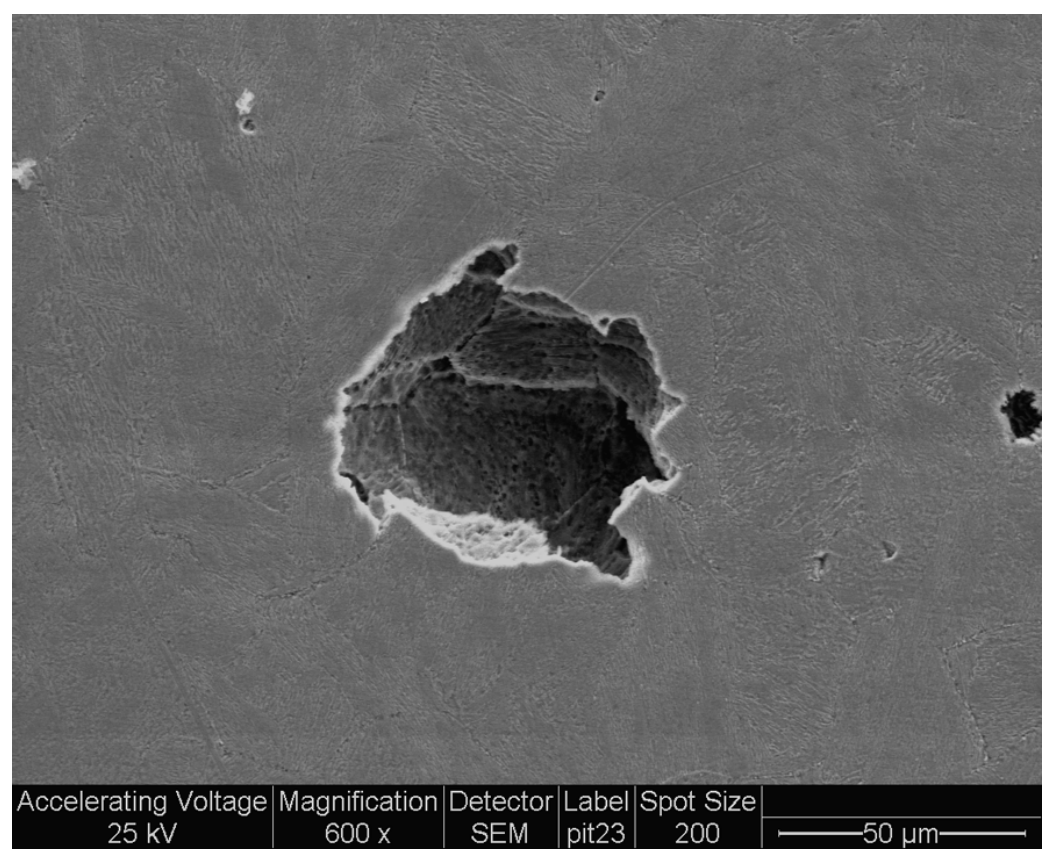

Figura 4.11. Micrografía SEM donde se observa el crecimiento de una picadura semiesférica en acero inoxidable $13 \mathrm{CrNiMo}$ en $0,05 \mathrm{M} \mathrm{K}_{2} \mathrm{SO}_{4}+0,04 \mathrm{M} \mathrm{NaCl}(\mathrm{pH}=4,1)$. 


\section{CAPÍTULO 5}

\section{Análisis del impacto de las propiedades microestructurales de la aleación $13 \mathrm{CrNiMo}$ sobre la formación de sus películas pasivantes}

\subsection{Objetivos}

Atento a los resultados y discusión presentados en el capítulo previo podemos afirmar que se puede esperar que los cambios microestructurales ocasionados por ciertos tratamientos térmicos post-soldadura aplicados a los aceros inoxidables estudiados pueden permitir la formación de películas pasivantes que eventualmente exhiban capacidades protectoras superiores, en relación con la resistencia que otorgan a la corrosión por picado. Por este motivo el objetivo de este capítulo es encontrar una relación entre las diversas propiedades microestructurales de las aleaciones, producto de los mencionados tratamientos térmicos, y la formación de películas pasivantes sobre las mismas.

\subsection{Resultados y Discusión}

\subsubsection{Curvas potenciodinámicas}

En la Figura 5.1 se presentan curvas de polarización potenciodinámicas para muestras sometidas a los tratamientos térmicos previamente detallados. Los experimentos fueron llevados a cabo a temperatura ambiente $\left(25 \pm 2^{\circ} \mathrm{C}\right)$ en solución $\mathrm{Na}_{2} \mathrm{HPO}_{4} 0,5 \mathrm{M}(\mathrm{pH} 9,2)$. La elección de la composición de la solución electrolítica obedeció al objetivo de asegurar una eficiente formación de capas anódicas protectoras. Más aún, para llevar a cabo un estudio de la dependencia del estado pasivo con el tratamiento térmico de la aleación base, utilizamos en los experimentos un electrolito con comprobada capacidad de formar películas anódicas pasivantes casi libres de defectos (en ausencia de iones agresivos iniciadores de picaduras como los iones cloruro) con la ventaja adicional de estar disponible un amplio cuerpo de conocimiento previo publicado a este respecto [122].

La Figura 5.1 contiene curvas de polarización iniciadas a un potencial $50 \mathrm{mV}$ más catódico que el potencial de corrosión $\left(\mathrm{E}_{\mathrm{corr}}\right)$ y que se registraron aplicando un barrido de potencial en dirección de los potenciales positivos a $1 \mathrm{mVs}^{-1}$. Los potenciales de corrosión 
para las muestras E, B, P y M, fueron medidos como el promedio de 5 experimentos antes de aplicar el barrido de potencial y luego de 2 horas al potencial de circuito abierto, resultando los siguientes valores $-0,758 \pm 0,04 \mathrm{~V},-0,698 \pm 0,04 \mathrm{~V},-0,596 \pm 0,03 \mathrm{~V}$ y $-0,526 \pm 0,03 \mathrm{~V}$, respectivamente. Ya que en este electrolito los mismos resultaron más nobles que el potencial de pasivación no es posible observar la transición entre estados activo y pasivo. Según Vetter el desplazamiento de los valores de potenciales de circuito abierto (PCA), está vinculado a cambios composicionales y estructurales de la película superficial [27]. Además, el corrimiento del potencial de corrosión en la dirección de los potenciales más nobles puede entenderse como relacionado a un engrosamiento de la película pasivante o a un cambio de su composición [110][123]. Esto permite confirmar entonces, que composición, espesor y estructura de los óxidos anódicos están claramente influenciados por la microestructura del metal base. Los (PCA) están seguidos por una región de pasividad y un máximo de corriente correspondiente al inicio de la región transpasiva (hombro a un potencial cercano a 0,6 V) que en la literatura, se asocia a la oxidación de una película interna de $\mathrm{Cr}(\mathrm{III})$ a especies de $\mathrm{Cr}(\mathrm{VI})$, bien en un óxido o como compuestos solubles [124]. El incremento final en los valores de corriente a potenciales anódicos muy altos corresponde a la reacción de evolución de oxígeno.

El comienzo de la región transpasiva tiene como explicación más usual a la disolución oxidativa de la capa barrera, que en nuestro caso corresponde a una compuesta de óxido crómico. Así, el inicio de la disolución transpasiva puede deberse a la ocurrencia de la siguiente reacción [125]:

$$
\mathrm{Cr}_{2} \mathrm{O}_{3}+5 \mathrm{H}_{2} \mathrm{O} \Leftrightarrow 2 \mathrm{CrO}_{4}{ }^{=}+10 \mathrm{H}^{+}+6 \mathrm{e}^{-}
$$

De acuerdo a la previsiones de un diagrama de Pourbaix [126] conteniendo las contribuciones combinadas de $\mathrm{Fe}, \mathrm{Cr}$ y $\mathrm{Mo}$, al $\mathrm{pH}$ del electrolito utilizado en nuestros experimentos la oxidación de Mo debe ser excluída como posible proceso en el rango de potencial del hombro de corriente detectado en las curvas de polarización [127][128].

Un dato muy importante y relevante a los resultados presentados aquí es que el corrimiento del PCA y el aumento del hombro debido a la transformación transpasiva para aceros austeníticos 304 con $\mathrm{Cr}^{+}$implantado se ha informado y esos fenómenos son más marcados frente a un aumento de la magnitud de implantación de $\mathrm{Cr}$ [129]. Esto confirmaría 
la mayor disponibilidad de $\mathrm{Cr}$ para formar película superficial en la muestra $\mathrm{M}$ ya que el máximo asociado a la oxidación de especies de $\mathrm{Cr}$ es más pronunciado para esa muestra, particularmente en su comparación con los resultados para la muestra $\mathrm{E}$.

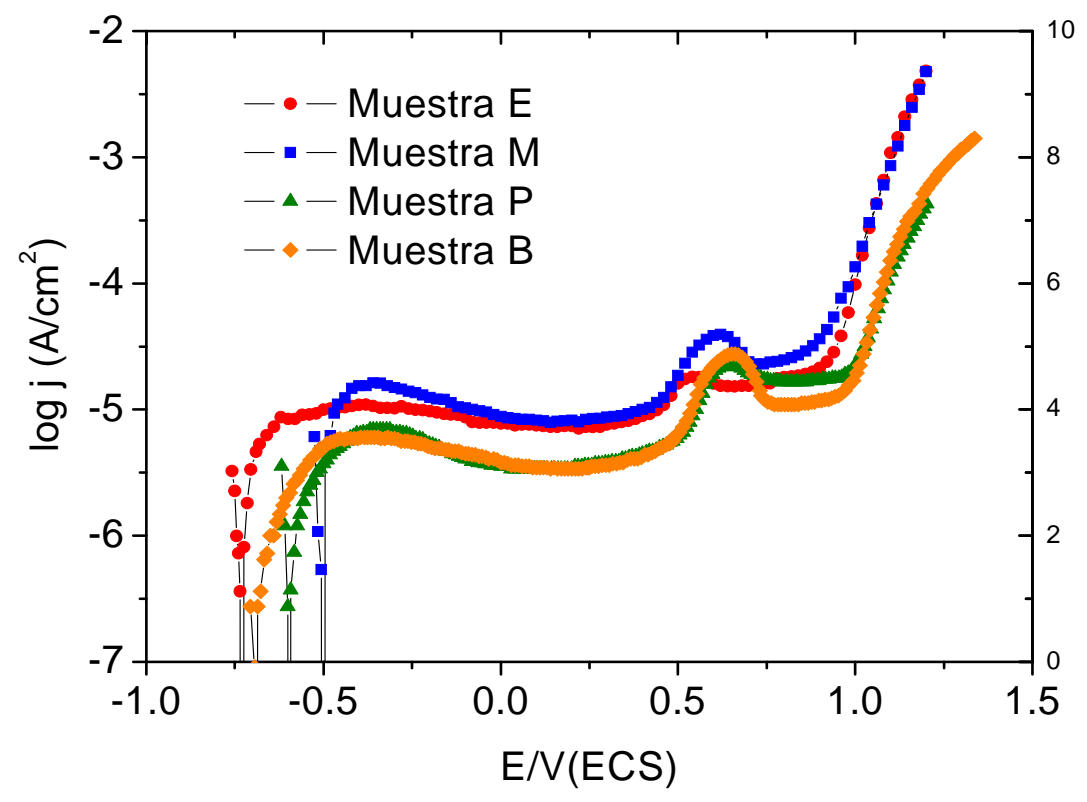

Figura 5.1. Curvas de polarización potenciodinámicas

En consecuencia, los datos presentados en la Figura 5.1 representan una fuerte indicación de que hay una influencia significativa de la microestructura del sustrato en las propiedades del óxido anódico, básicamente en sus composición, espesor y estructura.

De aquí en más se focaliza la presentación y discusión comparativa en los resultados de las muestras cuyos tratamientos térmicos generan los contenidos de austenita retenida extrema, es decir las muestra $\mathrm{E}$ y muestra $\mathrm{M}$.

La Figura 5.2 muestra valores de corriente en el estado estacionario medidos luego de 2 horas de estabilización a potenciales elegidos en las regiones de pasividad y transpasividad. La corriente de pasividad media fue de ca. $2 \times 10^{-7} \mathrm{~A} \mathrm{~cm}^{-2}$ esencialmente independiente del tratamiento térmico del material y del potencial en el alcance de potencial de pasividad hasta el inicio de la oxidación de especies de cromo en la película (desde $-0,3 \mathrm{~V}$ hasta $0,3 \mathrm{~V}$ ), a partir del cual exhibe un leve aumento con el potencial de anodizado. 


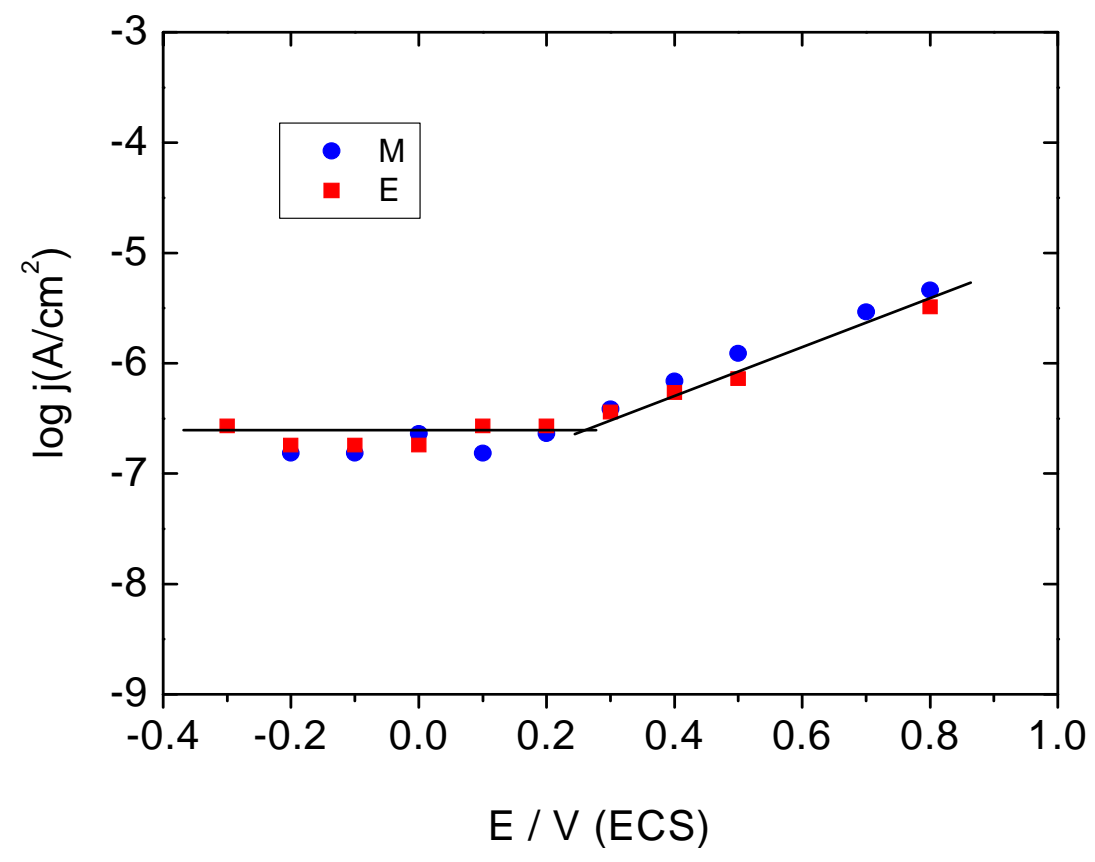

Figura 5.2. Datos de polarización quasi-estacionaria para la oxidación metálica a potenciales mayores que el de pasivación.

\subsubsection{Cronopotenciometría}

Se realizaron mediciones cronopotenciométricas luego de la aplicación de escalón de corriente de reducción sobre el acero cuya superficie fue oxidada previamente en la región de pasividad. La corriente aplicada al electrodo hace que las especies superficiales que pueden ser oxidadas más fácilmente inicien su oxidación de modo secuencial a velocidad constante y hasta consumir todo el reactivo previo a la iniciación de la descarga de otra especie. Así, transcurrido el denominado tiempo de transición, $\tau$, la cantidad de la especie que se reduce en la superficie del electrodo no es lo suficientemente grande como para satisfacer la corriente aplicada, entonces se produce una evolución del potencial hacia valores más negativos a los que ocurre una nueva electro-reducción, asociada, claro está, con un segundo tiempo de transición [122]. Se siguió el procedimiento descrito y propuesto en la referencia [123] para medir $\tau$ y el potencial asociado del plateau de corriente al cual ocurre la reducción de una dada especie superficial, $\mathrm{E}_{\mathrm{C}}$. Este procedimiento produce buenos resultados, incluso en presencia de distorsiones en las curvas Potencial vs tiempo debido al efecto de la doble capa durante la reducción galvanostática de la película pasiva.

Un transitorio de potencial típico de los obtenidos en este trabajo se presenta en la Figura 5.3 donde se indica la presencia de dos tiempos de transición distinguibles en la traza 
de la respuesta temporal $\left(\tau_{1}\right.$ y $\left.\tau_{2}\right)$ resultantes de la reducción secuencial de dos especies superficiales, cada una caracterizada por un potencial reversible diferente. El amesetamiento final en la curva de reducción galvanostática presenta un valor de potencial compatible con la reacción de evolución de hidrógeno en el extremo de potenciales más catódicos.

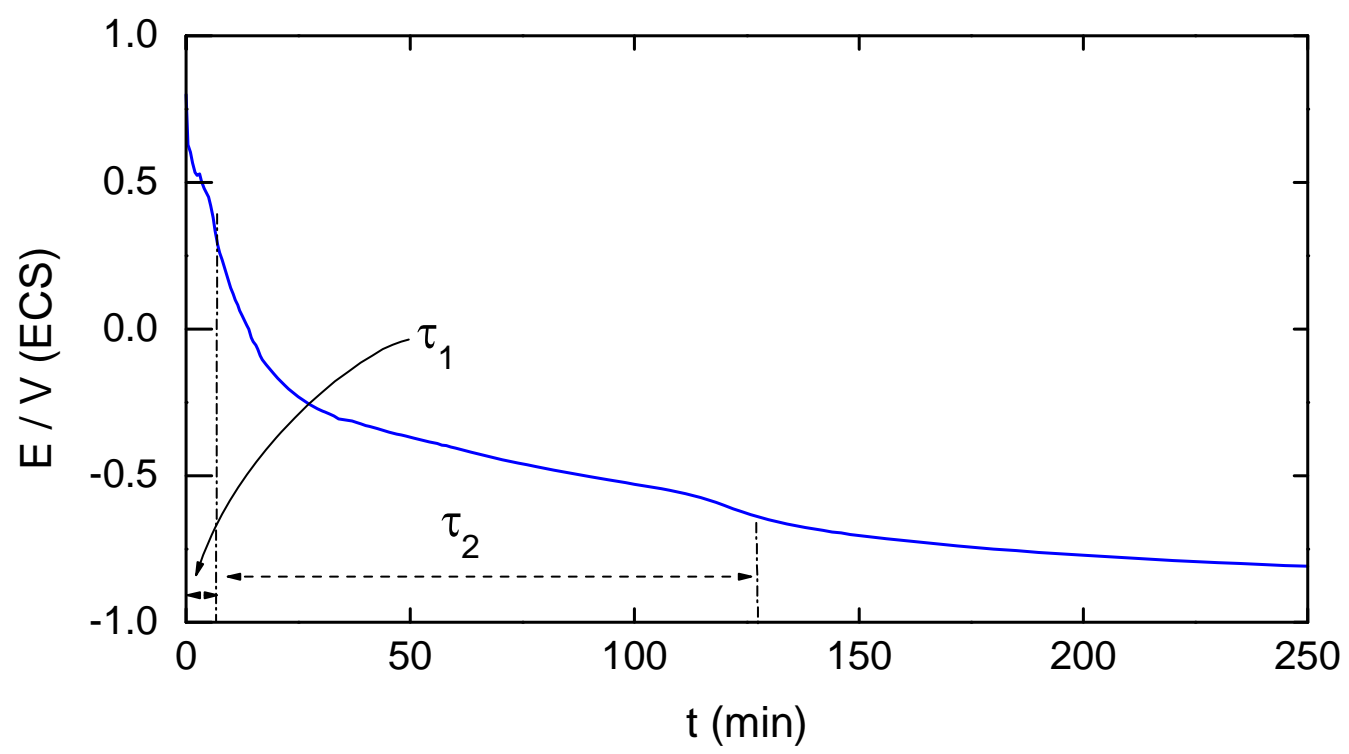

Figura 5.3. Transitorio de potencial típico obtenido por electrorreducción mediante la aplicación de un escalón galvanostático, de un film anódico pasivante previamente crecido y estabilizado sobre el electrodo.

Las Figuras 5.4 y 5.5 muestran los transitorios de potencial de ambas muestras a diferentes potenciales de formación. Se pudo observar, ver Figuras 5.4 y 5.5, que los tiempos de transición fueron mayores para la muestra M.

El proceso caracterizado por $\tau_{1}$ solo fue detectable cuando el potencial de formación de la película pasiva, $\mathrm{E}_{\text {form }}$, superó el inicio de la reacción de oxidación de especies de cromo en el film (Figuras 5.6 y 5.67). Por otra parte, tanto $\tau_{1}$ como $\tau_{2}$ resultaron siempre más grandes para la muestra $M$, mientras que los valores de $\tau_{1}$ fueron menores que los correspondientes a $\tau_{2}$ para cada muestra. Para ambas muestras, los potenciales tomaron valores de $E_{C 1} \cong 0,15 \vee$ y $E_{C 2} \cong-0,5 \vee$. Esto indica que se trata de los mismos procesos de electrorreducción independientemente del tratamiento térmico del metal base. 


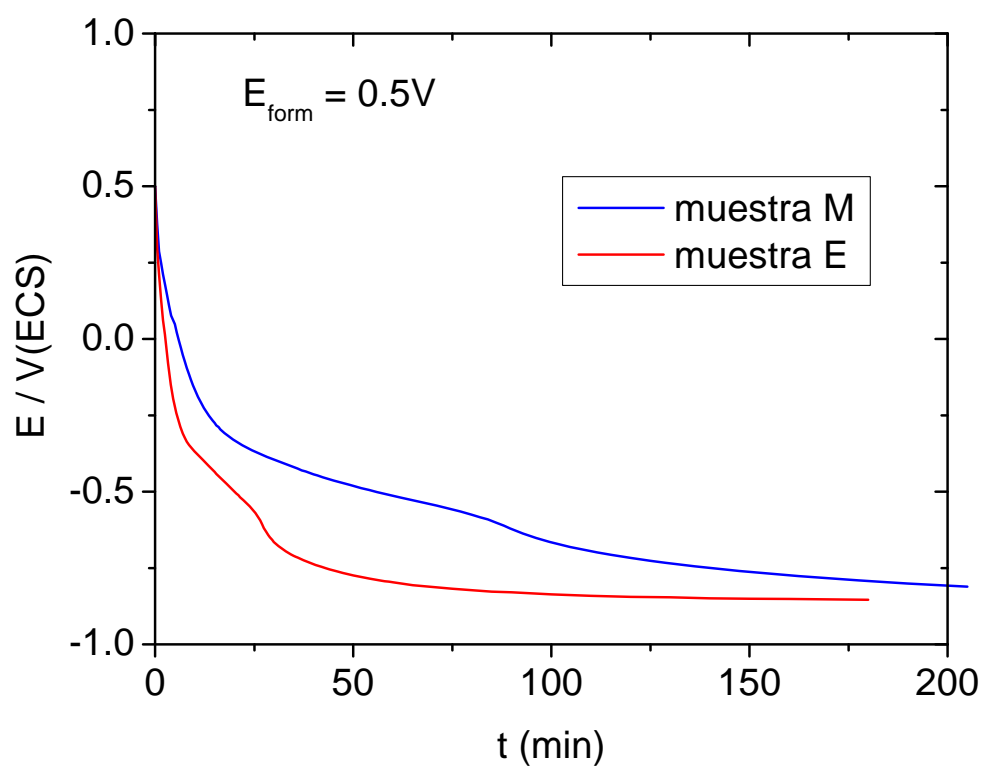

Figura 5.4. Transitorio de potencial típico de la reducción galvanostática del film anódico formado a un potencial de $0,5 \mathrm{~V}$.

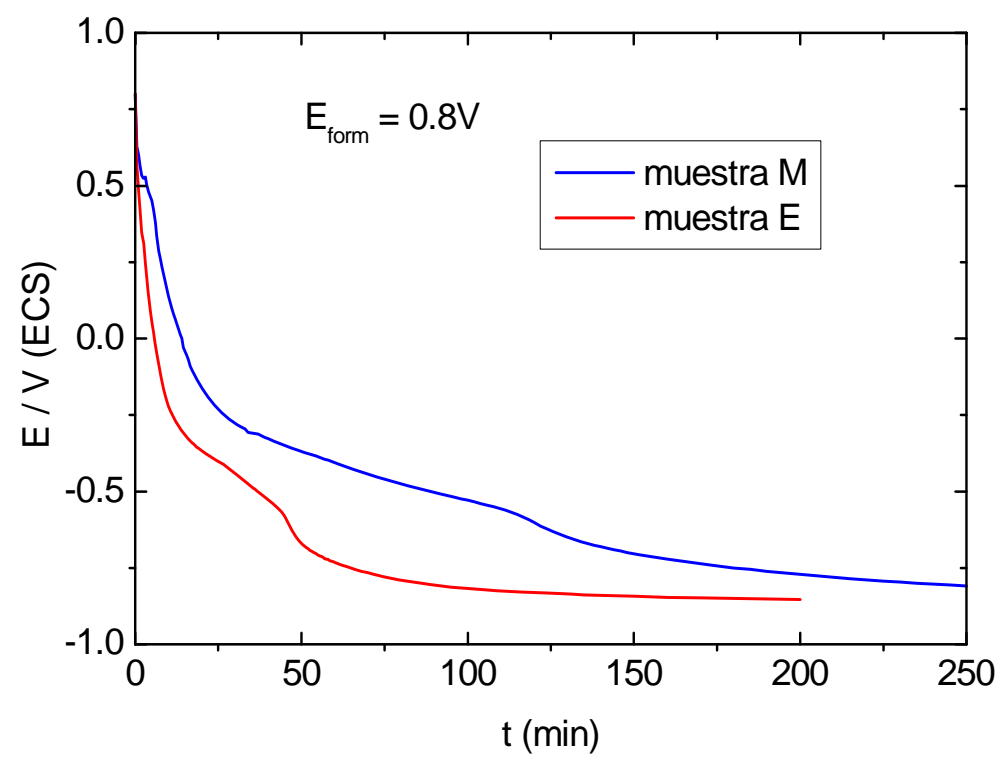

Figura 5.5. Transitorio de potencial típico de la reducción galvanostática del film anódico formado a un potencial de $0,8 \mathrm{~V}$.

En la Tabla 2, se muestra un resumen de los resultados obtenidos por reducción galvanostática en las diferentes condiciones experimentales. 
Tabla 2. Tiempos de transición y potenciales de amesetamiento obtenidos de los experimentos galvanostáticos

\begin{tabular}{|c|c|c|c|c|c|c|c|c|}
\hline \multirow[b]{2}{*}{$\begin{array}{l}E_{\text {form }} \\
\text { (V) }\end{array}$} & \multicolumn{4}{|c|}{ Muestra M } & \multicolumn{4}{|c|}{ Muestra E } \\
\hline & $\tau_{1}(\min )$ & $E_{1}(V)$ & $\tau_{2}(\min )$ & $E_{2}(V)$ & $\tau_{1}(\min )$ & $E_{1}(V)$ & $\tau_{2}(\min )$ & $E_{2}(V)$ \\
\hline$-0,2$ & & & 50 & $-0,500$ & & & 13 & $-0,497$ \\
\hline$-0,1$ & & & 60 & $-0,500$ & & & 12,5 & $-0,478$ \\
\hline 0 & & & 65 & $-0,496$ & & & 19,5 & $-0,452$ \\
\hline 0,1 & & & 70 & $-0,520$ & & & 12,7 & $-0,502$ \\
\hline 0,2 & 2 & 0,150 & 93 & $-0,470$ & & & 30 & $-0,440$ \\
\hline 0,3 & 2 & 0,100 & 77,5 & $-0,489$ & & & 27 & $-0,468$ \\
\hline 0,4 & & & & & 1 & 0,156 & 36,5 & $-0,464$ \\
\hline 0,5 & 5 & 0,133 & 86 & $-0,488$ & 1,5 & 0,160 & 26 & $-0,460$ \\
\hline 0,7 & 8,5 & 0,167 & 150 & $-0,482$ & & & & \\
\hline 0,8 & 10,5 & 0,165 & 118,5 & $-0,480$ & 3,2 & 0,165 & 43,3 & $-0,440$ \\
\hline
\end{tabular}

En las Figuras 5.6 y 5.7 se puede apreciar que a medida que el potencial de formación de óxido aumenta también aumenta el tiempo de transición correspondiente.

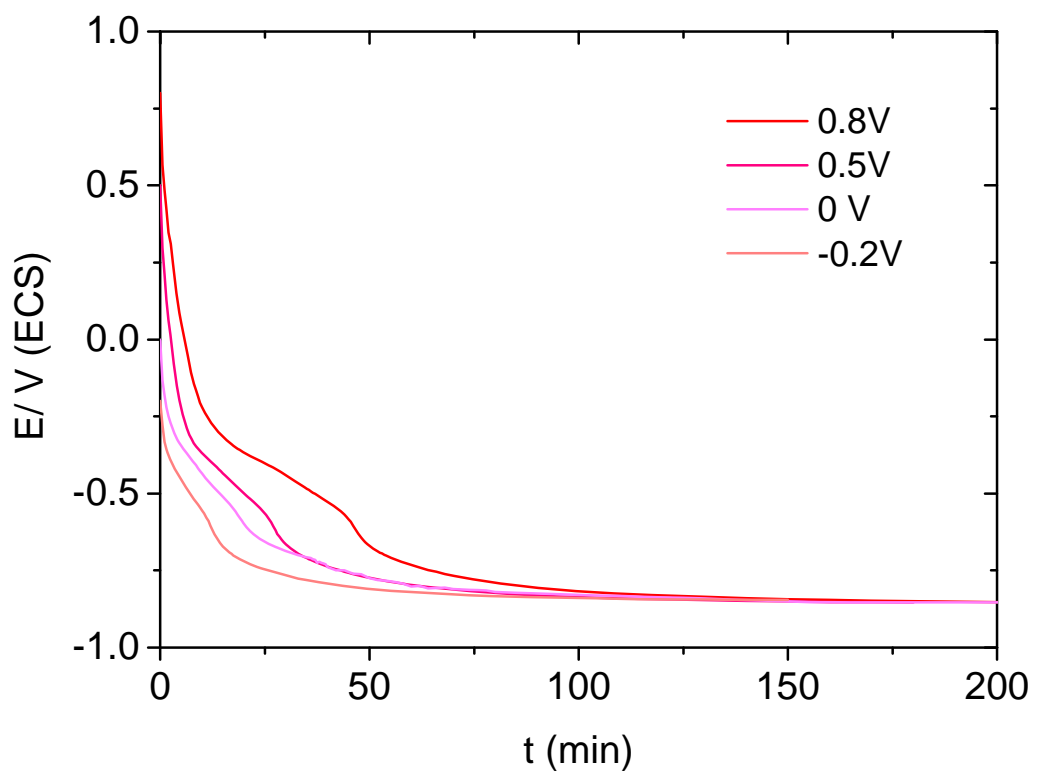

Figura 5.6. Transitorios de potencial típico de la reducción galvanostática del film anódico formado a diversos potenciales para la muestra $E$ 


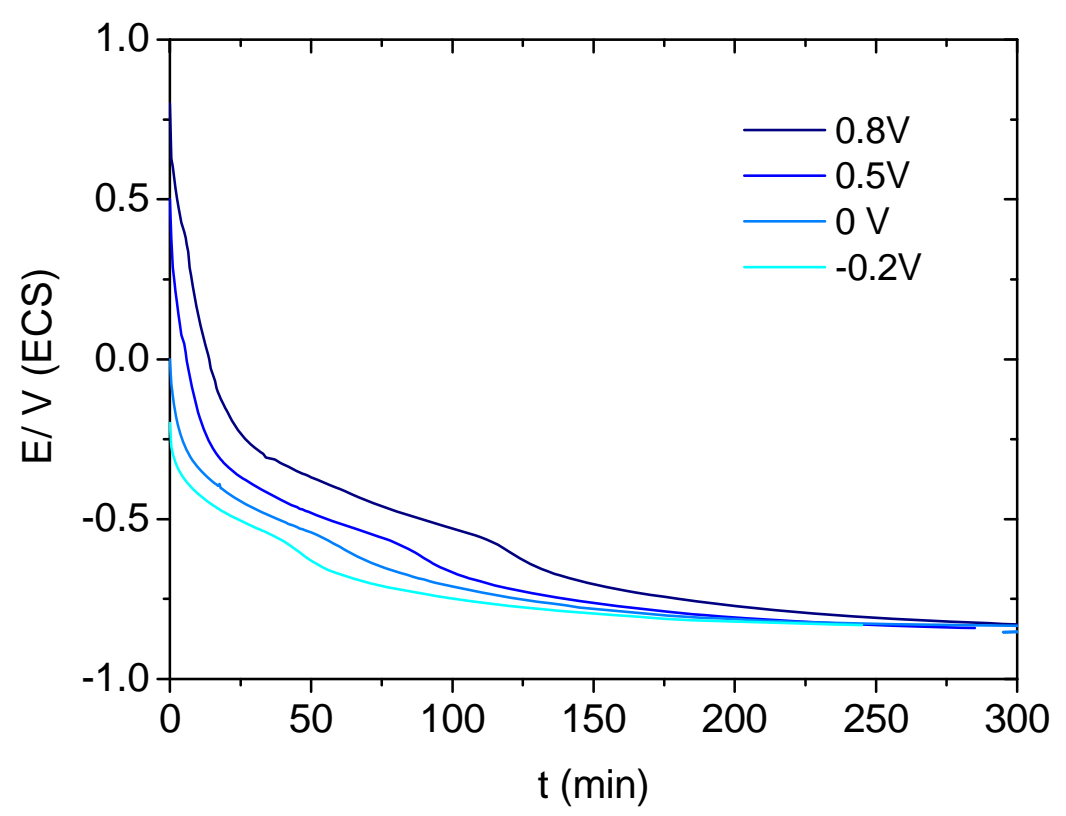

Figura 5.7. Transitorios de potencial típico de la reducción galvanostática del film anódico formado a diversos potenciales para la muestra $M$

Comparando los valores de potencial de los amesetamientos para cada proceso, con los datos termodinámicos de las posibles reacciones de electrodo en 0,5 $\mathrm{M} \mathrm{Na}_{2} \mathrm{HPO}_{4}$ [122] se puede plantear la ocurrencia de las siguientes reacciones de reducción

$$
2 \mathrm{CrO}_{4}{ }^{-}+5 \mathrm{H}_{2} \mathrm{O}+6 \mathrm{e}^{-} \Leftrightarrow \mathrm{Cr}_{2} \mathrm{O}_{3}+10 \mathrm{OH}^{-}
$$

que corresponde a la reducción del cromato en solución alcalina (reacción más aceptada en la literatura en conexión con películas pasivantes de aceros inoxidables [130] y que es el proceso inverso de la reacción 5.1. Esta reacción exhibe un potencial reversible $E_{r}=0,163+$ $0,0197 \log \left[\mathrm{CrO}_{4}{ }^{\circ}\right] \mathrm{V}(\mathrm{ECS})$ al $\mathrm{pH}$ de la solución utilizada y que resulta compatible con los valores de $E_{1}$ registrados durante el tiempo $\tau_{1}$. Cabe recordar (Figura 5.1) que solo a partir de un potencial anódico de $0,25 \mathrm{~V}$ es observable, en un barrido potenciodinámico, el proceso asociado a la oxidación de compuestos de $\operatorname{Cr}(\mathrm{III})$ a $\mathrm{Cr}(\mathrm{VI})$, caracterizado por un aumento de la corriente por encima del valor de pasividad.

Para el segundo proceso cuando el potencial de electrodo alcanza valores más catódicos durante $\tau_{2}$ el tiempo de reducción es proporcional a la carga de reducción de la película y la siguiente reacción tendría lugar: 


$$
\mathrm{Fe}_{2} \mathrm{O}_{3}+3 \mathrm{H}_{2} \mathrm{O}+4 \mathrm{e}^{-} \Leftrightarrow \mathrm{Fe}^{\circ}+\mathrm{Fe}^{2+}+6 \mathrm{OH}^{-}
$$

según fuese propuesto en la literatura para amesetamientos de potencial cercanos a $-0,5 \mathrm{~V}$ obtenidos con electrodos de hierro en solución buffer fosfato de $\mathrm{pH}$ comparable al del electrolito utilizado en este trabajo [131].

No se observa en los transitorios un potencial de amesetamiento adicional aunque a potenciales muy negativos, la fina capa barrera es reducida electroquímicamente a metal, por ejemplo, $\mathrm{Cr}_{2} \mathrm{O}_{3}+3 \mathrm{H}_{2} \mathrm{O}+6 \mathrm{e}^{-} \rightarrow 2 \mathrm{Cr}+6 \mathrm{OH}^{-}$, o bien podría ocurrir la reducción a estados de oxidación menores en especies en solución. Esto puede entenderse considerando la pequeña masa de óxido disponible para ser reducido, lo que determina los tiempos de transición muy cortos, así como los valores muy negativos del potencial de equilibrio a pH 9,2 (<-1,297 V) dentro de la región de desprendimiento de hidrógeno. El espesor (L) aparente en el estado estacionario de la capa externa de $\mathrm{Fe}_{2} \mathrm{O}_{3}$ puede determinarse a partir del tiempo de transición $\tau_{2}$ por medio de la ecuación de Faraday:

$$
L=-\frac{j}{z F} V_{o x} \tau_{2}
$$

donde, $\mathrm{j}$ la densidad de corriente catódica, $\mathrm{V}_{\mathrm{ox}}$ el volumen molar del óxido y es igual a 30,42 $\mathrm{cm}^{3} \mathrm{~mol}^{-1}[132]$ y $\mathrm{z}=4$.

Los resultados se observan en la Figura 5.8, y están caracterizados por un crecimiento lineal con el potencial de formación de la película superficial. 


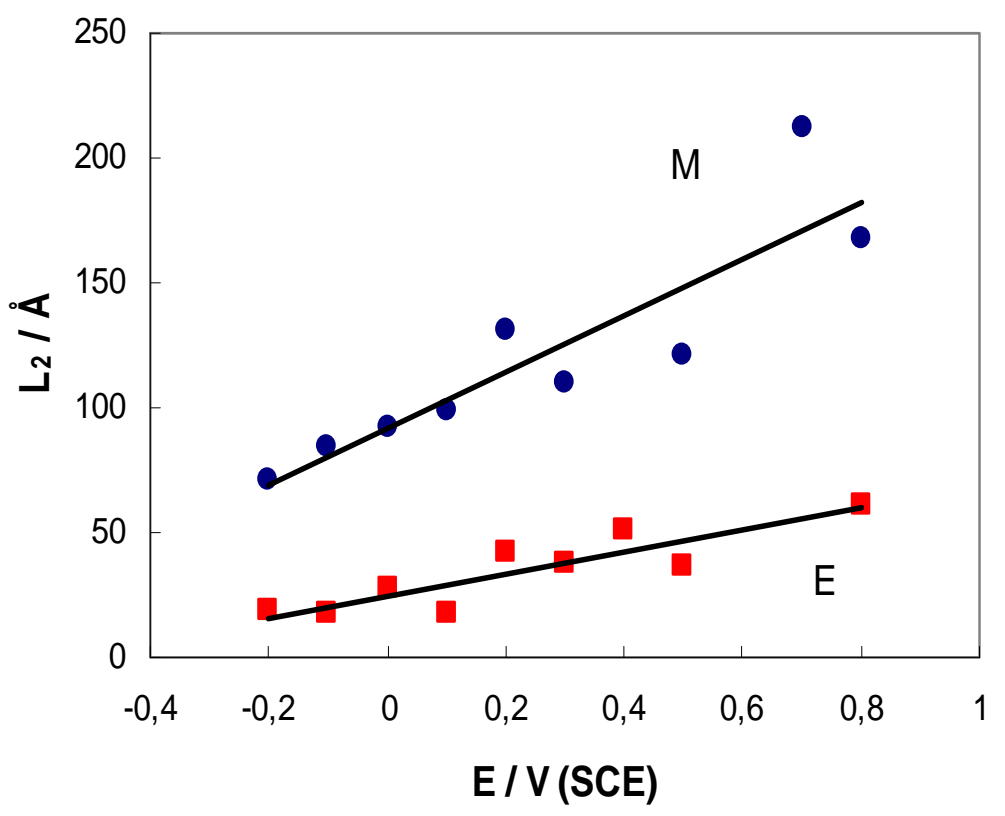

Figura 5.8. Variaciones de los espesores de las películas reducidas galvanostáticamente durante $\tau_{2}$.

Los valores de L para la muestra E son comparables a los informados en la literatura para películas anódicas en hierro en solución buffer de fosfato, pH 8,4 [133][134]. Finalmente, resulta interesante el hecho que los mayores valores de $L$ para la muestra $M$ se asemejan por comparación con los espesores de óxido obtenidos en aceros supermartensíticos en la ZAC de soldaduras por fusión [135].

Al repetir algunos de los experimentos de reducción galvanostática pero con películas formadas durante un tiempo de anodizado mayor ( $4 \mathrm{hs}$ ) se encuentra que, para la muestra M, los espesores de las capas anódicas varían sólo ligeramente respecto de los valores mostrados en la Figura 5.8, mientras que resultan claramente mayores para la muestra E. Esto indica un mayor velocidad de formación de la película anódica para la muestra $\mathrm{M}$ hasta alcanzar valores estacionarios.

Se ha indicado en la literatura [127] que la mayor protección anticorrosiva de las películas pasivas depende de su naturaleza y no necesariamente del espesor de las mismas. En efecto, ambas muestras con películas anódicas de diferentes espesores han mostrado el mismo valor de corriente pasiva. El material estudiado contiene algunas fases no metálicas como precipitados (carburos de $\mathrm{Cr}$ ). Es bien conocido que los carburos de cromo pueden conducir al agotamiento de cromo alrededor del precipitado, durante la soldadura o incluso al final del tratamiento térmico. Aún cuando este proceso sea débil como para conducir a 
una corrosión intergranular, si podría producir una disminución en la resistencia al picado. A través del procesamiento metalúrgico de los aceros inoxidables $13 \mathrm{CrNiMo}$, con un adecuado tratamiento térmico, es posible aumentar el contenido de austenita retenida mientras se produce una refinación estructural en esta fase que homogeiniza la distribución espacial. Ya que $\mathrm{C}$ y $\mathrm{N}$ se disuelven preferencialmente en la fase austenita como resultado del proceso metalúrgico disminuyendo la formación de precipitados de cromo. El resultado final es un aumento en el contenido de $\mathrm{Cr}$ en solución sólida [76] y la formación de una película superficial más estable con una mayor capacidad de protección. 


\section{CAPÍTULO 6}

\section{Propiedades semiconductoras, estructura de las películas pasivas y caracterización de la formación anódica de películas pasivas en solución buffer de fosfato por Espectroscopia de Impedancia Electroquímica (EIS)}

\subsection{Objetivo}

Ya que las modificaciones estructurales en los films pasivantes, ya sean de naturaleza química como electrónica, impactan en la resistencia a la corrosión por picado del material base, se establece como objetivo de este capítulo el interpretar la capacidad de los tratamientos térmicos de la aleación en generar cambios estructurales en el óxido pasivante y por lo tanto en el desarrollo de la corrosión localizada. Esta vinculación entre cambio estructural y óxido pasivante se lleva a cabo estudiando películas pasivantes electroformadas en solución buffer de fosfato. Además busca caracterizar las capas anódicas pasivantes formadas sobre electrodos de $13 \mathrm{CrNiMo}$ a distintos potenciales de formación dentro zona pasiva, empleando la técnica de EIS.

\subsection{Resultados y Discusión}

\subsubsection{Análisis de Mott Schottky}

Bianchi [136], fue el primer investigador que trató de correlacionar las propiedades electrónicas de la capa de óxido con la susceptibilidad al picado. Observó que un semiconductor tipo $\mathrm{n}$ promueve un mayor número de picaduras que un semiconductor tipo p. Al evaluarse la conductividad de la película pasiva en diferentes aleaciones se demostró que las propiedades semiconductoras del metal pasivo dependen de factores tales como: tratamiento térmico, composición de la solución, el potencial y la temperatura. Un cambio en la composición de la solución, o un aumento de temperatura, o del potencial, puede llegar a transformar un semiconductor tipo $p$ en un semiconductor tipo $n, o$ al revés. Algunos trabajos de investigación establecen las propiedades de las películas pasivantes dando valores de potencial de carga cero, potencial de banda plana, el salto de energía de la banda 
prohibida o band gap, y luego correlacionan estos parámetros característicos con la resistencia a la corrosión por picado [137][138][139].

Se midieron los espectros de impedancia del óxido anódico formado en solución buffer de fosfato a diferentes potenciales iniciando por el potencial de formación en zona de pasividad y prosiguiendo por valores de potencial más catódicos que no implicaron la electrorreducción de la película pasivante. De los datos de impedancia en la región de altas frecuencias se pudo derivar la capacidad del espacio de cargas en el óxido $C_{s c}$ a cada potencial. De acuerdo con la ecuación de Mott-Schottky, ecuación 3.1, se graficó $\mathrm{C}_{\mathrm{sc}}^{-2}$ en función del potencial de electrodo, obteniéndose dependencias lineales, esto permitió a su vez determinar de las pendientes de las rectas valores del nivel de dopantes (donores en este caso) $\mathrm{N}_{\mathrm{D}}$. La Figura 6.1 muestra una clara dependencia lineal que confirma el carácter semiconductor del óxido con dos pendientes de valores positivos compatibles con la presencia de especies donoras en el óxido, $N_{D}$, o semiconducción tipo $n$, para su variación con el potencial de formación. El valor de $N_{D}$ resulta dependiente del potencial de formación observándose que la concentración de donores es mayor cuando el potencial de formación es menor tanto para la muestra $\mathrm{M}$ como para la muestra $\mathrm{E}$ y en acuerdo a lo informado en la literatura [107]. 


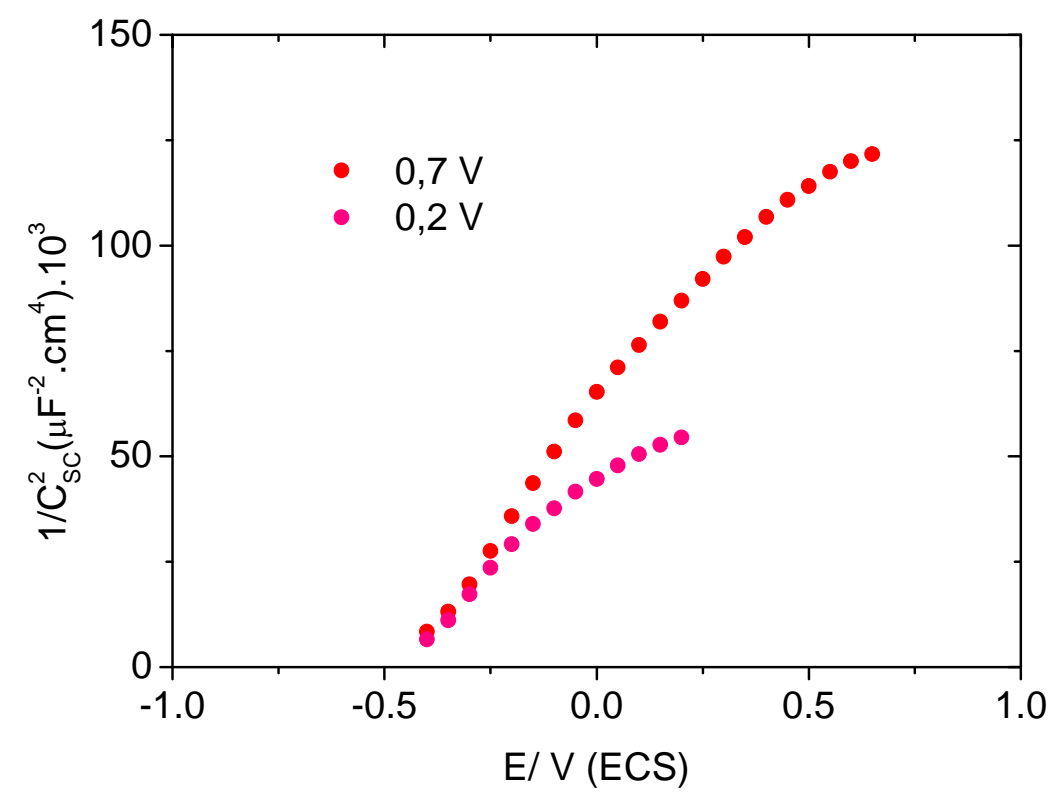

(a)

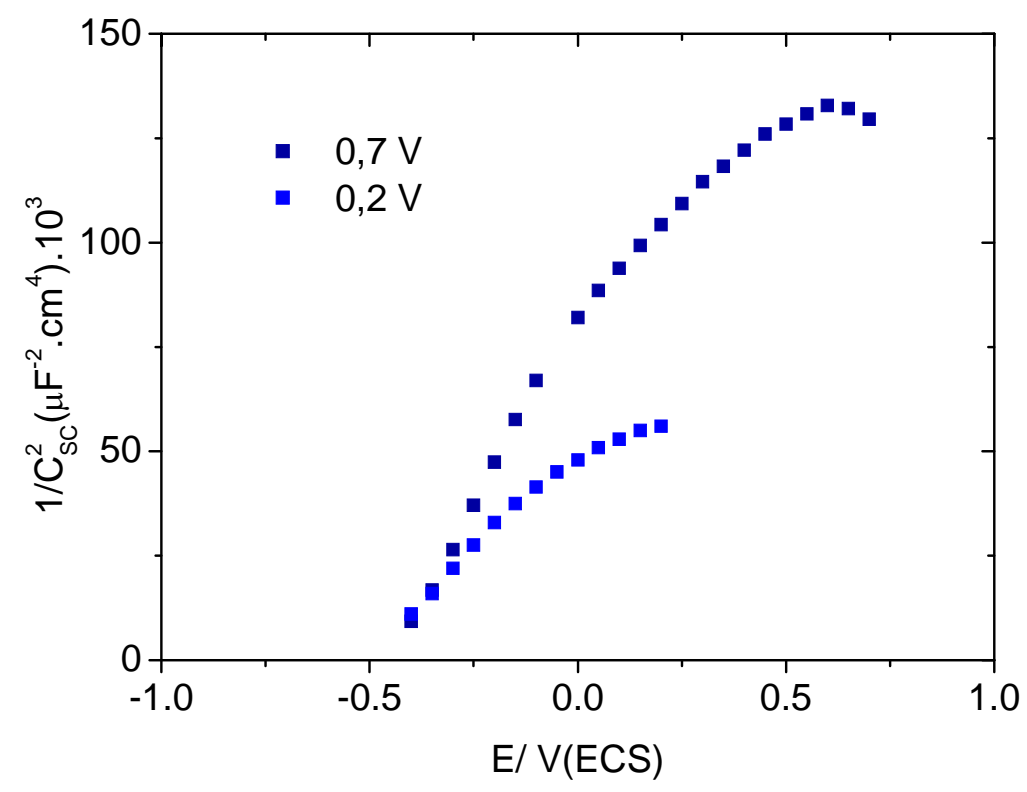

(b)

Figura 6.1. Gráficas de Mott-Schottky a diferentes potenciales de formación de película para las muestras $\mathrm{E}(\mathrm{a})$ y $\mathrm{M}(\mathrm{b})$

Graficando los valores de capacidades halladas de las dos formas ya explicadas en el Capítulo 3, se obtuvieron la Figura 6.2 mediante la expresión de Brug, y con los valores de capacidad a la frecuencia de $10.000 \mathrm{~Hz}$, la Figura 6.3. 


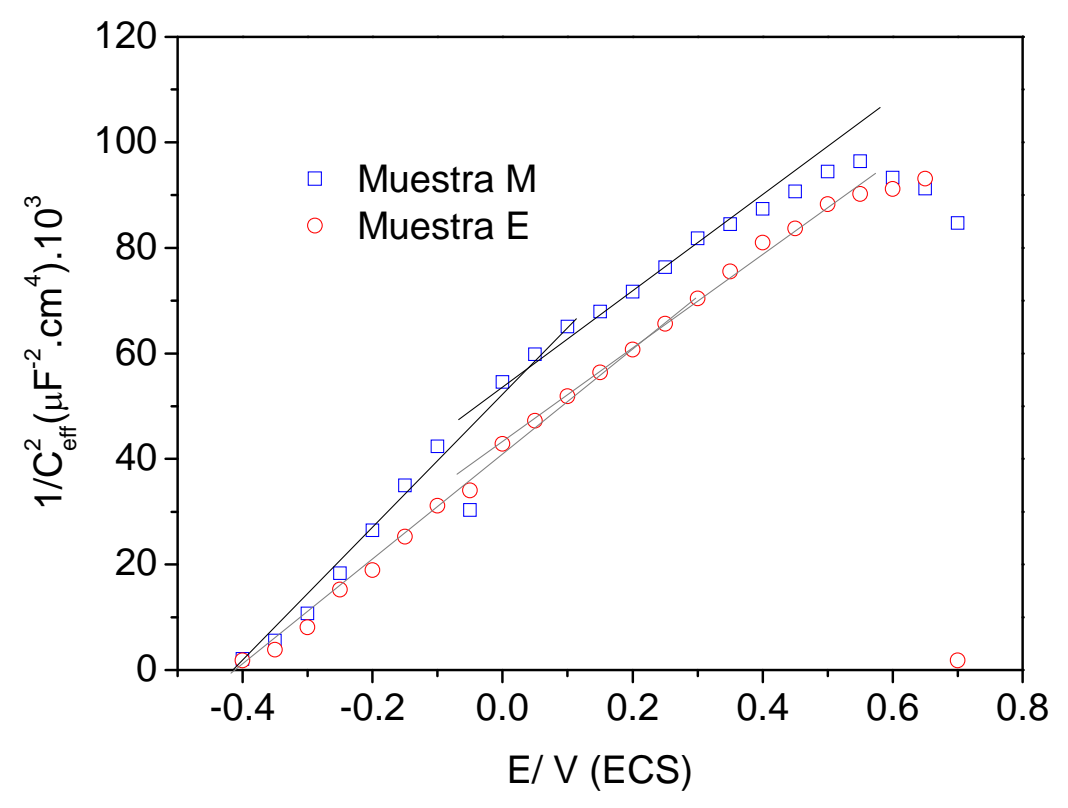

Figura 6.2. Gráficas de Mott-Schottky para las muestras $M$ y $E$ pasivadas durante 1 hora a 0,7 $\checkmark$ a partir de valores de $C$ obtenidos mediante la expresión de Brug.

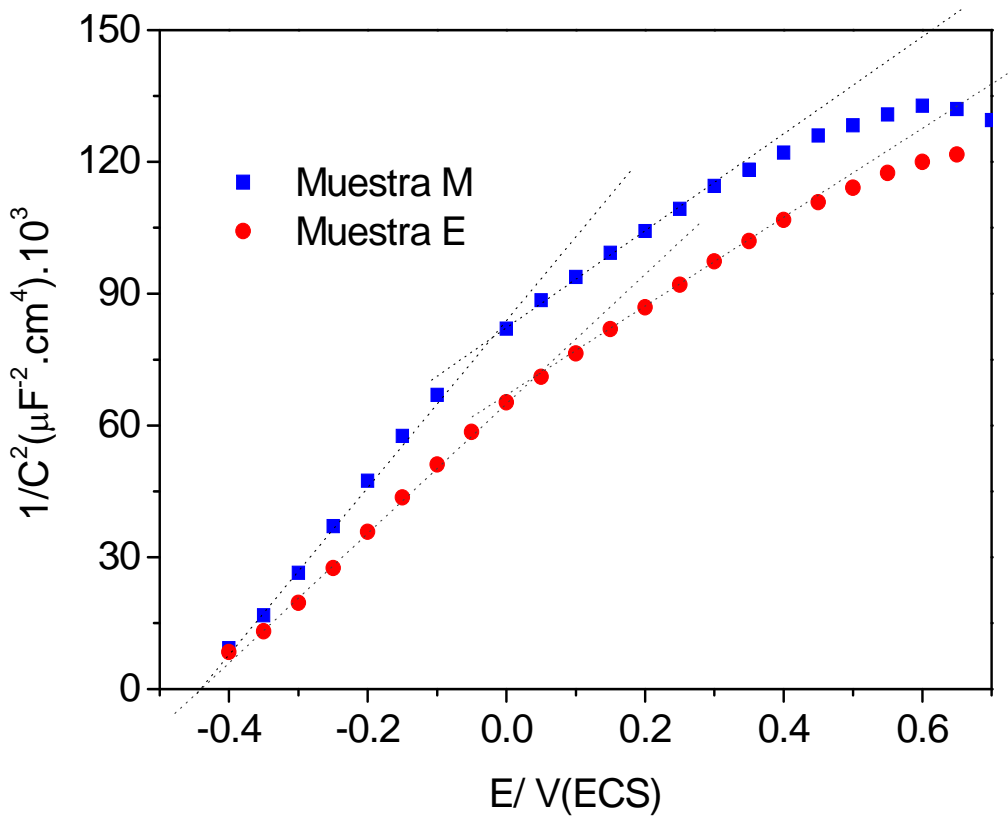

Figura 6.3. Gráficas de Mott-Schottky para las muestras $M$ y $E$ pasivadas durante 1 hora a 0,7 $\mathrm{V}$ a partir de $\mathrm{C}$ a $10 \mathrm{kHz}$.

Del análisis de las rectas de Mott Schottky (Figura 6.2 y 6.3) surge que:

i) el comportamiento lineal indica que los óxidos tienen características de semiconductor en el rango de potenciales estudiado, 
ii) las pendientes positivas de las rectas de Mott-Schottky corresponden a semiconducción del tipo $\mathrm{n}$, resultante probablemente de la parte externa de la película pasivante de $\mathrm{Fe}_{2} \mathrm{O}_{3}$ y/o $\mathrm{FeOOH}$. Los defectos puntuales dentro de la película pasivante pueden ser cationes metálicos intersticiales o vacancias de oxígeno, o ambas. No se encontró evidencia experimental de comportamiento de semiconducción tipo $p$, en el rango de potenciales estudiado, lo que indica que las vacancias catiónicas no tienen una densidad significativa en comparación con las especies donoras, como fuese encontrado con electrodos de Fe y aleaciones Fe-Cr en buffer alcalino de borato [140][141],

iii) el valor de $E_{b p} \cong-0,425 \pm 0,005 \vee$ es independiente del tratamiento térmico de la aleación, y exhibe un buen acuerdo con los valores de literatura para sistemas a $\mathrm{pH}$ comparable [142],

iv) las concentraciones de donores poco profundos $N_{D}$ determinadas a partir de las pendientes de las rectas para las dos muestras a potenciales menores y considerando las diferentes capacidades, se muestran en la tabla 6.1. Los valores de densidad de dopantes obtenidos son altos y dan cuenta del carácter no-estequiométrico y/o altamente desordenado de las películas de óxido. Sin embargo, estos valores son comparables y se encuentran en el rango de los valores informados para películas de óxidos sobre aceros inoxidables [143]. La mayor concentración de donores para la muestra E se puede interpretar como una mayor concentración de defectos puntuales, es decir una estructura más defectuosa de la capa pasivante. Más aun, una mayor concentración de donores ha sido vinculada en la literatura con una mayor tendencia a la nucleación de picaduras [144]. Una menor concentración de defectos puntuales, corresponde a una estructura menos defectuosa de la capa pasivante para la muestra M. Si bien los valores de densidad de donores no son iguales, según se tome a partir de uno u otro cálculo de la capacidad, la tendencia es la misma. Se observa también que exhiben una clara dependencia con el tratamiento térmico de la aleación el que, como se indicó antes, influye en el tipo de película pasivante obtenida. 
Tabla 6.1. Valores de densidad de donores calculados a partir de la capacidad total o desde la capacidad efectiva de las muestras $\mathrm{M}$ y $\mathrm{E}$ sobre películas formadas a $0,7 \mathrm{~V}$ durante 1 hora.

\begin{tabular}{|c|c|c|c|c|c|}
\hline & \multirow[b]{2}{*}{$\begin{array}{l}E_{b p} \pm 5,5 \\
(\mathrm{mV} / \mathrm{SCE})\end{array}$} & \multicolumn{2}{|c|}{ A partir de $C$} & \multicolumn{2}{|c|}{ A partir de $C_{\text {eff }}$} \\
\hline & & $\begin{array}{l}10^{19} \cdot N_{D} \\
\left(\mathrm{~cm}^{-3}\right)\end{array}$ & $\begin{array}{l}10^{19} \cdot N_{D}{ }^{\prime} \\
\left(\mathrm{cm}^{-3}\right)\end{array}$ & $\begin{array}{l}10^{19} \cdot N_{D} \\
\left(\mathrm{~cm}^{-3}\right)\end{array}$ & $\begin{array}{l}10^{19} \cdot \mathrm{N}_{\mathrm{D}}{ }^{\prime} \\
\left(\mathrm{cm}^{-3}\right)\end{array}$ \\
\hline Muestra M & $-425,5$ & 6,17 & 1,02 & 8,56 & 1,79 \\
\hline Muestra E & $-425,5$ & 7,87 & 0,75 & 11,47 & 0,41 \\
\hline
\end{tabular}

v) la aparición de una segunda zona recta de diferente pendiente en los gráficos de Mott-Schottky puede ser atribuída a la presencia de estados de superficiales o un segundo estado donor a energías dentro del bandgap [140] En este último caso, y atento a que la pendiente segunda (a potenciales más positivos) de la muestra E resulta similar a la pendiente segunda de la muestra $M$, resulta una mayor concentración de niveles profundos en el óxido $N_{D}$ ' para la muestra $M$. Tal situación ha sido vinculada en la literatura a un óxido de menor capacidad de resistir la corrosión por picado [138]. En cualquier caso se reconoce que existe una correlación entre la estructura de defectos y la estabilidad de la película de óxido.

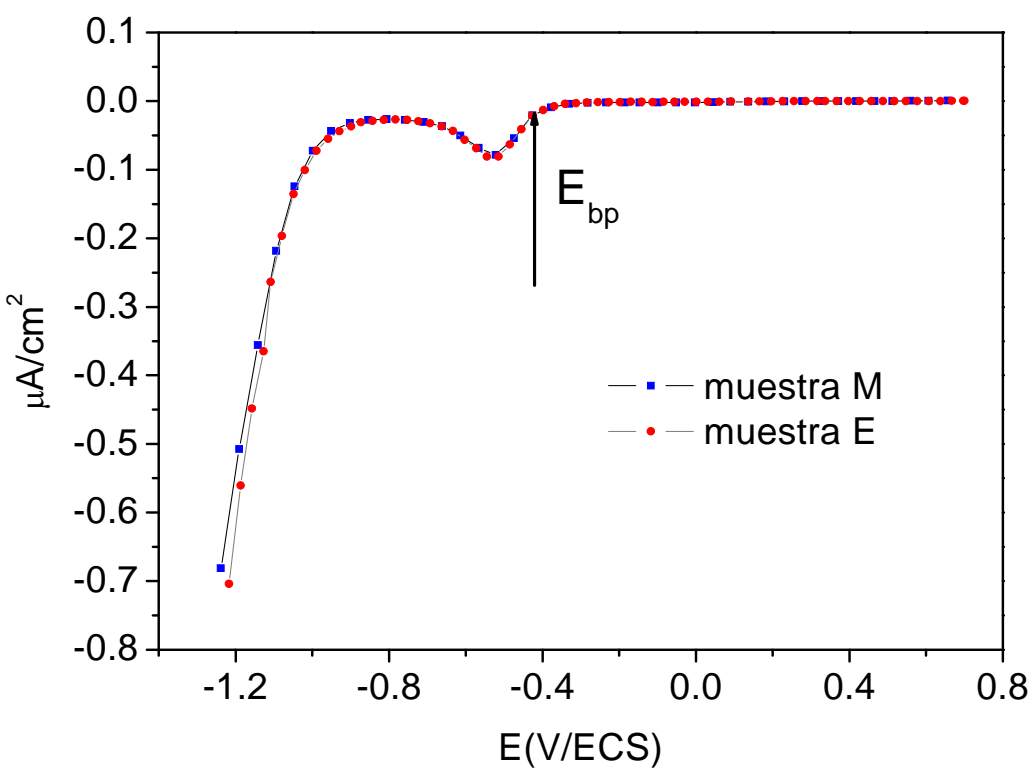

Figura 6.4. Curva de polarización obtenida mediante barrido del potencial a $10 \mathrm{mV} / \mathrm{s}$ en el sentido catódico en medio aireado.

Para un semiconductor tipo $\mathrm{n}$ las reacciones de electrorreducción no están impedidas a potenciales por debajo del potencial de banda plana pero a potenciales más positivos que 
aquel, aparece una barrera energética en la interfase película/electrolito en condiciones de una capa de agotamiento en el óxido, de modo que puede inhibir la transferencia de electrones entre la película y especies electrolíticas reducibles. Como se observa en el barrido de potencial catódico de la Figura 6.4 el potencial de banda plana coincide con el comienzo de la región de potencial donde se detectan crecientes corrientes de reducción. Esto valida las estrategias usadas para calcular el $E_{b p}$ en el sistema [145]. Por otra parte, si consideramos los potenciales de corrosión de las muestras $\mathrm{E}$ y $\mathrm{M}$ en el medio electrolítico desaireado y con oxígeno disuelto, Figura 6.5 , se observa que el delta de potencial ( $\left.E_{c o r r}-E_{b p}\right)$ es más grande para la muestra $\mathrm{E}$ en ambas condiciones, y por lo tanto el óxido de la muestra E tendría menos tendencia a impedir la reacción catódica de reducción de oxígeno en la boca de una picadura permitiendo sostener la corriente de disolución metálica en su interior, aún cuando la misma crezca y se desarrolle profusamente, dicho de otro modo, tiene una menor tendencia a la repasivación. Finalmente, estos datos concuerdan con lo postulado previamente en cuanto a la capacidad relativa de repasivación de cada muestra [146].

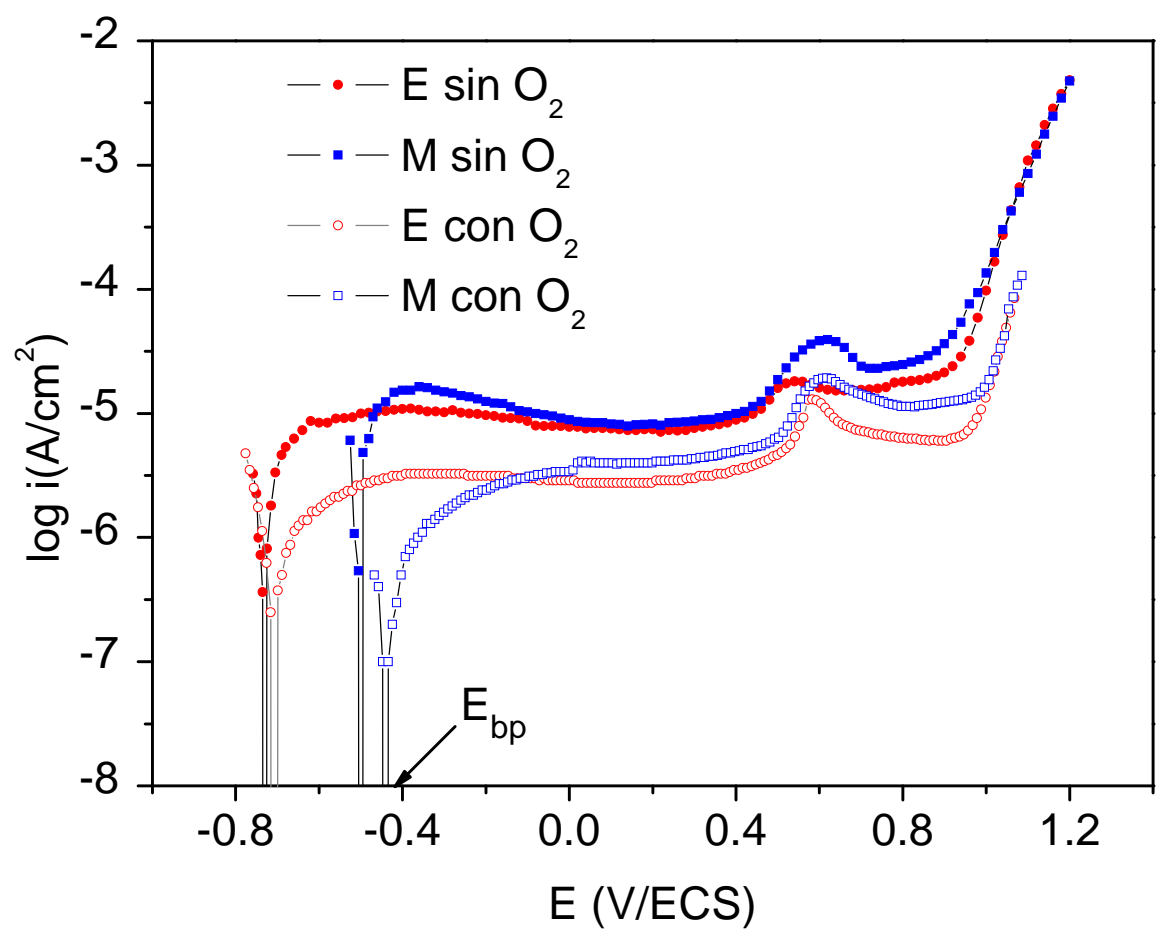

Figura 6.5. Curvas de polarización a $1 \mathrm{mV} / \mathrm{s}$ en sentido anódico con y sin oxígeno . Los potenciales de corrosión de las muestras $M$ y $E$ se encuentran por debajo del potencial de banda plana del semiconductor, Figura 6.6. Cuando el potencial de este electrodo semiconductor es muy negativo respecto del de banda plana, el nivel de Fermi se 
mueve dentro de la banda de energía cercana (de conducción), penetrando la misma. Los electrones que fluyen hacia la superficie del electrodo forman una capa de acumulación, la concentración de electrones se aproxima a niveles metálicos. Las cuplas redox presentes en la solución electrolítica en contacto con el óxido semiconductor y que exhiben potenciales formales negativos respecto del $E_{b p}$ pueden intercambiar sin inhibición electrones en ambas direcciones.

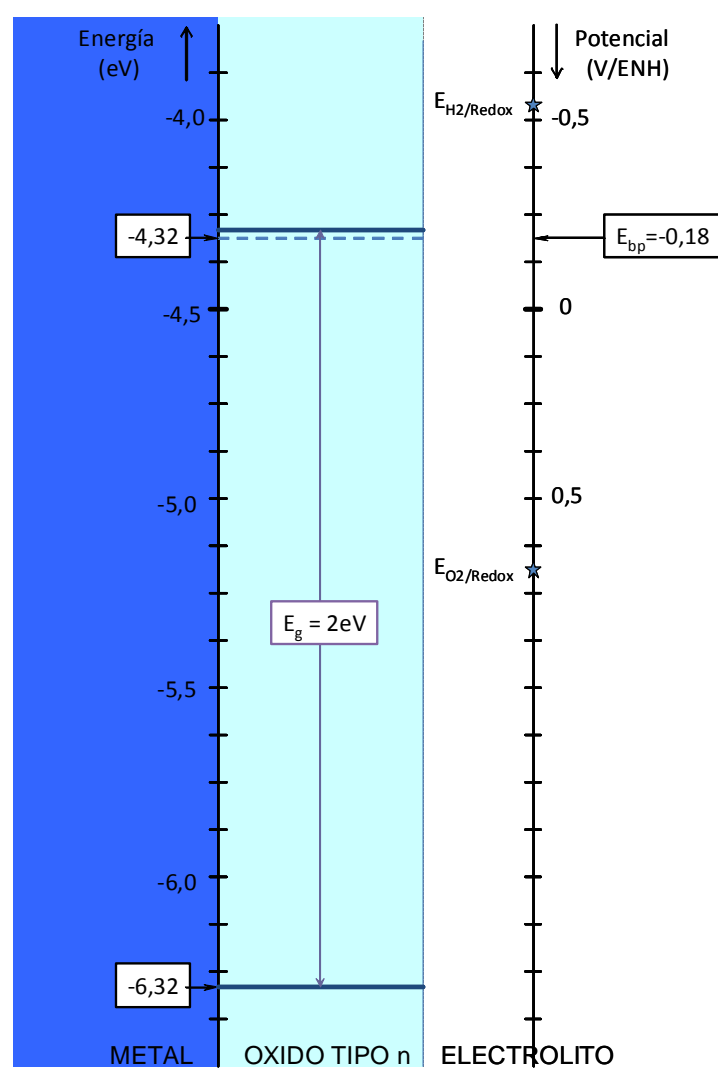

Condición de Banda Plana

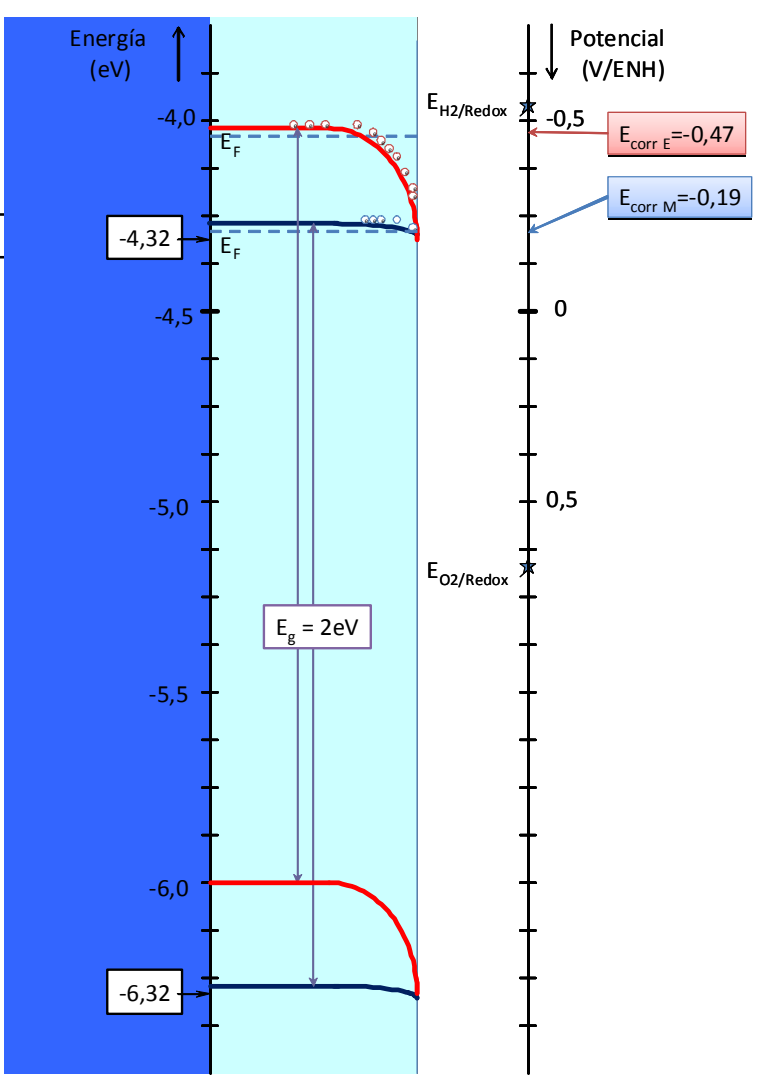

Con capa de Acumulación

Figura 6.6. Diagrama de bandas para el semiconductor tipo $\mathrm{n}$ derivados de la información de las gráficas de Mott-Schottky.

Para la muestra E se observa (Figura 6.6) una mayor disponibilidad de electrones que en la muestra $\mathrm{M}$, estos electrones podrán tomar parte en la reacción de reducción:

$$
\mathrm{O}_{2}+2 \mathrm{H}_{2} \mathrm{O}+4 \mathrm{e}^{-} \Leftrightarrow 4 \mathrm{OH}^{-}
$$

El salto energético de la banda prohibida para una aleación $\mathrm{Fe}-\mathrm{Cr}$ es 2,3 eV [147] y a 1,9 eV por sobre el nivel de la banda de valencia se ubicaría un segundo nivel donor.

La disminución neta de la concentración de estados aceptores de electrones en el óxido se relaciona con un menor desorden en su parte interna. En este caso, un proceso 
catódico global puede ser considerado como una secuencia de dos pasos: i) llenado de los niveles de captura de electrones desde el metal base, con una función cinética que depende de la altura de la barrera de potencial en la interfase metal / película y (ii) liberación de los electrones en la superficie donde la reacción catódica ocurre, con cinética determinada por el nivel de energía de las trampas de electrones y la altura de la barrera Schottky en la interfase película / electrolito. Lo que parece probable es que las propiedades electrónicas influyan fuertemente en la transición de picado metaestable a estable [140].

\subsubsection{Espectroscopía Fotoelectrónica de Rayos $X$}

En las Figuras $6.7 \mathrm{a}$ y $\mathrm{b}$ se observan las concentraciones de los elementos estudiados en porciento atómico a diferentes profundidades dadas por los tiempos acumulados de bombardeo de Ar iónico con fines erosivos, en las medidas de XPS.

Para la muestra E debido a la mayor cantidad de Na y P y a su variación en profundidad hay un impacto en la evolución de los perfiles porcentuales de los otros átomos en profundidad, que no se observa en la figura de abajo para la muestra $\mathrm{M}$ donde "parecen" los óxidos de concentraciones más constantes en su composición. Si se corrigen estas evoluciones restando los contenidos de $\mathrm{Na}$ y $\mathrm{P}$ como línea de base, esa diferencia de comportamiento tiende a desaparecer. Además en 60 minutos desaparece casi el oxigeno para la muestra $\mathrm{E}$ indicando que se llega a la aleación base mientras que en la muestra $\mathrm{M}$ el óxido sigue allí a tiempos comparables. Esto indicaría que es más delgado el óxido formado en la muestra E. Además la muestra E muestra una contaminación o incorporación más profunda de elementos provenientes de la solución electrolítica por lo que se puede tratar de una estructura de compuestos superficiales más abierta y porosa en comparación con el film superficial de la muestra M. 


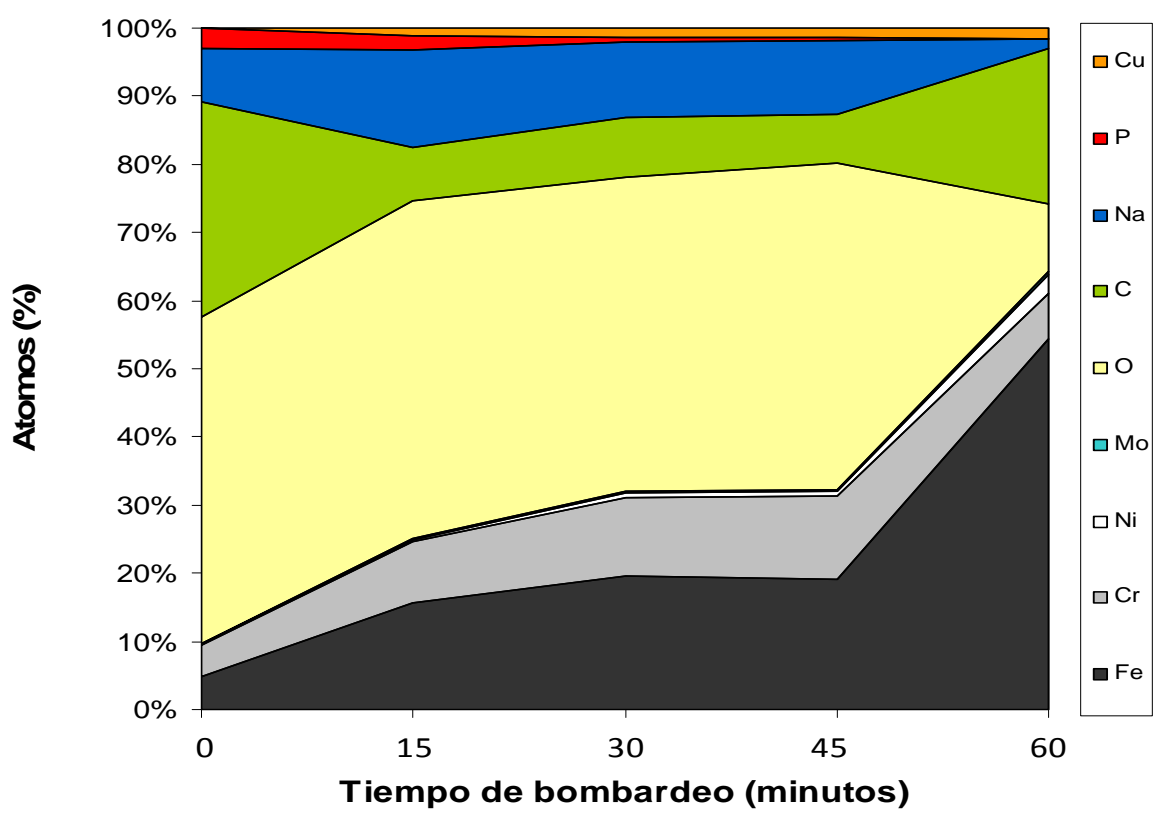

(a)

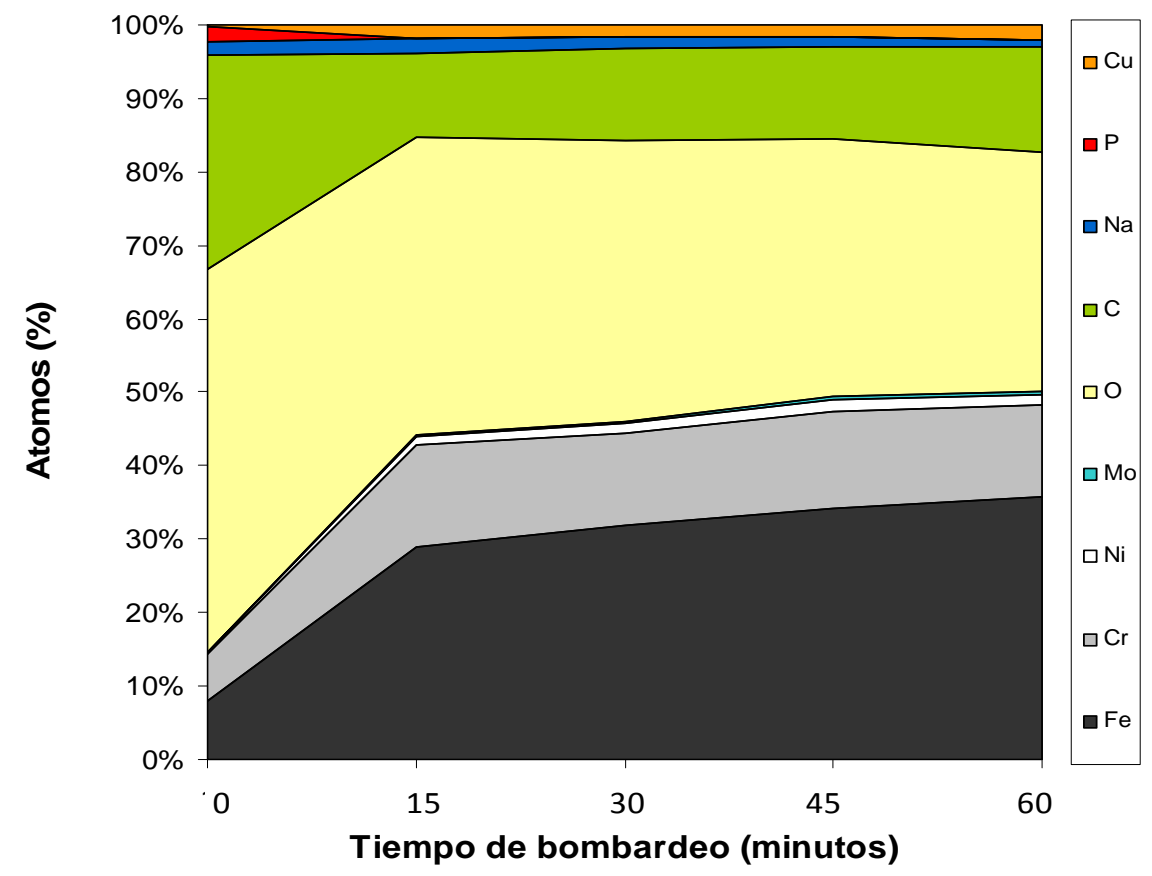

(b)

Figura 6.7. Porcentaje de elementos en la película formada sobre $13 \mathrm{CrNiMo}$ en función del tiempo de bombardeo, muestra $E(a)$ y $M(b)$.

Por lo demás no se observan diferencias significativas entre ambas muestras. La relación $\mathrm{Fe} / \mathrm{Cr}$ es mayor en la zona interior (capa barrera) que en la superficie. Para la 
muestra $M$ pasa de $1 / 1$ en la superficie a cerca de 3/1 incluso luego de 60 minutos de erosión, mientras que en la muestra $E$ pasa de $1 / 1$ en la superficie a cerca de $2 / 1$ a los 45 minutos. Entre 45 minutos y 60 minutos, para ésta última, hay una región de transición donde las concentraciones varían desde las de una mezcla de compuestos oxidados a valores propios de la aleación base. Obsérvese que el contenido medio de $\mathrm{C}$ proviene claramente de la contaminación.

Se detecta la presencia de Mo sólo en la muestra $M$ en la región del óxido, el contenido de $\mathrm{Ni}$ es levemente mayor que el que se presenta en la muestra $\mathrm{E}$, esto también se puede observar en los espectros de XPS resueltos por regiones de energía con la detección de la formación de un compuesto de $\mathrm{NiCr}_{2} \mathrm{O}_{4}$, ver Figura 6.12.

Es bien conocido el efecto beneficioso del Mo en la resistencia a la corrosión por picado del acero inoxidable. Las teorías acerca de la influencia de Mo en la resistencia a la corrosión pueden ser divididas en dos categorías: las que consideran que el Mo mejora la estabilidad de la película pasiva actuando desde la capa externa y las que indican que limitan la velocidad de disolución del Fe y $\mathrm{Cr}$ en el metal cerca de la interfase óxido/metal. Si bien la presencia de Mo no produciría un cambio significativo sobre la composición de la película, la presencia de $\mathrm{MoO}_{4}^{-2}$ en la capa externa puede cambiar la selectividad iónica de la película pasiva, promoviendo la formación de $\mathrm{Cr}_{2} \mathrm{O}_{3}$ y $\mathrm{CrO}_{3}$, en medios alcalinos [148].

Para el análisis de los espectros se utilizó una señal standard de 70-80\% Gauss-Lorenz y el ajuste con función Shirley para la forma asimétrica. En los casos de Fe y Ni se tomó solamente el estado $2 p_{3 / 2}$.

En los aceros inoxidables los estudios analíticos revelan una estructura de la película pasiva que consiste generalmente de una capa exterior de hidróxido y una interior, mezcla de óxidos. La pasivación induce un aumento neto del espesor del óxido de la capa interior a expensas de las del hidróxido externo. El óxido en la capa interna se compone mayormente por $\mathrm{Cr}(+3)$ y generalmente son unas pocas capas atómicas de óxido crómico en contacto con el metal. La parte exterior de la película, en la interfaz con el electrolito, se compone mayormente de óxidos e hidróxidos de $\mathrm{Fe}(+2)$ y $\mathrm{Fe}(+3)$. Las partes más externas de las películas pasivas formadas sobre hierro y sobre aceros inoxidables son muy similares. También se comprueba la existencia de Ni en la capa pasiva.

Hakiki et al [149], observaron en aceros inoxidables en solución buffer de $\mathrm{H}_{3} \mathrm{BO}_{3}$ $(0,05 \mathrm{M})+\mathrm{Na}_{2} \mathrm{~B}_{4} \mathrm{O}_{7} \cdot 10 \mathrm{H}_{2} \mathrm{O}(0,075 \mathrm{M})$ de $\mathrm{pH}=9,2$, el carácter dúplex de la película pasiva formada a 0,3 V/ECS, encontrándose óxidos de cromo, níquel y hierro, donde el óxido de 
cromo (espesor de tres - cuatro átomos de monocapa) se encuentra en la cercanía del metal. La densidad de este óxido es de 8,7 at $/ \mathrm{nm}^{2}$, y corresponde al $\mathrm{Cr}_{2} \mathrm{O}_{3}$. La región externa está compuesta por una mezcla de óxidos de hierro y níquel. Cerca de la base del metal los espesores de $\mathrm{Cr}$ aumentan notablemente, más aún cuando la capa pasiva se forma a altos valores de potencial. La capa externa de hierro, $\mathrm{Fe}_{2} \mathrm{O}_{3}$, aumenta considerablemente a medida que aumenta el potencial anódico de formación de película. En esta región, la mezcla de óxidos de cromo y hierro se vuelve crecientemente enriquecida con el aumento de la concentración de cromo en la aleación. La presencia de un exceso de huecos es esperada en el espacio de cargas formado por la interfase metal/ $\mathrm{Cr}_{2} \mathrm{O}_{3}$. De similar modo también se espera un agotamiento de electrones en el espacio de carga en el otro extremo de la película donde se forma $\gamma-\mathrm{Fe}_{2} \mathrm{O}_{3}$.

En el trabajo de Feng et al [150] realizando un análisis por espectroscopía de absorción atómica de la solución, luego de la polarización (0-0,2 V/SCE) durante 12 horas, de una muestra de acero inoxidable 316 en solución buffer de borato, permitió postular la ocurrencia de los siguientes procesos:

$$
\begin{aligned}
& 2 \mathrm{Fe}^{+2}+6 \mathrm{OH}^{-} \Rightarrow \mathrm{Fe}_{2} \mathrm{O}_{3}+3 \mathrm{H}_{2} \mathrm{O}+2 \mathrm{e}^{-} \\
& \mathrm{Cr} \Rightarrow \mathrm{Cr}^{+3}+3 \mathrm{e}^{-}
\end{aligned}
$$

la polarización entre $0,2-0,4 \mathrm{~V} / \mathrm{SCE}$ de

$$
\begin{aligned}
& \mathrm{Ni}^{+2}+2 \mathrm{OH}^{-} \Rightarrow \mathrm{NiO}+\mathrm{H}_{2} \mathrm{O} \\
& 2 \mathrm{Cr}^{+3}+6 \mathrm{OH}^{-} \Rightarrow \mathrm{Cr}_{2} \mathrm{O}_{3}+3 \mathrm{H}_{2} \mathrm{O} \\
& \mathrm{Fe}^{+2}+\mathrm{Fe}_{2} \mathrm{O}_{3}+2 \mathrm{OH}^{-} \Rightarrow \mathrm{Fe}_{3} \mathrm{O}_{4}+\mathrm{H}_{2} \mathrm{O}
\end{aligned}
$$

y finalmente la polarización por encima de los $0,4 \mathrm{~V} / \mathrm{SCE}$ de

$$
\begin{aligned}
& \mathrm{Cr}^{+3}+6 \mathrm{OH}^{-} \Rightarrow \mathrm{CrO}_{3}+3 \mathrm{H}_{2} \mathrm{O}+3 \mathrm{e}^{-} \\
& \mathrm{Cr}+6 \mathrm{OH}^{-} \Rightarrow \mathrm{CrO}_{3}+3 \mathrm{H}_{2} \mathrm{O}+6 \mathrm{e}^{-}
\end{aligned}
$$

ésta última reacción aporta gran cantidad de electrones.

Cuando el potencial es mayor a 0,6 V aumentan las cantidades disueltas de $\mathrm{Fe}, \mathrm{Cr}$ y Mo.

Las diversas capas de óxidos formadas sobre el acero inoxidable presentan propiedades semiconductoras, de uno u otro tipo, dependiendo del defecto predominante en la película pasiva. La película de óxido pasivo con una deficiencia en iones metálicos o con excesos de vacancias catiónicas generalmente son del p-tipo $\left(\mathrm{Cr}_{2} \mathrm{O}_{3}, \mathrm{MoO}_{2}, \mathrm{FeCr}_{2} \mathrm{O}_{4}, \mathrm{NiO}\right.$, $\mathrm{Fe}_{3} \mathrm{O}_{4}$ etc), mientras que la semiconducción del tipo $\mathrm{n}\left(\mathrm{Fe}_{2} \mathrm{O}_{3}, \mathrm{MoO}_{3}, \mathrm{FeOOH}\right.$, etc) se 
desarrolla en las películas pasivas por el transporte de cationes a través de un proceso de difusión intersticial o por difusión-migración de vacancias de aniones [150].

\subsubsection{Elemento 0}

En la muestra $\mathrm{M}$ la especie $\mathrm{OH}^{-}$está caracterizada por un contenido mayoritario para todos los tiempos de erosión, la segunda especie que aparece es el agua. Esto mismo se detecta en los espectros correspondientes a la muestra E, Figuras 6.8 y 6.9.

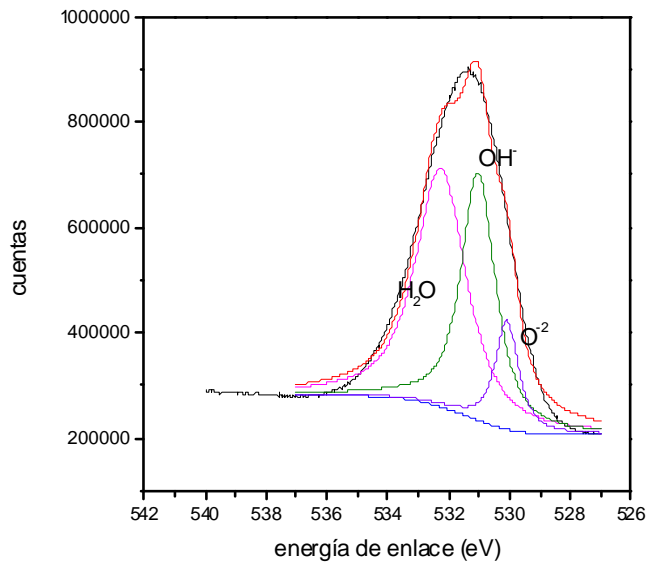

(a)

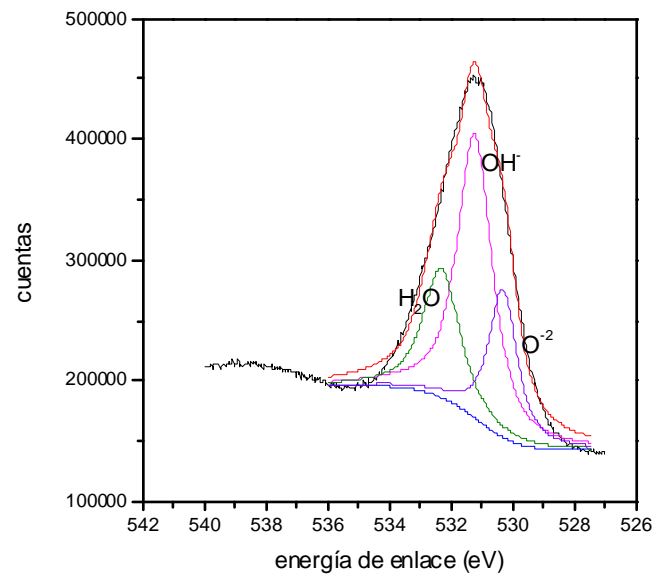

(b)

Figura 6.8. Espectro de $O$ 1s para la muestra $M$ a 0 min(a) y 60 min (b).

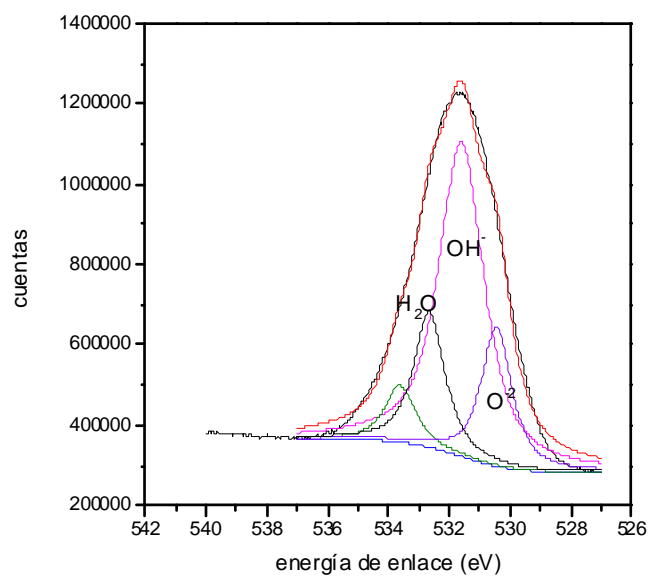

(a)

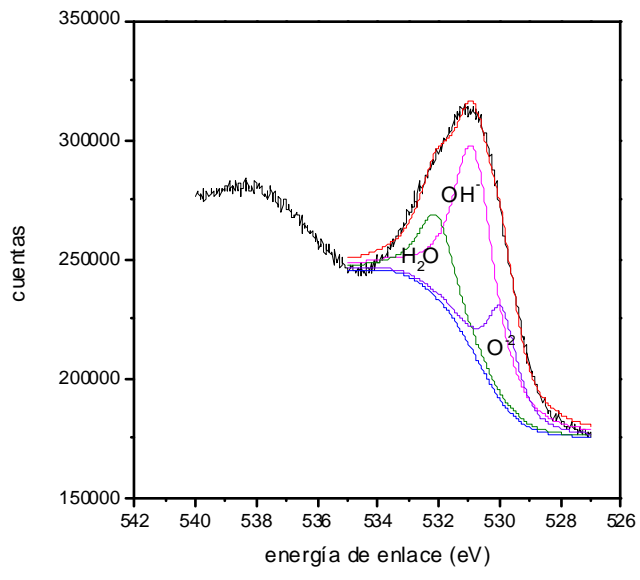

(b)

Figura 6.9. Espectro de $O 1$ s para la muestra $E$ a 0 min(a) y 60 min (b). 
Espectros de XPS obtenidos con muestras de hierro oxidado en soluciones de fosfato, exhiben un pico a $530 \mathrm{eV}$ aproximadamente, correspondiente a la especie $\mathrm{O}^{-2}$ y representa el oxígeno enlazado al hierro en $\mathrm{Fe}_{2} \mathrm{O}_{3}$ [14].

En nuestro sistema aparece un pico en $530-530,5 \mathrm{eV}$. No se observan los picos de FeOOH en 531,8 eV y el de $\mathrm{H}_{2} \mathrm{PO}_{4}^{-2}$ a $533 \mathrm{eV}$. Sin embargo en los espectros XPS del elemento P aparecen contribuciones de compuestos conteniendo este elemento. La concentración de los grupos fosfatos decrece a medida que analizamos planos más cercanos a la superficie del metal, con lo cual se deduce que está presente, principalmente, en la superficie de la película, más adentro se detectan las especies $\mathrm{Fe}_{2} \mathrm{O}_{3}$ y $\mathrm{Fe}_{3} \mathrm{O}_{4}$, estando este último ausente en la interfaz electrolito/película.

\subsubsection{Elementos $\mathrm{Fe} \mathrm{y} \mathrm{Cr}$}

Se pudo observar que en la muestra $\mathrm{M}$ domina la forma más oxidada, $\mathrm{Fe}_{2} \mathrm{O}_{3}$, en la superficie, mientras que no hay evidencia de la presencia de iones $\mathrm{Fe}^{+2}$. A partir de los 15 minutos domina la presencia de $\mathrm{Fe}_{3} \mathrm{O}_{4}$ coexistiendo con $\mathrm{Fe}^{+2}$ oxidado y se mantiene la composición global bastante constante con el tiempo de erosión (Figura 6.10).

En la muestra $E$, hasta los 15 minutos se observó el pico correspondiente a $\mathrm{FePO}_{4} \cdot 2 \mathrm{H}_{2} \mathrm{O}$, coincidentemente aparece el pico correspondiente también en los espectros del elemento fósforo a los 0 y 15 minutos, ver Figura 6.11, siendo el ión $\mathrm{Fe}^{+3}$ la especie que predomina.

De acuerdo a I.V. Sieber et al [134] dentro del rango de $\mathrm{pH}$ de 7 a 12 se puede producir $\mathrm{FeHPO}_{4} \cdot \mathrm{XH}_{2} \mathrm{O}$. Pero en presencia de oxígeno estas sales ferrosas pueden formar compuestos como $\mathrm{Fe}_{3}\left(\mathrm{PO}_{4}\right)_{2} \mathrm{u}$ oxidarse a $\mathrm{FePO}_{4}$, que son más estables presentándose un pico correspondiente al fosfato férrico $712,1 \mathrm{eV}$. La identificación de fosfato férrico se encuentra apoyada en una señal adicional en la región de 0 1s, a energías mayores de compuestos polifosfatos a 531,1eV, no observada en nuestras medidas, y otra en el espectro de $\mathrm{P} 2 \mathrm{p}_{3 / 2}$ a 133,5 eV, Figura 6.15 espectros a 15 y 0 minutos. La capa de fosfato se encuentra en la parte externa de la película. Entre los pHs de 8,5 a 11, los iones fosfatos se encuentran primeramente en forma de $\mathrm{HPO}_{4}{ }^{-2}$. Existe la posibilidad que la especie $\mathrm{HPO}_{4}{ }^{-2}$ reaccione con los iones $\mathrm{Fe}$ y no el anión $\mathrm{PO}_{4}{ }^{-3}$. Por lo tanto la etapa inicial puede consistir en la formación de $\mathrm{FeHPO}_{4}$. En la capa externa de la película se ubicarían los fosfatos y los hidróxidos. En otros trabajos se ha reportado también la presencia de compuestos de fosfato de Fe en medioambientes con P. La formación de fosfato puede ser atribuida a la baja solubilidad del 
mismo. El producto de solubilidad para $\mathrm{Fe}_{3}\left(\mathrm{PO}_{4}\right)_{2}$ es de $10^{-36}$ a $10^{-25}$ y para $\mathrm{FePO}_{4} \cdot 2 \mathrm{H}_{2} \mathrm{O}$, es de $10^{-34}$ a $10^{-26}$ muchos menores que para el $\mathrm{Fe}(\mathrm{OH})_{2}\left(10^{-17}-10^{-14}\right)$. Sieber indicó que el espesor de la capa de fosfato es independiente del potencial. Esto puede indicar que los compuestos de fosfato pueden formarse a bajos potenciales predominantemente y un incremento del potencial anódico no muestra ninguna influencia en la cantidad de compuestos fosfatados

Algunos trabajos sobre hierro en fosfato de pH básico [122] muestran en las curvas potenciodinámicas que la pasivación del hierro es por acumulación de $\gamma$-FeOOH, que estuvo precedido por $\mathrm{Fe}_{3}\left(\mathrm{PO}_{4}\right)_{2}$ y $\mathrm{Fe}(\mathrm{OH})_{2}$, especies formadas durante la oxidación inicial. En las medidas voltamperométricas se ve la formación de $\mathrm{Fe}_{3}\left(\mathrm{PO}_{4}\right)_{2}$ y $\mathrm{Fe}(\mathrm{OH})_{2}$ a $-0,87 \mathrm{~V} / \mathrm{SCE}$ y un segundo pico que corresponde a la oxidación a $\gamma$-FeOOH a -0,36 V/SCE, siendo este último transformado en $\mathrm{Fe}_{2} \mathrm{O}_{3}$ en la región pasiva. Las medidas que se realizaron a diferentes concentraciones de $\mathrm{Na}_{2} \mathrm{PO}_{4}$, sugieren que a medida que la concentración de fosfato aumenta, la disolución de hierro en el sistema pasivo es más lento, esto se observa en la disminución de la corriente. La disolución del electrodo decrece con el incremento de concentración de fosfato por esto va en aumento el potencial de circuito abierto [151]. 

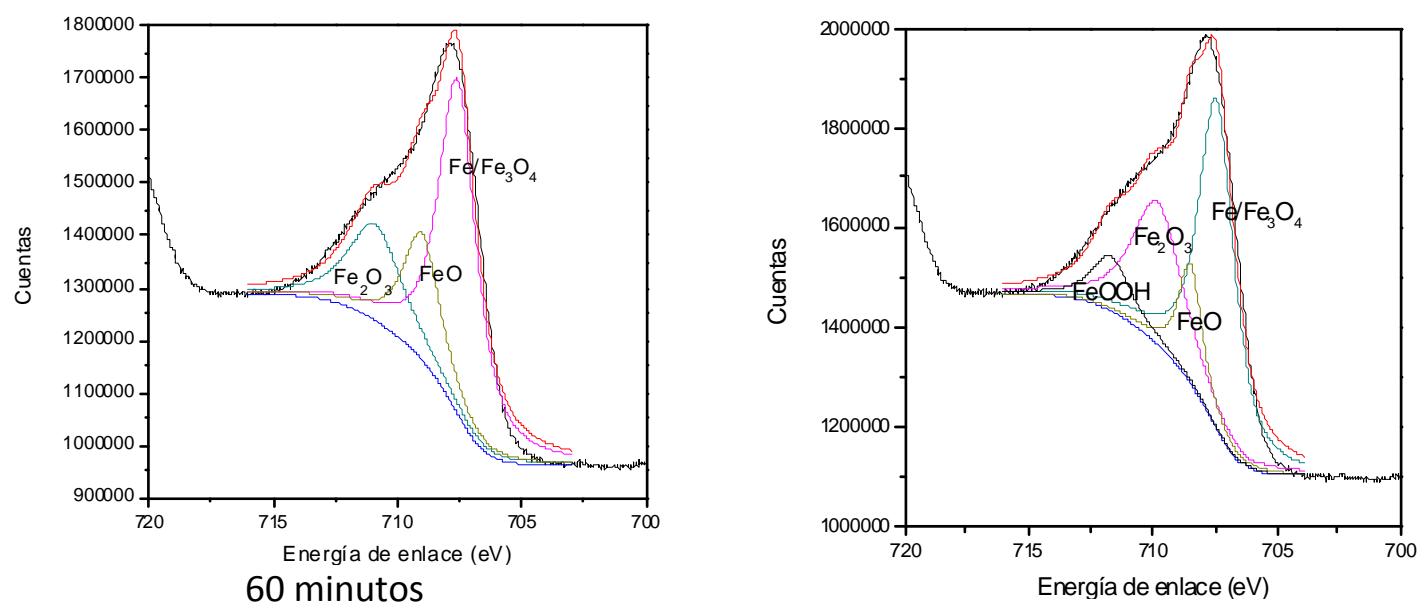

45 minutos
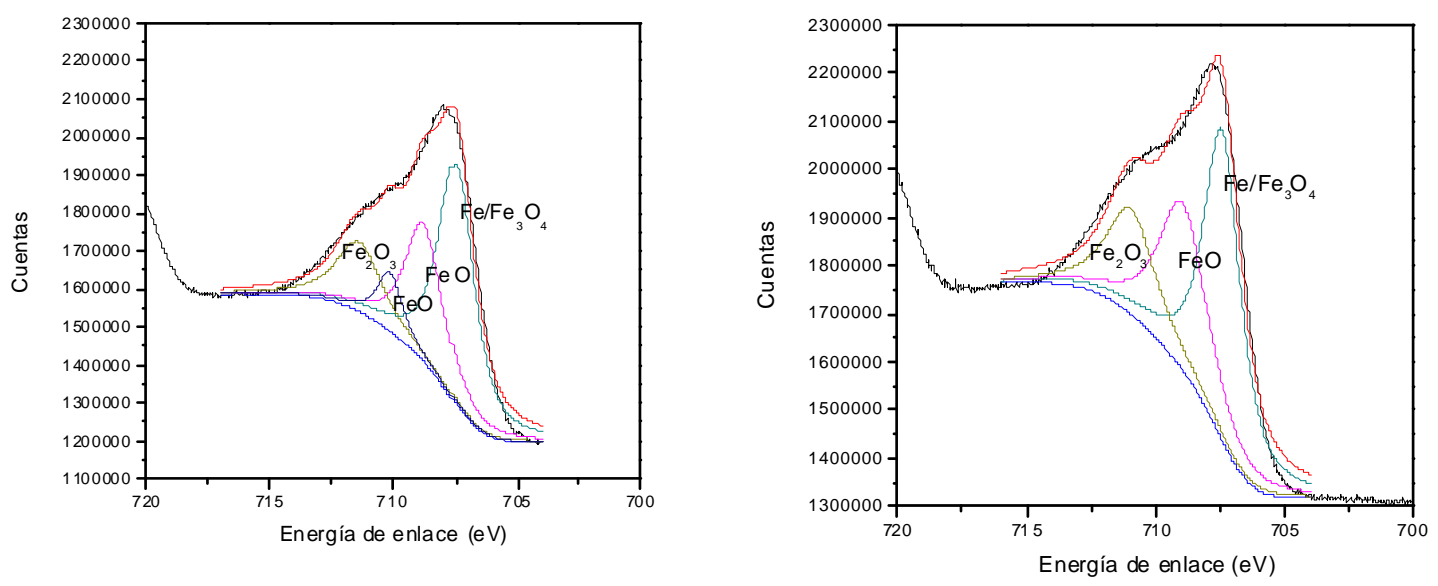

30 minutos

15 minutos

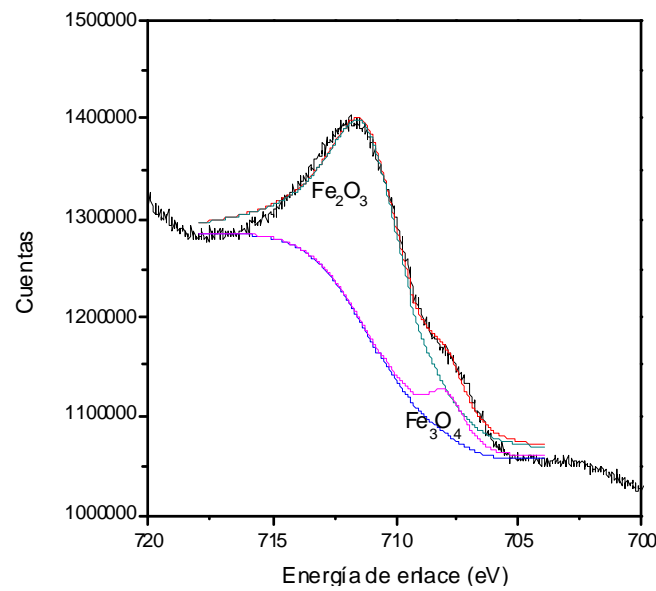

0 minutos

Figura 6.10. Espectro de Fe2 $p_{3 / 2}$ para la muestra $\mathrm{M}$ 


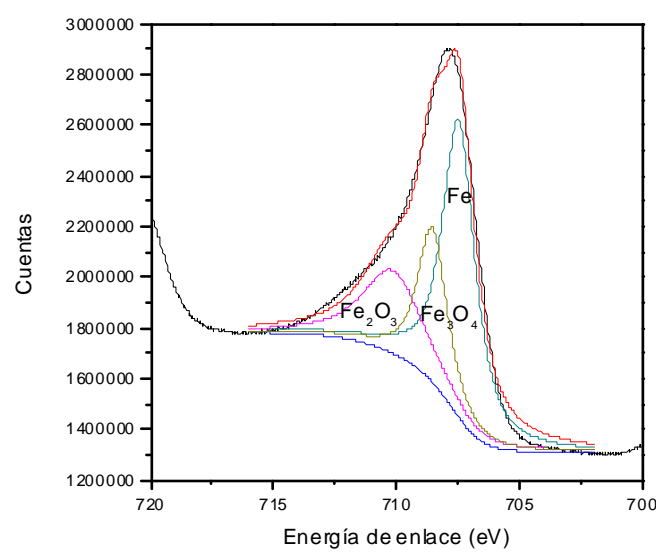

60 minutos

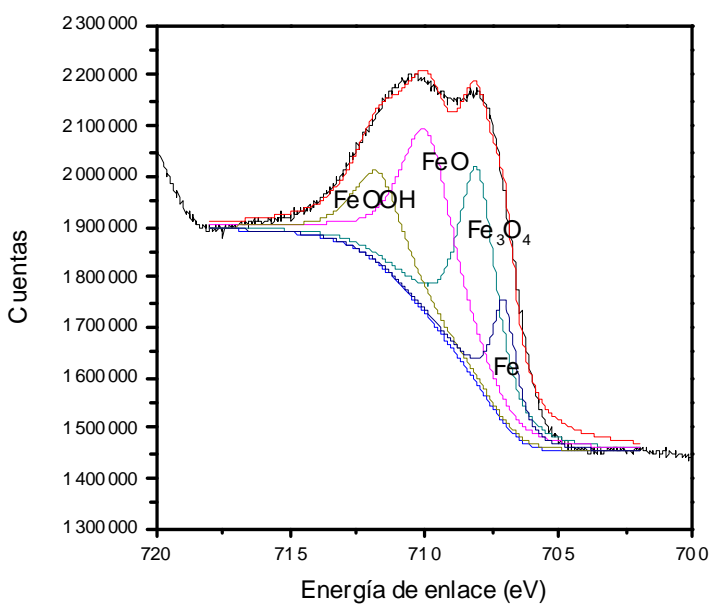

30 minutos

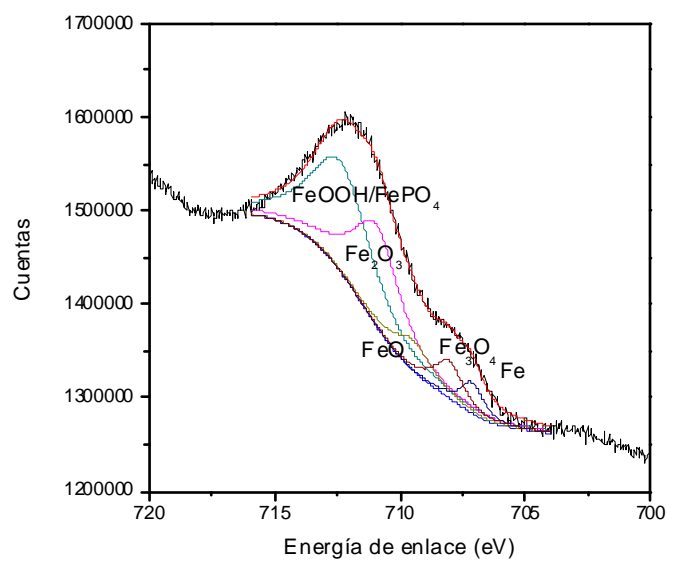

0 minutos

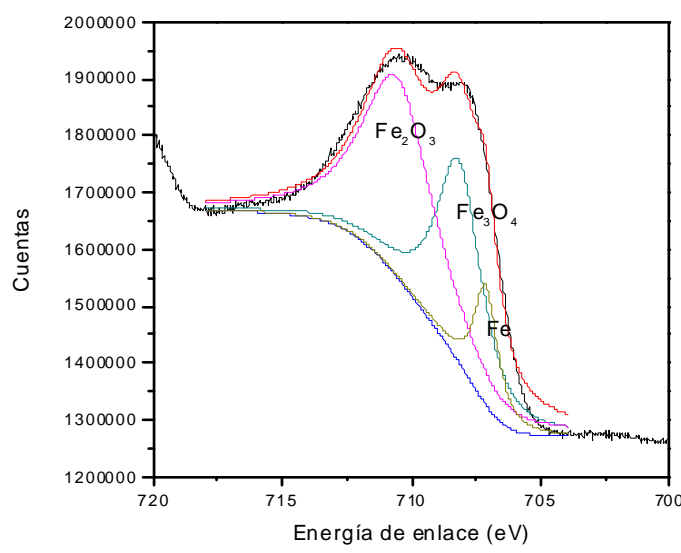

45 minutos

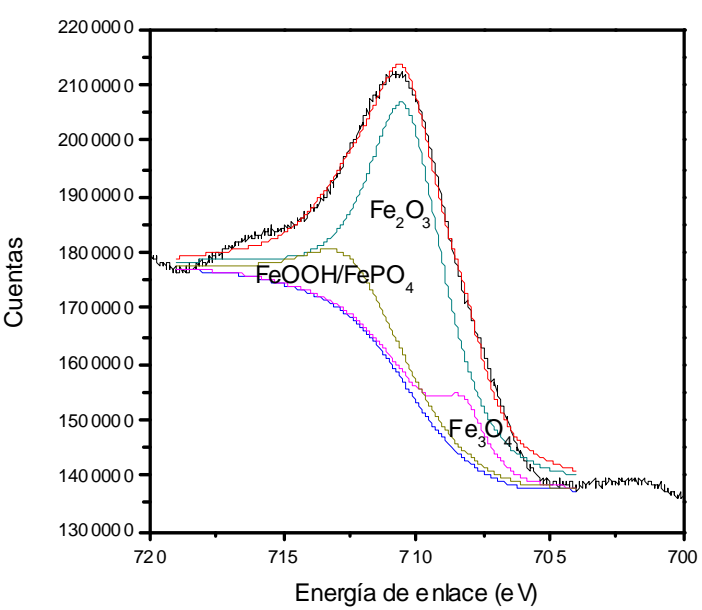

15 minutos

Figura 6.11. Espectro de $\mathrm{Fe} 2 \mathrm{p}_{3 / 2}$ para la muestra $\mathrm{E}$ 
En los aceros el óxido de cromo y de hierro se encuentran distribuidos por toda la capa pasiva. Al aire la película pasiva se encuentra con la capa de hierro oxidado concentrado en la superficie, generalmente en la forma $\alpha-\mathrm{Fe}_{2} \mathrm{O}_{3}$ y una pequeña proporción de $\mathrm{FeO}$ que no se ha oxidado, luego el cromo se oxida localizándose en la interfaz de la capa pasiva/metal [152][153][151][154].

De acuerdo a Giacomelli et al [122] el crecimiento de la película protectora básicamente se realiza en tres pasos: primero la corriente disminuye rápidamente debido a la barrera que se forma inmediatamente en la superficie del electrodo. Luego un ligero aumento atribuído a la interrupción de la forma original de óxido-aire, debido al desplazamiento efectivo de la conversión de oxido/hidróxido de fosfato. Este proceso expone de nuevo la superficie metálica, ahora sin protección, para un rápido ataque convirtiéndose todo en una capa de protección de fosfato. El último paso, donde hay una disminución de corriente, se debe al crecimiento de la película. Después de un tiempo de polarización el valor de la corriente llega a un estado estacionario. En estas condiciones la velocidad de disolución es la misma que la de crecimiento, entonces las características de la película se conservan.

La muestra $\mathrm{M}$, contiene siempre $\mathrm{Cr}^{+3}$ en forma de $\mathrm{Cr}(\mathrm{OH})_{3}$ y algo de óxido de $\mathrm{Cr}^{+6}$, aquí aparece el compuesto de $\mathrm{Cr}$ con $\mathrm{Ni}\left(\mathrm{NiCr}_{2} \mathrm{O}_{4}\right)$ que en la muestra $\mathrm{E}$ no aparece (Figura 6.12).

La muestra $\mathrm{E}$ entre los 15 y 30 minutos el $\mathrm{Cr}(\mathrm{OH})_{3}$ es el compuesto más importante (Figura 6.13). 


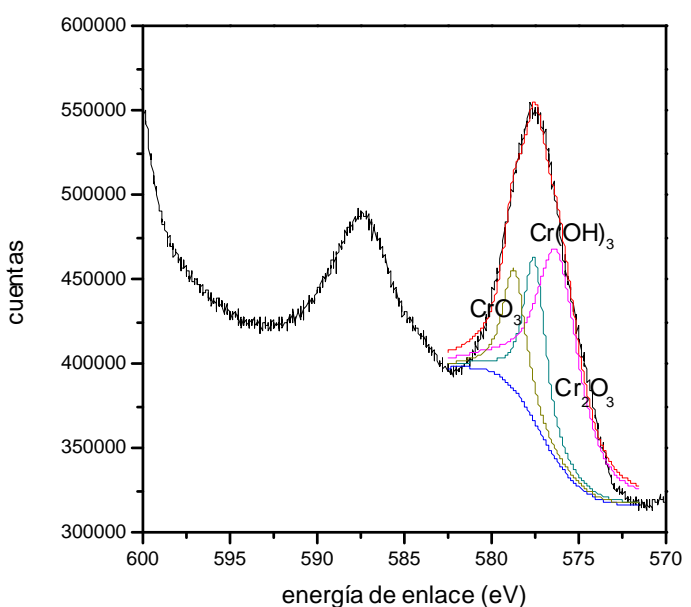

60 minutos

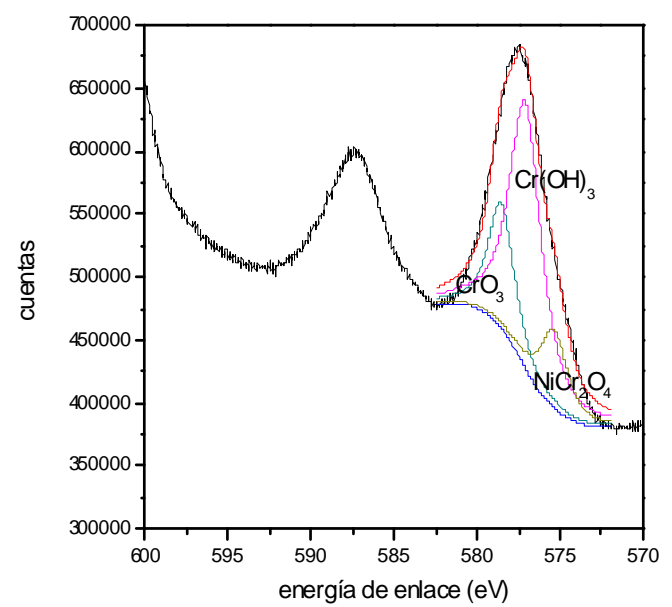

30 minutos

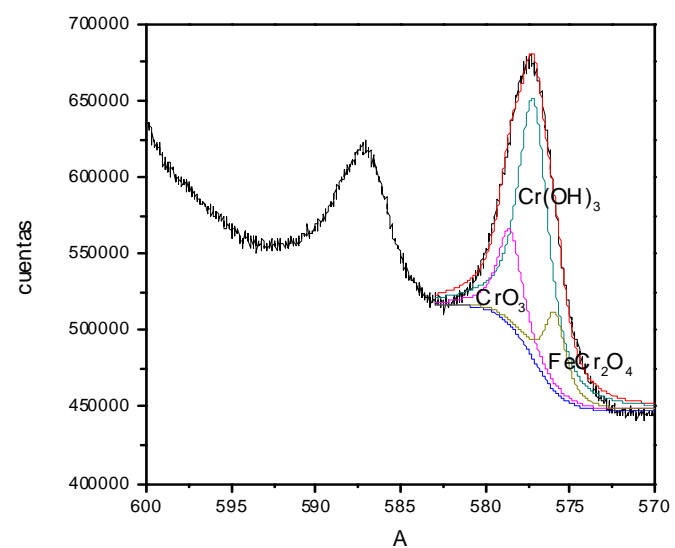

0 minutos

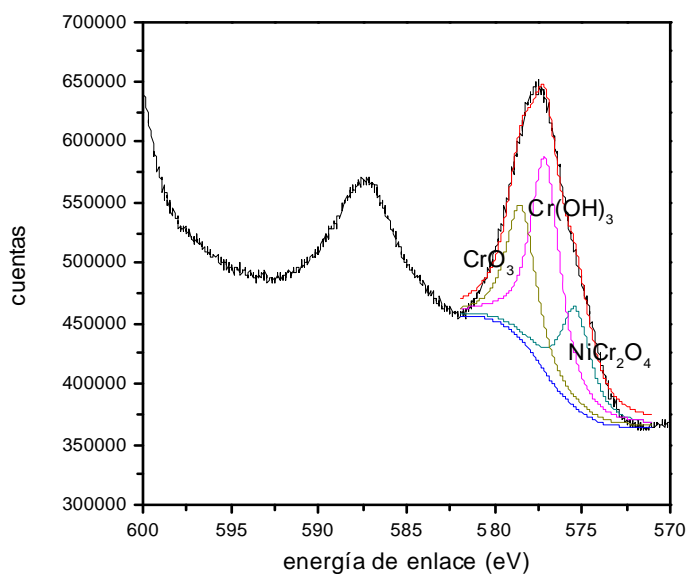

45 minutos

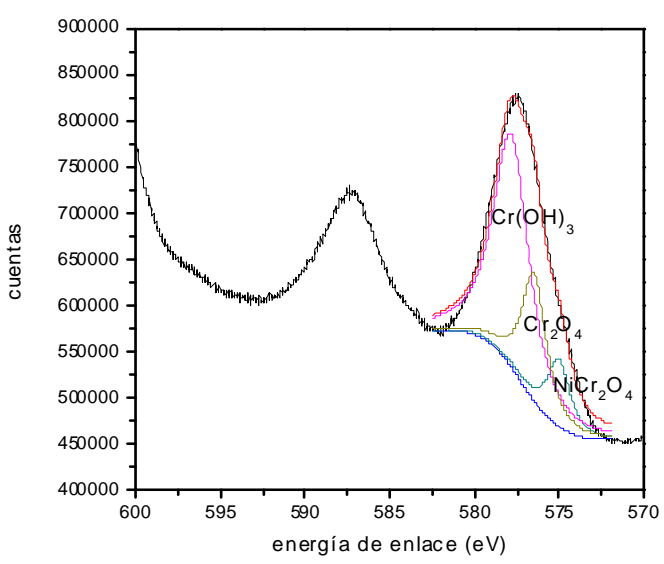

15 minutos

Figura 6.12. Espectro de $\mathrm{Cr} 2 \mathrm{p}_{3 / 2}$ para la muestra $\mathrm{M}$. 


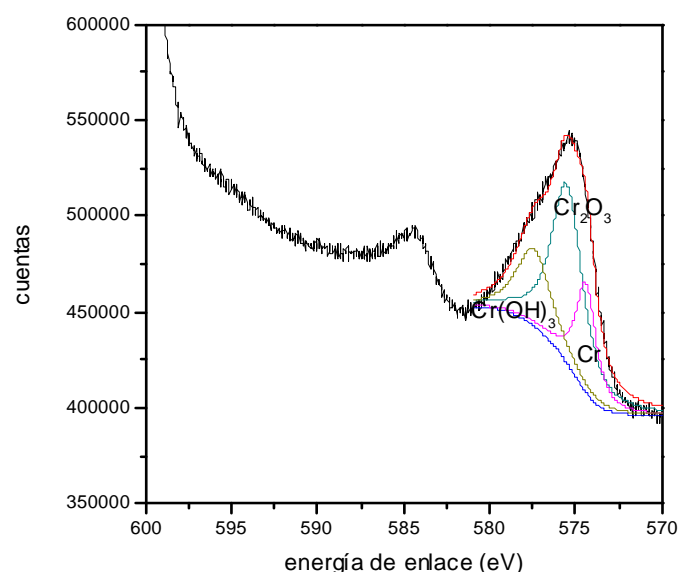

60 minutos

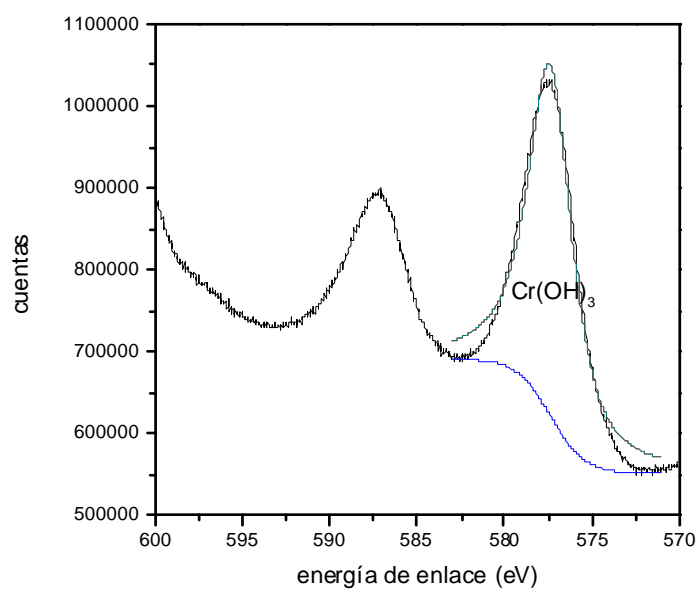

30 minutos

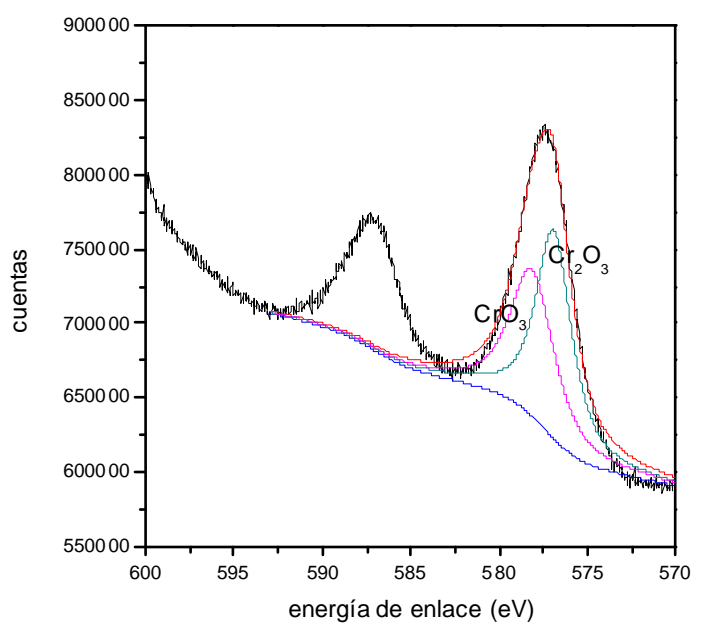

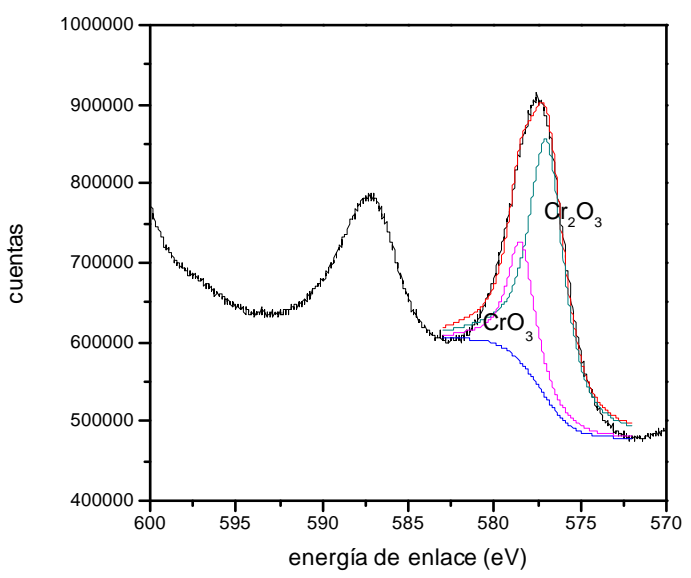

45 minutos

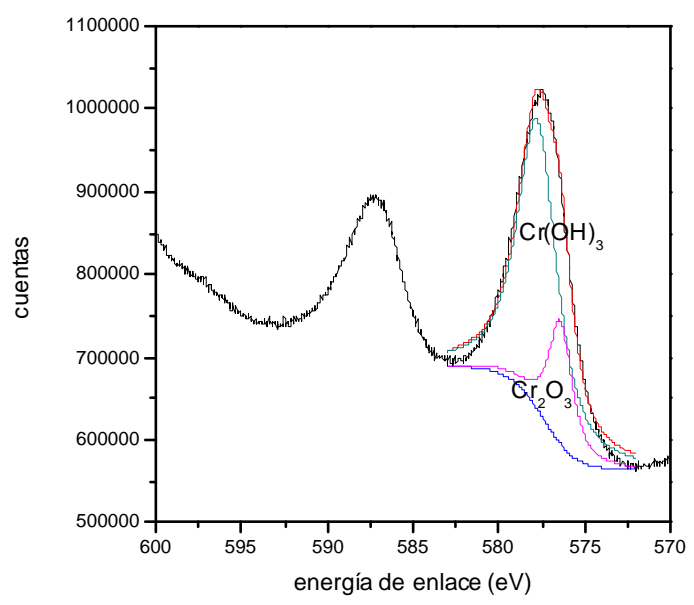

15 minutos

\section{0 minutos}

Figura 6.13. Espectro de $\mathrm{Cr} 2 \mathrm{p}_{3 / 2}$ para la muestra $\mathrm{E}$. 


\subsubsection{Elemento $P$}

La muestra $\mathrm{M}$ contiene $\mathrm{P}$ a 0 y 15 minutos (Figura 6.14), mientras que en la muestra $\mathrm{E}$ la presencia de $\mathrm{P}$ se detecta hasta los 45 minutos, además se observa el pico correspondiente a la formación de $\mathrm{FePO}_{4} \cdot 4 \mathrm{H}_{2} \mathrm{O}$. (Figura 6.15 )

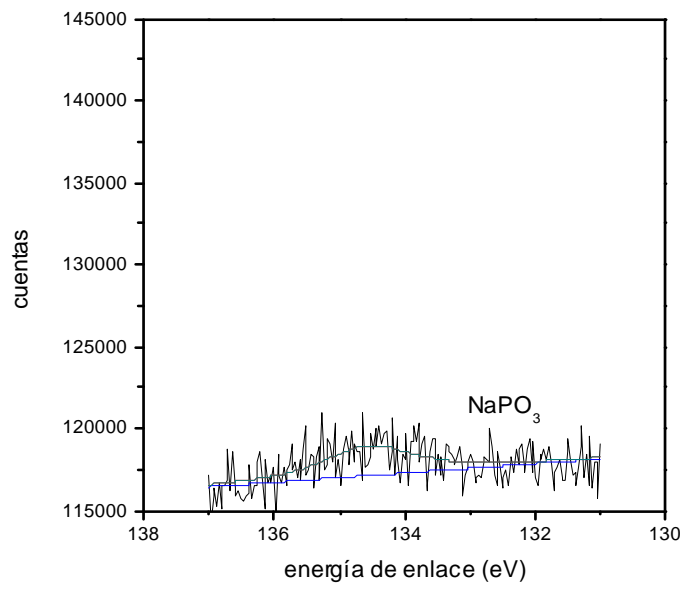

15 minutos

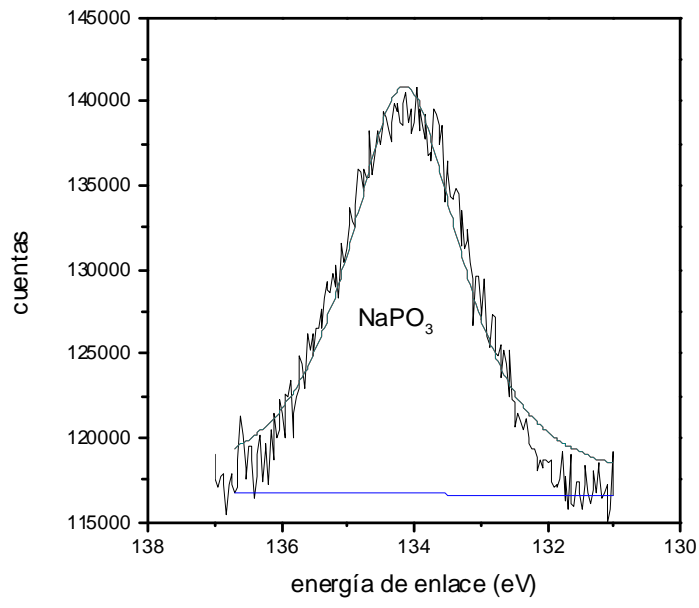

0 minutos

Figura 6.14. Espectro de $P 2 p_{3 / 2}$ para la muestra $M$ 


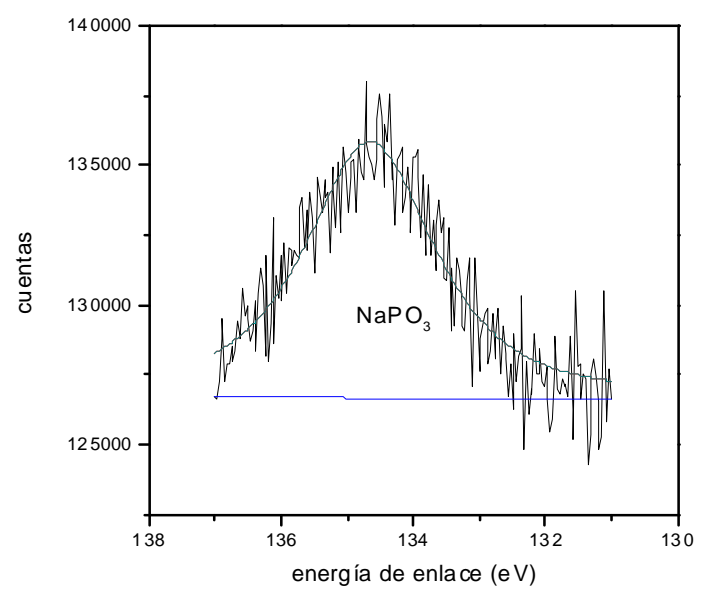

45 minutos

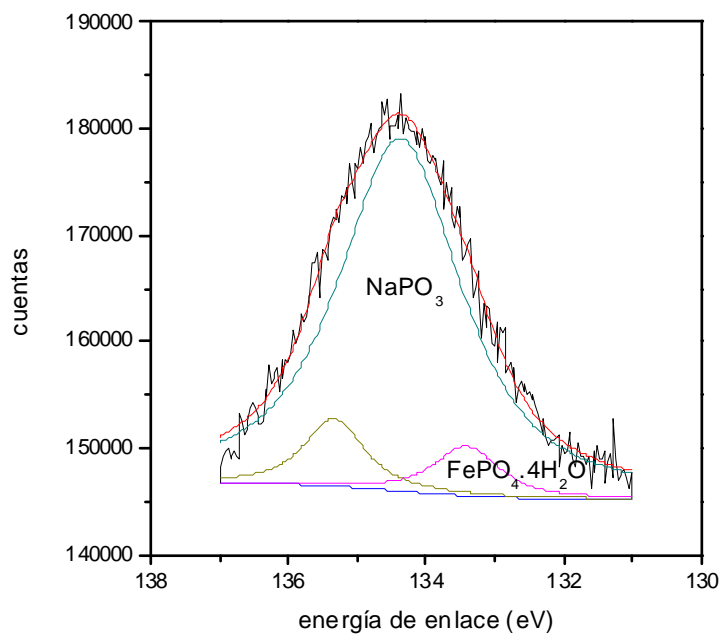

15 minutos

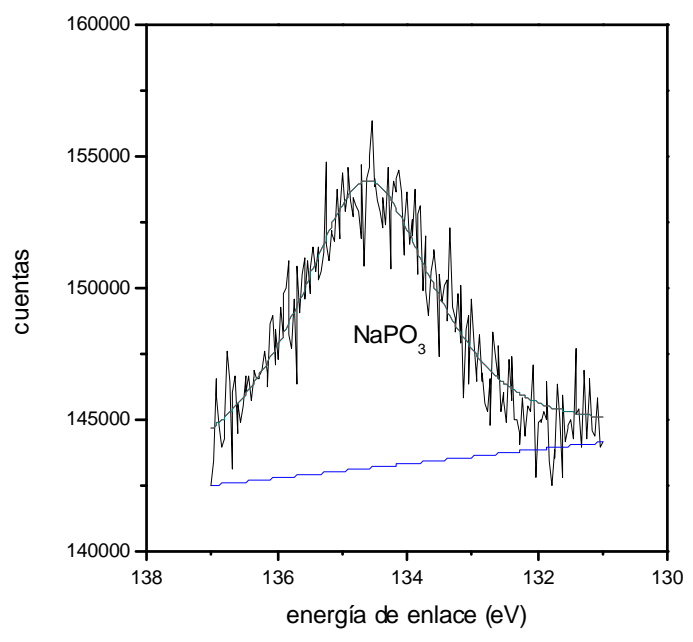

30 minutos

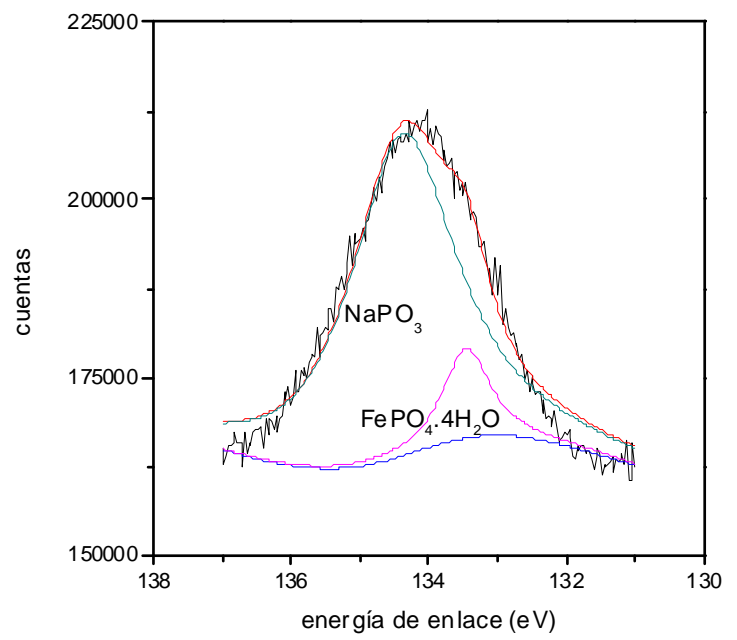

0 minutos

Figura 6.15. Espectro de $P 2 p_{3 / 2}$ para la muestra $E$.

\subsubsection{Análisis teórico de la impedancia de películas pasivantes de acero inoxidable softmartensíticos}

Las películas pasivas han sido ampliamente estudiadas en las últimas décadas y un gran número de modelos se han propuesto para interpretar la cinética de crecimiento y la estructura electrónica de estos compuestos superficiales [58][155][156][157][158]. Se emplearon una gran variedad de técnicas electroquímicas y ópticas para obtener información de la composición química, la estructura cristalina, el transporte iónico y las propiedades electrónicas. En este sentido la impedancia electroquímica demostró ser una herramienta poderosa [159][160][161] . 
A continuación se detalla el modelo utilizado para describir el comportamiento dinámico de las películas anódicas de aceros inoxidables softmartensíticos. Las suposiciones básicas son similares a las del Point Defect Model [157][160], sin embargo el transporte iónico en el óxido esta descripto en este trabajo en términos de la ecuación de transporte de alto campo derivada por Fromhold y Cook [162][163] y se utilizan aquí distintas condiciones de contorno en la interfase óxido/solución. Los cambios considerados respecto del PDM se refieren a dos aspectos, que tal como han sido allí planteados, no tienen aplicabilidad al acero en estado pasivo. Por una parte, en el PDM se asume una relación lineal entre el campo eléctrico dentro de la película y los flujos iónicos a través del mismo lo cual es dudoso para campos eléctricos al menos del order de $10^{6} \mathrm{~V} \mathrm{~cm}^{-1}$, como los que se estudian en este trabajo. Por otro lado, se encuentra experimentalmente un plateau en la curva estacionaria corriente-potencial (Figura 5.2) determinado por una caída de potencial constante en la interfase óxido-solución para el estado estacionario, mientras que en el PDM se asume que esa caída de potencial depende del potencial aplicado [164][165].

\subsubsection{Suposiciones básicas}

1) El metal pasivado está cubierto de una capa no porosa que domina la impedancia de la interfase con espesores típicos de entre 10 y $100 \AA$. En condiciones de estado estacionario el espesor del óxido L es constante. La disolución del óxido que tiene lugar en la interfase óxido-solución está compensada por su crecimiento en la interfase metal-óxido, y el transporte simultáneo de vacancias de oxígeno y vacancias catiónicas a través de la película. Las vacancias son generadas y consumidas en las dos interfases del óxido de acuerdo a los procesos electroquímicos presentados en la Figura 5.1.

2) El campo eléctrico en el óxido, se supone homogéneo (independiente de la distancia), es decir, la contribución de un campo inducido, debido a la existencia de un espacio de cargas representa una contribución despreciable al campo total en el óxido [163][157].

3) Como en el PDM, la señal de perturbación de potencial no afecta el espesor del óxido. Esta suposición se basa en el hecho que bajo condiciones estacionarias la dependencia del espesor de la película $L$ con el potencial aplicado $E_{\text {ext }}$ es aproximadamente $\mathrm{dL} / \mathrm{dE}_{\mathrm{ext}}=113,6 \AA / \mathrm{V}$ para la muestra $\mathrm{M}$ y dL/dV $\mathrm{ext}=47,6 \AA \mathrm{N} / \mathrm{V}$ para la muestra $\mathrm{E}$ (ver Figura 5.8). Si la perturbación aplicada tiene una amplitud $\mathrm{I} \Delta \mathrm{E}_{\mathrm{ext}} \mathrm{I}=10 \mathrm{mV}$, el correspondiente cambio en $L$ alcanzando el estado estacionario, es decir a frecuencias de medida $\omega \rightarrow 0$ es 
$|\Delta \mathrm{L}|=1 \AA$ ( $\approx 1 \%$ de $\mathrm{L})$. Además se requieren no menos de dos horas para alcanzar el estado estacionario luego de un cambio de potencial, en consecuencia bajo las condiciones experimentales de los experimentos de impedancia esta suposición resulta razonable.

4) El potencial $E_{\text {ext }}$ es:

$$
\mathrm{E}_{\mathrm{ext}}=\mathrm{E}_{\mathrm{l}}+\phi_{\mathrm{r}}
$$

donde $\phi_{r}$ es la caída de potencial electrodo de referencia-solución y $E_{1}$ es la parte polarizable de la interfase: $E_{l}=E_{m f}+E_{f}+E_{f s}$

$E_{m f}, E_{f}$ and $E_{f s}$ son las diferencias de potencial metal-film, film y film-solución respectivamente.

Cualquier cambio en $\mathrm{E}_{\mathrm{ext}}$ se distribuye linealmente entre estas tres regiones [157][165].

$$
\begin{aligned}
& d E_{e x t}=d E_{1} \\
& d E_{m f}=a_{1} d E_{e x t} \\
& d E_{f}=a_{2} d E_{e x t} \\
& d E_{f s}=a_{3} d E_{e x t} \\
& \text { con } a_{1}+a_{2}+a_{3}=1
\end{aligned}
$$

De acuerdo con Vetter $[156,166,167][168]$ y publicaciones posteriores [169][170][51][171], en estado estacionario $\mathrm{E}_{\mathrm{fs}}$ está determinado solamente por el equilibrio entre los iones oxígeno en la superficie de la película y el agua o las especies $\mathrm{OH}^{-}$en solución, si el óxido tiene una estequiometría constante [165]:

$\mathrm{E}_{\mathrm{fs}}=\mathrm{G}-(\mathrm{RT} / \mathrm{F}) 2,303 \mathrm{pH}$

donde $\mathrm{G}$ es una constante independiente de $\mathrm{E}_{\mathrm{ext}}$, de modo que:

$$
\mathrm{dE}_{\mathrm{fs}} / \mathrm{dE}_{\mathrm{ext}}=\mathrm{a}_{3}=0
$$

Cuando esta ecuación es aplicable, la corriente de estado estacionario resulta constante en el rango de pasividad [172]. 


\subsubsection{Procesos electroquímicos}

En la figura 6.16 se muestra un esquema de los procesos electroquímicos que tienen lugar en el sistema pasivo completo.

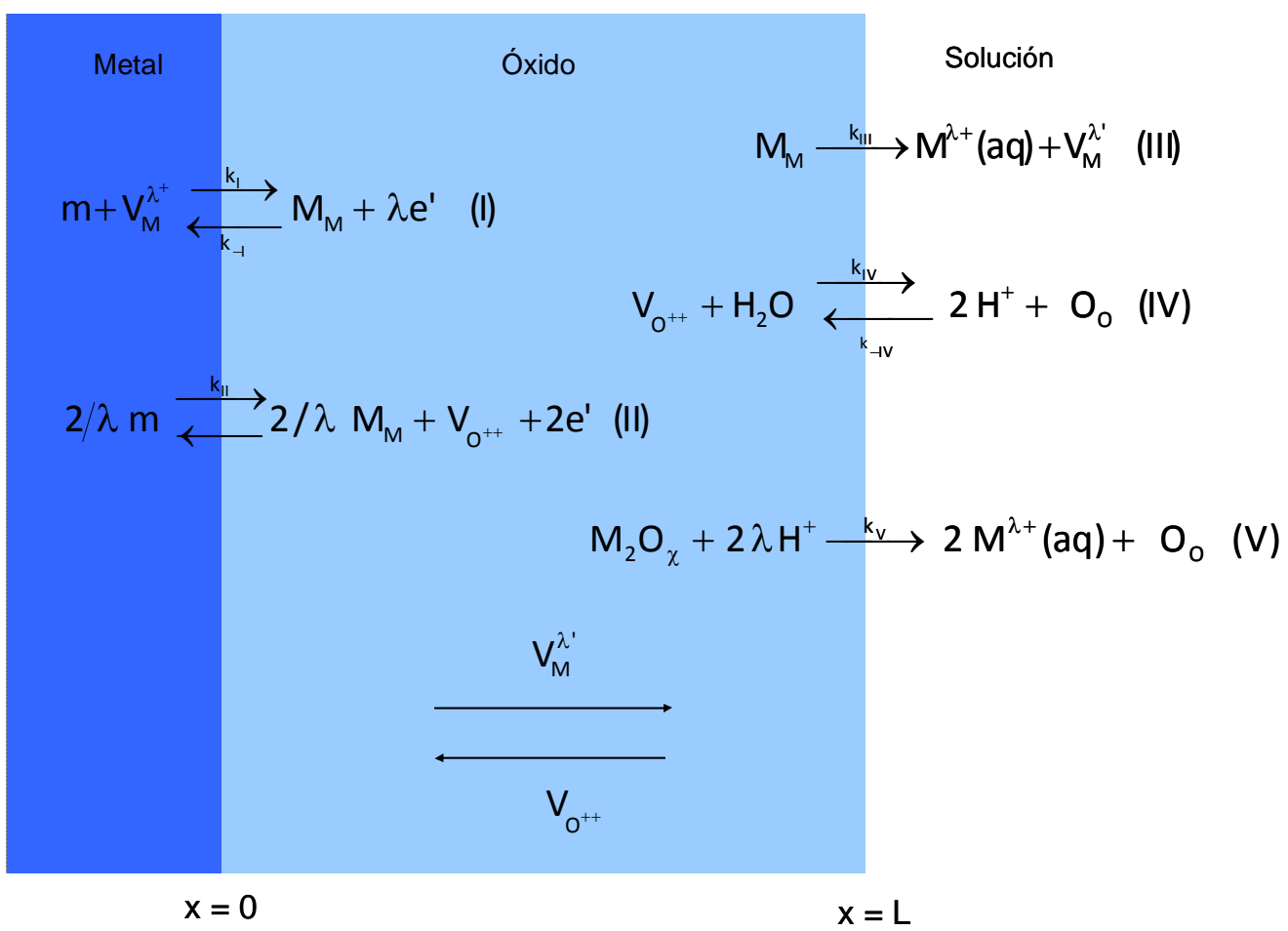

Figura 6.16. Esquema de los procesos de transportes de vacancias y de las reacciones interfaciales que ocurren en la película pasivante.

\section{Interfase metal-film}

En esta interfase $(x=0)$, los iones del metal se transfieren al óxido según las siguientes reacciones:

$$
\begin{aligned}
& \mathrm{m}+\mathrm{V}_{\mathrm{M}}^{\lambda^{\prime}} \Leftrightarrow \mathrm{M}_{\mathrm{M}}+\lambda \mathrm{e}^{\prime} \\
& 2 / \lambda \mathrm{m} \Leftrightarrow 2 / \lambda \mathrm{M}_{\mathrm{M}}+\mathrm{V}_{\mathrm{O}} \cdot+2 \mathrm{e}^{\prime}
\end{aligned}
$$

donde $\mathrm{m}$ significa un átomo del metal en la fase metal, $\mathrm{V}_{\mathrm{M}}{ }^{\lambda^{\prime}}$ es una vacancia catiónica en el óxido, $\mathrm{M}_{\mathrm{M}}$ es un catión metálico en una posición normal de la red de la fase óxido y $\mathrm{V}_{\mathrm{O}} \cdot$ ” es una vacancia de oxígeno en el óxido. [Se adoptó aquí la notación Kroeger-Vink para designar las especies asociadas a los defectos puntuales. De acuerdo a esta notación, $X_{y}$ significa que la especie $X$ ocupa un sitio $Y$ de la red (por ejemplo $V_{M}$ refiere a una vacancia que ocupa un 
sitio de metal en el óxido, es decir una vacancia de metal); e y h son electrones y huecos. El superíndice informa el número y el signo de la carga. Así, ".." quiere decir dos cargas positivas y " $\lambda^{\prime}$ " designa $\lambda$ cargas negativas (por ejemplo $\mathrm{V}_{\mathrm{M}}{ }^{\lambda^{\prime}}$ significa una vacancia de metal que lleva $\lambda$ cargas negativas].

La reacción (I) está relacionada al pasaje de átomos del metal al óxido mientras que la reacción (II) da origen al crecimiento de la fase óxido dentro del metal.

Las constantes de velocidad de las reacciones (I) y (II), $k_{1}, k_{-1}, k_{\|}$y $k_{-\|}$dependen exponencialmente de $E_{m f}$ según: $k_{i}=k_{i}^{0} \exp \left(b_{i} \cdot E_{m f}\right)$ [160][165] con $b_{i}-b_{-i}=z F / R T$, y z el número de cargas elementales transferidas en la reacción.

El crecimiento del óxido en la interfase $\mathrm{m} / \mathrm{f}$ es consistente con experimentos de marcadores [173] y ha sido reportado en numerosas publicaciones [64].

\section{Interfase film-solución}

En $x=L$ ocurren los siguientes procesos:

$$
\begin{aligned}
& \mathrm{M}_{\mathrm{M}} \rightarrow \mathrm{M}^{\lambda+}(\mathrm{aq})+\mathrm{V}_{\mathrm{M}^{\lambda^{\prime}}} \\
& \mathrm{V}_{\mathrm{O}} \cdot+\mathrm{H}_{2} \mathrm{O} \Leftrightarrow 2 \mathrm{H}^{+}+\mathrm{O}_{\mathrm{O}} \\
& \mathrm{M}_{2} \mathrm{O} \chi+2 \lambda \mathrm{H}^{+} \rightarrow 2 \mathrm{M}^{\lambda+}(\mathrm{aq})+\lambda \mathrm{H}_{2} \mathrm{O}
\end{aligned}
$$

donde $\mathrm{O}_{\mathrm{O}}$ corresponde a un ión oxígeno en un sitio aniónico del óxido.

Las constantes de velocidad de las reacciones (III) y (IV) dependen exponencialmente de $\mathrm{V}_{\mathrm{fs}}$, según $\mathrm{k}_{\mathrm{i}}=\mathrm{k}_{\mathrm{i}}^{\mathrm{O}} \exp \left(\mathrm{b}_{\mathrm{i}} . \mathrm{E}_{\mathrm{fs}}\right)$. La reacción $(\mathrm{V})$ representa la disolución química del óxido.

Se asume una condición de quasi-equilibrio para la reacción (IV), de acuerdo con el equilibrio global de las especies de oxígeno en esta interfase, discutida antes. Las reacciones (III) y (V) son procesos irreversibles, a menos que la solución esté saturada con iones $\mathrm{M}^{\lambda+}(\mathrm{aq})$, lo cual es muy infrecuente. Si el óxido tiene una composición estequiométrica en $\mathrm{x}$ $=\mathrm{L}, \mathrm{V}_{\mathrm{III}}$ la velocidad de la reacción III, no cambia con $\mathrm{E}_{\mathrm{ext}}$ debido a la ecuación 6.1.

El resultado neto de la migración de $V_{0}$." puede verse de la combinación de las reacciones (II) y (IV) según:

$$
2 / \lambda m+\mathrm{H}_{2} \mathrm{O} \Leftrightarrow 2 / \lambda \mathrm{M}_{M}+2 \mathrm{H}^{+}+\mathrm{O}_{\mathrm{O}}+2 \mathrm{e}^{\prime}
$$


del mismo modo combinando las reacciones (I) y (III) obtenemos:

$$
m \Leftrightarrow M^{\lambda^{\prime}}(a q)+\lambda e^{\prime}
$$

que muestra el resultado neto de la migración de $\mathrm{V}_{\mathrm{M}}{ }^{\lambda^{\prime}}$.

Está claro entonces que el transporte de $V_{0} \cdot$ (o lo que es equivalente de aniones oxígeno) resulta en el crecimiento del óxido, mientras que el transporte de $\mathrm{V}_{\mathrm{M}}{ }^{\lambda^{\prime}}$ (o de modo equivalente de cationes metálicos) resulta en la disolución del metal solamente.

\section{Transporte iónico en el film}

Para derivar una expresión de la función de transferencia del sistema, las ecuaciones de transporte en la fase óxido deben ser resueltas con las correspondientes condiciones de contorno. En los modelos iniciales de la literatura, revisada más arriba, se asume que la concentración de las especies iónicas transportadas y responsables del crecimiento del óxido no varía con la distancia dentro de la película, estando su movimiento sólo gobernado por la influencia del campo eléctrico. Esto se ha demostrado que, en principio, no es de validez general y se ha corregido en los modelos más recientes [157][164,174].

El transporte iónico en la película pasiva será descripta en términos de la ecuación de transporte derivada por Fromhold y Cook, ya que como se adelantó, la ecuación de transporte lineal no se aplica para películas muy delgadas $(L<10 \mathrm{~nm})$ y altos campos eléctricos $\left(E>10^{6} \mathrm{~V} / \mathrm{cm}\right.$ ). Debido a la presencia de barreras de energía discretas en el óxido, la corriente varía exponencialmente con el campo eléctrico local [175][58][155][163] y la relación lineal entre el flujo iónico y el campo eléctrico E puede solo ser observada en el caso de pequeños campos eléctricos, típicamente $\mathrm{E}<1000 \mathrm{~V} \mathrm{~cm}^{-1}$ [163] o espesores de óxido muy gruesos:

$$
J(x, t)=-D \frac{\partial C(x, t)}{\partial x} \cosh \left[\frac{z F E(x, t) a}{R T}\right]+\frac{D}{a} C(x, t) \sinh \left[\frac{z F E(x, t) a}{R T}\right]
$$

donde $J(x, t)$ es el flujo de defectos iónicos (bien $V_{M}{ }^{\lambda^{\prime}} \circ V_{0} \cdot$ ) en el punto $x$, $D$ es el coeficiente de difusión, $\mathrm{C}(\mathrm{x}, \mathrm{t})$ es la concentración de defectos dependiente del tiempo y la posición, $z F$ es la carga en coulombs $\mathrm{mol}^{-1}$ (en este caso $z=-\lambda$ para $V_{M}{ }^{\lambda}$ y $z=2$ para $V_{0} \cdot{ }^{*}$ ), 
$\mathrm{E}(\mathrm{x}, \mathrm{t})$ es el campo eléctrico local y "a" es un parámetro geométrico que corresponde a la mitad de la distancia de separación de la barrera de energía [163].

En el límite de alto campo, es decir para $|z F E a / R T|>1$ y asumiendo un campo eléctrico homogéneo es decir independiente de x:

$$
J(x, t)=-\frac{D}{2} \exp \left(\frac{E^{o}}{E^{*}}\right) \frac{\partial C(x, t)}{\partial x} \pm \frac{D}{2 a} \exp \left(\frac{E^{o}}{E^{*}}\right) C(x, t)
$$

donde $E^{\circ}$ es el valor de estado estacionario del campo eléctrico, $\left.E^{*}=(\mathrm{RT} /|\mathrm{z}| \mathrm{Fa}),{ }^{+}\right)$ corresponde a vacancias aniónicas y $(-)$ a vacancias catiónicas.

De acuerdo a esto la dependencia temporal de la concentración de defectos en el punto x es:

$$
\begin{aligned}
& \frac{\partial C(x, t)}{\partial t}=-\frac{\partial J(x, t)}{\partial x} \\
& \frac{\partial C(x, t)}{\partial t}=\frac{D}{2} \exp \left(E^{\circ} / E^{*}\right) \frac{\partial^{2} C(x, t)}{\partial x^{2}} \pm \frac{D}{2 a} \exp \left(E^{\circ} / E^{*}\right) \frac{\partial C(x, t)}{\partial x}
\end{aligned}
$$

\subsubsection{Derivación de la función de transferencia del sistema}

La corriente eléctrica total I medida en el circuito externo es la suma de dos contribuciones, $I_{e}$ la corriente electrónica debida al flujo de electrones (e') o huecos $\left(h^{\bullet}\right)$ e $I_{\mathrm{I}}$ la corriente iónica debido a la inyección de iones desde las interfases y transportada a través de la película por los defectos iónicos. En el caso más simple [176] estas dos corrientes son independientes una de la otra y la impedancia del sistema m-f-s puede expresarse como:

$$
\frac{1}{Z}=\frac{1}{Z_{1}}+\frac{1}{Z_{e}}
$$

\section{Análisis de la impedancia $Z_{I}$}

La corriente $\mathrm{I}_{1}$ está relacionada a la oxidación de átomos del metal $(\mathrm{m})$ para ser incorporados al film de óxido existente (reacción I) y para producir el crecimiento de nuevo óxido hacia adentro del metal (reacción II) 


$$
I_{1}=F\left(\lambda v_{1}+2 v_{l I}\right)
$$

que para alta velocidad de crecimiento en comparación con la velocidad de disolución $\left(v_{\|}>>v_{1}\right)$ se puede expresar como [177]:

$$
\mathrm{I}_{I}=2 \mathrm{Fv}_{\| I}=2 \mathrm{~F}\left[\mathrm{k}_{\| I}-\mathrm{k}_{-I \mid} \mathrm{C}_{\mathrm{O}}(0, \mathrm{t})\right]
$$

donde $\mathrm{C}_{\mathrm{O}}(0, \mathrm{t})$ es la concentración de $\mathrm{V}_{\mathrm{O}} \cdot$ en $\mathrm{x}=0$.

De este modo la corriente iónica tiene la siguiente funcionalidad:

$$
I_{I}=I_{1}\left(E_{m f} ; C_{O}(0, t)\right)
$$

comportándose el óxido como un conductor aniónico, como a priori sugiere la consideración de las energías de formación de las vacancias catiónicas y aniónicas. Así, la especie usualmente informada como componente principal de la película barrera de los aceros inoxidables responsable del fenómeno de pasividad contiene especies catiónicas como el $\mathrm{Cr}$ (+3) y el Fe $(+2$ y +3) y la energía de formación de vacancias catiónicas se espera que sea mucho más alta que aquella para la formación de vacancias de oxígeno [178]. De acuerdo a esto el defecto principal es la vacancia aniónica $\left(V_{0} \cdot{ }^{*}\right)$ siendo la película pasiva un conductor de oxígeno.

La expresión de la impedancia puede calcularse de la ecuación 6.7 en la forma usual $[179,180]$ que involucra una expansión en serie de Taylor reteniendo sólo los términos de primer orden y una subsecuente aplicación de la transformada de Fourier y finalmente dividiendo a ambos lados del signo igual por $\Delta \mathrm{E}_{\mathrm{ext}}$ se obtiene:

$$
\frac{1}{\mathrm{Z}_{\mathrm{I}}}=\frac{\Delta \mathrm{I}_{\mathrm{l}}}{\Delta \mathrm{V}_{\mathrm{ext}}}=\left(\frac{\partial \mathrm{I}_{\mathrm{I}}}{\partial \mathrm{V}_{\mathrm{mf}}}\right)_{\hat{V}_{\text {ext }}, \hat{c}_{0}} \frac{\Delta \mathrm{V}_{\mathrm{mf}}}{\Delta \mathrm{V}_{\text {ext }}}+\left(\frac{\partial \mathrm{I}_{\mathrm{l}}}{\partial \mathrm{C}_{\mathrm{o}}}\right)_{\hat{V}_{\text {ext }}, \hat{c}_{0}} \frac{\Delta \mathrm{C}_{0}(0, \omega)}{\Delta \mathrm{V}_{\text {ext }}}
$$

las derivadas parciales deben evaluarse para valores estacionarios del potencial externo aplicado $\hat{E}_{\text {ext }}$ y de la concentración de vacancias de oxígeno $\hat{C}_{0}$. 
$\frac{1}{\mathrm{Z}_{\mathrm{I}}}=\frac{1}{\mathrm{R}_{\mathrm{T}}}+\alpha_{\mathrm{O}} \frac{\Delta \mathrm{C}_{\mathrm{O}}(0, \omega)}{\Delta \mathrm{E}_{\mathrm{ext}}}$

donde la inversa de la resistencia de transferencia de carga $R_{T}$ y el parámetro $\alpha_{0}$ tienen las siguientes formas:

$$
\begin{aligned}
& \frac{1}{R_{T}}=2 F\left[k_{\|} b_{\|}-k_{-\|} C_{0}(0, t)\right] a_{1} \\
& \alpha_{O}=-2 F k_{-\|}
\end{aligned}
$$

Para determinar la expresión de $Z_{1}$ se requiere evaluar primeramente la forma que adopta el término $\Delta \mathrm{C}_{0}(0, \omega) / \Delta \mathrm{E}_{\mathrm{ext}}$ de la ecuación 6.9 .

Al aplicar una señal sinusoidal de baja amplitud del potencial externo $E_{\text {ext }}(t)=\hat{E}_{\text {ext }}+$ $\Delta \mathrm{E}_{\text {ext }}(\mathrm{t})$ resultan variaciones temporales de la concentración y del campo eléctrico: $\mathrm{C}(\mathrm{x}, \mathrm{t})=$ $\hat{C}(x)+\Delta C(x, t)$ y $E(t)=E^{\circ}+\Delta E(t)$ donde $E^{\circ}$ es el valor estacionario del campo eléctrico que se ha supuesto independiente de la distancia $x$, es decir homogéneo. La ecuación 6.4 se puede escribir entonces:

$$
\begin{aligned}
\frac{\partial[\hat{C}(x)+\Delta C(x, t)]}{\partial t} & =\frac{D}{2} \frac{\partial^{2}[\hat{C}(x)+\Delta C(x, t)]}{x^{2}} \exp \frac{E^{\circ}+\Delta E(t)}{E^{*}} \pm \\
& \pm \frac{D}{2 a} \frac{\partial[\hat{C}(x)+\Delta C(x, t)]}{\partial x} \exp \frac{E^{\circ}+\Delta E(t)}{E^{*}}
\end{aligned}
$$

para el estado estacionario considerando que en la ecuación $6.4 \mathrm{C}(\mathrm{x}, \mathrm{t})=\hat{\mathrm{C}}(\mathrm{x})$ y ya que

$$
\frac{\partial \hat{\mathrm{C}}(\mathrm{x})}{\partial \mathrm{t}}=0 \text { resulta: } \frac{\partial^{2} \hat{\mathrm{C}}(\mathrm{x})}{\partial \mathrm{x}^{2}} \pm \frac{1}{\mathrm{a}} \frac{\partial \hat{\mathrm{C}}(\mathrm{x})}{\partial \mathrm{x}}=0
$$

con lo que la ecuación 7.13 se puede escribir:

$$
\frac{\partial \Delta C(x, t)}{\partial t}=\frac{D}{2} \frac{\partial^{2} \Delta C(x, t)}{x^{2}} \exp \frac{E^{\circ}+\Delta E(t)}{E^{*}} \pm \frac{D}{2 a} \frac{\partial \Delta C(x, t)}{\partial x} \exp \frac{E^{\circ}+\Delta E(t)}{E^{*}}
$$


Como la amplitud de la perturbación $\Delta \mathrm{E}(\mathrm{t})$ es pequeña se puede realizar la siguiente aproximación: $\exp \left(\frac{\Delta \mathrm{E}(\mathrm{t})}{\mathrm{E}^{*}}\right) \cong\left[1+\frac{\Delta \mathrm{E}(\mathrm{t})}{\mathrm{E}^{*}}\right] \cong 1$

por lo que exp $\left[\frac{E^{\circ}+\Delta E(t)}{E^{*}}\right]=\exp \left(\frac{E^{\circ}}{E^{*}}\right)$

Con esta última consideración la ecuación 6.14 queda:

$\frac{\partial \Delta C(x, t)}{\partial t}=\frac{D}{2} \exp \left(\frac{E^{0}}{E^{*}}\right)\left[\frac{\partial^{2} \Delta C(x, t)}{x^{2}} \pm \frac{1}{a} \frac{\partial \Delta C(x, t)}{\partial x}\right]$

La transformada de Fourier arroja:

$j \omega \Delta C_{0}(x, \omega)=D^{\prime} \frac{\partial^{2} \Delta C_{0}(x, \omega)}{\partial x^{2}} \pm \frac{D^{\prime}}{a} \frac{\partial \Delta C_{0}(x, \omega)}{\partial x}$

donde $D^{\prime}=\frac{D_{0}}{2} \exp \left(\frac{E^{\circ}}{E^{*}}\right)$

La solución general de la ecuación diferencial 6.16 es:

$\Delta C_{0}(x, \omega)=A_{O} \exp \left(h_{1}^{\circ} x\right)+B_{0} \exp \left(h_{2}^{\circ} x\right)$

donde

$h_{1}^{\circ}=\frac{1 / a+\left(a^{-2}+4 j \omega / D^{\prime}\right)}{2} y h_{2}^{\circ}=\frac{1 / a-\left(a^{-2}+4 j \omega / D^{\prime}\right)}{2}$

considerando que la especie que transporta la corriente es una vacancia aniónica (signo + antes del término 1/a).

La solución general evaluada en $\mathrm{x}=0 \mathrm{y}$ dividida por $\Delta \mathrm{E}_{\mathrm{ext}}$ es:

$$
\frac{\Delta \mathrm{C}_{0}(0, \omega)}{\Delta \mathrm{E}_{\mathrm{ext}}}=\frac{\mathrm{A}_{\mathrm{o}}}{\Delta \mathrm{E}_{\mathrm{ext}}}+\frac{\mathrm{B}_{\mathrm{o}}}{\Delta \mathrm{E}_{\mathrm{ext}}}
$$

El flujo de $V_{O}$ ” evaluado en $x=0$ es: $J_{O}(0, t)=v_{\|}$por lo que considerando la ecuación 6.7 la corriente de transporte iónico puede escribirse: 
$I_{1}=2 F J_{0}(0, t)$

que mediante transformación de Fourier puede relacionarse a la impedancia según:

$\frac{1}{\mathrm{Z}_{\mathrm{I}}}=\frac{\Delta \mathrm{I}_{\mathrm{l}}}{\Delta \mathrm{E}_{\mathrm{ext}}}=2 \mathrm{~F} \frac{\Delta \mathrm{J}_{0}(0, \omega)}{\Delta \mathrm{E}_{\text {ext }}}$

Transformando la ecuación 6.3 y evaluándola en $x=0$ podemos escribir:

$\left.\Delta \mathrm{J}_{0}(\mathrm{x}, \omega)\right|_{\mathrm{x}=0}=-\left.\mathrm{D}^{\prime} \frac{\partial \Delta \mathrm{C}_{0}(\mathrm{x}, \omega)}{\partial \mathrm{x}}\right|_{\mathrm{x}=0}+\frac{\mathrm{D}^{\prime}}{\mathrm{a}} \Delta \mathrm{C}_{\mathrm{O}}(0, \omega)$

Derivando la solución general (ecuación 6.17) y evaluándola en $x=0$ se obtiene:

$\left.\frac{\partial \Delta C_{0}(x, \omega)}{\partial x}\right|_{x=0}=A_{0} h_{1}^{\circ} \exp \left(h_{1}^{\circ} x\right)+B_{0} h_{2}^{\circ} \exp \left(h_{2}^{\circ} x\right)_{x=0}=A_{0} h_{1}^{\circ}+B_{0} h_{2}^{\circ}$

que llevado a 6.20 junto con la expresión de $\Delta C_{0}(0, \omega)$ de la solución general para $x=0$ permite obtener la variación del flujo en la interfase $m-f$ con el potencial externo en el campo transformado:

$$
\frac{\Delta \mathrm{J}_{\mathrm{O}}(0, \omega)}{\Delta \mathrm{E}_{\mathrm{ext}}}=\frac{\mathrm{A}_{\mathrm{O}}}{\Delta \mathrm{E}_{\mathrm{ext}}} \mathrm{K}_{1}^{\circ}+\frac{\mathrm{B}_{\mathrm{O}}}{\Delta \mathrm{E}_{\mathrm{ext}}} \mathrm{K}_{2}^{\circ}
$$

donde $K_{1}^{\circ}=\left(\frac{1}{a}-h_{1}^{\circ}\right) D^{\prime}$ y $K_{2}^{\circ}=\left(\frac{1}{a}-h_{2}^{\circ}\right) D^{\prime}$

Combinando las ecuaciones 6.19 y 6.21 obtenemos la expresión de la impedancia del transporte iónico $Z_{1}$ en función de las constantes $A_{\circ}$ y $B_{O}$ :

$$
\frac{1}{Z_{1}}=2 F\left[\frac{\mathrm{A}_{\mathrm{o}}}{\Delta \mathrm{E}_{\text {ext }}} \mathrm{K}_{1}^{\circ}+\frac{\mathrm{B}_{\mathrm{o}}}{\Delta \mathrm{E}_{\mathrm{ext}}} \mathrm{K}_{2}^{\circ}\right]
$$

Debemos hacer uso finalmente de las condiciones de borde en la interfase f-s, es decir para $\mathrm{x}=\mathrm{L}$. Como se explicó previamente la condición de equilibrio para la reacción IV implica que esta interfase es no polarizable $\left(a_{3}=0\right)$ y por lo tanto la concentración de vacancias de 
oxígeno allí es una constante igual al valor estacionario de corriente continua. En consecuencia $\Delta C_{O}(L, \omega)=0$ y podemos escribir:

$$
\frac{\Delta \mathrm{C}_{\mathrm{o}}(\mathrm{L}, \omega)}{\Delta \mathrm{E}_{\mathrm{ext}}}=0=\left[\frac{\mathrm{A}_{\mathrm{o}}}{\Delta \mathrm{E}_{\mathrm{ext}}} \mathrm{h}_{3}^{\circ}+\frac{\mathrm{B}_{\mathrm{o}}}{\Delta \mathrm{E}_{\mathrm{ext}}} \mathrm{h}_{4}^{\circ}\right]
$$

donde $h_{3}^{\circ}=\exp \left(h_{1}^{\circ} L\right)$ y $h_{4}^{\circ}=\exp \left(h_{2}^{\circ} L\right)$

Resolviendo el sistema de ecuaciones $6.18,6.22$ y 6.23 se puede obtener la siguiente expresión:

$$
\frac{\Delta \mathrm{C}_{\mathrm{o}}(0, \omega)}{\Delta \mathrm{V}_{\text {ext }}}=\frac{1}{2 \mathrm{FZ}, \mathrm{D}^{\prime}}\left[\frac{1}{\frac{1}{2 \mathrm{a}}+\frac{\mathrm{y}_{\mathrm{O}}}{\tanh \left(\mathrm{y}_{\mathrm{O}} \mathrm{L}\right)}}\right]
$$

donde $Y_{0}=\frac{\left(a^{-2}+4 j \omega / D^{\prime}\right)^{1 / 2}}{2}$

Llevando este cociente a la expresión de la impedancia (ecuación 6.10) y despejando $Z_{\text {I }}$ resulta:

$$
\mathrm{Z}_{\mathrm{I}}=\mathrm{R}_{\mathrm{T}}-\frac{\mathrm{R}_{\mathrm{T}} \alpha_{\mathrm{O}}}{2 \mathrm{FD}}\left[\frac{1}{\frac{1}{2 \mathrm{a}}+\frac{\mathrm{y}_{\mathrm{O}}}{\tanh \left(\mathrm{y}_{\mathrm{O}} \mathrm{L}\right)}}\right]
$$

La ecuación 6.25 admite una simplificación cuando $4 j \omega / D^{\prime}>>a^{-2}$, es decir cuando $y_{0}=\sqrt{\frac{j \omega}{D^{\prime}}}$, quedando la expresión de la impedancia:

$$
Z_{1}=R_{T}+\frac{1}{\frac{1}{R_{1}}+\frac{(j \omega)^{1 / 2}}{\sigma_{O} \tanh \left[\frac{(j \omega)^{1 / 2}}{D^{1 / 2}} L\right]}}
$$

donde $R_{1}=\frac{-R_{T} \alpha_{O} 2 a}{2 F D^{\prime}}$ y $\sigma_{O}=\frac{-R_{T} \alpha_{O}}{2 F D^{1 / 2}}$ 
Cabe mencionar que $\alpha_{0}<0$ (ecuación 6.12) con lo cual $R_{1}$ y $\sigma_{0}$ son valores positivos.

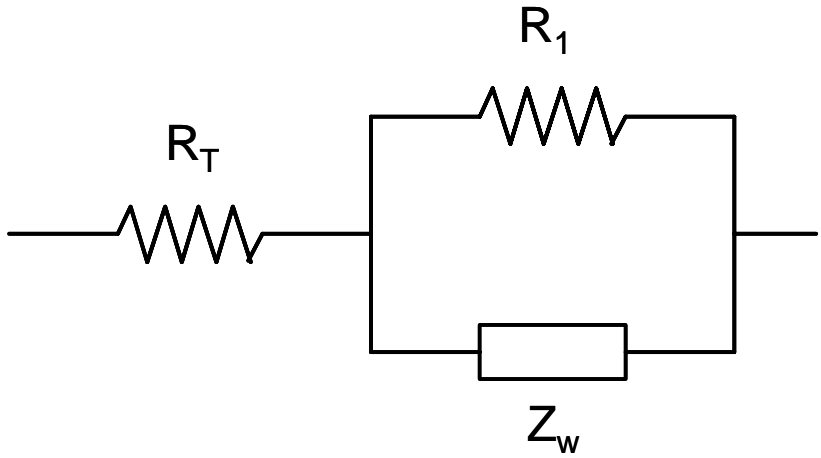

Figura 6.17. Circuito equivalente correspondiente a la ecuación 6.26.

La ecuación 6.26 puede representarse mediante el siguiente circuito equivalente, Figura 6.17, que corresponde a una conexión en serie entre la resistencia $\mathrm{R}_{\mathrm{T}}$ y el subcircuito paralelo entre la resistencia $R_{1}$ y la impedancia de difusión de espesor finito $Z_{W}$.

\section{Análisis de la impedancia $Z_{e}$}

Finalmente se necesita una expresión para $Z_{e}$ de la cual se podrán caracterizar las propiedades electrónicas de la película pasivante formada en buffer fosfato. Cabe destacar que la reacción de corrosión es una reacción redox del metal. En consecuencia no sólo el flujo iónico (la velocidad directa de corrosión) sino las propiedades de transporte electrónico a través del film pueden ser determinantes de la velocidad. La película formada sobre los aceros softmartensíticos $\left(\mathrm{Cr}_{2} \mathrm{O}_{3}\right.$ y $\left.\mathrm{Fe}_{2} \mathrm{O}_{3}\right)$ es un semiconductor tipo-n con un ancho de banda prohibida de aproximadamente $2 \mathrm{eV}$.

En ausencia de cuplas redox en solución $Z_{\mathrm{e}}$ está relacionada a la corriente desplazativa $I_{d}(t)$ [181]. Para el caso de oxidos pasivantes $I_{d}$ corresponde a la corriente de carga de la capacidad de Helmholtz $\left(\mathrm{C}_{\mathrm{H}}\right)$, de la capacidad del espacio de cargas debido a estados poco profundos $\left(\mathrm{C}_{\mathrm{sc}}\right)$ y la correspondiente a estados cuya energía cae en la banda prohibida. Estas dos últimas, entonces, corresponden a modos de acumulación de carga de estados en el óxido. Como $\mathrm{C}_{\mathrm{H}}$ y $\mathrm{C}_{\mathrm{sc}}$ representan dos contribuciones capacitivas en arreglo eléctrico serie y como en el caso de películas semiconductoras $\mathrm{C}_{\mathrm{sc}}<<\mathrm{C}_{\mathrm{H}}$, en la medida de la impedancia prevalece $C_{s c}$. Las constantes de tiempo de los procesos no faradaicos relacionados con $I_{d}$ son menores que, por ejemplo, la correspondiente al proceso de transporte iónico caracterizados por $\mathrm{I}_{1}$. De este modo en los espectros de impedancia los procesos electrónicos 
determinan la respuesta a las más altas frecuencias de medida. El modelo teórico utilizado para analizar esta región del espectro será brevemente presentado en términos de un circuito equivalente por razones de simplicidad. Sin embargo, esta aproximación no es satisfactoria sino se realiza el paso desde estimaciones de elementos macroscópicos de un buen circuito equivalente a estimaciones de valores de parámetros microscópicos. Esto requiere del desarrollo de un modelo matemático en términos de las ecuaciones microscópicas correspondientes, cuya impedancia es igual a la del circuito equivalente utilizado.

Antes de presentar los resultados es importante mencionar tres cuestiones finales:

1) En todos los casos se supuso que la $C_{s c} \ll C_{H}$ por lo cual la capacidad medida a las más altas frecuencias corresponde solo al espacio de cargas en el semiconductor, como que las dos capacidades se encuentran en serie en el sistema. Esto fue verificado, calculando $C_{H}$ en la zona de potenciales donde ésta domina la impedancia $Z_{e}$, es decir para valores del potencial más catódicos que el de banda plana.

2) Por otra parte, un cambio abrupto en la pendiente del diagrama de Mott-Schottky puede ser interpretado como la ionización de dopantes en la banda prohibida (estados electrónicos profundos) que a diferencia de los estados profundos anteriormente mencionados están asociados a un proceso que relaja rápido y por lo tanto no se manifiestan como una constante de tiempo adicional a menores frecuencias sino dentro de $\mathrm{C}_{\mathrm{sc}}$, ver Figuras 6.2 y 6.3 . La pendiente del diagrama de Mott-Schottky disminuye y es proporcional entonces a $\left(N_{D}+N^{\prime}{ }_{D}\right)^{-1}$ donde $N^{\prime}{ }_{D}$ son los estados profundos adicionales que se ionizan cuando el nivel de Fermi alcanza su propio nivel de energía durante el bias de potencial externo aplicado en sentido de engrosar la capa de agotamiento. Esta segunda región lineal, claro está, no puede ser extrapolada para obtener el $E_{b p}$. Este comportamiento ha sido informado en películas de óxidos formadas sobre acero inoxidable 304 en solución buffer de borato [182] y en películas pasivas formadas sobre acero inoxidable $316 \mathrm{~L}$ en solución buffer de borato, $\mathrm{pH} 8,4,[140]$.

3) Los parámetros derivados del ajuste a este circuito son dependientes del potencial pero independientes de la frecuencia de medida.

La impedancia debida a los procesos electrónicos puede ser escrita en consecuencia como: 


$$
\mathrm{Z}_{\mathrm{e}}=\frac{1}{\mathrm{j} \omega \mathrm{C}_{\mathrm{sc}}}
$$

Habiendo sido derivadas las expresiones de $Z_{1}$ y $Z_{e}$ se puede utilizar la ecuación 6.26 para describir en forma teórica la impedancia del sistema.

\subsubsection{Resultados de la impedancia de películas pasivantes de aceros inoxidables softmartensíticos}

La Figura 6.18 muestra espectros de impedancia para películas anódicas de aceros inoxidables softmartensíticos, muestras $\mathrm{E}$ y $\mathrm{M}$, formadas a diferentes potenciales en la zona de pasividad en solución. Se puede observar también en esta figura los resultados del ajuste por cuadrados mínimos no lineales y complejos de los datos experimentales utilizando el modelo general de la ecuación 6.5. La teoría y el experimento presentan un buen acuerdo en todo el rango de frecuencias de medida. 

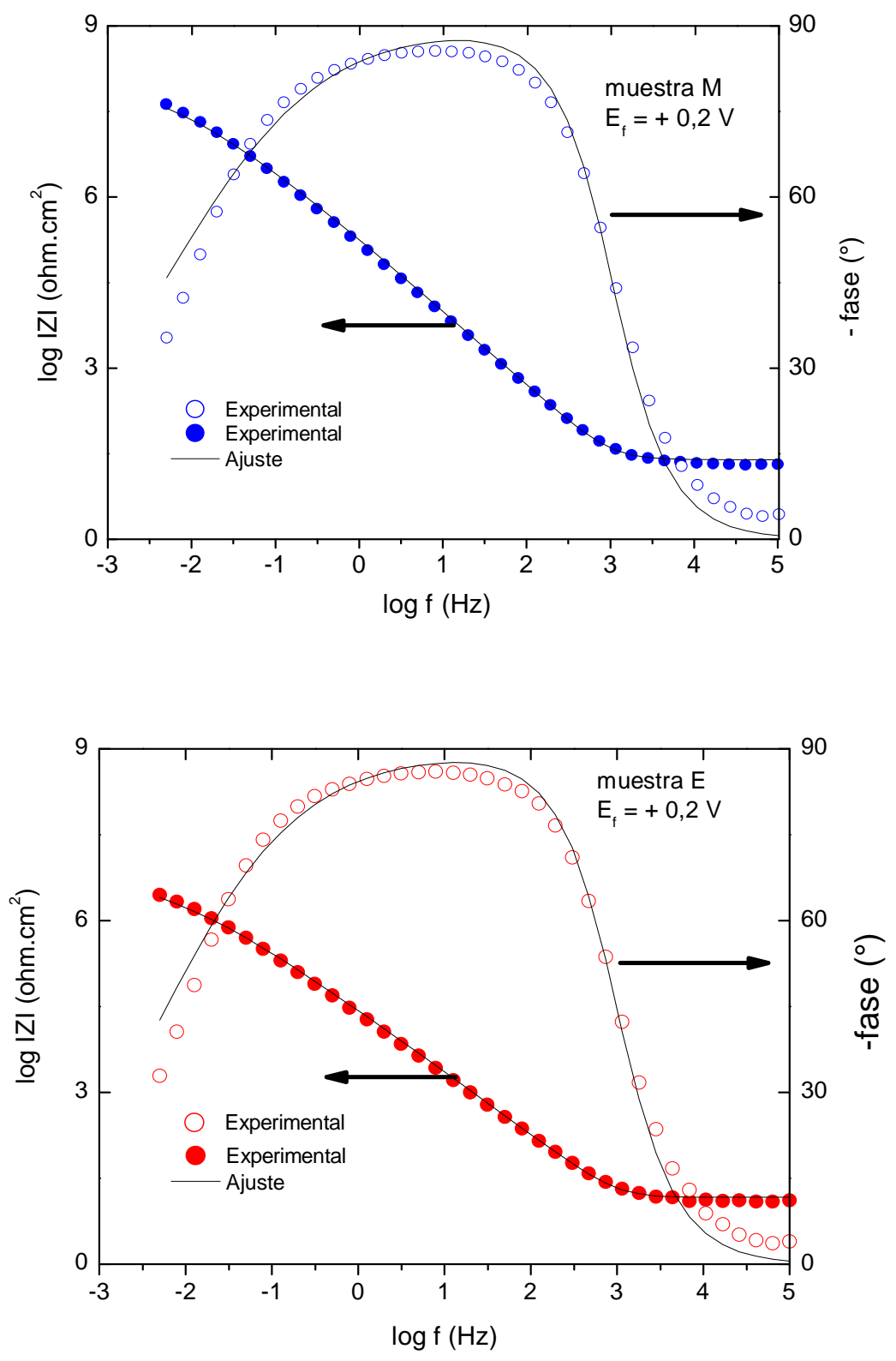

Figura 6.18. Diagramas de Bode para los aceros inoxidables softmartensíticos pasivados a un potencial de $0,2 \mathrm{~V}$ en solución buffer de fostato.

Se estimaron los valores de D' para distintos potenciales de formación de la película superficial a partir de los valores de $\sigma$ y $\mathrm{R}_{1}$ generados mediante ajuste paramétrico a la ecuación 7.5. Asumiendo un valor de $a=310^{-8} \mathrm{~cm}[140]$ resulta $E^{*}=2,1410^{5} \mathrm{Vcm}^{-1}$ y $E^{\circ}=$ $2,1 \cdot 10^{6} \mathrm{Vcm}^{-1}$ para la muestra $\mathrm{E} \mathrm{y}^{0}=8,6.10^{5} \mathrm{Vcm}^{-1}$ para la muestra $\mathrm{M}$ (obtenido de la figura 4.17) con lo cual se pueden calcular valores del coeficiente de difusión de vacancias de oxígeno $D_{0} \approx 10^{-21}-10^{-19} \mathrm{~cm}^{2} \mathrm{~s}^{-1}$ que son razonablemente independientes del potencial de formación $E_{f}=\hat{E}_{e x t}$. Valores comparables a Point Defect Model for Anodic Passive Films [157]. 
En general las películas pasivas consisten de dos capas, una capa barrera interna delgada y una externa hidratada que se puede extender hasta distancias significativas de la superficie dependiendo del sistema considerado. La capa externa se forma a partir de los cationes metálicos expulsados de la capa barrera que eventualmente hidrolizan y precipitan como una fase de hidróxido sobre ésta. La impedancia total está dominada por la capa barrera ya que es difícil que una estructura abierta de un hidróxido como la de la capa externa pueda ofrecer suficiente resistencia al movimiento iónico para explicar la pasividad [160]. De este modo mientras la impedancia puede sensar solo el espesor de la capa barrera (que varía linealmente con el potencial de formación) la carga de electrorreducción obtenida por aplicación de escalones galvanostáticos, alcanza también a la película externa. Esto permitiría explicar la diferencia en los valores de espesor calculados por las dos técnicas de medida para potenciales muy anódicos, ya que para un potencial de formación de película de $0,5 \mathrm{~V}$ los valores de espesores a través de medidas de impedancia nos dan $52,5 \AA$ para la muestra $M$ y $14,6 \AA$ para la muestra $E$, mientras las medidas de electrorreducción son mayores los espesores, $150 \AA ̊$ y $48 \AA ̊$ para las muestras M y E respectivamente. 


\section{CAPÍTULO 7}

\section{Conclusiones}

De acuerdo a los objetivos planteados y al desarrollo del presente trabajo de tesis se pueden extraer las siguientes conclusiones:

- En el estudio de la corrosión por picado es altamente recomendable adoptar un enfoque estocástico para el tratamiento de datos caracterizados por un alto grado de aleatoriedad como lo son el potencial de picado y el potencial de repasivación.

- La resistencia al picado del metal de soldadura $13 \mathrm{CrNiMo}$ puede ser fuertemente afectado por los cambios microestructurales inducidos por los tratamientos térmicos. Siendo el número y tamaño de carburos o carbonitruros así como el porcentaje de austenita retenida los factores microestructurales más relevantes.

- El borde de grano entre partículas de carburo y la matriz del metal puede actuar como sitio de nucleación de picaduras. Los potenciales característicos (potencial de picado y potencial de repasivación) se desplazan hacia valores más nobles de acuerdo al contenido de austenita retenida. Estos resultados pueden entenderse en términos de un proceso de refinamiento estructural como producto de la aplicación de un tratamiento térmico de doble revenido.

- Existe una correlación directa entre la fracción en volumen de austenita retenida en la aleación y la resistencia al picado. Por lo tanto, la calificación de procedimientos de soldadura debe estar basado no solo en la evaluación de las propiedades en servicio sino también en el exámen microestructural de la soldadura.

- La presencia y contenido de austenita retenida como componente microestructural resultante de la aplicación de tratamientos térmicos tiene un efecto beneficioso en la resistencia a la corrosión por picado de los aceros inoxidables $13 \mathrm{CrNiMo}$. Cuando el contenido de austenita retenida se encuentra en $20-25 \%$ en volumen, tanto en la forma de metal base cuanto como metal de soldadura, exhiben valores comparables de resistencia a la corrosión por picado, dando no sólo potenciales críticos similares para el crecimiento de la picadura estable, sino que también exhiben análoga cinética de repasivación. 
- El espesor y la estructura de las películas anódicas formadas sobre los aceros inoxidables softmartensíticos se encuentran influenciados por los tratamientos térmicos a los cuales se someten previamente las aleaciones, provocando modificaciones en sus microestructuras. Por lo tanto, las microestructuras con alto contenido de austenita retenida previenen la precipitación de cromo manteniendo un mayor contenido del mismo en solución sólida y permitiendo la obtención de mayores espesores de película anódica. Por otro lado, considerando los resultados previos donde se muestra el incremento de la resistencia al picado en medios clorurados para las aleaciones con alto contenido de austenita retenida, y comparándolos con aquellos de menor contenido de austenita retenida, se puede inferir que las propiedades de la película pasivante mejoran con el tratamiento térmico para los aceros inoxidables softmartensíticos. El beneficio de la microestructura generada con el tratamiento térmico también se vincula con las altas velocidades de formación de la película anódica. Los resultados presentados permiten discutir un probable mecanismo de electrorreducción de los productos anódicos superficiales. La estructura sandwich o de doble capa aceptada como la estructura de la película anódica para otros aceros inoxidables se confirmó para las aleaciones aquí estudiadas.

- Las características de conducción electrónica en las películas anódicas en aceros inoxidables martensíticos $13 \mathrm{CrNiMo}$ con bajo C están afectadas por el tratamiento térmico aplicado a través de modificaciones microestructurales como aumento del tenor de austenita retenida y de $\mathrm{Cr}$ en solución. Estas características, a su vez, impactan en la susceptibilidad a la corrosión localizada.

- Defectos catiónicos intersticiales de Fe o vacancias de oxígeno son las especies donoras que determinan un modo de semiconducción electrónica tipo n. Una mayor concentración de defectos puntuales poco profundos en el óxido, formado sobre un sustrato metálico con bajo contenido de austenita retenida en su microestructura, se corresponde con una estructura más defectuosa de la capa pasivante y una mayor tendencia a la nucleación de picaduras.

- El mayor contenido de $\mathrm{Cr}$ en la película pasiva formada sobre muestras con mayor contenido de austenita retenida en la microestructura del sustrato metálico también explica su mayor resistencia a la corrosión localizada frente a la de la condiciones con menor contenido de austenita retenida. Los tratamientos térmicos post soldadura sobre el metal 
base producen en ellos la precipitación de austenita retenida, en diversos porcentajes de acuerdo a las condiciones de tratamiento.

En futuros trabajos se planea estudiar el comportamiento de estos materiales, sometidos a tensión de tracción, en medios clorurados y sulfurados, y analizar la influencia del contenido de austenita retenida en los mismos. 


\section{Bibliografía}

[1] W. Gysel, G-X5Cr Ni 13 4: Neuentwicklungen auf der Basis von 20 Jahren Erfahrung, Konstruieren and GieBen. 7 (1982) 16-33.

[2] H. Van DerWinden, P. Toussaint, CoudreuseL., Past, present and future of weldable supermartensitic alloys, in: Supermartensitic Stainless Steel, 2002: pp. 1-7.

[3] J.C.M. Farrar, Super Martensitic Stainless Steels - Overview and Weldability, IIW Doc. IX-H423 (1998).

[4] A.W. Marshal, J.C.M. Farrar, Welding of Ferritic and Martensitic $13 \% \mathrm{Cr}$ Steels, IIW Doc. IX-H422 (1998).

[5] P. Woollin, D. Carrouge, Heat affected zone microstructures in supermartensitic stainless steels, in: Supermartensitic Stainless Steels, 2002.

[6] J.C.M. Farrar, The alloy tree - A guide to low-alloy steels, stainlees steels and nickelbase alloys, Woodhead publishing limited, 2005.

[7] P. Brezina, Martensitic CrNi steels with low carbon content, Escher Wyss News, 1980.

[8] E. Folkhard, G. Rabensteiner, Welding metallurgy of stainless steels, Springer-Verlag, New York, 1988.

[9] R.D. Kane, M. Watkins, J.B. Greer, Improvement of Sulfide Stress Cracking Resistance of 12\% Chromium Stainless Steels Through Heat Treatment, Corrosion. 33 (1977) 231.

[10] H. Niederau, Present state of the development of stainless soft martensitic chromiumnickel steels with special consideration of steel X5 CrNi 13 4, Stahl Und Eisen. 98 (1978) 385-392.

[11] C.A. Gervasi, P.. Bilmes, C.L. Llorente, Metallurgical factors affecting localized corrosion of low-C 13CrNiMo martensitic stainless steels, in: E.I.S. WNG (Ed.), CORROSION RESEARCH TRENDS, 2007: pp. 1-34.

[12] P.D. Bilmes, Rol de la austenita en las propiedades mecánicas de metales de soldadura de aceros inoxidables soft martensíticos, Facultad de Ingeniería, University of La Plata, 2000.

[13] A. Kulmburg, F. Korntheuer, O. Grundler, K. Hutterer, Umwand-lungsund Ausscheidungsverhalten von Weichmartensitischen und Hochfesten Korrosionsbeständigen Stählen, Berg. U. Huttenm. Mh. 126 (1981) 104-108.

[14] M.C. Balmforth, J.C. Lippold, A new ferritic-martensitic stainless steels constitution diagram, Welding Journal. 79 (2000) 339-345. 
[15] C. Leymonie, M.C. Lecocq, M.C. Ottmann, Relations entre la Structureet les Proprietes Mecaniques de Deux Aciers a 16\%Cr - 4\%Ni, Traitement Thermiques. 165 (1982) 5762.

[16] P. Brezina, E. Erdoes, T. Geirger, L. Habel, M. Loresnz, Contribution to the Methodology of Phase Analysis in Commercial Alloys - 1., Prakt. Metallog. 10 (1973) 343-357.

[17] X.P. Ma, L.J. Wang, C.M. Liu, S.V. Subramanian, Microstructure and properties of $13 \mathrm{Cr} 5 \mathrm{Ni} 1 \mathrm{Mo0} .025 \mathrm{Nb} 0.09 \mathrm{~V} 0.06 \mathrm{~N}$ super martensitic stainless steel, Materials Science and Engineering: A. 539 (2012) 271-279.

[18] G. Rabensteiner, E. Pertender, J. Tösch, Optimierung von weichmartensitischen Chrom-Nickel-Schweißgutlegierungen für den Einsatz im Kernreaktorbau, DVSBerichte Band. 75 (1982) 261-265.

[19] W. Gysel, E. Gerbes, A. Trautwein, CA6NM: New Developments Based on 20 Years'Experience, in: V.G. Behal, A.S. Melilli (Eds.), Stainless Steels Casting, 1982: pp. 403-435.

[20] W. Gysel, I. Seydl, Report Nº3, 1971.

[21] P.D. Bilmes, M. Solari, C.. Llorente, Characteristics and effects of austenite resulting from tempering of $13 \mathrm{Cr}-\mathrm{NiMo}$ martensitic steel weld metals, Materials Characterization. 46 (2001) 285-296.

[22] C.. Apple, G. Krauss, The effect of heating rate on the martensite to austenite transformation in Fe-Ni-C alloys, Acta Metallurgica. 20 (1972) 849-856.

[23] P. Monnartz, Beitrag sum studium der eisenchromlegierungen unter besonderer Berücksichtigung der Säurebeständigkeit, Metallurgie. 8 (1911) 161-176,193-203.

[24] W.R. Cieslak, D.J. Duquette, Properties of the Passive Films Formed on Ferritic Stainless Steels in Cl - Solutions,, Corrosion. 40 (1984) 545-549.

[25] T. Ohtsuka, Passivation Oxide Films and Rust Layers on Iron, in: Y. Waseda, S. Suzuki (Eds.), Characterization of Corrosion Products on Steel Surfaces, 2006: pp. 19-31.

[26] U.F. Franck, No Title, Corr. Et Anticorrosion. 7 (1959).

[27] K.J. Vetter, Electrochemical Kinetics: Theoretical and Experimental Aspects, Academic P, New York, 1967.

[28] M.G. Fontana, Surface Studies of Metals from the Corrosion Standpiont, Corrosion. 3 (1947) 567-579.

[29] E.M. Mahla, N.A. Nielsen, Passivation of stainless steels, Trans. Electrochem. Soc. 93 (n.d.). 
[30] I. Olefjord, B.-O. Elfstrom, Composition of the Surface During Passivation of Stainless Steels, Corrosion. 38 (1982) 46-52.

[31] V. Maurice, W.P. Yang, P. Marcus, XPS and STM Study of Passive Films Formed on Fe22Cr(110) Single Crystal Surfaces, J. Electrochem. Soc. 143 (1996) 1182-1200.

[32] H.H. Uhlig, Passivity in metals and alloys, Corrosion Science. 19 (1979) 777-791.

[33] N. Sato, An overview on the passivity of metals, Corrosion Science. 31 (1990) 1-19.

[34] J.W. Schultze, M.M. Lohrengel, Stability, reactivity and breakdown of passive films. Problems of recent and future research, Electrochimica Acta. 45 (2000) 2499-2513.

[35] R. Kirchheim, B. Heine, S. Hofmann, H. Hofsäss, Compositional changes of passive films due to different transport rates and preferential dissolution, Corrosion Science. 31 (1990) 573-578.

[36] H.-H. Strehblow, Paper no. 5, in: Corrosion and Prevention '97, 1997.

[37] C.-O. Olsson, D. Landolt, Passive films on stainless steels-chemistry, structure and growth, Electrochimica Acta. 48 (2003) 1093-1104.

[38] S. Haupt, H.-H. Strehblow, A combined surface analytical and electrochemical study of the formation of passive layers on FeCr alloys in $0.5 \mathrm{M} \mathrm{H} 2 \mathrm{SO} 4$, Corrosion Science. 37 (1995) 43-54.

[39] H.W. Hoppe, S. Haupt, H.-H. Strehblow, Combined surface analytical and electrochemical study of the formation of passive layers on $\mathrm{Fe} / \mathrm{Cr}$ alloys in $1 \mathrm{M} \mathrm{NaOH}$, Surface and Interface Analysis. 21 (1994) 514-525.

[40] L. Wegrelius, I. Olefjord, No Title, in: 12th International Corrosion Congress -NACE, 1993: p. 3887.

[41] V. Maurice, W.P. Yang, P. Marcus, X Ray Photoelectron Spectroscopy and Scanning Tunneling Microscopy Study of Passive Films Formed on (100) Fe-18Cr-13Ni Single-Crystal Surfaces, J. Electrochem. Soc. 145 (1998) 909-920.

[42] J.A. Bardwell, G.I. Sproule, B. MacDougall, M.J. Graham, A.J. Davenport, H.S. Isaacs, In Situ XANES Detection of $\mathrm{Cr}(\mathrm{VI})$ in the Passive Film on Fe26Cr, J. Electrochem. Soc. 139 (1992) 371-373.

[43] H.-H. Strehblow, Breakdown of passivity an localized corrosion: Theoretical concepts and fundamental esperimental results RESULTS, Werkstoffe Und Korrosion. 35 (1984) 437-448.

[44] P. Marcus, J.M. Grimal, The anodic dissolution and passivation of NiCrFe alloys studied by ESCA, Corrosion Science. 33 (1992) 805-814. 
[45] B. Brox, I. Olefjord, ., in: Stainless Steel 1984, Gothenburg, Sweden, 1984: p. 134.

[46] I. Olefjord, L. Wegrelius, Surface analysis of passive stat, Corrosion Science. 31 (1990) 89-98.

[47] S. Mischler, A. Vogel, H.J. Mathieu, D. Landolt, The chemical composition of the passive film on Fe24Cr and Fe24Cr11Mo studied by AES, XPS and SIMS, Corrosion Science. 32 (1991) 925-944.

[48] V. Mitrovic-Scepanovic, B. MacDougall, M.J. Graham, The effect of Cl-ions on the passivation of Fe26Cr alloy, Corrosion Science. 27 (1987) 239-247.

[49] C. Hubschmid, D. Landolt, H.J. Mathieu, XPS and AES analysis of passive films on Fe25Cr-X (X = Mo, V, Si and Nb) model alloys, FRESENIUS' JOURNAL OF ANALYTICAL CHEMISTRY. 353 (1995) 234-239.

[50] P. Schmutz, D. Landolt, In-situ microgravimetric studies of passive alloys: potential sweep and potential step experiments with $\mathrm{Fe}-25 \mathrm{Cr}$ and $\mathrm{Fe}-17 \mathrm{Cr}-33 \mathrm{Mo}$ in acid and alkaline solution, Corrosion Science. 41 (1999) 2143-2163.

[51] K.E. Heusler, Growth and dissolution of passivating films, Corrosion Science. 31 (1990) 597-606.

[52] S. Haupt, C. Calinski, U. Collisi, H.-W. Hoppe, H.-D. Speckmann, H.-H. Strehblow, XPS AND ISS EXAMINATION OF ELECTRODE SURFACES AND PASSIVE LAYERS WITH A SPECIMEN TRANSFER IN A CLOSED SYSTEM., Surface and Interface Analysis. 9 (1986) 357-365.

[53] R.D. Willenbruch, C.R. Clayton, M. Oversluizen, D. Kim, Y. Lu, An XPS and electrochemical study of the influence of molybdenum and nitrogen on the passivity of austenitic stainless steel, Corrosion Science. 31 (1990) 179-190.

[54] P.J. Uggowitzer, R. Magdowski, M.O. Speidel, Nickel Free High Nitrogen Austenitic Steels, ISIJ International. 36 (1996) 901-908.

[55] B. Wallén, M. Liljas, P. Stenvall, Avesta 654 SMO -a new high molybdenium, in: 12Th Scandinavian Corrosion Congress - Eurocorr 92, 1992: pp. 81-89.

[56] C.-O.A. Olsson, S.E. Hörnström, An AES and XPS study of the high alloy austenitic stainless steel $254 \mathrm{SMO}^{\circledR}$ tested in a ferric chloride solution, Corrosion Science. 36 (1994) 141-151.

[57] C.L. McBee, J. Kruger, Nature of passive films on iron-chromium alloys, Electrochimica Acta. 17 (1972) 1337-1341.

[58] E.J.W. Verwey, ., Physica. 2 (1935) 1059. 
[59] C.Y. Chao, L.F. Lin, D.D. Macdonald, A Point Defect Model for Anodic Passive Films: I . Film Growth Kinetics, J. Electrochem. Soc. 128 (1981) 1187-1194.

[60] L.F. Lin, C.Y. Chao, D.D. Macdonald, A Point Defect Model for Anodic Passive Films: II . Chemical Breakdown and Pit Initiation, J. Electrochem. Soc. 128 (1981) 1194-1198.

[61] D.D. Macdonald, M. Al Rifaie, G.R. Engelhardt, New Rate Laws for the Growth and Reduction of Passive Films, J. Electrochem. Soc. 148 (2001) B343-B347.

[62] D.D. Macdonald, L. Zhang, E. Sikora, J. Sikora, No Titl, in: Passivity and Its Breakdown : Proceedings of the Symposium on Passivity and Its Breakdown, The Electr, 1997: p. 411.

[63] D.D. Macdonald, M.U. Macdonald, Theory of Steady-State Passive Films, J. Electrochem. Soc. 137 (1990) 2395-2402.

[64] D.D. Macdonald, The Point Defect Model for the Passive State, J. Electrochem. Soc. 139 (1992) 3434-3449.

[65] L. Zhang, On the Kinetics of Growth of Anodic Oxide Films, Journal of The Electrochemical Society. 145 (1998) 898.

[66] D. Callister, J. William, Materials Science and Engineering an Introduction, New York, 1999.

[67] J. Pleva, S. Nordin, Properties of Different MMA Welds on Modified Type 329 FerriticAustenitic Stainless Steel, in: Duplex Stainless Steels '82', 1982: pp. 603-629.

[68] K. Kondo, K. Ogawa, H. Amaya, M. Ueda, H. Ohtani, Development of Weldable Super 13Cr Martensitic Stainless Steel for Flowline, in: Proceedings of The Twelfth (2002) International Offshore and Polar Engineering Conference, 2002: pp. 303-309.

[69] K. Kondo, K. Ogawa, H. Amaya, H. Hirata, Alloy Design of Super 13 Cr Martensitic Stainless Steel, in: Supermartensitic Stainless Steels '99, Belgium, 1999: pp. 11-18.

[70] 2001 Nace International, Sulphide Stress Cracking Resistant Metallic Materials for Oilfield Equipment, in: Standard MR0175, 2001.

[71] J.M. Drugli, T. Rogne, M. Svenning, S. Axelsen, The effect of buffered solutions in corrosion testing of alloyed $13 \% \mathrm{Cr}$ martensitic steels for mildly sour applications, in: Corrosion 99, Houston, 1999: p. Paper No. 586.

[72] S. Sakamoto, K. Maruyama, H. Kaneta, Corrosion Property of API and Modified $13 \mathrm{Cr}$ Steels in Oil and Gas Field Environment, in: Corrosion 96, Houston, 1996: p. paper $\mathrm{n}^{\circ}$ 77.

[73] H. Asahi, T. Hara, M. Sugiyama, Corrosion performance of modified $13 \mathrm{Cr}$ OCTG, in: Corrosion 96, Houston, 1996: p. paper $n^{\circ} 61$. 
[74] S. Hashizume, Y. Inohara, Y. Minami, K. Masamura, Paper No. S99-36, in: Supermartensitic Stainless Steels 99, Belgian, 1999: p. 307.

[75] M. Kimura, Y. Miyata, T. Toyooka, Y. Kitahaba, Effect of Retained Austenite on Corrosion Performance for Modified 13\% Cr Steel Pipe, in: Corrosion 2000, 2000: p. paper $n^{0} 137$.

[76] M. Kimura, Y. Miyata, T. Toyooka, Y. Kitahaba, Effect of Retained Austenite on Corrosion Performance for Modified 13\% Cr Steel Pipe,, Corrosion. 57 (2001) 433439.

[77] C.T. Kwok, H.C. Manb, F.T. Cheng, Cavitation erosion and pitting corrosion behaviour of laser surface-melted martensitic stainless steel UNS S42000, Surface and Coatings Technology. 126 (2000) 238-255.

[78] M. Ueda, H. Amaya, K. Ogawa, K. Kondo, T. Mori, Corrosion Resistance of Weldable Super $13 \mathrm{Cr}$ Stainless Steel in H2S Containing CO2 Environments, in: Corrosion 96, 1996: p. Paper No. 58.

[79] D. Abayarathna, R.D. Kane, Definition of Safe Use Limits for Use of Stainless Alloys in Petroleum Production, in: Corrosion 97, 1997: p. paper $n^{\circ} 34$.

[80] R. Case, R.C. Newman, S. Olsen, G. Rorvik, Pit Growth Behaviour of Modified $13 \mathrm{Cr}$ Steel in Sour Environments, in: Eurocorr 2000, 2000.

[81] P. Felton, M.J. Schofleld, Extending of limits of corrosion behaviour of modified $13 \% \mathrm{Cr}$ martensitic OCTG at high temperatures, in: Supermartensitic Stainless Steels'99, 1999: p. paper $n^{\circ} 32$.

[82] S. Huizinga, W.E. Liek, Corrosion Behavior of $13 \%$ Chromium Steel in Acid Stimulations, Corrosion. 50 (1994) 555-566.

[83] A. Turnbull, M. Saenz de Santa, N.D. Thomas, The effect of H2S concentration and $\mathrm{pH}$ on hydrogen permeation in AISI 410 stainless steel in $5 \% \mathrm{NaCl}$, Corrosion Science. 29 (1989) 89-91,93-104.

[84] M. Ueda, T. Kudo, Evaluation of SCC resistance of CRAs in sour service, in: Corrosion 91, 1991: p. paper $n^{\circ} 2$.

[85] J.M. Aquino, C.A. Della Rovere, S.E. Kuri, Localized Corrosion Susceptibility of Supermartensitic Stainless Steel in Welded Joints, Corrosion. 64 (2008).

[86] S. Olsen, P.E. Kvaale, J. Enerhaug, Experience in the use of EFC-17 for qualification of supermartensitic stainless steel girth welds, in: Supermartensitic Stainless Steels 99, 1999: p. paper $n^{\circ} 10$. 
[87] P.D. Bilmes, C.L. Llorente, L. Saire Huamán, L.M. Gassa, C.A. Gervasi, Microstructure and pitting corrosion of $13 \mathrm{CrNiMo}$ weld metals, Corrosion Science. 48 (2006) 32613270.

[88] M.D. Pereda, C. a. Gervasi, C.L. Llorente, P.D. Bilmes, Microelectrochemical corrosion study of super martensitic welds in chloride-containing media, Corrosion Science. 53 (2011) 3934-3941.

[89] J.M. Aquino, C. a. Della Rovere, S.E. Kuri, Intergranular corrosion susceptibility in supermartensitic stainless steel weldments, Corrosion Science. 51 (2009) 2316-2323.

[90] N. Anselmo, J.E. May, N.A. Mariano, P.A.P. Nascente, S.E. Kuri, Corrosion behavior of supermartensitic stainless steel in aerated and CO 2 -saturated synthetic seawater, 428 (2006) 73-79.

[91] G. Fierro, G.M. Ingo, F. Mancia, Corrosion Behavior of $13 \%$ Cr Martensitic Stainless Steel in CO2-H2S-Cl- Environments, Corrosion. 45 (1989) 814-823.

[92] T.R. Beck, R.C. Alkire, Occurrence of Salt Films during Initiation and Growth of Corrosion Pits, Journal of The Electrochemical Society. 126 (1979) 1662-1666.

[93] H.S. Isaacs, G. Kissel, Surface Preparation and Pit Propagation in Stainless Steels, Journal of The Electrochemical Society. 119 (1972) 1628-1632.

[94] S. Scheiner, C. Hellmich, Stable pitting corrosion of stainless steel as diffusioncontrolled dissolution process with a sharp moving electrode boundary, Corrosion Science. 49 (2007) 319-346.

[95] J. Enerhaug, U.M. Steinsmo, O. Grong, L.R. Hellevik, J.E. Soc, P. B-b, Dissolution and Repassivation Kinetics of a 12 . 3Cr-2 . 6Mo-6 . 5Ni Super Martensitic Stainless Steel : A Comparative Study service, Journal of The Electrochemical Society. 149 (2002) 256264.

[96] J. Enerhayg, O. Grong, U.M. Steinsmo, Factors affecting initiation of pitting corrosion in super martensitic stainless steel weldments,, Science and Technology of Welding and Joining. 6 (2001) 330-338.

[97] H.M. Rietveld, Line Profiles of Neutron Powder-diffraction Peaks for Structure Refinement, Acta Cryst. 22 (1967) 151-152.

[98] B.D. Cullity, Elements of X-rayDiffraction, 1978.

[99] C. Rodriguez, FULLPROF: A Program for Rietveld Refinement and Pattern Matching Analysis, in: Satellite Meeting on PowderDiffraction on the XV Congress of the IUCr, 1990: p. 127

[100] G.S. Frankel, Pitting Corrosion of Metals A Review of the Critical Factors, J. Electrochem. Soc. 145 (1998) 2186-2198. 
[101] S. Hashizume, K. Masamura, I. Matsushima, Pitting corrosion resistance of $13 \% \mathrm{Cr}$ steel in oil field environments, Trans. ISIJ. 23 (1993) B351.

[102] H.P. Leckie, H.H. Uhlig, Environmental Factors Affecting the Critical Potential for Pitting in 18-8 Stainless Steel, J. Electrochem. Soc. 113 (1966) 1262-1267.

[103] Y. Zuo, H. Wang, J. Zhao, J. Wiong, The effects of some anions on metastable pitting of 316L stainless steel, Corrosion Science. 44 (2002) 13-24.

[104] Tor Hurlen, Passive behaviour of Tin, Electrochemica Acta. 39 (1994) 1359-1364.

[105] J.E.B. Randles, Kinetics of rapid electrode reactions, Discuss. Faraday Soc. 1 (1947) 1119.

[106] N. Sato, Electrochemistry at metal and semiconductor electrodes, 1998.

[107] I. Nicic, D.D. Macdonald, The passivity of Type 316L stainless steel in borate buffer solution, Journal of Nuclear Materials. 379 (2008) 54-58.

[108] D.D. Macdonald, Passivity -the key to our metals- based civilization, Pure Appl.Chem. 71 (1999) 951-978.

[109] P. Schmuki, H. Böhni, Illumination effects on the stability passive film on iron, Electrochimica Acta. 40 (1995) 775-783.

[110] A.J. Sedriks, Corrosion of Stainless Steels, 1996.

[111] G.S. Frankel, Corrosion: Fundamentals, Testing and Protection - Vol13 A, ASM Handbook, ASM International, 2003.

[112] P.D. Bilmes, C. Llorente, J. Desimoni, R. Mercader, M. Solari, Microestructuras y propiedades de metales de soldadura FCAW de aceros inoxidables soft martensíticos, in: II Encuentro De Ingeniería De Materiales, La Habana, Cuba, 1998.

[113] P.D. Bilmes, C. Llorente, M. Solari, Efecto de los tratamientos térmicos post soldadura sobre depósitos FCAW de aceros $13 \% \mathrm{Cr} 4 \% \mathrm{NiMo}$, in: V Congreso Iberamericano De Soldadura, Buenos Aires, Argentina, 1999.

[114] D.E. Williams, R.C. Newman, Q. Son, R.G. Kelly, Passivity breakdown and pitting corrosion of binary alloy, Nature. 350 (1991) 216-219.

[115] M.P. Ryan, N.J. Laycock, R.C. Newman, H.S. Isaacs, The pitting behavior of ironchromium thin film alloys in hydrochloric acid, Journal of The Electrochemical Society. 145 (1998) 1566-1571.

[116] H.-H. Strehblow, Pitting Corrosion, in: M. Stratmann, G.S. Frankel (Eds.), Encyclopedia of Electrochemistry, 2003: pp. 308-343. 
[117] K. Sugimoto, Characterization of Corrosion Products on Steel Surfaces, Chapter 1, in: S. Suzuki, Y. Waseda (Eds.), Advances in Materials Research, Vol. 7, 2006.

[118] T. Shibata, T. Takeyama, Stochastic Theory of Pitting Corrosion, Corrosion. 33 (1977) 243-251.

[119] B.E. Wilde, A Critical Appraisal of Some Popular Laboratory Electrochemical Tests for Predicting the Localized Corrosion Resistance of Stainless Alloys in Seawater, Corrosion. 28 (1972) 283-291.

[120] C.A. Gervasi, P.D. Bilmes, C.L. Llorente, Chapter 1, in: I.S. Wang (Ed.), Corrosion Research Trends, 2007: pp. 1-34.

[121] M. Kimura, Y. Miyata, T. Toyooka, Y. Kitahaba, Effect of Retained Austenite on Corrosion Performance for Modified 13\% Cr Steel Pipe,, Corrosion. 51 (2001) 433439.

[122] C. Giacomelli, F.C. Giacomelli, R.L. Bortolluzzi, A. Spinelli, Properties of potentiostatic passive films grown on iron electrodes immersed in weak-alkaline phosphate solutions, Anti-Corrosion Methods and Materials. 53 (2006) 232-239.

[123] J.-H. Wang, C.C. Su, Z. Szklarska-Smialowska, Effects of Cl- Concentration and Temperature on Pitting of AISI 304 Stainless Steel, Corrosion. 44 (1988) 732-737.

[124] H. Kaesche, Metallic Corrosion, 2da ed., 1985.

[125] D.D. Macdonald, On the tenuous nature of passivity and its role in the isolation of HLNW, Journal of Nuclear Materials. 379 (2008) 24-32.

[126] M. Pourbaix, Atlas of Electrochemical Equilibria in Aqueous Solutions, 1974.

[127] C.-C. Shih, C.-M. Shih, Y.-Y. Su, L.H.J. Su, M.-S. Chang, S.-J. Lin, Effect of surface oxide properties on.pdf, Corrosion Science. 46 (2004) 427-441.

[128] G.O. llevbare, G.T. Burstein, The inhibition of pitting corrosion of stainless steels by chromate and molybdate ions, Corrosion Science. 45 (2003) 1545-1569.

[129] N.M. S. Fujimoto, T. Shibata, Improvement of Localized Corrosion Resistance of Austenitic Stainless Steel by $\mathrm{N}, \mathrm{Cr}$ and $\mathrm{Mo}$, in: Ion Implantation Technology Proceedings, 1999: pp. 1074-1077.

[130] H.-H. Strehblow, Passivity of Metals, in: R.C. Alkire (Ed.), Advances in Electrochemical Science and Engineering - Vol.8, 2002: pp. 271-374.

[131] K. Ogura, T. Majima, Formation and reduction of the passive film on iron in phosphate-borate buffer solution, Electrochimica Acta. 23 (1978) 1361-1365.

[132] D.R. Lide, CRC Handbook of Chemistry and Physics, 85th ed., 2004. 
[133] C.-G. Duan, C.-W. Nan, S.S. Jaswal, E.Y. Tsymbal, Universality of the surface magnetoelectric effect in half-metals, Physical Review. B79 (2009) 140403.

[134] I.V. Sieber, H. Hildebrand, S. Virtanen, P. Schmuki, Investigations on the passivity of iron in borate and phosphate buffers, pH 8.4, Corrosion Science. 48 (2006) 34723488.

[135] J. Enerhaug, $\varnothing$. Grong, U.M. Steinsmo, Factors affecting initiation of pitting corrosion in super martensitic stainless steel weldments, Science and Technology of Welding and Joining. 6 (2001) 330-338.

[136] G. Bianchi, A. Cerqumi, F. Mazza, S. Torchio, Chemical etching and pitting ofstainless steel, Corrosion Science. 10 (1970) 19-27.

[137] Z. Szklarska-Smialowska, Progress in understanding pitting corrosion, in: G.S. Frankel, H.S. Isaacs, J.R. Scully, J.D. Sinclair (Eds.), Corrosion Science: a Retrospective and Current Status in Honor of Rober P. Frankenthal, The electrochemical society,, 2002: pp. 251-265.

[138] P. Schmuki, H. Bohni, Metastable Pitting and Semiconductive Properties of, Journal of The Electrochemical Society. 139 (1992) 1908-1913.

[139] J.O. Bockris, Y. Kang, The protectivity of aluminum and its alloys with transition metals, Journal of Solid State Electrochemistry. 1 (1997) 17-35.

[140] F. Gaben, B. Vuillemin, R. Oltra, Influence of the Chemical Composition and Electronic Structure of Passive Films Grown on 316L SS on Their Transient Electrochemical Behavior, Journal of The Electrochemical Society. 151 (2004) B595-B604.

[141] H. Tsuchiya, S. Fujimoto, T. Shibata, Semiconductive Properties of Passive Films Formed on Fe-18Cr in Borate Buffer Solution, Journal of The Electrochemical Society. 151 (2004) B39.

[142] L. Hamadou, A. Kadri, N. Benbrahim, Impedance investigation of thermally formed oxide films on AISI 304L stainless steel, Corrosion Science. 52 (2010) 859-864t.

[143] D. Thierry, D. Persson, C. Leygraf, In-Situ Raman Spectroscopy Combined with X-Ray Photoelectron Spectroscopy and Nuclear Microanalysis for Studies of Anodic Corrosion Film Formation on Fe-Cr Single Crystals, Journal of The Electrochemical Society. 135 (1988) 305-310.

[144] J. Amri, T. Souier, B. Malki, B. Baroux, Effect of the final annealing of cold rolled stainless steels sheets on, Corrosion Science. 50 (2008) 431-435.

[145] S.P. Harrington, T.M. Devine, The Influence of the Semiconducting Properties of Passive Films on Localized Corrosion Rates, ECS Transactions. 16 (2009) 117-123. 
[146] C.A. Gervasi, C.M. Méndez, P.D. Bilmes, C.L. Llorente, Analysis of the impact of alloy microstructural properties on passive films formed on low-C $13 \mathrm{CrNiMo}$ martensitic stainless steels, Materials Chemistry and Physics. 126 (2011) 178-182.

[147] N.E. Hakiki, Electronic Structure of Passive Films Formed on Molybdenum-Containing Ferritic Stainless Steels, Journal of The Electrochemical Society. 143 (1996) 3088.

[148] A. Kocijan, Č. Donik, M. Jenko, Electrochemical and XPS studies of the passive film formed on stainless steels in borate buffer and chloride solutions, Corrosion Science. 49 (2007) 2083-2098.

[149] N.E. Hakiki, B. Rondot, S. Boudin, THE ELECTRONIC FORMED STRUCTURE OF PASSIVE FILMS ON STAINLESS STEELS, Corrosion Science. 37 (1995) 1809-1822.

[150] Z. Feng, X. Cheng, C. Dong, L. Xu, X. Li, Passivity of 316L stainless steel in borate buffer solution studied by Mott-Schottky analysis, atomic absorption spectrometry and Xray photoelectron spectroscopy, Corrosion Science. 52 (2010) 3646-3653.

[151] C. Giacomelli, A. Spinelli, A potentiodynamic and SEM study of the behaviour of iron in pH 8.9-11.0 phosphate solutions, Anti-Corrosion Methods and Materials. 51 (2004) 189-199.

[152] R. Natarajan, N. Palaniswamy, M. Natesan, V.S. Muralidharan, XPS Analysis of Passive Film on Stainless Steel, The Open Corrosion Journal. 2 (2009) 114-124.

[153] J. Benzakour, A. Derja, Characterisation of the pasz ;: ve film on iron in phosphate medium by voltammetry and XPS measurements, Journal of Electroanalytical Chemistry. 437 (1997) 119-124.

[154] M. Vayer, I. Reynaud, R. Erre, XPS characterisations of passive films formed on martensitic stainless steel: qualitative and quantitative investigations, Journal of Materials Science. 35 (2000) 2581-2587.

[155] N. Cabrera, N.F. Mott, Theory of the oxidation of metals, Rep. Prog. Phys. 12 (1949) 163-184.

[156] K.J. Vetter, General kinetics of passive layers on metals, Electrochimica Acta. 16 (1971) 1923-1937.

[157] C.Y. Chao, L.F. Lin, D.D. Macdonald, A Point Defect Model for Anodic Passive Films, Journal of The Electrochemical Society. 129 (1982) 1874-1879.

[158] H. Gerischer, Remarks on the electronic structure of the oxide film on passive iron and the consequences for its electrode behaviour, Corrosion Science. 29 (1989) 191-195.

[159] E.B. Castro, Analysis of the impedance response of passive iron, Electrochimica Acta. 39 (1994) 2117-2123. 
[160] D.D. Macdonald, S.I. Smedley, An electrochemical impedance analysis of passive films on nickel(111) in phosphate buffer solutions, Electrochimica Acta. 35 (1990) 19491956.

[161] H.J. de Wit, C. Wijenberg, C. Crevecoeur, Impedance Measurements during Anodization of Aluminum, Journal of The Electrochemical Society. 126 (1979) 779785.

[162] A.T. Fromhold Jr., E.L. Cook, Kinetics of Oxide Film Growth on Metal Crystals: Electron Tunneling and Ionic Diffusion, Physical Review. 158 (1967) 600-612.

[163] A.T. Fromhold Jr., Justification of the local space charge neutrality hypothesis in metal oxidation, Physics Letters A. 58 (1976) 118-120.

[164] R. Kirchheim, Growth kinetics of passive films, Electrochimica Acta. 32 (1987) 16191629.

[165] E.B. Castro, Analysis of the impedance response of passive iron, Electrochimica Acta. 39 (1994) 2117-2123.

[166] K.J. Vetter, No Title, Elektrochem. 55 (1951) 274.

[167] K.J. Vetter, Das Elektrische Feld Innerhalb der Passivschicht des Eisens, Elektrochem. 58 (1954) 230.

[168] C. Wagner, Models for lattice deffects in oxide layers on passivated iron and nickel, Ber. Bunsenges. Physik. Chem. 77 (1973) 1090.

[169] T. Valand, K.E. Heusler, Reactions at the oxide-electrolyte interface of anodic oxide films on aluminum, Journal of Electroanalytical Chemistry. 149 (1983) 71-82.

[170] K.E. Heusler, The influence of electrolyte composition on the formation and dissolution of passivating films, Corrosion Science. 29 (1989) 131-147.

[171] O.A. Petrii, Surface electrochemistry of oxides: Thermodynamic and model approaches, Electrochimica Acta. 41 (1996) 2307-2312.

[172] K.J. Vetter, F. Gorn, Kinetics of layer formation and corrosion processes of passive iron in acid solution, Electrochimica Acta. 18 (1973) 321-326.

[173] W.D. Mackintosh, H.H. Plattner, The identification of the mobile ion during the anodic oxidation of silicon, Journal of The Electrochemical Society. 124 (1977) 396-400.

[174] R. Kirchheim, The growth kinetics of passive films and the role of defects, Corrosion Science. 29 (1989) 183-190.

[175] M.J. Dignam, Vol.4, in: J.O. Bockris, B.E. Conway, E. Yeager, E. White (Eds.), Comprehensive Treatise of Electrochemistry, New York, 1981: p. 247. 
[176] D.D. Macdonald, M.C.H. McKubre, Impedance spectroscopy emphasizing solid materials and systems, Wiley-Interscience, 1987.

[177] H. Konno, S. Kobayashi, H. Takahashi, M. Nagayama, Composition of barrier type oxide films anodically formed on aluminium in a neutral borate solution, Electrochimica Acta. 25 (1980) 1667-1672.

[178] D.D. Macdonald, S.R. Biaggio, H. Song, Steady State Passive Films- Interfacial Kinetic Effects and Diagnostic Criteria, Journal of The Electrochemical Society. 139 (1992) 170-177.

[179] M. Keddam, O.R. Mattos, H. Takenouti, Reaction Model for Iron Dissolution Studied by Electrode Impedance II. Determination of the Reaction Model, Journal of The Electrochemical Society. 128 (1981) 266-274.

[180] M. Keddam, O.R. Mattos, H. Takenouti, Reaction Model for Iron Dissolution Studied by Electrode Impedance I. Experimental Results and Reaction Model, Journal of The Electrochemical Society. 128 (1981) 257-266.

[181] V.A. Myamlin, Y.V. Pleskov, Electrochemistry of Semiconductors, Plenum Pre, 1967.

[182] N.E. Hakiki, M.F. Montemor, M.G.S. Ferreira, M.C. Belo, Semiconducting properties of thermally grown oxide ${ }^{\circledR}$ Ims on AISI 304 stainless steel, Corrosion Science. 42 (2000) 687-702. 